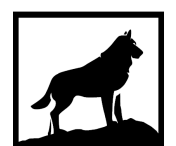

1885

Michigan

\title{
A MULTI-YEAR ANALYSIS FROM 2014 TO 2017 OF SNOWFALL TYPES IN MARQUETTE, MICHIGAN: A DIFFERENTIATION BETWEEN SYNOPTIC SNOW EVENTS AND LAKE EFFECT SNOW EVENTS IMPACTED BY THE PRESENCE OF LAKE SUPERIOR
}

Roberto Piemontese

Michigan Technological University, rpiemont@mtu.edu

Copyright 2020 Roberto Piemontese

Recommended Citation

Piemontese, Roberto, "A MULTI-YEAR ANALYSIS FROM 2014 TO 2017 OF SNOWFALL TYPES IN MARQUETTE, MICHIGAN: A DIFFERENTIATION BETWEEN SYNOPTIC SNOW EVENTS AND LAKE EFFECT SNOW EVENTS IMPACTED BY THE PRESENCE OF LAKE SUPERIOR", Open Access Master's Thesis, Michigan Technological University, 2020.

https://doi.org/10.37099/mtu.dc.etdr/1129

Follow this and additional works at: https://digitalcommons.mtu.edu/etdr

Part of the Geology Commons 
A MULTI-YEAR ANALYSIS FROM 2014 TO 2017 OF SNOWFALL TYPES IN MARQUETTE, MICHIGAN: A DIFFERENTIATION BETWEEN SYNOPTIC SNOW EVENTS AND LAKE EFFECT SNOW EVENTS IMPACTED BY THE PRESENCE OF LAKE SUPERIOR

\author{
By \\ Roberto Piemontese
}

A THESIS

Submitted in partial fulfillment of the requirements for the degree of MASTER OF SCIENCE

In Geology

MICHIGAN TECHNOLOGICAL UNIVERSITY

2020

(C) 2020 Roberto Piemontese 
This thesis has been approved in partial fulfillment of the requirements for the Degree of MASTER OF SCIENCE in Geology.

Department of Geological and Mining Engineering and Sciences

\author{
Thesis Co-Advisor: Dr. Simon A. Carn \\ Thesis Co-Advisor: Dr. Claudia Pasquero \\ Committee Member: Dr. Luke Bowman \\ Department Chair Dr. Aleksey Smirnov
}




\section{Table of Contents}

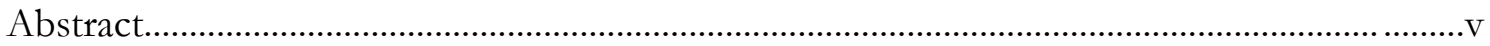

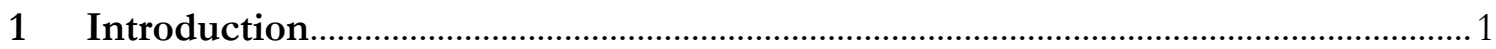

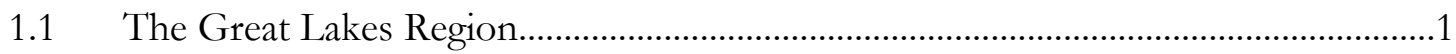

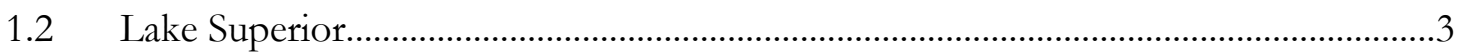

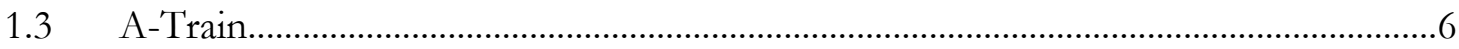

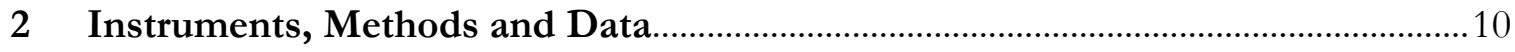

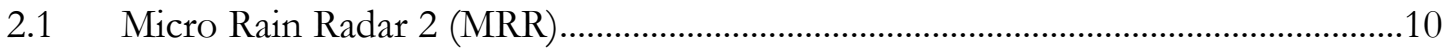

2.2 Precipitation Imaging Package (PIP) ........................................................................12

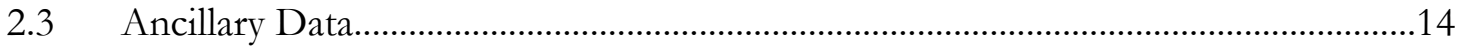

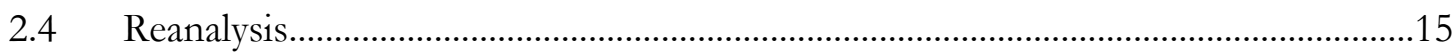

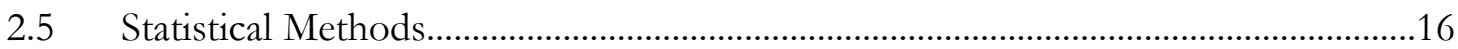

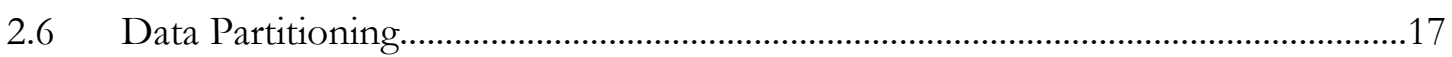

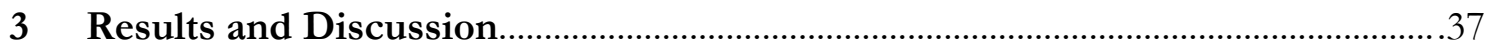

3.1 Precipitation Imaging Package (PIP) Observations...................................................38

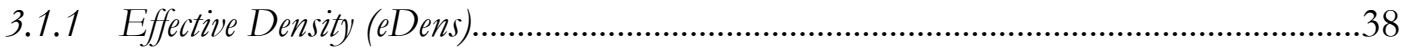

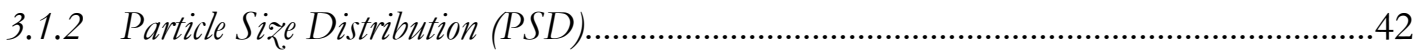

3.2 Micro Rain Radar 2 (MRR) Observations...................................................................... 45

3.2.1 Cloud Top Height (CTH) and Vertical Reflectivity Difference $(\Delta Z)$..............................45

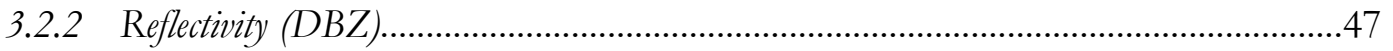

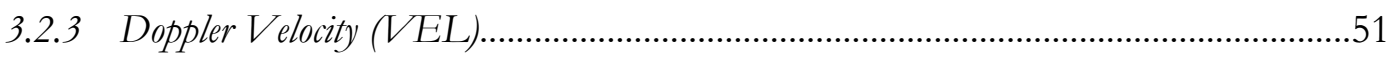

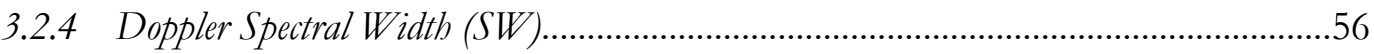

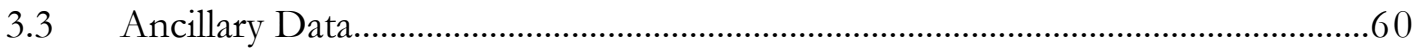

3.3.1 Wind Direction \& Speed (WDIR \& WSPD)..............................................................60

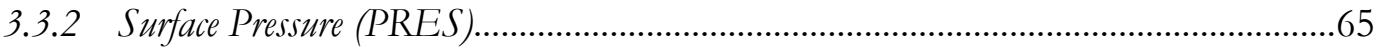

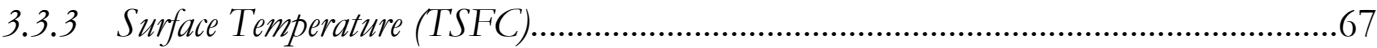

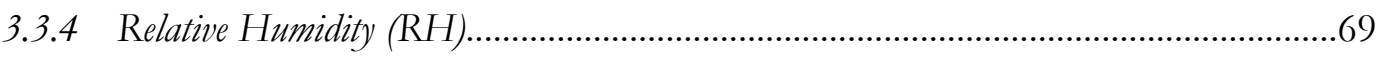

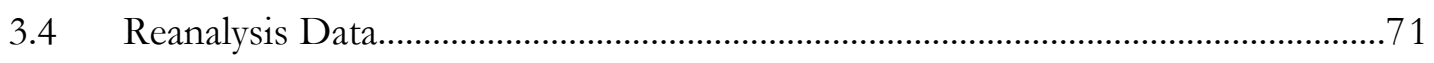

3.4.1 Comparison between data from ERA5 and NWS Office..........................................72

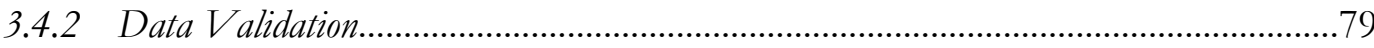

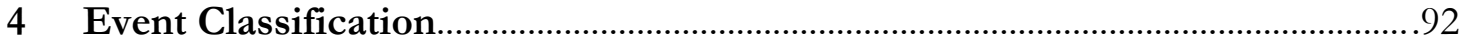




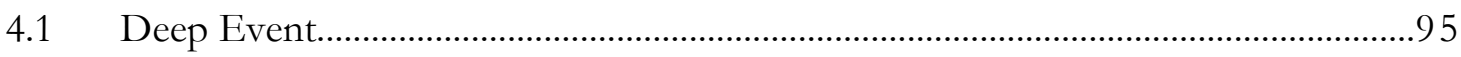

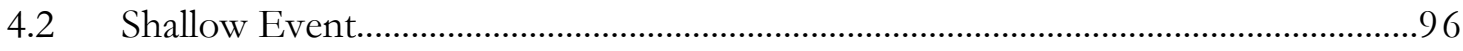

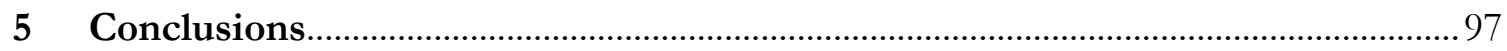

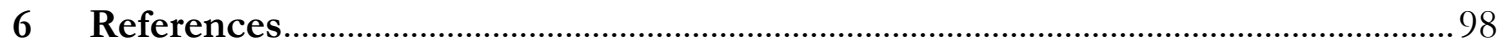

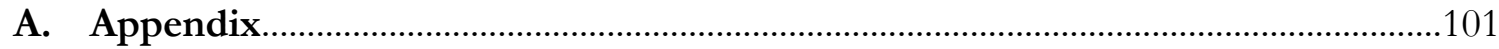

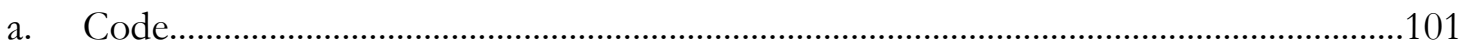

b. Sea Level Pressure Examples......................................................................................123 


\section{Abstract}

The present study analyzes four winter seasons of data from 2014 to 2017 collected from the National Weather Service in Marquette, Michigan. The two main instruments installed are the MRR, which provides a vertical reflectivity profile from ground level to $3 \mathrm{~km}$, and the PIP, a horizontal camera pointing towards a light source, which measures the physical characteristics of each particle. The observations show that LES events are shallow, with heights of up to $1500 \mathrm{~m}$, meanwhile synoptic events are deep, with vertical profile of $3000 \mathrm{~m}$ or beyond. The shallow events have bigger and low-density particles and synoptic events have smaller and high-density particles. Moreover, LES events are linked with low temperature and high-pressure mid-latitude cyclones, with winds from NW, meanwhile deep events have winds from SW. An automated algorithm has been written to recognize these two events. 


\section{Introduction}

\subsection{The Great Lakes Region}

The Great Lakes Region (Figure 1.1 .1 ) is located in the upper mid-east part of North America, on the Canada-United States border and is considered the largest group of freshwater lakes on Earth by total area with over than $770000 \mathrm{~km} 2$. This zone has broad seasonal temperature changes, since the air temperatures in winter average $-2.5^{\circ} \mathrm{C}$ to $-22.5^{\circ} \mathrm{C}$ and the water temperatures range from $10^{\circ} \mathrm{C}$ in the northern lakes to $25^{\circ} \mathrm{C}$ in southern lakes during summer (Fuller et al, 1995). The whole system has five geologically young lakes: Erie, Huron, Michigan, Ontario and Superior, but hydrologically there are only four lakes, since lakes Houron and Michigan merge at the Straits of Mackinac. Even if part of a single system, each lake is different and the group could be classified into three categories: Lake Superior, an oligotrophic lake with low anthropogenic impact, the remaining four lakes, which are more productive with a higher anthropogenic impact and the Saint Lawrence River. All together, they hold nearly $20 \%$ of the world's supply of freshwater. Lake Superior is the largest, deepest and coldest of the lake and due to its volume of water and mean rate of outflow has a retention time of 191 years (Waples et al, 2008).

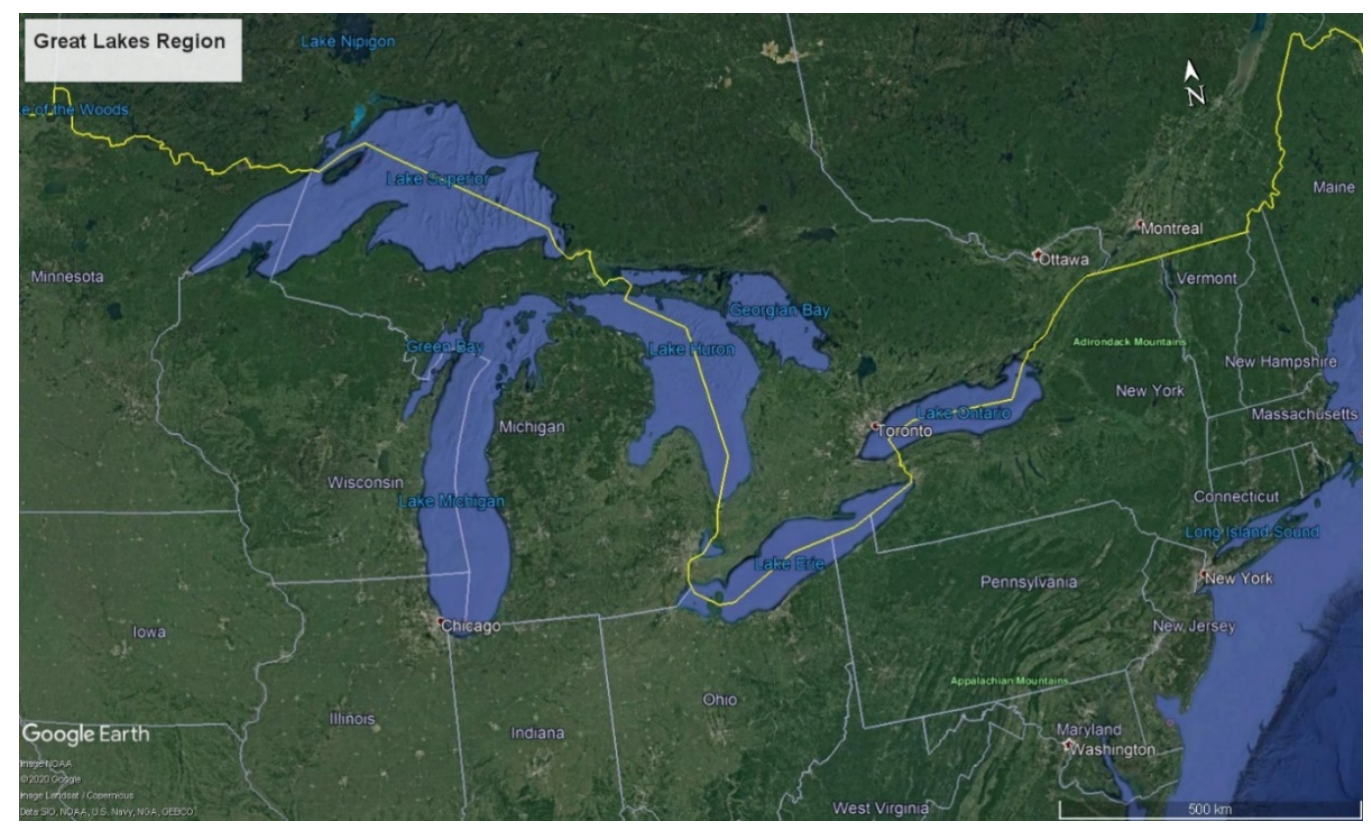

Figure 1.1.1 The Great Lakes Region located at the border between United States of America and Canada. North America. (Google Earth image). 
The main feature of this region are the frequent and heavy snow events during the cold season, which goes from November to April. This condition has a high socioeconomic impact on agriculture, transportation, commerce, infrastructures, water supply and regional ecology (Norton and Bolsenga, 1993). Economy has completely adapted to the weather and whereas activities might be in difficulty, others gained an important profit, such as the recreational industry or the snow removal one. According to Kunkel et al. (2009), significant positive snowfall trends occurred in the snowbelt zone (Figure 1.1 .2) of Lakes Superior and Michigan since the turn of the twentieth century in response to warming water, declining ice cover and enhanced evaporation. The increase or the decrease of the number of these events could undermine the delicate economy of this area.

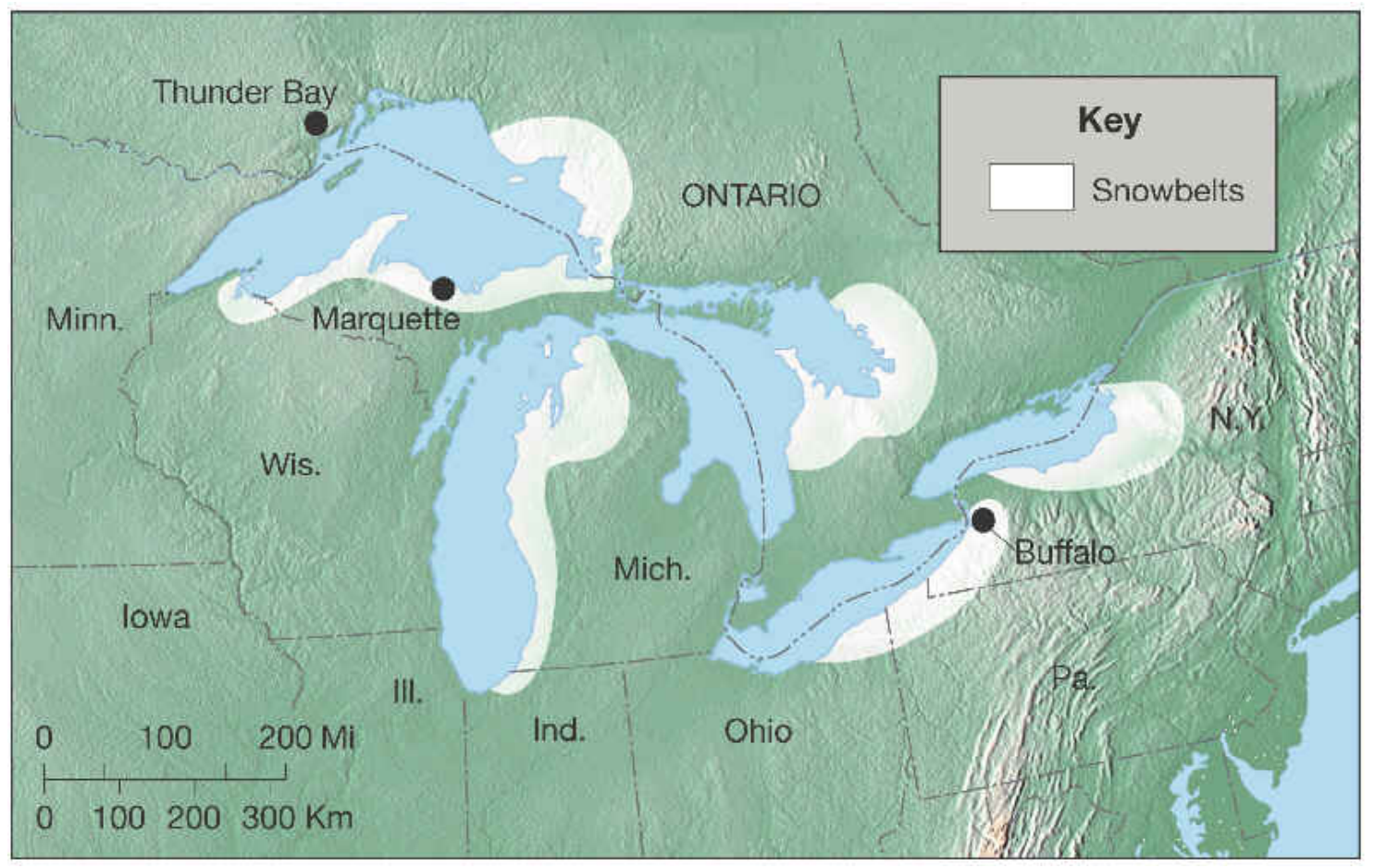

Figure 1.1.2 Snowbelt regions in the Great Lakes Region. (glisa.umich.edu). 


\subsection{Lake Superior}

This study takes place in Marquette, Michigan at the National Weather Service office $\left(46^{\circ} 31^{\prime} 53.5^{\prime \prime} \mathrm{N} 87^{\circ} 32^{\prime} 55.1^{\prime \prime W}\right)$. It is located inland, $13 \mathrm{~km}$ away from Lake Superior and is 80 $\mathrm{km}$ southeast from the Upper Peninsula (UP), which is $32 \mathrm{~km}$ wide and it does not have a high elevation (Figure 1.2 .3). The decision to use this office as main location has several reasons: the main one is the high snow accumulation per year, providing enough snow events to elaborate a satisfactory statistic and obtain a significant threshold for each attribute.

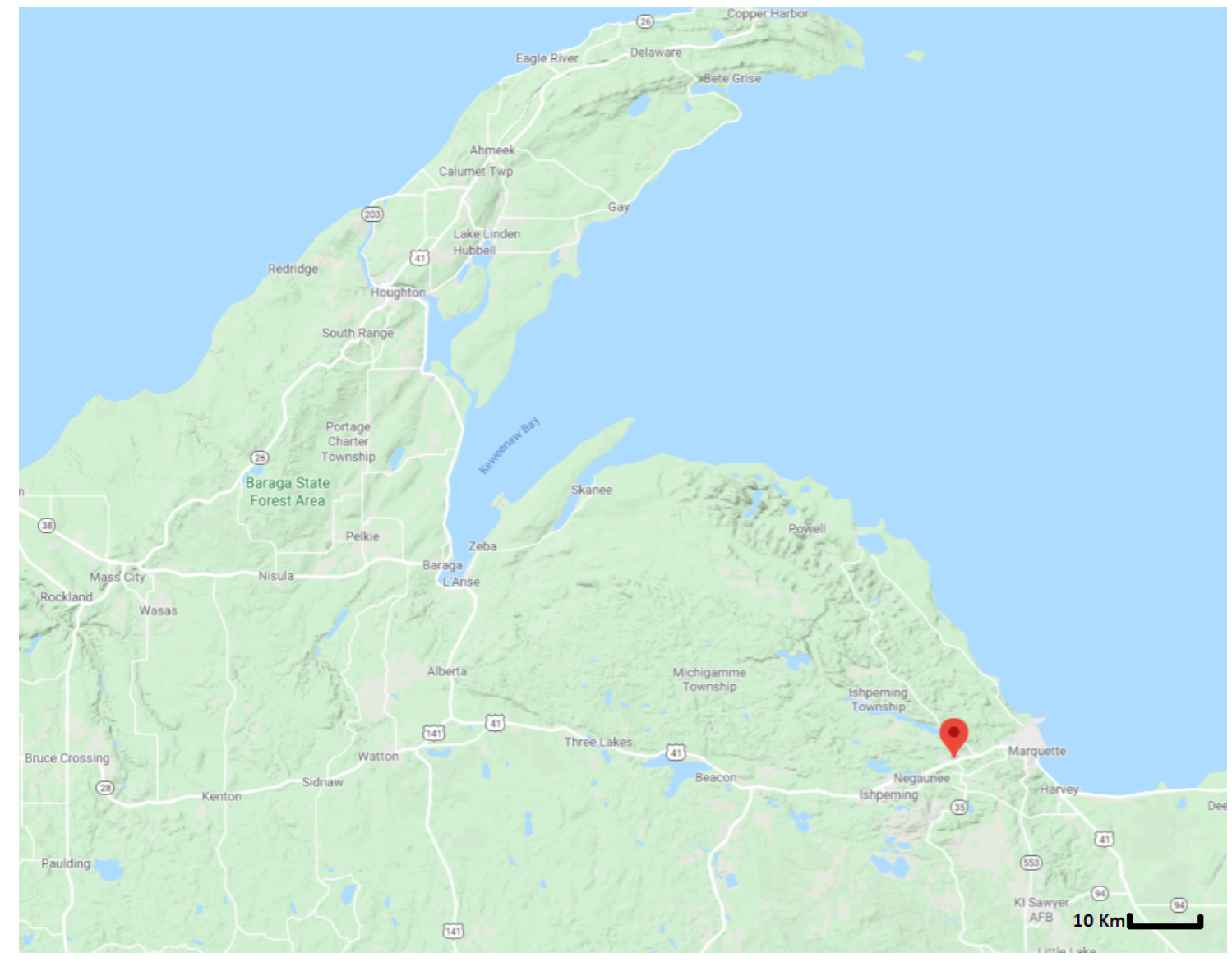

Figure 1.2.3 Topography map of the region. NWS office indicated with the red dot. (Google Maps). 
According to the NWS (https://www.weather.gov/mqt/) website, Marquette has on average between 350 and $500 \mathrm{~cm}$ of snow accumulation per year (Figure 1.2 .4), placing it among the snowiest location in the Upper Peninsula. Although utilizing the location with the most snow accumulation would be ideal for this study, it was necessary to have an office with a high percentage of uptime ( $>97 \%$ over 5 years) and continuous remote access to instrument for analysis, maintenance and real-time transfer of data. Technicians and meteorologists working at the NWS office collect and process the data into daily plots published on a public website (https://www.ssec.wisc.edu/lake effect/mqt/) (Pettersen et al, 2020).

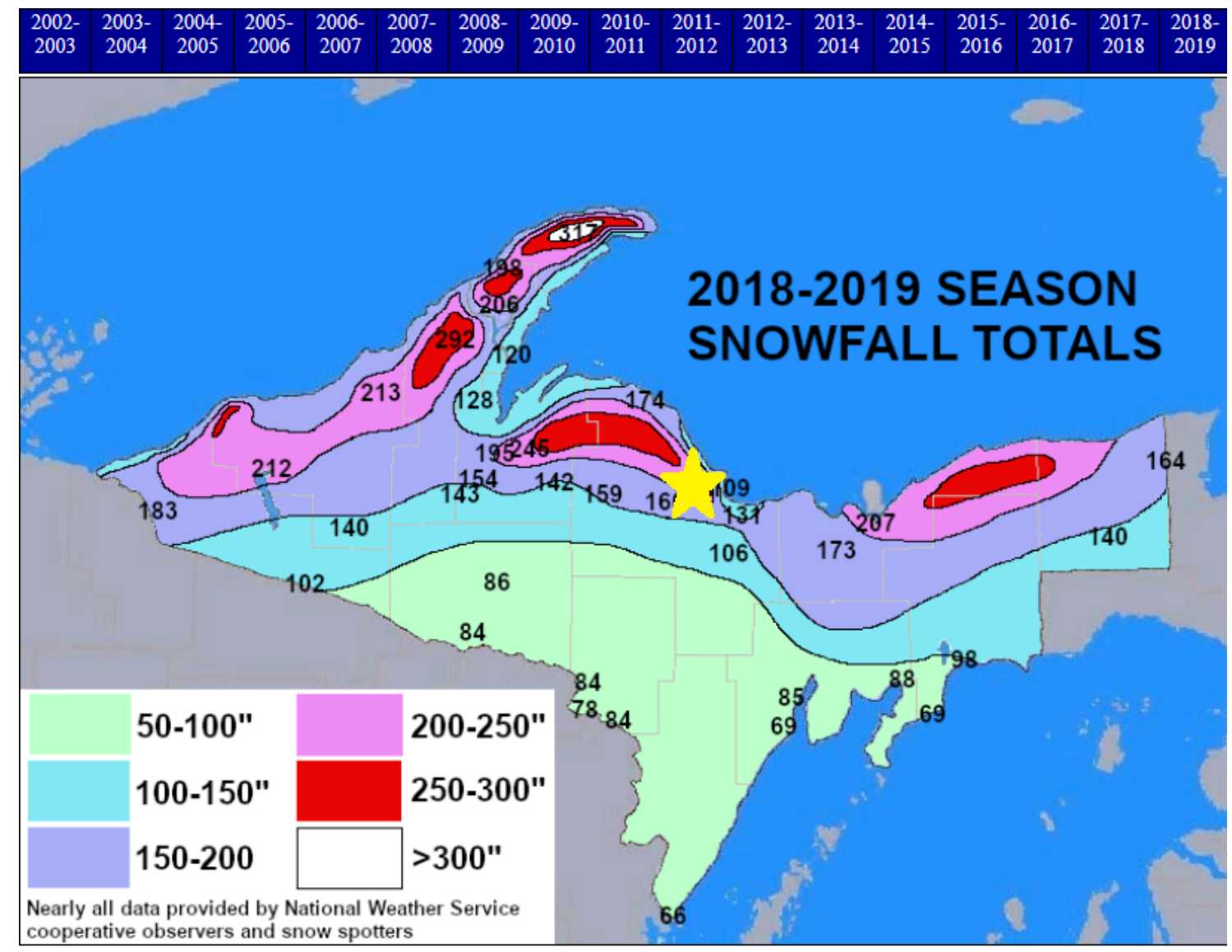

Figure 1.2.4 Snowfall totals measured in inches. 2018-2019 Season. The National Weather Service Office in Marquette is (NWS website). 
On January 20142 two main instruments for the presented study have been installed: the Micro Rain Radar (MRR) and the Precipitation Imaging Package (PIP). Their data is published on a daily basis on a website with the collaboration of the Space Science and Engineering Center (SSEC) and the University of Wisconsin (Figure 1.2 .5). The main properties presented are reflectivity, fall speed, particle size distribution and particle density distribution.

\section{MQTBrowser}

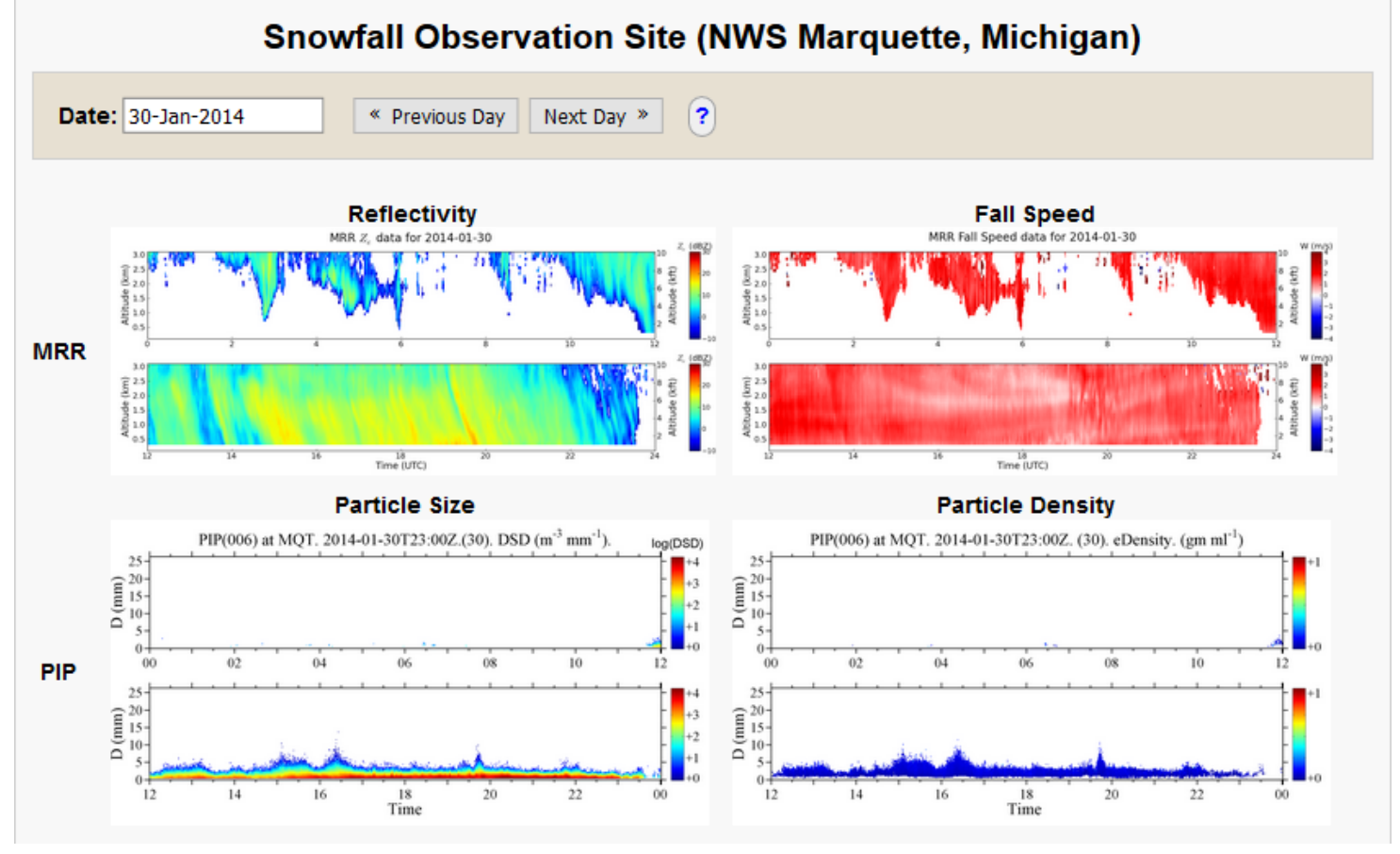

Figure 1.2.5 30 January 2014 presented on the website. (https:/ / www.ssec.wisc.edu/lake_effect/mqt/). 


\subsection{A-Train}

Space-borne radar observations with the latest generation operational geostationary satellites have provided significant analyses in the recent years for better understandings regarding the distribution and behavior of clouds in our atmosphere, since they influence climate variability and change by affecting the efficiency at which the hydrological cycle operates. (Kulie et al, 2016, Stephens et al, 2002). On the $28^{\text {th }}$ April of 2006 a new satellite CloudSat has been launched on a Delta II rocket carrying the first W-band $(94 \mathrm{GHz})$ cloud profiling radar (CPR) as the only payload instrument, although the original project included the combination of lidar, radar and precipitation measurements (GEWEX 1994) (Stephens et al, 2002, Stephens et al, 2008). The satellite observations were designed to match closely in time with the lidar observations of CALIPSO (Winker et al, 2007) and although the requirement was to overlay measurements of CALIPSO at least $50 \%$ of the time, studies indicated that the overlap occurred for more than $90 \%$ of the time (Figure 1.3 .6 ).

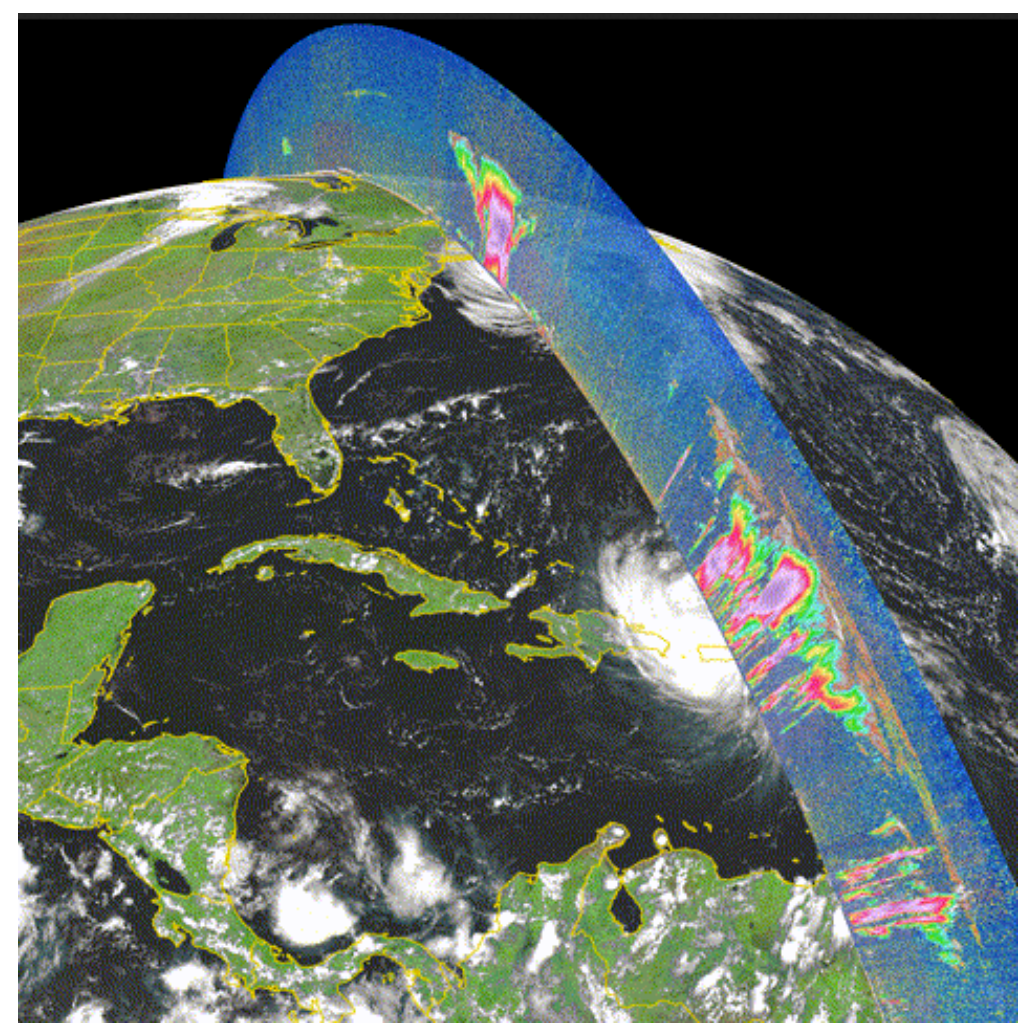

Figure 1.3.6 The scene shows two tropical cyclones from September 20, 2017. Data from the CALIPSO lidar and CloudSat radar appear as vertical slices in the atmosphere. (NASA/Roman Kowch). 
The project, developed as a collaboration between NASA, the Canadian Space Agency (CSA) and the U.S. Air Force, was supposed to operate only for 22 months, but then NASA approved the extension of mission to September 2011 and after that date, it has been working in daytime-only operations, due to battery malfunction and necessity of sunlight to power the radar.

Initially, CloudSat, paired with CALIPSO, was part of the A-Train constellation (Figure $1.3 .7)$, formed by five satellites that includes the EOS Aqua and EOS Aura at each end of the constellation and another small satellite, PARASOL, carrying the POLDER polarimeter (Deschamps et al, 1994). In June 2017, it experienced some technical difficulties that could have led to the inability to maneuver or change its orientation, making the drifting into another satellite very probable, so on February 22, it exited the A-Train orbit to enter a lower orbit called C-Train (Greicius Feb 2018, www.nasa.gov). The observations obtained by the interaction between CloudSat and CALIPSO were too important to have the two satellites separated and, in September, CALIPSO joined CloudSat on the lower orbit of C-Train, with C being the first letter of the two satellites (Atkinson Sep 2018, www.nasa.gov) 


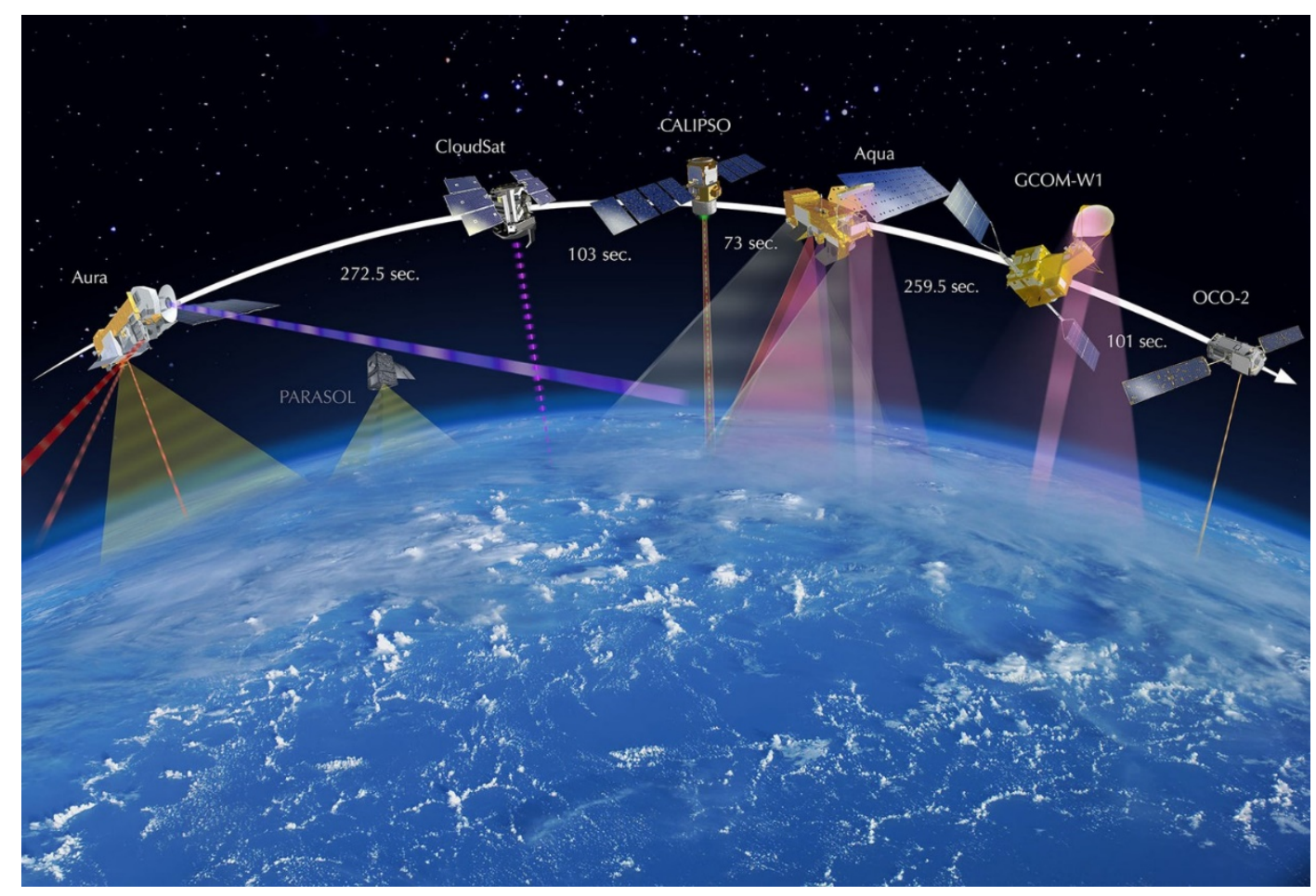

Figure 1.3.7 A-Train constellation. (NASA).

The CPR (Cloud Profiling Radar or CloudSat) acquired the first-ever, continuous, global time series of vertical could structures with $485 \mathrm{~m}$ vertical resolution and $1.4 \mathrm{~km}$ antenna 3 $\mathrm{dB}$ footprint with outstanding results (Tanelli et al, 2008). Both ground-based scanning radars and spaceborne remote sensing instruments lack the capability to provide good near surface observations, due to their "blind zones" generated by sky or ground conditions and the grid intrinsic properties (Figure 1.3 .8) from the spatial orbit (Kulie et al, 2010, Casella et al, 2017). 


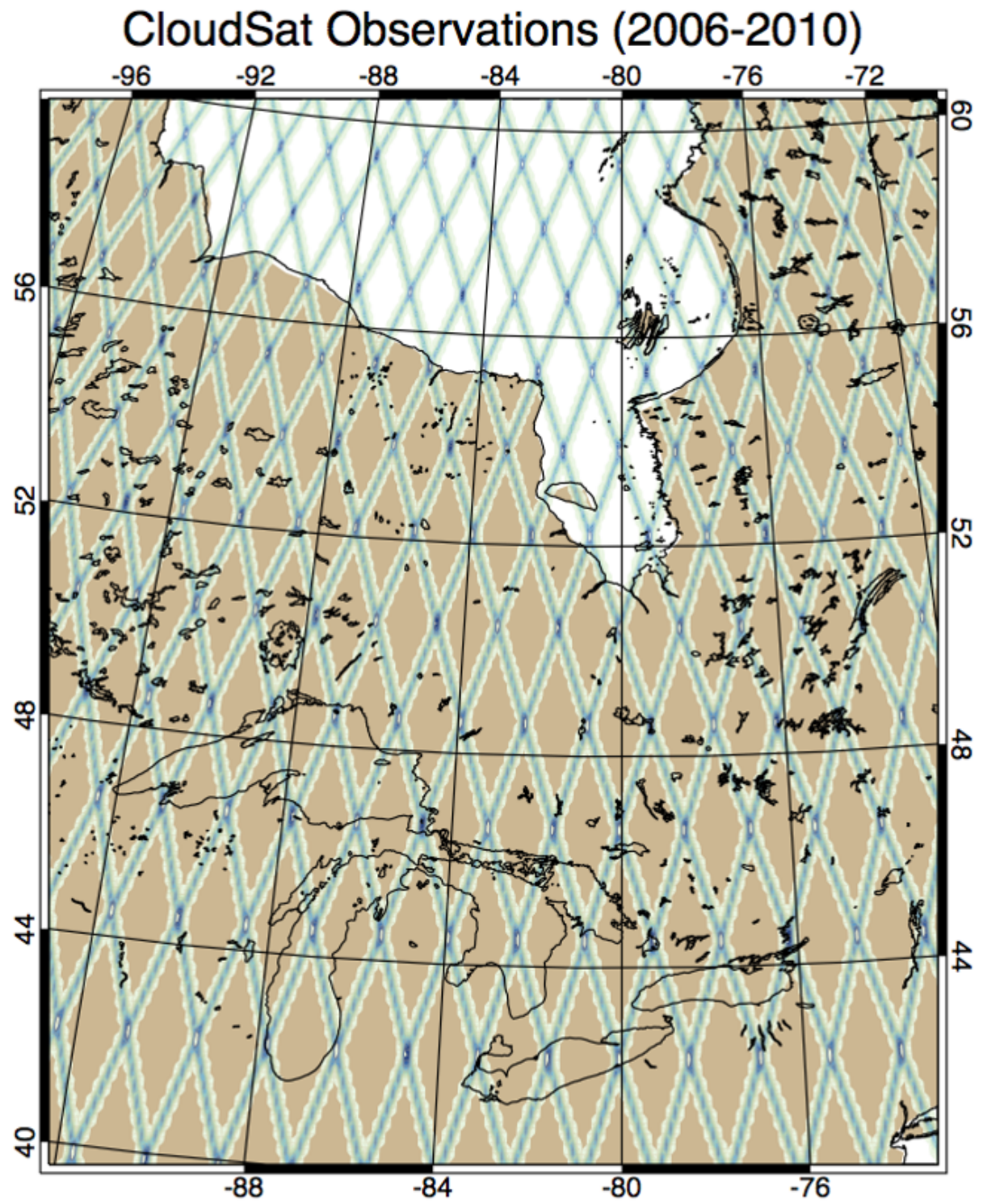

Figure 1.3.8 CloudSat grid over the North America area. Blue lines indicate the trajectory of the satellite.

Therefore, it was necessary to validate the results obtained from remote sensing instruments with a near-surface method that would improve the snowfall estimates and augment the observational capabilities. Several studies have been performed to better characterize LES (Lake Effect Snow) events and many of them were focused on the lower Great Lakes due to the intensity of events in those regions (Kristovich et al 2017) and most of them were only one winter long or related to some specific events (Wood et al, 2015). Due to this lack of continuous information, this study will present an analysis of observations obtained from January 2014 to December 2017 in the upper Great Lakes region, Lake Superior, trying to 
have a better insight in the differences between deep and shallow events and in the uncertainties from various physical parameterizations (Conrick et al, 2015). Most studies used the term "shallow snowfall event" to relate to a Lake Effect Snow event, due to its shallowness and occurrence up to $1.5-2 \mathrm{~km}$ above ground level, meanwhile the term "deep snowfall event" is used to describe synoptic snowfall events that extend over that vertical threshold and reach higher altitudes.

Observations will be provided from a vertically pointing Micro Rain Radar, which will be used to separate the snowfall events into two distinct categories: either deep or shallow; additionally, these analyses are compared with the results obtained from a Precipitation Image Packaging that investigates specific microphysical properties of the falling particles. As a support of these two instruments, ancillary data from surface instruments based at the National Weather Service Office located in Marquette will support each snow category.

Another aim of this study is to provide a threshold for each characteristic and produce an algorithm that is able to process the aforementioned analysis automatically; therefore, it is necessary to be able to separate rain events from snowfall events.

\section{Instruments, Methods and Data}

\subsection{Micro Rain Radar 2 (MRR)}

The Micro Rain Radar (Figure 2.1 .9), produced by Meteorologische Messtechnik GmbH (METEK) is a vertical pointing Frequency Modulated Continuous Wave (FMCW) radar that operates at a frequency of $24 \mathrm{GHz}$ (Peters et al, 2002). Its main purpose was to measure precipitation at buoys in the North Sea without any disruption by sea spray, subsequently it has been successfully used to observe any kind of precipitation, providing observations of 
both rain and snow (Peters et al, 2002, Yuter et al, 2008). The small dimension of the MRR makes it feasible to fieldwork, having an antenna dish of $0.6 \mathrm{~m}$ in diameter and a low power transmitter $(50 \mathrm{~mW})$ that uses approximately $25 \mathrm{~W}$. During winter months the power usage can go up to $525 \mathrm{~W}$, when a heating system is turned on, in order to ensure optimal performance during wet snowfall and low wind speed conditions, which could produce snow accumulation on the dish.
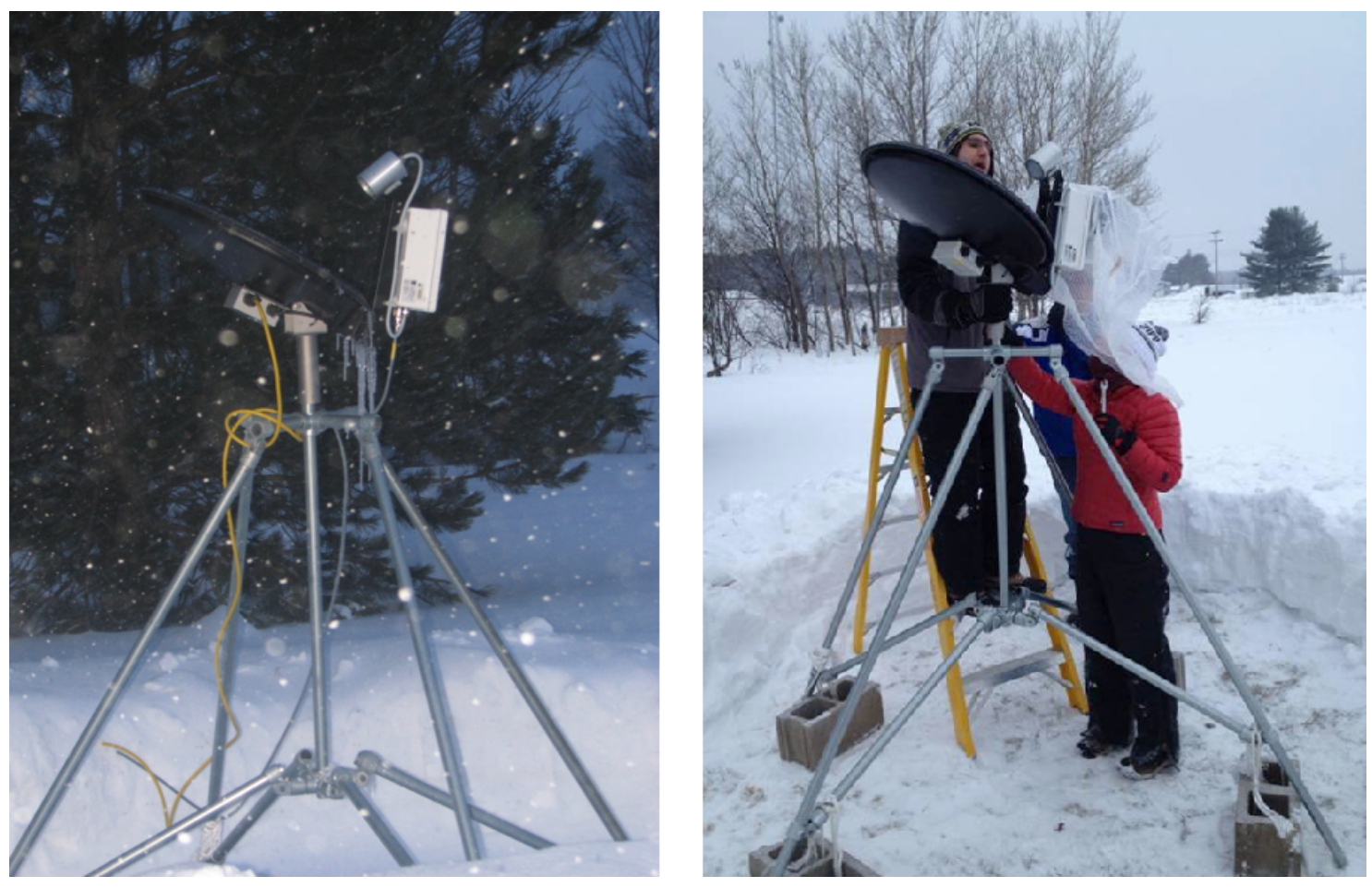

Figure 2.1.9 MRR installation in January 2014.

In this specific case of study, the instrument has been configured to profile up to a height of $3000 \mathrm{~m}$ above ground level (AGL) with 30 fixed gates, having a vertical resolution of $100 \mathrm{~m}$ each. The first bin, corresponding to $0 \mathrm{~m} \mathrm{AGL}$ is rejected and the following two are omitted from the processing, due to near-field effects that could produce misleading results, therefore the observable range goes from $300 \mathrm{~m}$ to $3000 \mathrm{~m}$, which is sufficient to analyze both deep and shallow events in this location. The data obtained from the MRR include measurements of reflectivity, Doppler velocity and spectral width with a resolution of $1 \mathrm{~min}$ 
per bin. Utilizing the reflectivity observations, it is possible to retrieve the snowfall rate from the Z-S relationship used widely in the literature:

$$
Z_{e}=a S^{b}
$$

The effective reflectivity factor (Ze) has units of $\mathrm{mm}^{6} \mathrm{~m}^{-3}$, the liquid water equivalent (LWE) $\mathrm{S}$ in $\mathrm{mm} \mathrm{h}^{-1}$ and $\mathrm{a}$ and $\mathrm{b}$ being coefficients are summarized in table 1 (Kneifel et al, 2011)

\begin{tabular}{lcc}
\hline \multicolumn{1}{c}{ Reference } & $a$ & $b$ \\
\hline Kulie and Bennartz (2009), & 24.04 & 1.51 \\
LR3 & & \\
Kulie and Bennartz (2009), & 313.29 & 1.85 \\
HA & & \\
Kulie and Bennartz (2009), & 19.66 & 1.74 \\
SS & & \\
Matrosov (2007) & 56.00 & 1.20 \\
Noh et al. (2006) & 88.97 & 1.04 \\
\hline \hline
\end{tabular}

Table 3.1.1.1 Prefactor $a$ and exponent $b$ for the Z-SR equation.

\subsection{Precipitation Imaging Package (PIP)}

The Precipitation Imaging Package (PIP) is a NASA-developed video disdrometer (Figure 2.2 .10), designed by Dr. Larry Bliven at the Wallops Flight Facility (https://wallopsprf.gsfc.nasa.gov) and evolved from the Snowflake Video Imager (SVI), used to evaluate the physical properties of snow particles (Newman et al, 2009). The main difference between PIP and SVI are the camera and improved software. The PIP consists in a high-speed 
camera that records grey-scale images at a frequency of nearly 380 frames per second over a $640 \times 460$ pixel window, allowing measurements of both particle size and fall speed in either rain or snow events. The instruments consist in a camera pointing at a bright $(150 \mathrm{~W})$ halogen lamp positioned approximately $2 \mathrm{~m}$ away. The lens focus is set at $1.3 \mathrm{~m}$ with a field of view (FOV) of $64 \times 48 \mathrm{~mm}$, producing an image resolution of 0.1 x $0.1 \mathrm{~mm}$. Previous measurements of snowflake properties have been accomplished on a particle-by-particle basis and despite being precise and detailed, this method was limiting, due to the small number of observations and the high amount of time spent on the data analysis (Locatelli and Hobbs, 1974). Therefore, the main advantage of PIP, as well of SVI, is the open particle catch volume that reduces the effect of wind on quantitative measurements and increases the number of observations, having a particle size error due to blurring of $18 \%$ (Newman et al, 2009). The shadows of particles are recorded as they fall through the area observation and the volume is used to calculate the particle size distribution (PSD) and the fall speed estimates with 1 min resolution. The software processes the images obtained also to elaborate and estimate of the diameter of each particle and its density (Tiira et al, 2016). The PIP is able to produce Boolean type results concerning the precipitation, as it could be rain or not rain (snow). (Le and Chandrasekar, 2019). 


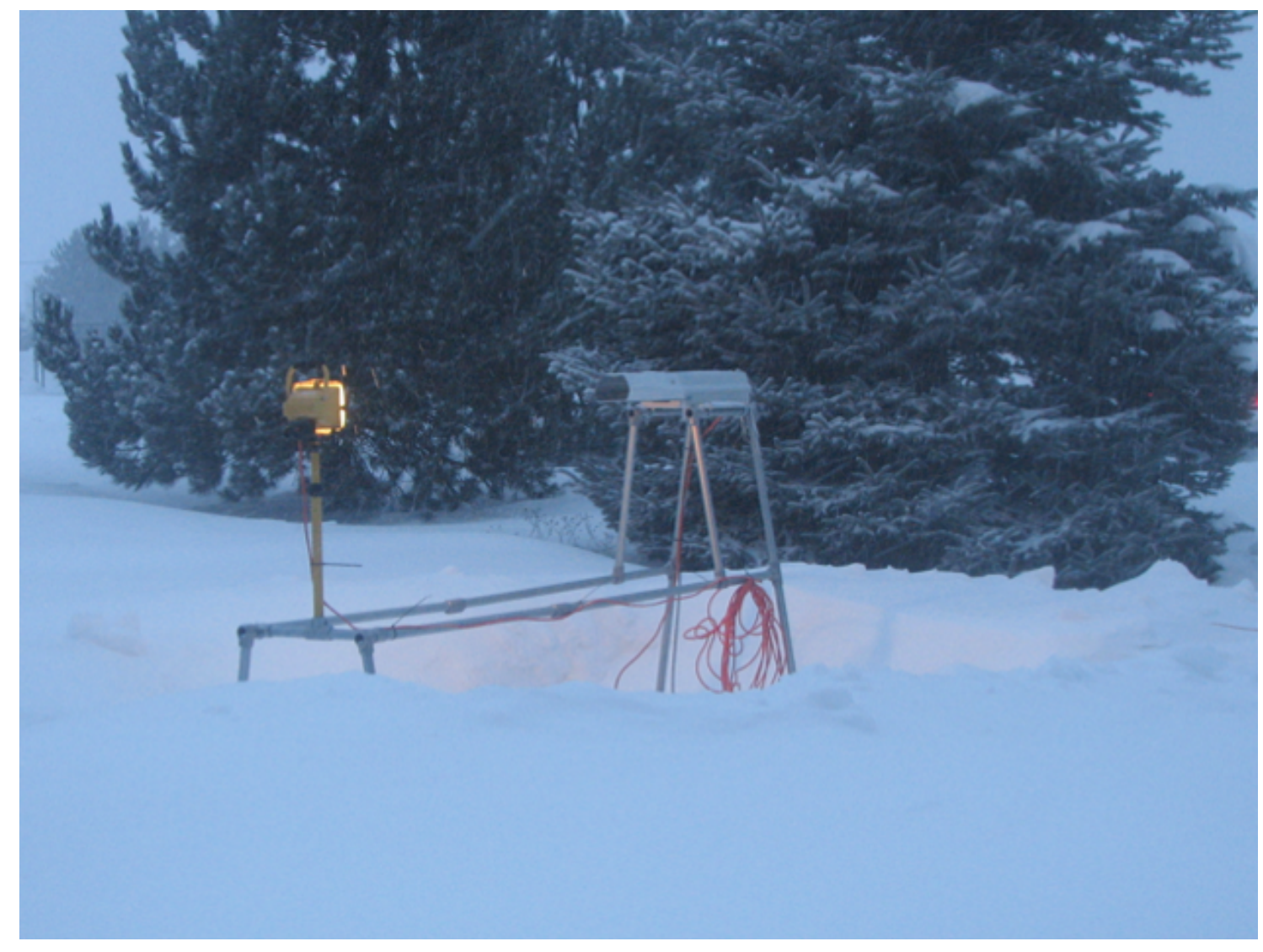

Figure 2.2.10 Precipitation Imaging Package (PIP). National Weather Service Office, Marquette, Michigan. 


\subsection{Ancillary Data}

Ancillary data are obtained from surface meteorological instruments installed at the NWS office (Figure 2.3 .11 ) and they provide additional information regarding each event recorded. The parameters analyzed are measurements of the surface temperature, relative humidity, surface pressure, wind speed and direction and each of them is divided into bins of $1 \mathrm{~min}$ each, hence it is possible to relate them easily to the observations acquired from MRR and PIP.

Additionally, the NWS office in Marquette has a snowfield aimed to record and calculate the snow accumulation continuously. It consists in four $150 \mathrm{~cm}$ snow stakes distributed across an area of $36 \mathrm{~m}^{2}$, the snow depth is calculated averaging the four boxes, and measurements are taken every 6 hours, starting at midnight local time. To retrieve the Liquid Water Equivalent (LWE) snow accumulation, a $20.32 \mathrm{~cm}$ diameter standard rain gauge (SRG) is

used and the snow is melted to convert from geometric to LWE accumulation (Pettersen et al, 2020). 


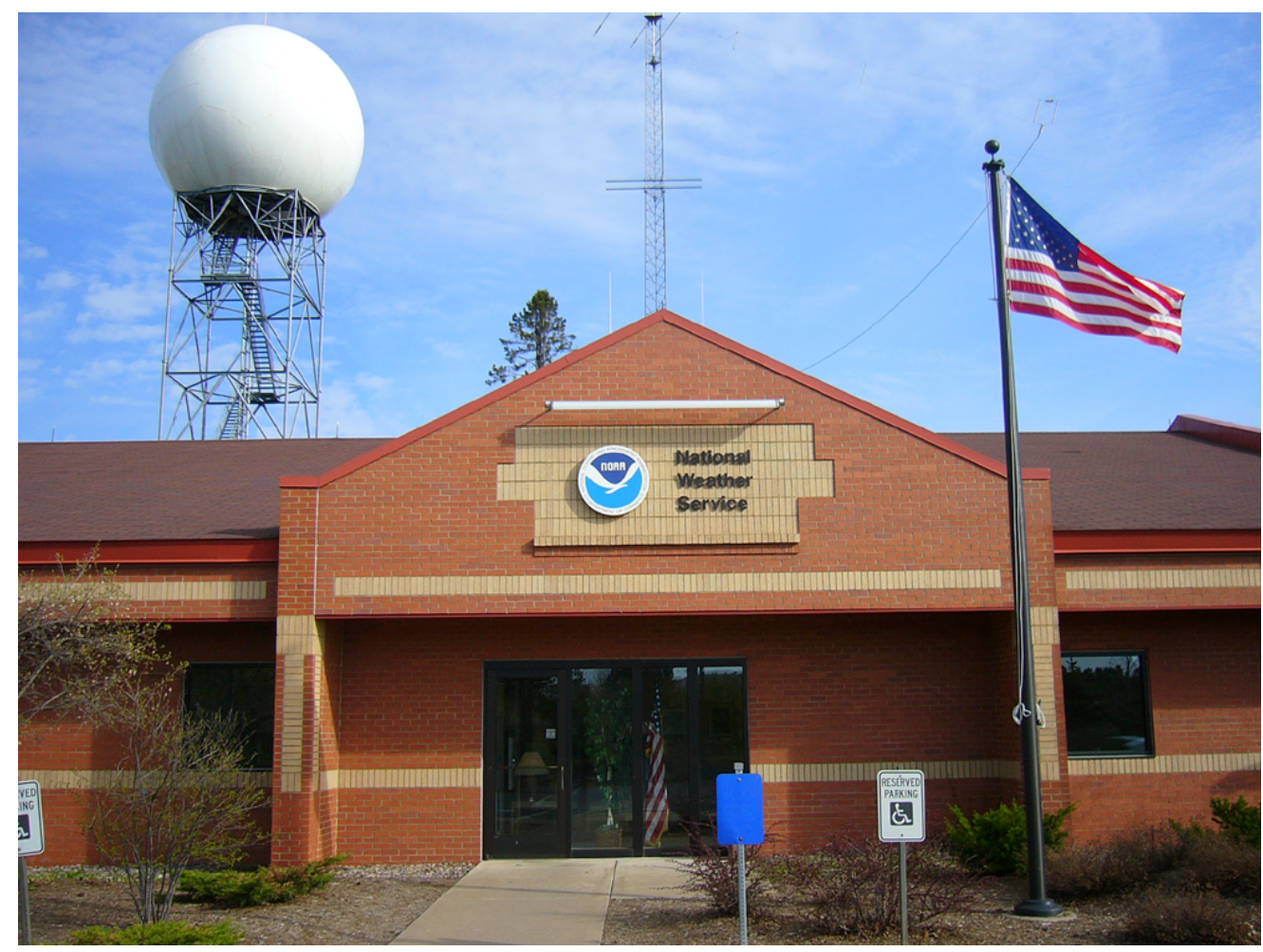

Figure 2.3.11 National Weather Service Office in Marquette. (bttps:/ / www.weather.gov/mqt/stationhistory).

\subsection{Reanalysis}

The last external dataset used to evaluate the observations of this study is the reanalysis product from ERA5, obtained from its related website. ERA5 is the successor of ERAInterim, provides global, hourly estimates of atmospheric variables from 1979 through the preset, and have a horizontal spatial resolution of $31 \mathrm{~km}$ and 137 vertical levels from the surface to $1 \mathrm{~Pa}$ (https://cds.climate.copernicus.eu). The period used is related to this specific study and goes from 2014 to 2017 and values of surface temperature and relative humidity are retrieved from the data available to compare them with their counterpart obtained from other instruments. 


\subsection{Statistical Methods}

The dataset of this study is composed of several files, each of them representing one day. In order to improve the accuracy of the statistical analysis and speed up the process avoiding any misinterpretation of the dataset, only days with one type of event are being taken into consideration and the rest will be used later for the algorithm validation. The distinction is not only based on snow or not snow (rain), but also if the event is either deep (synoptic) or shallow (Lake Effect Snow).

Once the statistical analyses have been performed, it is necessary to evaluate the significance of differences of the characteristics of the deep and shallow events using the difference of means method and the student's t-test. The following equation is applied to test the significance of the difference between two independent sample means:

$$
z=\frac{\bar{x}_{1}-\bar{x}_{2}}{\left(\frac{s_{1}^{2}}{N_{1}}+\frac{s_{2}^{2}}{N_{2}}\right)^{1 / 2}}
$$


where $\bar{x}$ is the sample mean, $s$ is the sample standard deviation and $\mathrm{N}$ is the effective sample size (Wilks et al, 2011).

The t-test is any statistical hypothesis test in which the test statistic follows a Student's tdistribution under the null hypothesis and in this case of study is used to inspect two separate vectors of data and evaluate if the two mean values obtained from them belong to the same family of data or two different ones. This analysis is useful to inspect the significance of each threshold obtained for all the parameters.

For the entire study, the differences are considered statistically significant at a confidence level of $95 \%$.

\subsection{Data Partitioning}

Before starting with the statistical analysis of each day, it has been necessary to divide the data set into several categories, having three main event types used to process the sorting. The MRR and ground observation instruments have been utilized widely in past studies to investigate meteorological events and grouped by conditions (frontal, cyclonic or LES) (Kristovich et al, 2017); however, most of them were carried on for a short period of time and produced specific results, that might be accurate only with distinct conditions. This study will use a time span of 4 years (from 2014 to 2017) to improve the reliability of threshold collected and develop an automated algorithm to sort the different types of events.

Following it will be presented each type of event and underlined their specific properties that are used for the sorting method, before starting with the statistical analysis. Figure 2.6 .12 shows the difference between a snow event and a rain one based on the data available at the public snowfall observation website that represent the reflectivity, fall speed, particle size and particle density distribution. The first two parameters are distributed along a $3000 \mathrm{~m}$ vertical profile and the last two are related to surface measurements. It is noticeable how the 
differences between a snow event and a rain event are distinct. The reflectivity and fall speed values are clearly higher in a rain event and this can be explained with the intrinsic physical properties of a rain droplet, which is heavier than a snowflake and therefore has a higher fall speed. Negative values of fall speed in the snow event indicate the presence of uplift movements generated by air masses. In addition, the particle density distribution shows a drastic difference between rain and snow, which is still due to the physical characteristic of the two events, having the effective density of water larger than that of snow by almost one order of magnitude. In this specific example, the particle size distribution presents a similar behavior between the two events, but this does not reflect the complete data set, where there are many fluctuations in values, therefore this parameter is not considered significant for the purpose of a preliminary sorting. Despite values from reflectivity and fall speed are clearly different, the effective density will be used as the main factor for an initial classification into rain and not rain (snow). 


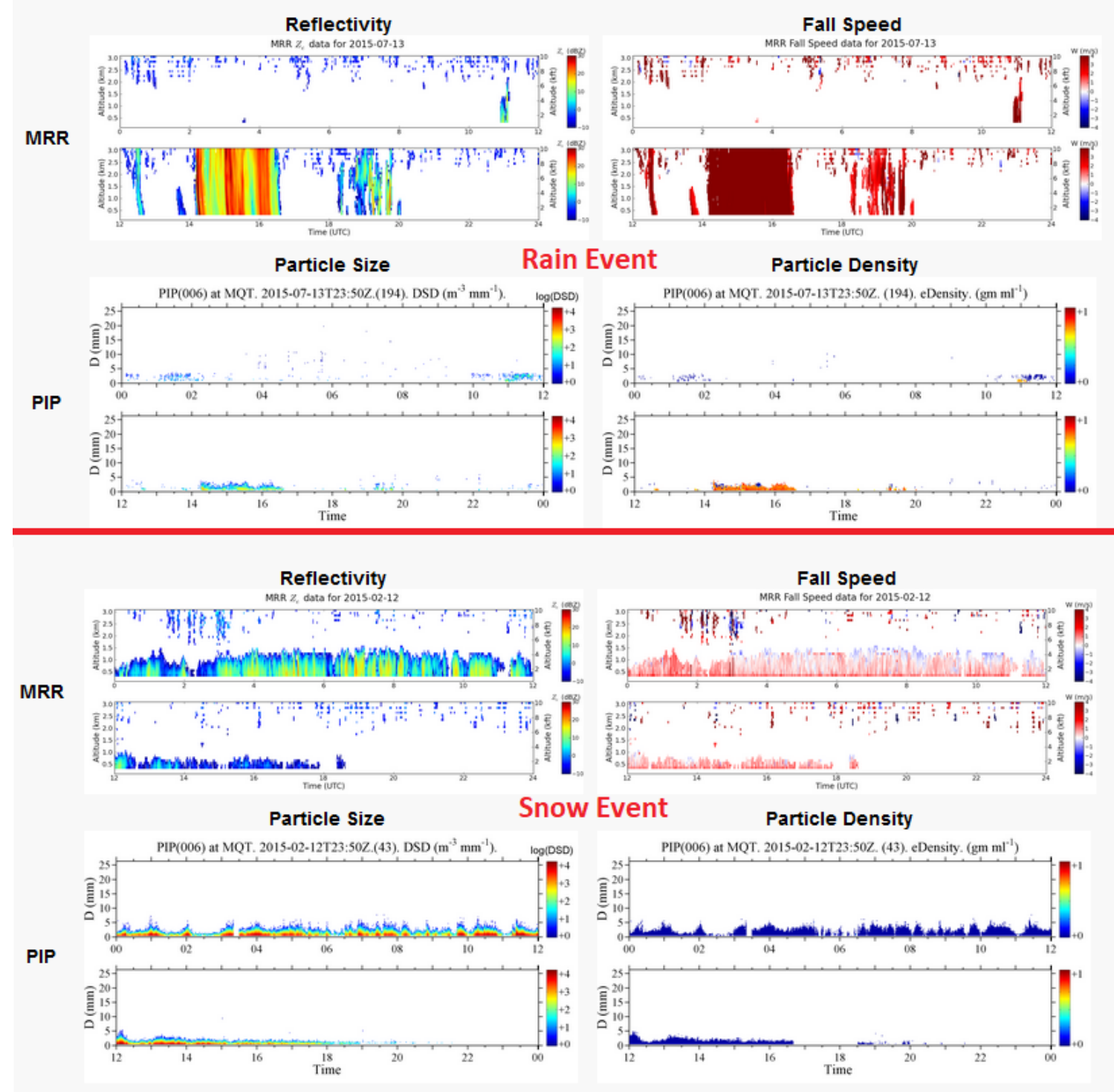

Figure 2.6.12 Comparison between a rain event (13 July 2015) on the top panel and a snow event (12 February 2015) on the bottom panel. 
The next step into the preliminary sorting will be dividing each event into two separate categories, either deep (Synoptic Snow) or shallow (Lake Effect Snow). Deep events are mainly linked to extratropical cyclonic influence (Leathers and Ellis, 1996). They appear to be vertically spaced, filling the whole profile up to $3 \mathrm{~km}$ and probably over that limit, having a homogeneous distribution both along the time and height axis. These events are generally wide and affect large portions of land. To better understand the difference between the aforementioned types of snow, with the following images it will be presented a visual comparison with the data obtained from WSR-88D (NEXTRAD) and MRR.

Figure 2.6 13 represents the elaboration provided from Mosaic3D and shows the reflectivity all over the Lake Superior, Lake Michigan and the Upper Peninsula. The main characteristic of a deep snow event is the extensive distribution in the area and its homogeneity in reflectivity values, whereas the properties of the Lake Effect Snow are remarkably different: it is a local event, not as spatially wide as the synoptic snowfall, and shows its banded feature that is represented also in the MRR plot. The wind direction is from NW-NNW and the strip of land from the Keweenaw Peninsula is wide $\sim 35 \mathrm{~km}$, making possible for the air mass to carry the moisture and generate a snowfall in the Marquette area.

Figure 2.6.14 presents the differences using the data obtained from the MRR instrument. The deep event is vertical extensive and reaches the altitude of $3000 \mathrm{~m}$ but could also extend over that value; the reflectivity is mainly uniform without any distinct pattern with values that range from +10 to $+20 \mathrm{dBZ}$. The Lake Effect Snow is identified as shallow event because the height of the profile is drastically lower compared to the deep event. The reflectivity values have a higher variance, with a range from +5 to $+25 \mathrm{dBZ}$, and are pulsed in time due to the multi-banded event. Different studies have demonstrated how LES events preserve this characteristic, but, based on the position, the height could reach values of 2000 - $3000 \mathrm{~m}$ (Kristovich et al, 2017). This pulsating behavior is reflected also in the particle size/density distribution, where it is possible to observe high peaks in diameter for a Lake Effect Snow event, meanwhile with a synoptic snow event the values presented are uniform and lower. 


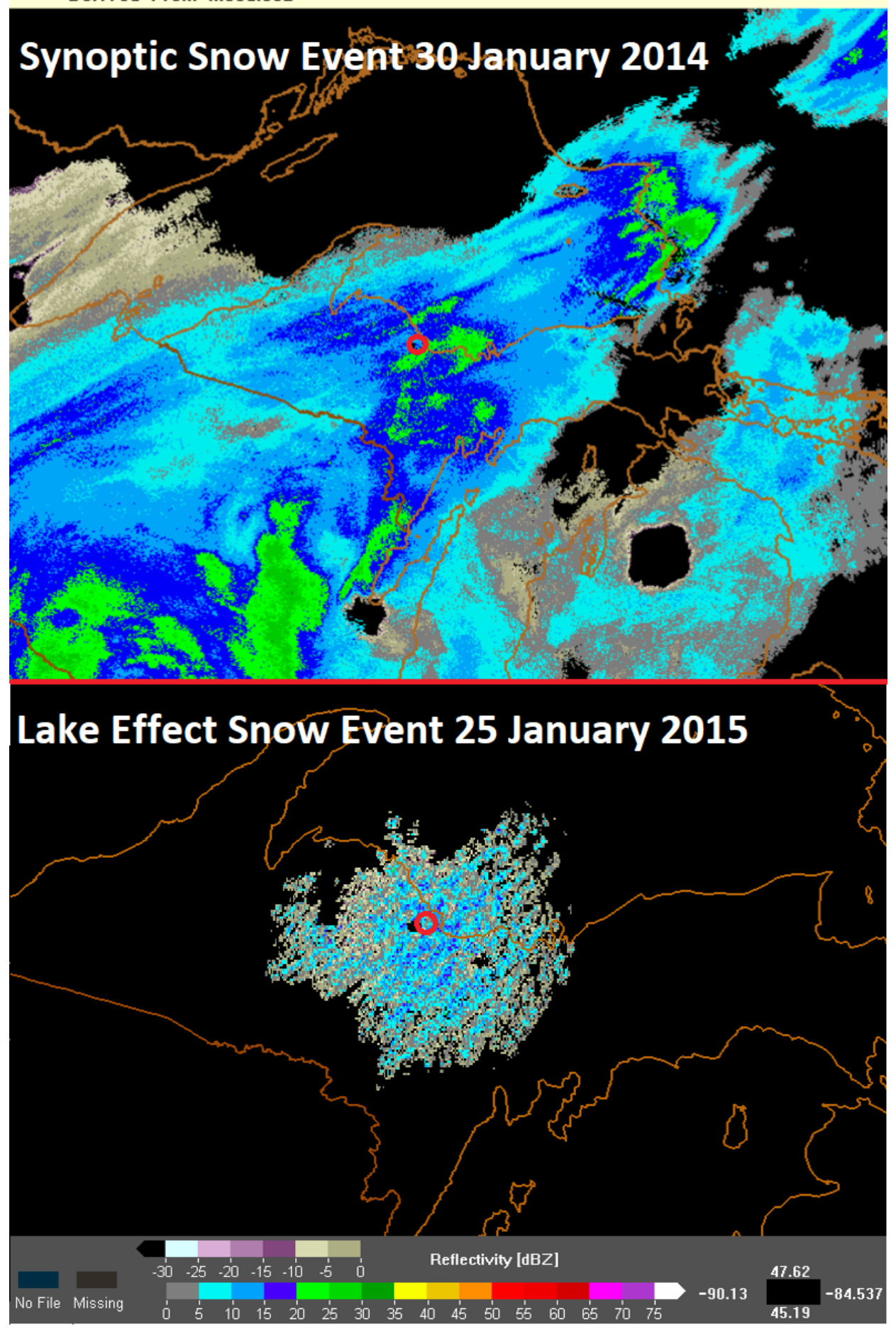

Figure 2.6.13 Comparison between a deep event (30 Jan '14) and a shallow event (25 Jan '15). The NWS Office in Marquette is identified with a red circle. The shallow event is local and show the classic banded behavior. (MRMS NSSL). 

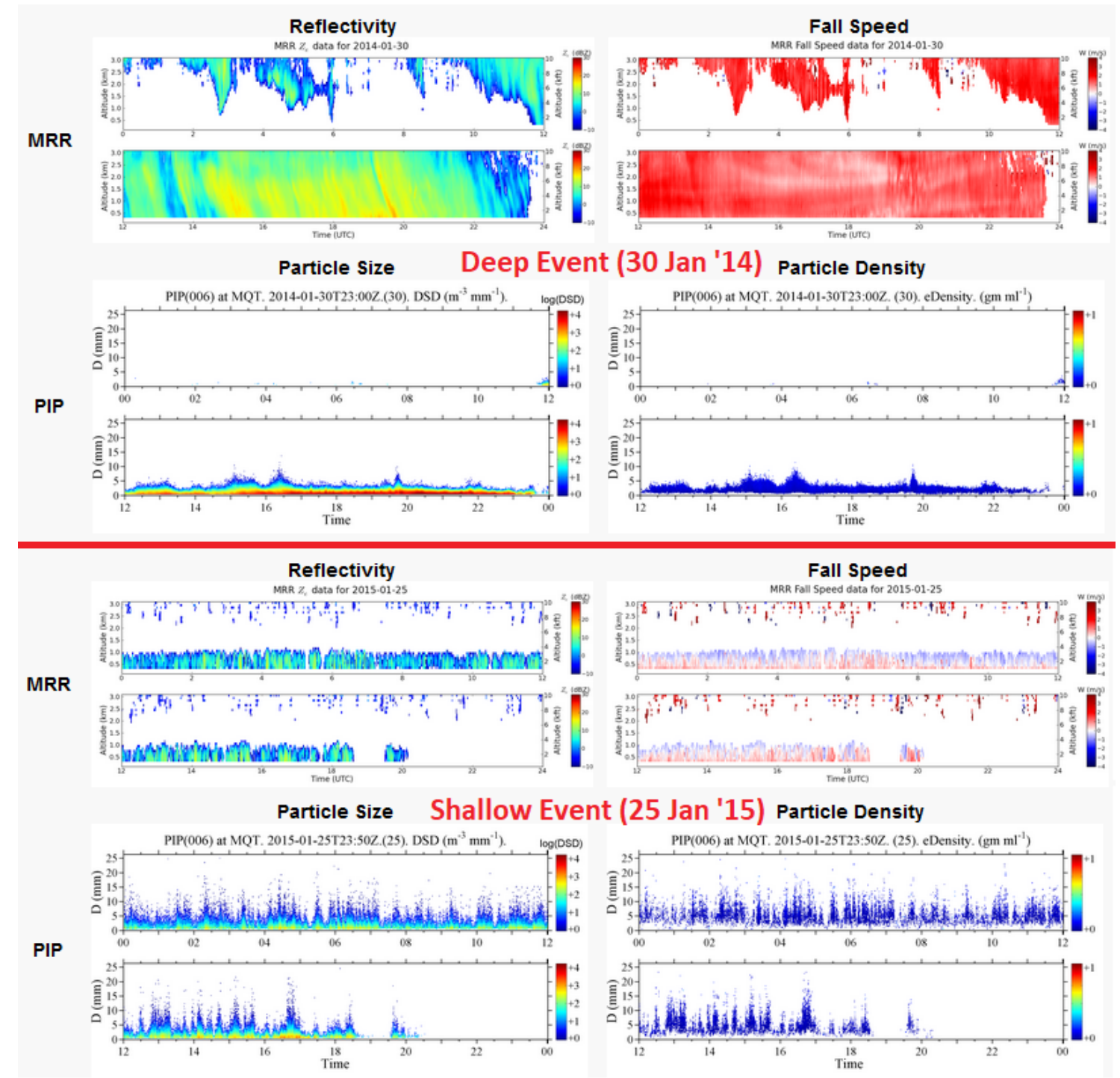

(25 Jan '15) Particle Density

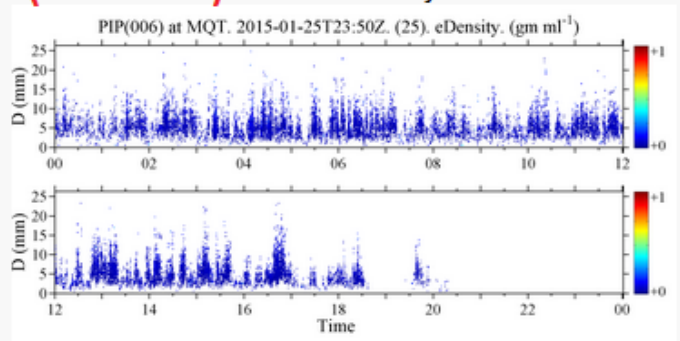

Figure 2.6.14 Comparison between a deep event (30 Jan '14) and a shallow event (25 Jan '15). The particle size distribution underlines the remarkable difference as far as it concerns snowflakes dimensions. 
In order to validate the two main characteristic from the MRR instrument, in the following images will be presented the differences between a Synoptic Snowfall Event and a Lake Effect Snow Event (Figure 2.6 .15) that are underlined with the parameters Cloud Top Height $(\mathrm{CTH})$ and vertical $\Delta \mathrm{Z}$ (Figure 2.6 .16). The CTH value is calculated for each minute of the MRR profile and starts from the first bin available (300 $\mathrm{m}$ above ground level) analyzing the vertical profile, until the next bin does not have any value of reflectivity or has reached the highest bin available, providing the height of the top of the cloud. It is noticeable how the trend of CTH for the deep event is quite constant and is represented by a horizontal line at a value of $3000 \mathrm{~m}$, meanwhile, for the shallow event, the line has a distinct pulse already discussed previously and it does not extend over $1500 \mathrm{~m}$. Another main key observed from the MRR plot is that the reflectivity for a synoptic snowfall is overall uniform along the time axis and the vertical axis. The vertical $\Delta \mathrm{Z}$ evaluates the difference of reflectivity between the first bin available at $300 \mathrm{~m}$ and the last bin identified by CTH value. A deep event and a shallow event present a different characteristic as far as concerns the $\Delta \mathrm{Z}$ values during the period of investigation, having a small range of values for the synoptic snowfall $(0-5 \mathrm{dBZ})$ and a bigger range (almost $20 \mathrm{dBZ})$ for the LES. It can be assumed that $\Delta \mathrm{Z}$ is almost constant and slowly varying for a synoptic event and pulsating for a LES event, showing that the fluctuation is not only visible by the cloud top height, but also the reflectivity values.
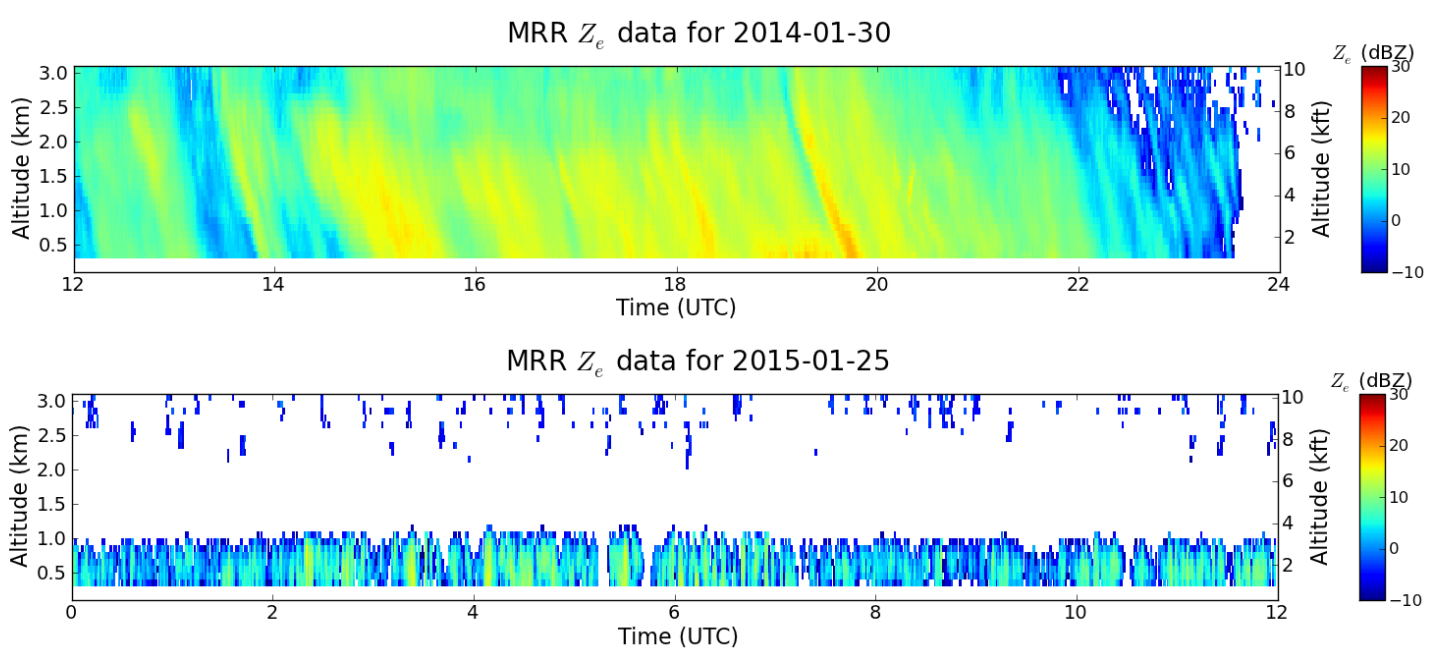

Figure 2.6.15 Reflectivity profiles of a deep event (30 Jan' 14) and a shallow event (25 Jan '15). Portion of 12 hours used for the analysis. 

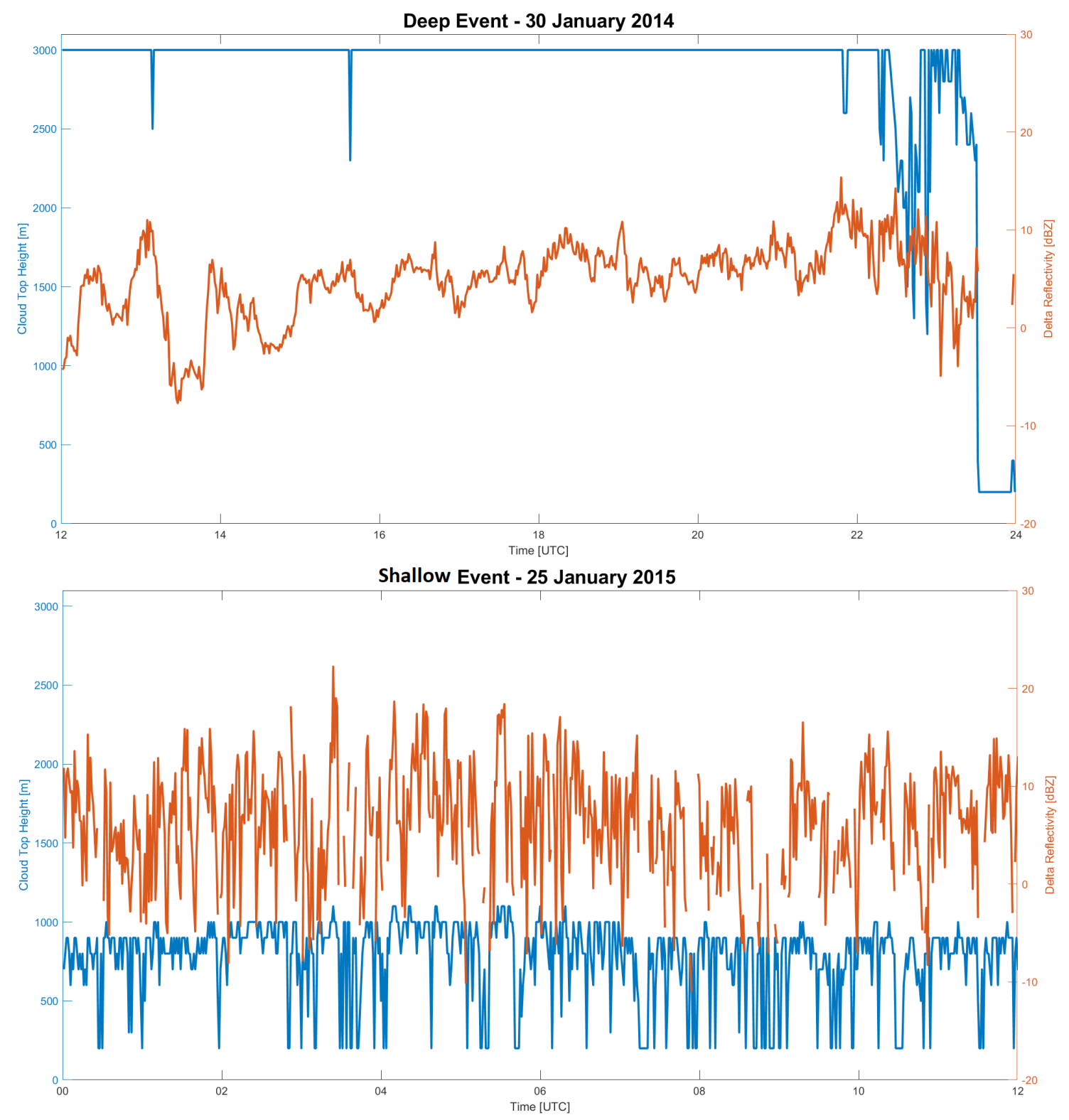

Figure 2.6.16 CTH and $\triangle Z$ profiles of a deep event (30 Jan '14) and a shallow event (25 Jan '15). The blue lines represents the trend of the Cloud Top Height and the red line represents the trend of $\Delta Z$. The shallow event shows its characteristic pulse in both profiles. 
Using the aforementioned values it is clear that the characteristic of the two events are significantly different and therefore it is possible to use them to have a preliminary sorting of the events, in order to continue with the statistical analysis. As already discussed, only days with one type of event will be taken into consideration to evaluate possible thresholds, in favor of reducing any statistical error. Six types of categories (Table 3.1.1 .2) have been created and their distribution has been normalized to the total number of days available and then plotted into a bar histogram (Figure 2.6 .17 ) to evaluate the frequency of each class.

\begin{tabular}{cc}
\hline Used Categories & Not Used Categories \\
\hline Synoptic Snow (Syn) & Nothing \\
Lake Effect Snow (LES) & Rain \\
& SnowRain \\
& MixSnow \\
\hline
\end{tabular}

Table 3.1.1.2 Categories created for the preliminary sorting.

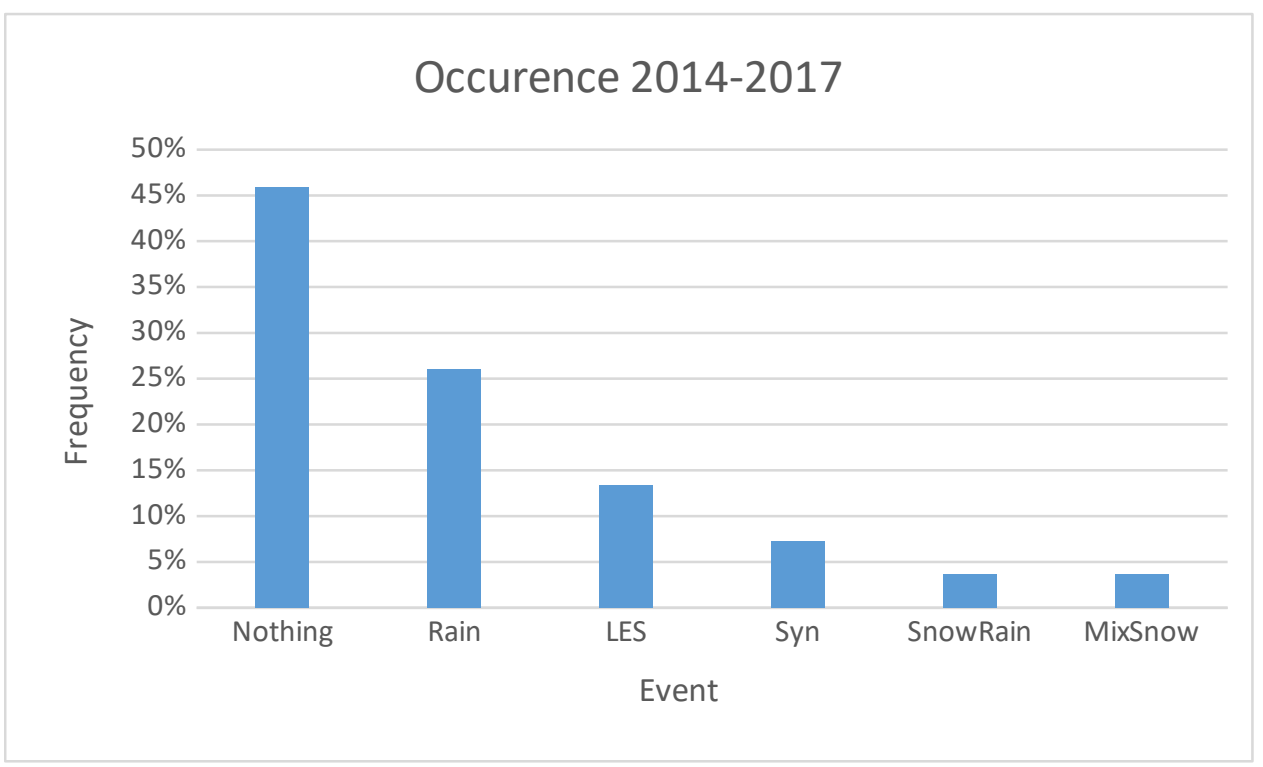

Figure 2.6.17 Occurrence of each category during the 2014-2017 period. "Nothing" includes every day that did not record any precipitation (rain or snow), "Rain" includes every day that presented a rain precipitation, "LES" includes every day that had a Lake Effect Snow type precipitation, "Syn" includes every day that showed a synoptic snow type precipitation, "SnowRain" includes every day where happened both a snow type and a rain type precipitation, simultaneously or during different period of the day and "Mix Snow" includes every day that recorded more than one type of snow precipitation, whether it was simultaneously and creating and embedded effect or during different period of the day. 
The high frequency on the class "nothing" is due because every day of the year has been taken into consideration and the snow events occur only during few months, therefore most of the time there are days without any precipitation, that could include snow or rain, and they are predominant in the statistic. Remarkable is the difference between the occurrence of a synoptic snowfall and a Lake Effect Snow, where, even if they produce the same amount of snow accumulation, the LES occurs twice as much as a deep event (Maahn and Kollias, 2012).

Considering a monthly distribution of the events (Figure 2.6 .18 ), it is clear how there are two distinct season: a rainy one (from April to October) and a snowy one (from November to April). For this reason, in this study only months from November to April will be taken into consideration for the statistical analysis of snowfall characteristics. Plotting the same data, but normalizing to a yearly distribution (Figure 2.6 .19), it is possible to assume a specific trend for each event during the years 2014, 2015, 2016 and 2017. Suriano and Leathers (2017) have found that the LES event exhibits a 60-years increasing trend, our dataset is too small to produce an accurate statistic and therefore it is not possible to elaborate a precise hypothesis regarding this subject.

Figure 2.6 .20 presents the distribution for each event during the period 2014-2017, showing the number of days of occurrence for each year. It is noticeable a positive trend for the rain event that keeps increasing, going from 64 days in 2014 to 106 days in 2017, almost doubling its occurrence. Anyway, it is necessary to clarify that days from the category "SnowRain" have not been taken into consideration for this plot, but their occurrence can be considered constant, having 12 days of "SnowRain" in 2014, 2016 and 2017 and 14 days in 2015, meaning that they would not change the distribution of the "Rain" category. As already mentioned in the previously image, the "LES" category still presents a slightly positive trend, going from 27 days in 2014 to 52 days in 2017, meanwhile the "Synoptic" category has a minor negative trend, having 35 days in 2014 and 14 days in 2017. As previously stated, the dataset has only a 4 years period, therefore it is difficult to demonstrate if these numbers are part of an ongoing trend or they are just yearly fluctuations and in a longer period, the statistics flatten out. 


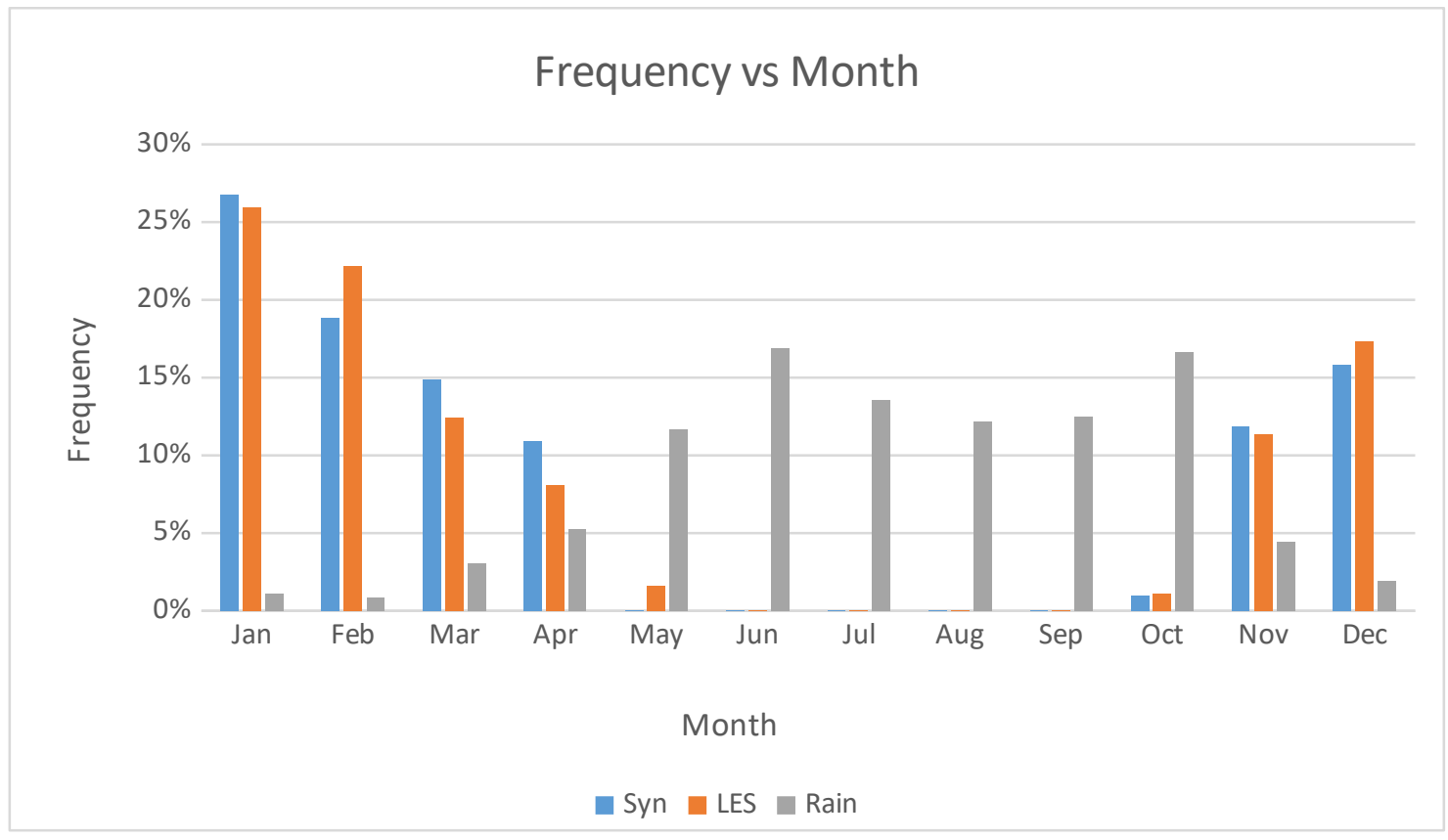

Figure 2.6.18 Monthly distribution for Synoptic Snow, Lake Effect Snow and Rain events. Each event has been normalized on the whole year and it shows the frequency for each month.

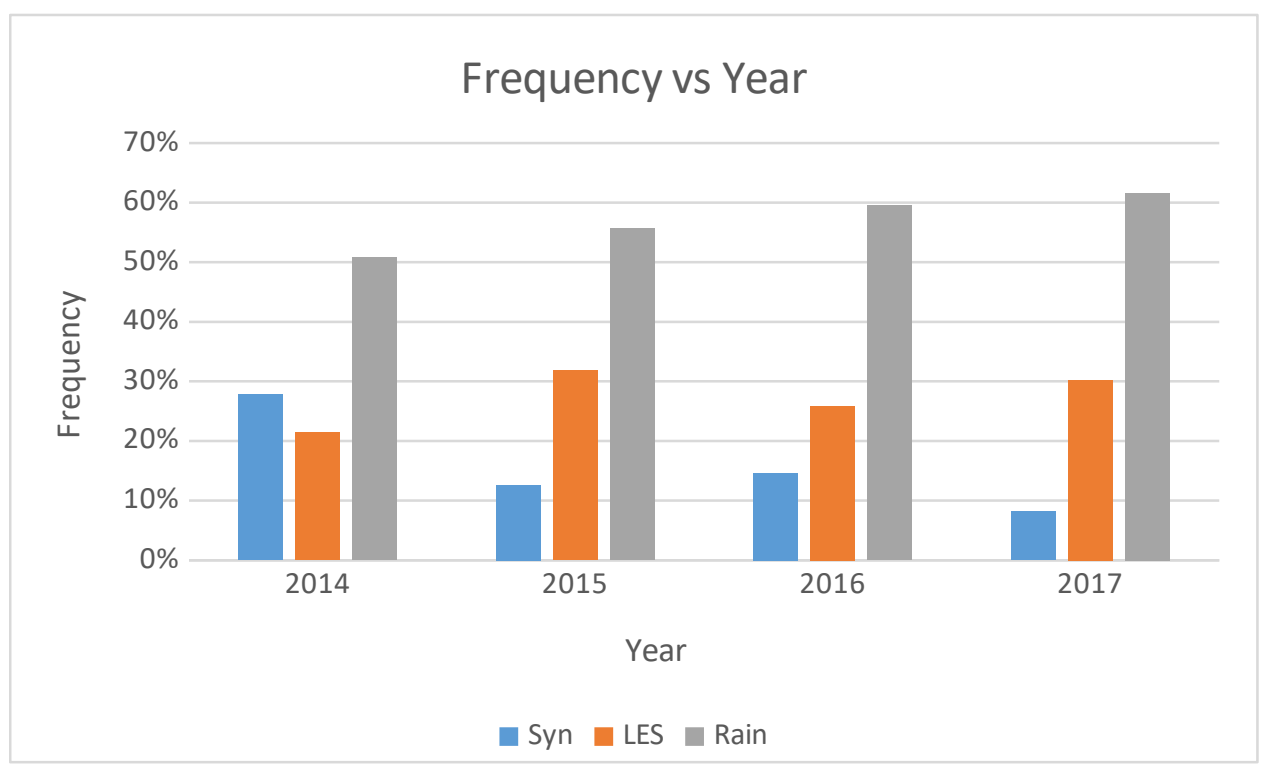

Figure 2.6.19 Yearly distribution for Synoptic Snow, Lake Effect Snow and Rain events. Each event has been normalized on each year. 


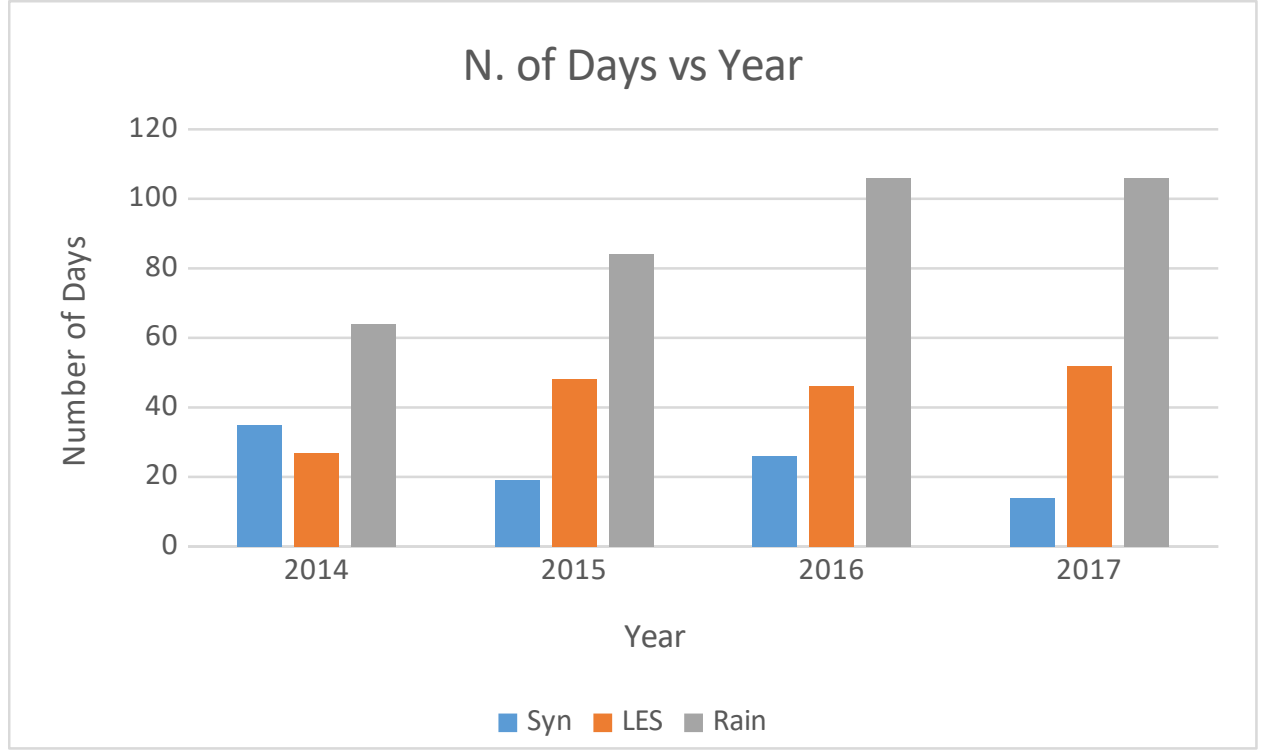

Figure 2.6.20 Yearly distribution for Synoptic Snow, Lake Effect Snow and Rain events. The histogram shows the number of days for each category divided by years.

After all the data set has been sorted into different classes, dividing mainly days into rain, synoptic snow and Lake Effect Snow categories, it is possible to proceed with the statistical study of each variable, listed in Table 3.1.1 .3, where they are divided based on the information provided. To increase the significance of each analysis, every value has been merged into its corresponding day (Figure 2.6 .21) and few portions have been discharged, because they did not have all the information available, due to some instrument technical problems.

\begin{tabular}{|c|c|c|c|c|c|c|c|}
\hline \multicolumn{2}{|c|}{ From 0 to $3000 \mathrm{~m}$ AGL } & \multicolumn{2}{|c|}{$300 \mathrm{~m}$ AGL } & \multicolumn{4}{|c|}{ Surface Data $0 \mathrm{~m}$ AGL } \\
\hline Reflectivity (DBZ) & $\overline{[\mathrm{dBZ}]}$ & $\overline{D B Z}$ & {$[\mathrm{dBZ}]$} & $\begin{array}{l}\text { Particle } \\
\text { (PSD) }\end{array}$ & Size & Distribution & {$\left[\mathrm{m}^{-3} \mathrm{~mm}^{-1}\right]$} \\
\hline Dop. Velocity (VEL) & {$\left[\mathrm{m} \mathrm{s}^{-1}\right]$} & $V E L$ & {$\left[\mathrm{~m} \mathrm{~s}^{-1}\right]$} & Surface & emperatur & & {$\left[{ }^{\circ} \mathrm{C}\right]$} \\
\hline \multirow[t]{4}{*}{ Spectral Width (SW) } & {$\left[\mathrm{m} \mathrm{s}^{-1}\right]$} & $S W$ & {$\left[\mathrm{~m} \mathrm{~s}^{-1}\right]$} & Relative & Humidity & & {$[\%]$} \\
\hline & & & & Surface & ressure & & [hPa] \\
\hline & & & & Wind S & & & {$\left[\mathrm{m} \mathrm{s}^{-1}\right]$} \\
\hline & & & & Wind I & rection & & {$\left[{ }^{\circ}\right]$} \\
\hline
\end{tabular}

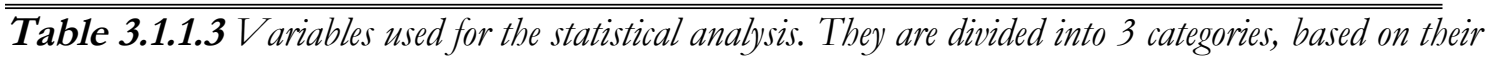
resolution. 


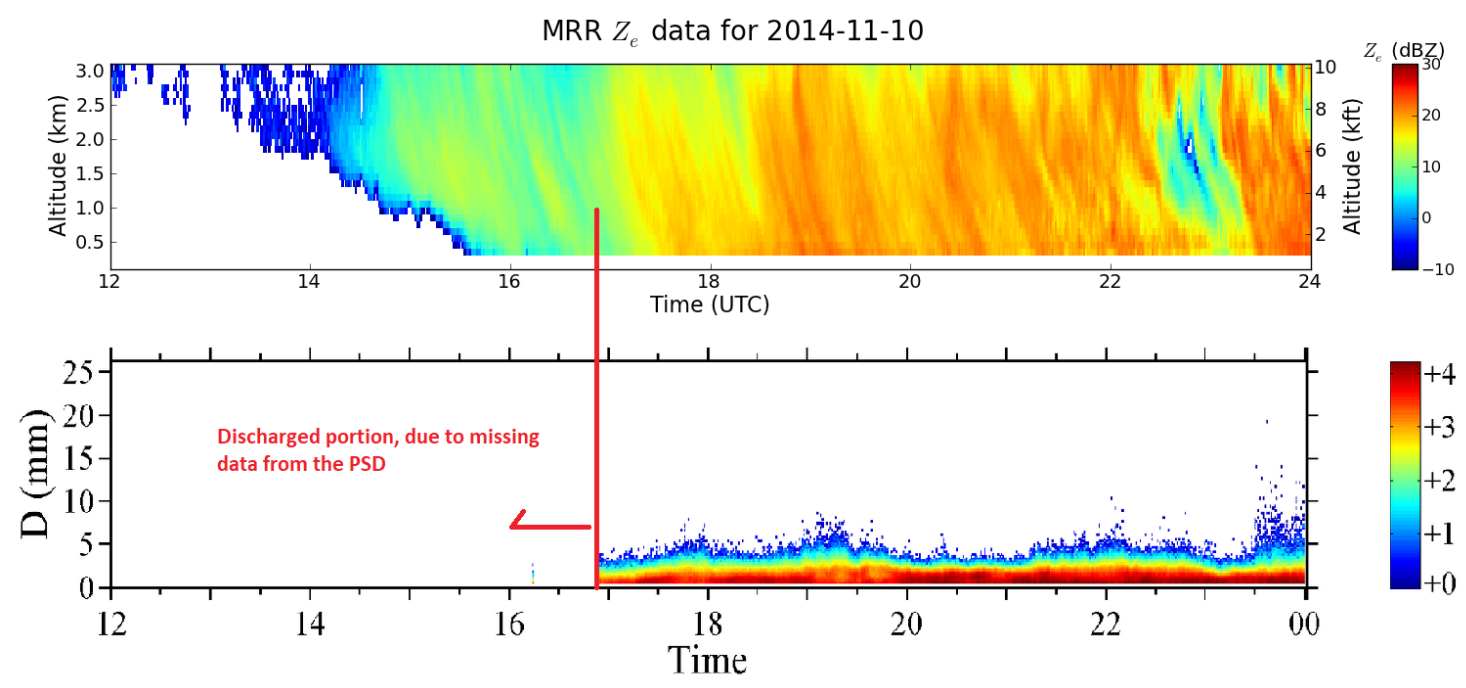

Figure 2.6.21 Deep event (10 Nov '14). Top panel reflectivity profile and bottom profile Particle Size Distribution. The first part of the event has been discharged because the PSD data was missing and could not be merged.

Additionally, only portions of the day with snowfall events are taken into consideration, reducing the amount of noise and errors in the data set. An algorithm compares iteratively reflectivity with effective density and only bins with both of those values will be used, meaning that in that specific time there is a particle reaching the surface and it is available its reflectivity vertical profile (Figure 2.6 .22). This process removes parts of clouds that do not produce any snowfall and removes most of the signal noises in the top layers; it increases significantly the accuracy of the study, but, due to its simplicity, sometimes will cut off the first or last portion of some events. 


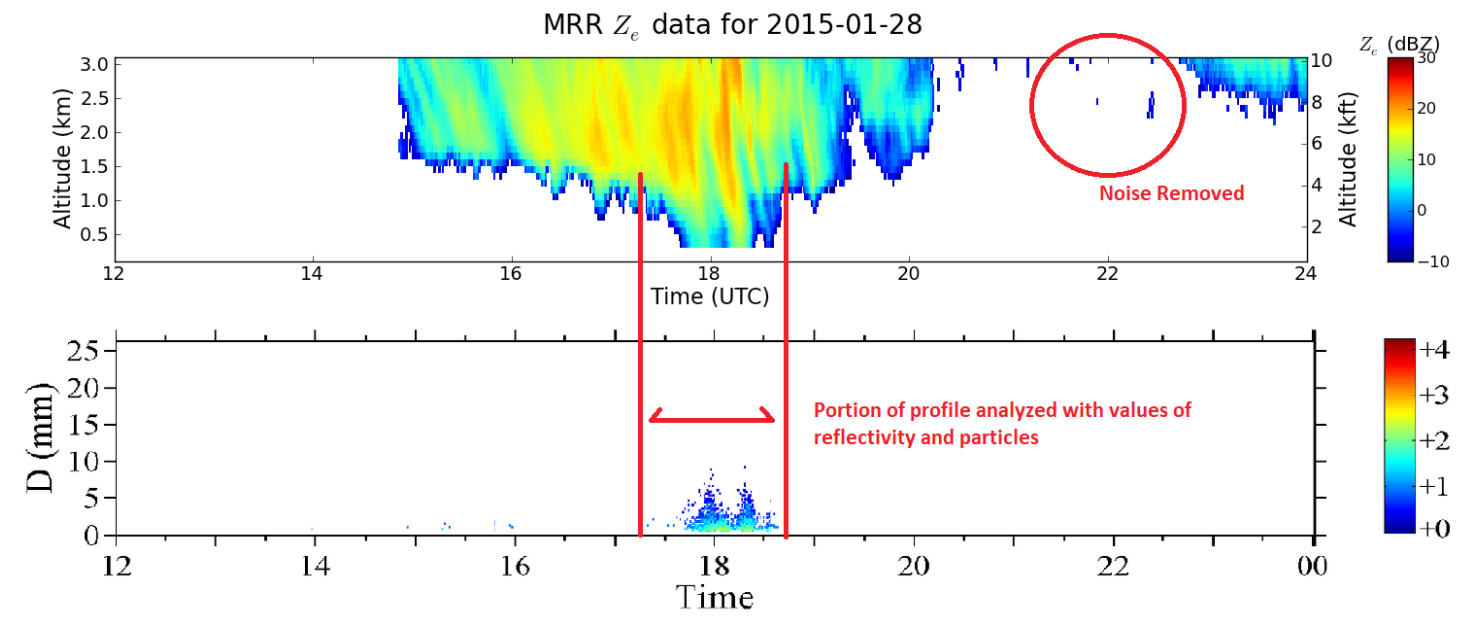

Figure 2.6.22 Synoptic Event and Virga (28 Jan '15). The image shows the type of noise removed and the portion of the event used for the analysis.

Before starting with the elaboration of the data and provide the results, in the following images will be presented the characteristic of each category that is not being considered in the main study to obtain threshold values, but will eventually be used to validate the algorithm.

Figure 2.6 23 presents an event that has been classified as mixed snow and it could have either two separate events in the same day or two events happening at the same time. The characteristics proposed previously regarding the MRR and PIP instruments are both present. The reflectivity has a pulse behavior below $1500 \mathrm{~m}$, which could indicate a LES event, but then starts to become uniform past that level, which is typical of a synoptic event. In addition, the particle size distribution suggests a bimodal trend, with both a pulse and uniform behavior. 

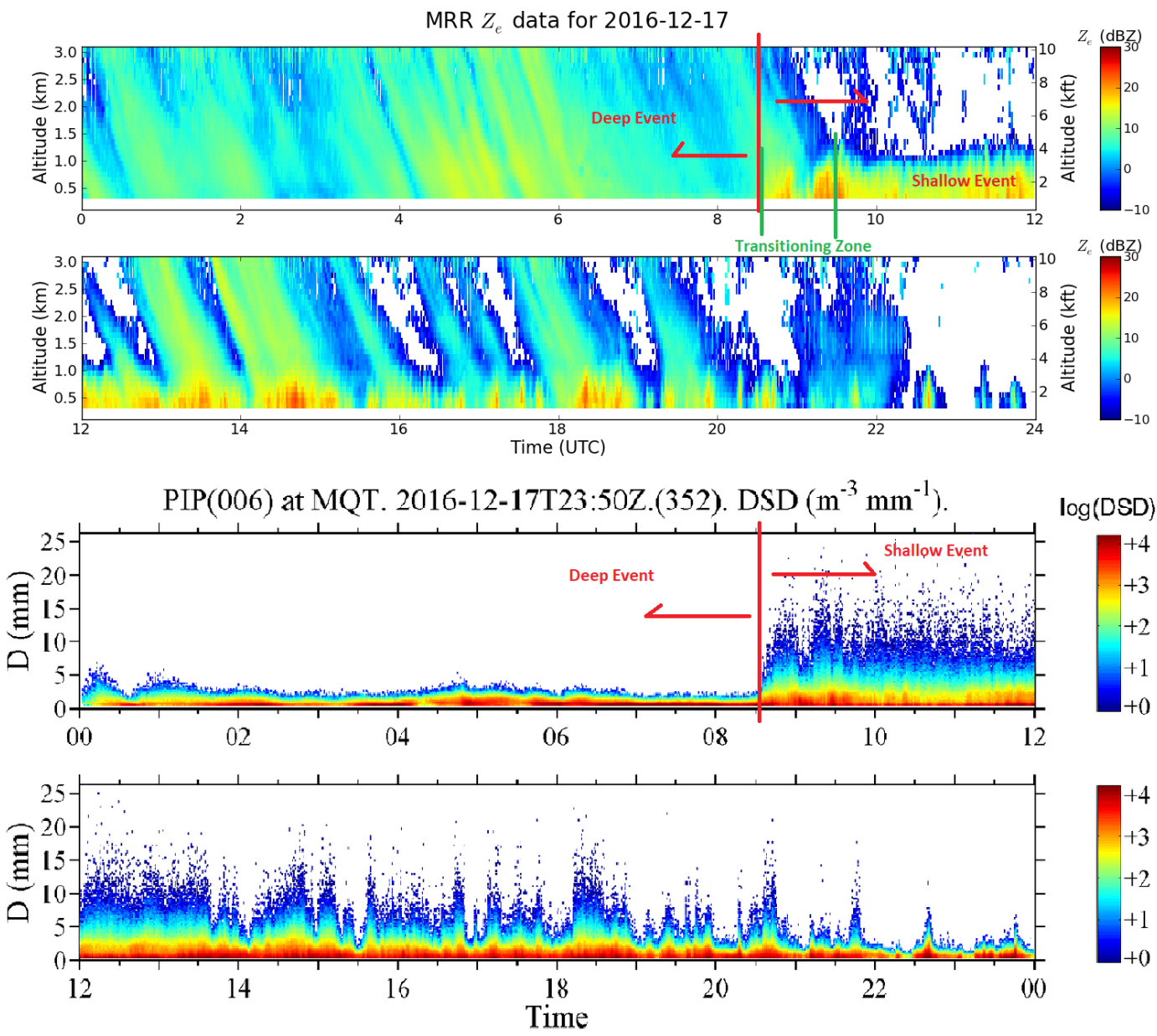

Figure 2.6.23 Deep and Shallow event presented in the same day (17 Dec '16). The green area suggests a transitioning portion from a synoptic system to a Lake Effect Snow event. Remarkable is the difference in the PSD profile, with low diameter values in the first part and high diameter with a pulse trend in the second part.

Figure 2.6.24 shows a day with a transition from a wet event to a snowy one. It is not possible to distinguish rain from snow using reflectivity or fall speed values, since it is not possible to find any difference. For this reason, it is helpful to utilize the particle size and density distribution, where it is evident that there are two separate events. Looking at the particle size distribution, the first portion is dominated by small particles until 02h00 UTC and then the plot shows a higher number of particles with a diameter that could reach up to $10 \mathrm{~mm}$. The same behavior can be found with the particle density distribution, where the density of each particle averages from 0.6 to $1.0 \mathrm{~g} \mathrm{ml}^{-1}$ and then, from $02 \mathrm{~h} 00 \mathrm{UTC}$, values drop to $0.3 \mathrm{~g} \mathrm{ml}^{-1}$ that would mean the presence of snowflakes. In this case, the wet event could be identified as sleet and not proper rain. 

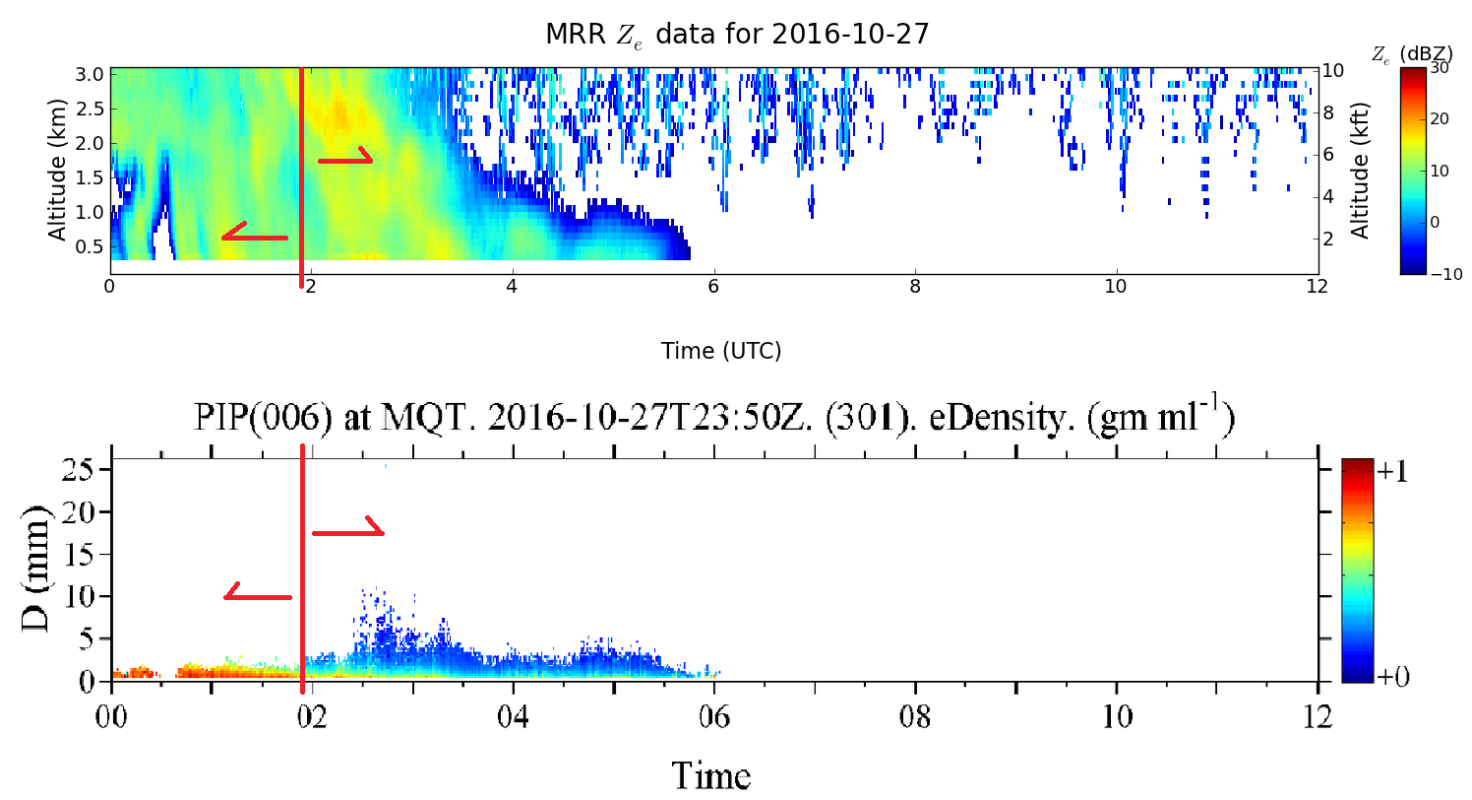

Figure 2.6.24 Transition from a wet event to a snowy one on 27 Oct'16.

Another snowfall event captured by the MRR is the orographic event (Figure 2.6 .25). An orographic lift occurs when an air mass is forced from a low elevation to a higher elevation, as it moves over rising terrains. As the air mass gains altitude it quickly cools adiabatically, which can raise the relative humidity to $100 \%$ and create clouds and, under the right conditions, precipitation. While the orographic enhancement of rainfall has been widely studied by numerical and field studies, a smaller number of studies investigated the precipitation during a winter storm (Mott et al, 2014). 


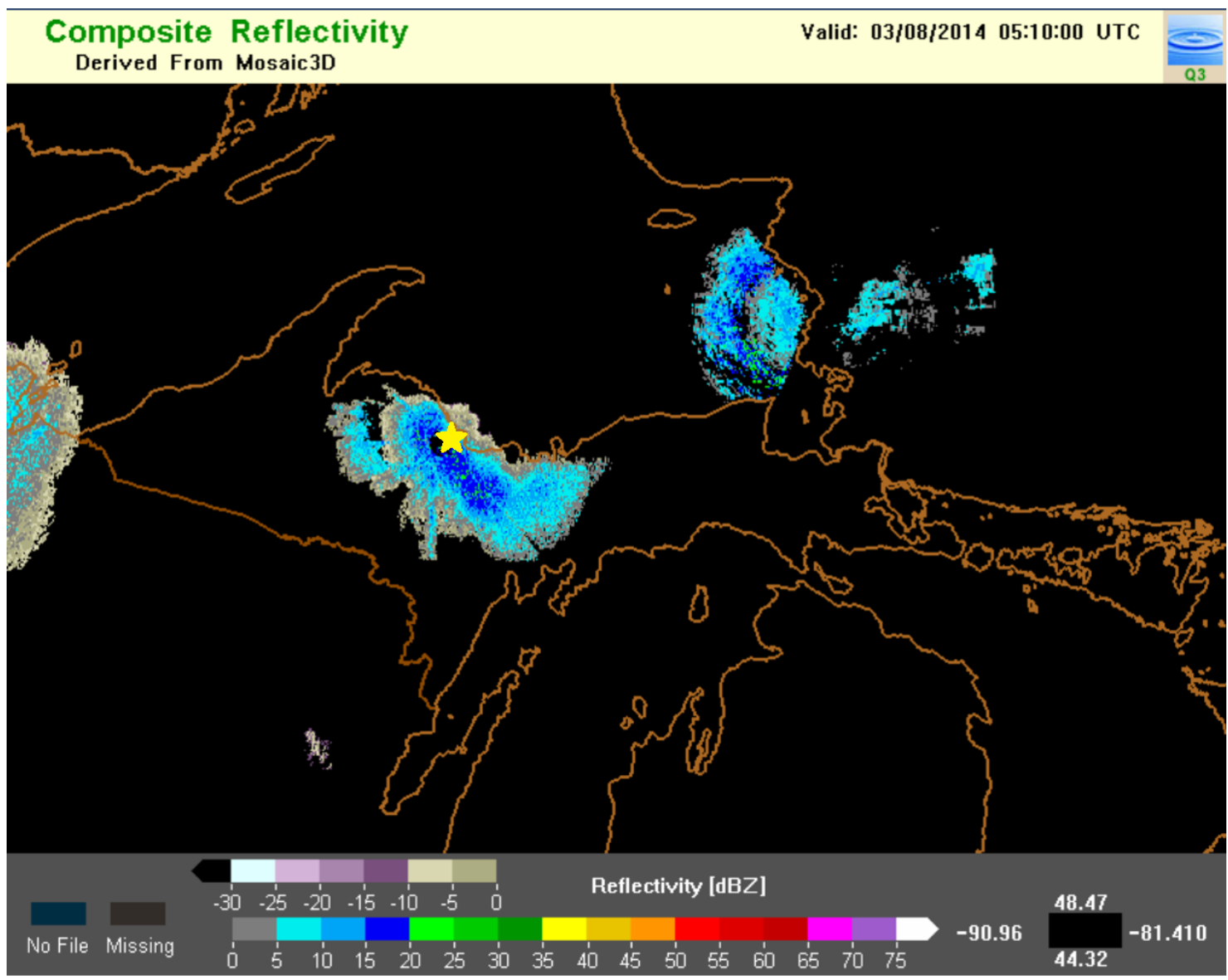

Figure 2.6.25 Orographic event (08 Mar '14). The National Weather Service Office in Marquette is indicated with the yellow star. (MRMS NSSL).

During this study, only few events have been identified as an orographic enhancement snowfall and therefore it has not been possible to produce a significant statistical analysis for them. The characteristics are different from the deep or shallow event, the reflectivity profile is still below the $1000-1500 \mathrm{~m}$ level, but there is no clear pulse and the reflectivity values (Figure 2.6 .26 ) are uniform and range from 0 to $10 \mathrm{dBZ}$. The particles have huge dimensions, almost reaching a $25 \mathrm{~mm}$ diameter, but do not present a significant pulse in the particle size distribution (Figure 2.6 .27), as it was noticed with the Lake Effect Snow event. In this day, the wind direction was from NNE and the lake was mostly frozen. 


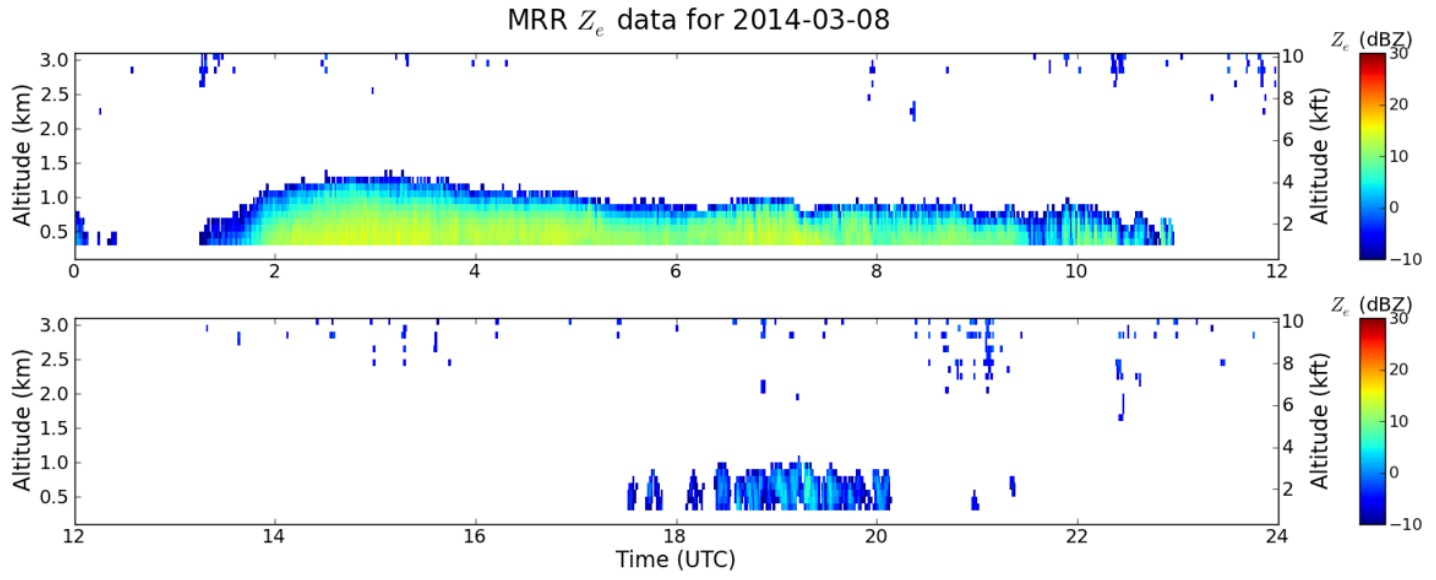

Figure 2.6.26 Orographic Event (08 Mar'14). Reflectivity profile from MRR. No pulse in either CTH or reflectivity values.
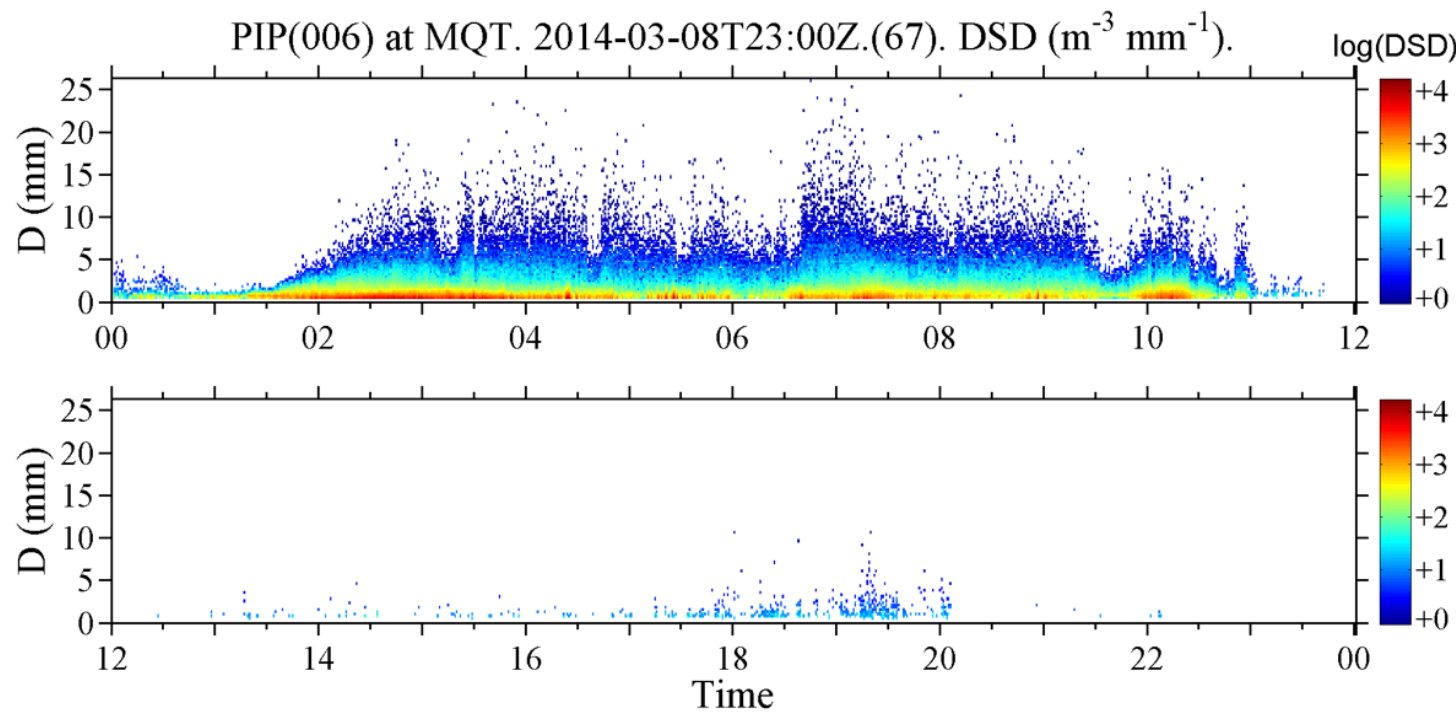

Figure 2.6.27 Orographic Event (08 Mar'14). No clear pulse in the PSD and high diameter values. 
Figure 2.6.28 shows a phenomenon described as Virga, which is a shaft of precipitation falling from a cloud that evaporates or sublimates before reaching the ground, hence the PIP instrument does not record any falling particle. In this specific case, the PIP measures some particles falling in that period due to the orographic event still happening. The reflectivity is similar to a deep event.

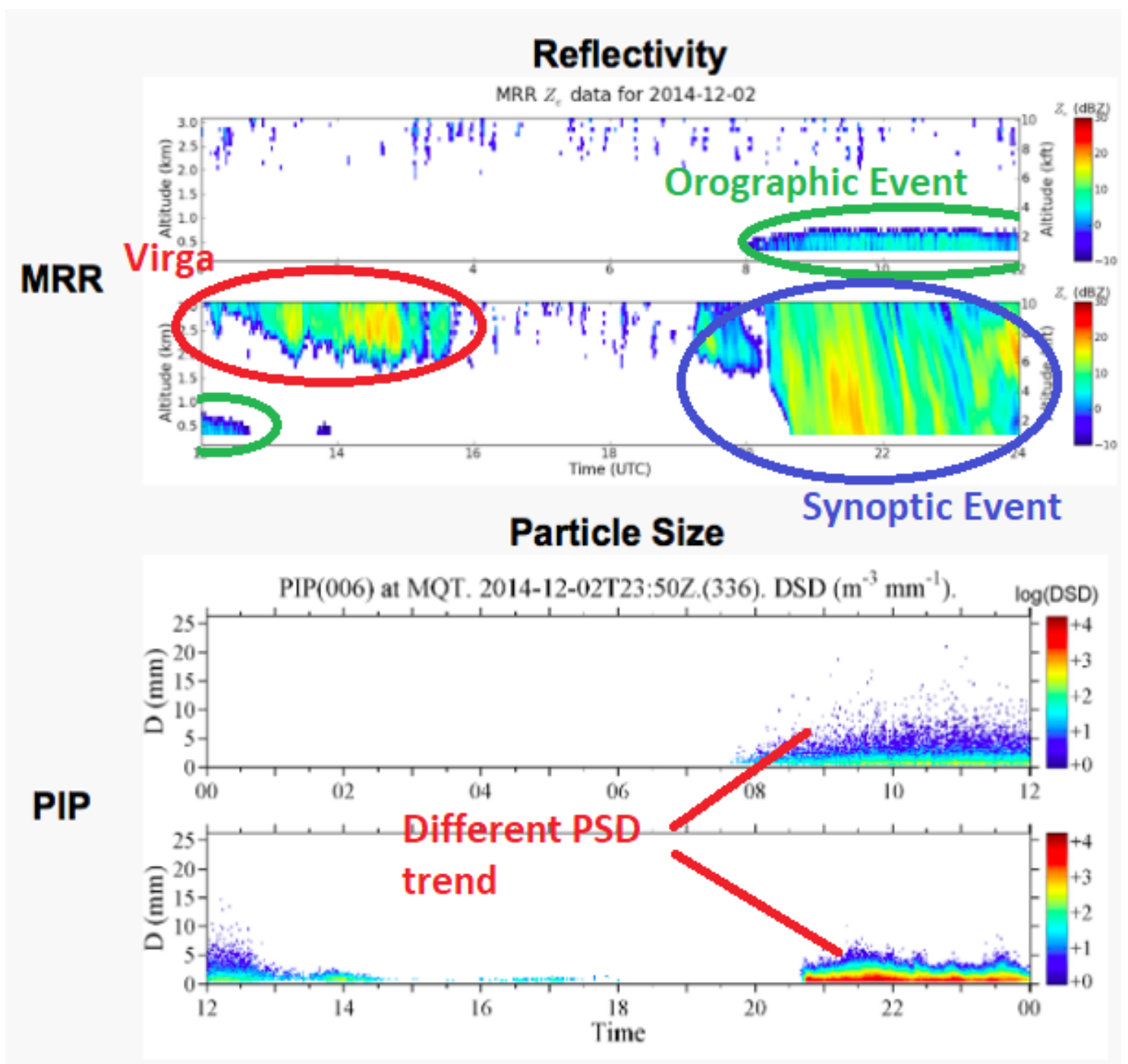

Figure 2.6.28 Single day (02 Dec'14) with multiple types of event. In the red circle is presented a Virga event, in green an Orographic event and in blue a Synoptic event. 
Lastly, Figure 2.6 .29 shows a Lake Effect Snow event embedded in a Synoptic event. In the NEXRAD map it is possible to notice how the event is widely spaced, characteristic of a deep event, but, with a higher reflectivity, it is evident the banded patter of a LES event.

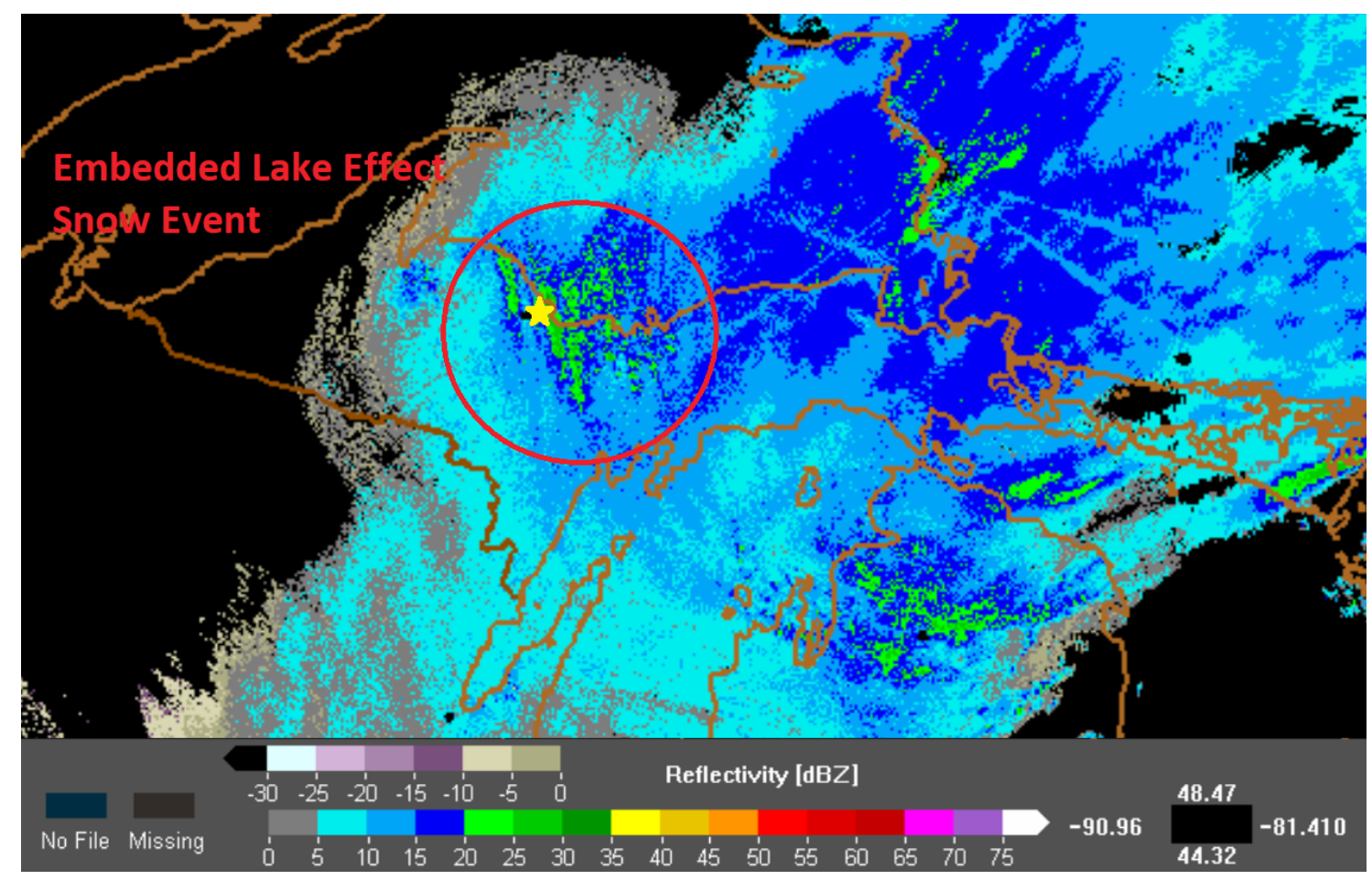

Figure 2.6.29 Embedded LES event (11 Nov '14). The National Weather Service Office in Marquette is indicated with the yellow star. (MRMS NSSL). 
In addition, the reflectivity profile obtained from the MRR (Figure 2.6 .30) suggests both characteristics from a deep event and a shallow event. The reflectivity values below $1000 \mathrm{~m}$ have a pulsating pattern, but after that altitude, they start becoming uniform. In the PSD plot, there are alternations of high diameter particles with a fluctuating pattern and low diameter particles with a constant trend.

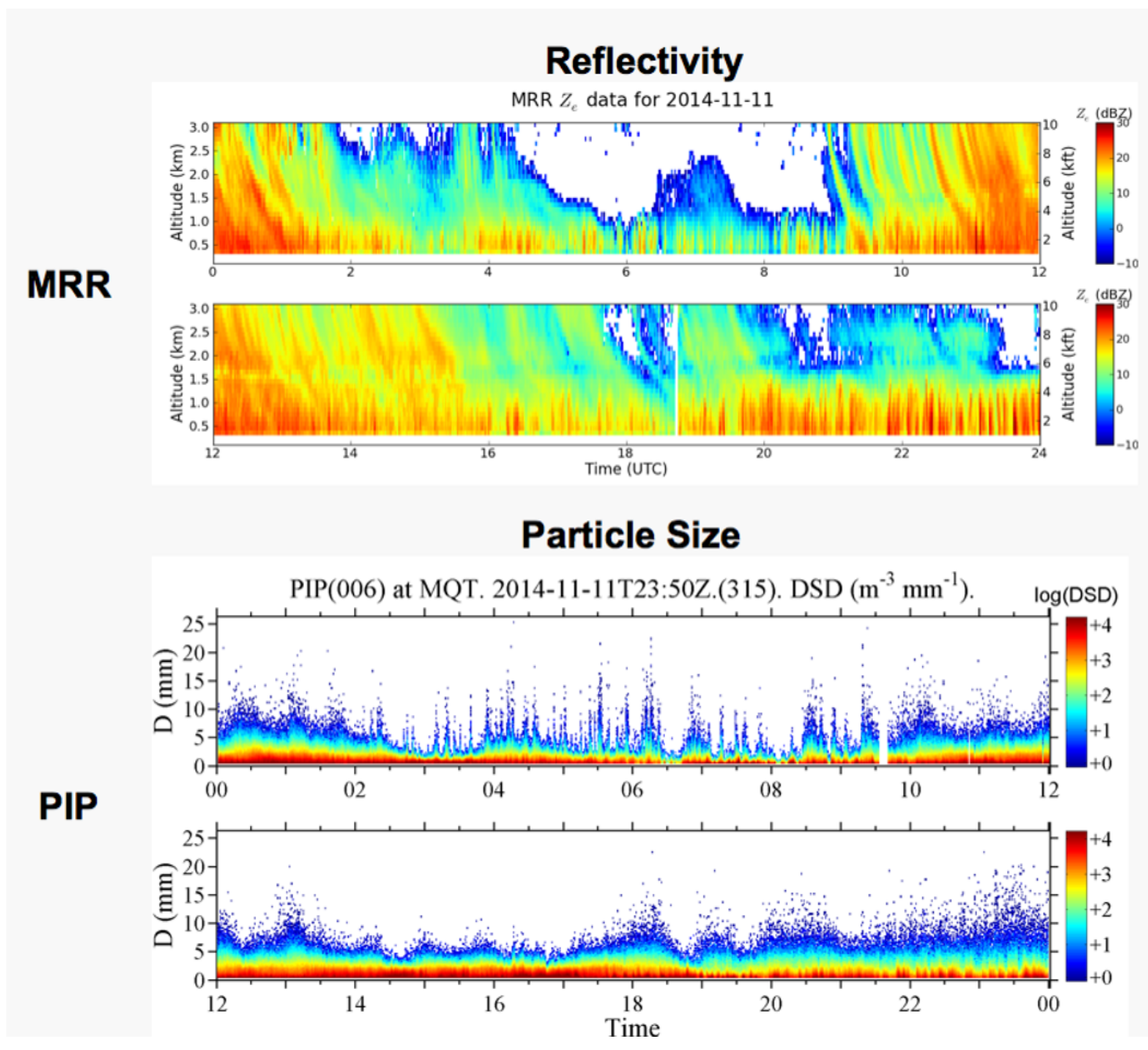

Figure 2.6.30 MRR and PIP profiles of an embedded LES event (11 Nov'14). 


\section{Results and Discussion}

As it has been discussed previously, a preliminary sorting has been performed on the entire dataset from 2014 to 2017 and it identified 101 deep event days, 185 shallow event days and 361 rain days. This method did not take into account the duration of the event, but only if a precipitation of a specific type was either happening or not. Subsequently, MRR data and PIP data have been merged and only bins with values from both instruments are used, providing a more accurate information regarding the duration of each event. Based on the parameter used and the instrument availability, the time length could fluctuate for each event type, but, on average, 101 deep event days had 642 hours of precipitation, 185 shallow event days had 1433 hours of precipitation and 361 rain days had 1180 hours of precipitation. These results show that snow, on average, occurred the $26.5-32.2 \%$ of the time and rain, on average, occurred the $13.6 \%$ of the time (Table 3.1.1.4).

\begin{tabular}{lccc}
\hline Event Type & Total days & Total Hours & $\%$ Occurrence \\
\hline Deep Event & 101 & 642 & $26.5 \%$ \\
Shallow Event & 185 & 1433 & $32.2 \%$ \\
Rain & 361 & 1180 & $13.6 \%$ \\
\hline \hline
\end{tabular}

Table 3.1.1.4 Occurrence of each event type during the period 2014 - 2017. 


\subsection{Precipitation Imaging Package (PIP) Observations}

The Precipitation Imaging Package has proven to be a powerful instrument to analyze microphysical properties of an ongoing precipitation at a surface level. In the following chapters there will be presented the results regarding two main information obtained with the PIP: effective density (eDens) and the Particle Size Distribution (PSD). As discussed previously, the analysis regarding the density values is a great tool to separate rain events from snow events. In addition, the PSD could give a substantial insight regarding this categorization, but with certain precipitation types, it will not provide a considerable level of confidence.

\subsubsection{Effective Density (eDens)}

Density is an important physical property, it is well known when it comes to a rain event, since rain droplets are made of liquid water and its density is recognized widely to be close to $1 \mathrm{~g} \mathrm{ml}^{-1}$, but it is not as easy to define that value for a snowflake. The snow density is regulated by (a) in-cloud processes that affect the shape and size of growing ice crystals, (b) subcloud processes that modify the ice crystal as it falls, and (c) ground-level compaction due to prevailing weather conditions and snowpack metamorphism (Robber et al., 2003). Generally, a bigger crystal will have a lower density value, compared to a smaller crystal. The current prediction of snowfall amounts is obtained either by using empirical techniques or using a standard correlation of Liquid Water Equivalent (LWE) precipitation such as the "10 to 1" ratio. This rule is particularly popular among operational forecasters, even if it comes to a study that Potter J.G. did in 1965 (Roebber et al., 2003). Judson and Doesken (2000) conducted a study on freshly fallen snow to evaluate its density, using the snow depth and the LWE from melted snow and study plots ranged from 0.01 to $0.25 \mathrm{~g} \mathrm{ml}^{-1}$, while peak frequencies were between $0.07 \mathrm{~g} \mathrm{ml}^{-1}$ and $0.11 \mathrm{~g} \mathrm{ml}^{-1}$. The density value used in this study is not calculated from LWE and its correlation with snow depth, meaning that it is not affected

by the compaction once the snowflakes reach the ground, but it is obtained from an empirical algorithm from the PIP instrument, which provides measurements as the particles fall and therefore it is used the term effective density. 
For this analysis have been investigated $587 \mathrm{~h}$ for deep events, $1444 \mathrm{~h}$ for shallow events and $1107 \mathrm{~h}$ for rain events in order to obtain a statistic concerning the effective density of the particles passing through the PIP instruments. It has been processed a histogram analysis to evaluate the central tendency, variability, and shape of each distribution. Values higher than 1 $\mathrm{g} \mathrm{ml}^{-1}$ have been disregarded, because not related to this specific case of study of snow/rain and values below or equal to $0 \mathrm{~g} \mathrm{ml}^{-1}$ have been removed, due to probable errors and being physically impossible to have a negative or null density value.

Each distribution has been normalized as a probability function, so that the sum of each element is equal to 1 and the bin width has been set up equal to 0.02 units. Figure 3.1 .31 proposes a plot with all three types of events ranging from 0 to $1 \mathrm{~g} \mathrm{ml}^{-1}$ and fig Figure 3.1 .32 shows a close up with deep and shallow events, having a smaller scale, going from 0 to $0.3 \mathrm{~g} \mathrm{ml}^{-1}$ and a bin width of 0.1 units. It is evident how each type of precipitation has a distinct effective density. It is evident how the eDens values are mostly below $0.3 \mathrm{~g} \mathrm{ml}^{-1}$ for any type of snow event observed in this study, whereas there are two clear peaks for the rain type. The smaller peak at $0.6-0.7 \mathrm{~g} \mathrm{ml}^{-1}$ could be linked to the type of precipitation called sleet, which is composed of rain and partially melted snow and it contains some traces of ice crystals, from partially fused snowflakes. The prominent peak at $0.9-1 \mathrm{~g} \mathrm{ml}^{-1}$ demonstrates the intrinsic physical property of a rain droplet, which is formed by liquid water and therefore has a density value close to it. Figure 3.1 .32 suggests a lower density and narrower distribution for the shallow event, than a deep event, which presents a slightly higher value and a wider distribution.

Figure 3.1 .33 presents the distribution categorized with boxplots for each month during the winter season (November-April) and it is clear how throughout the entire period a shallow event has always a lower density that a deep event, having the months of February and March with the lowest densities recorded. These numbers could explain how usually a shallow event produces a dry and fluffier type of snow. 


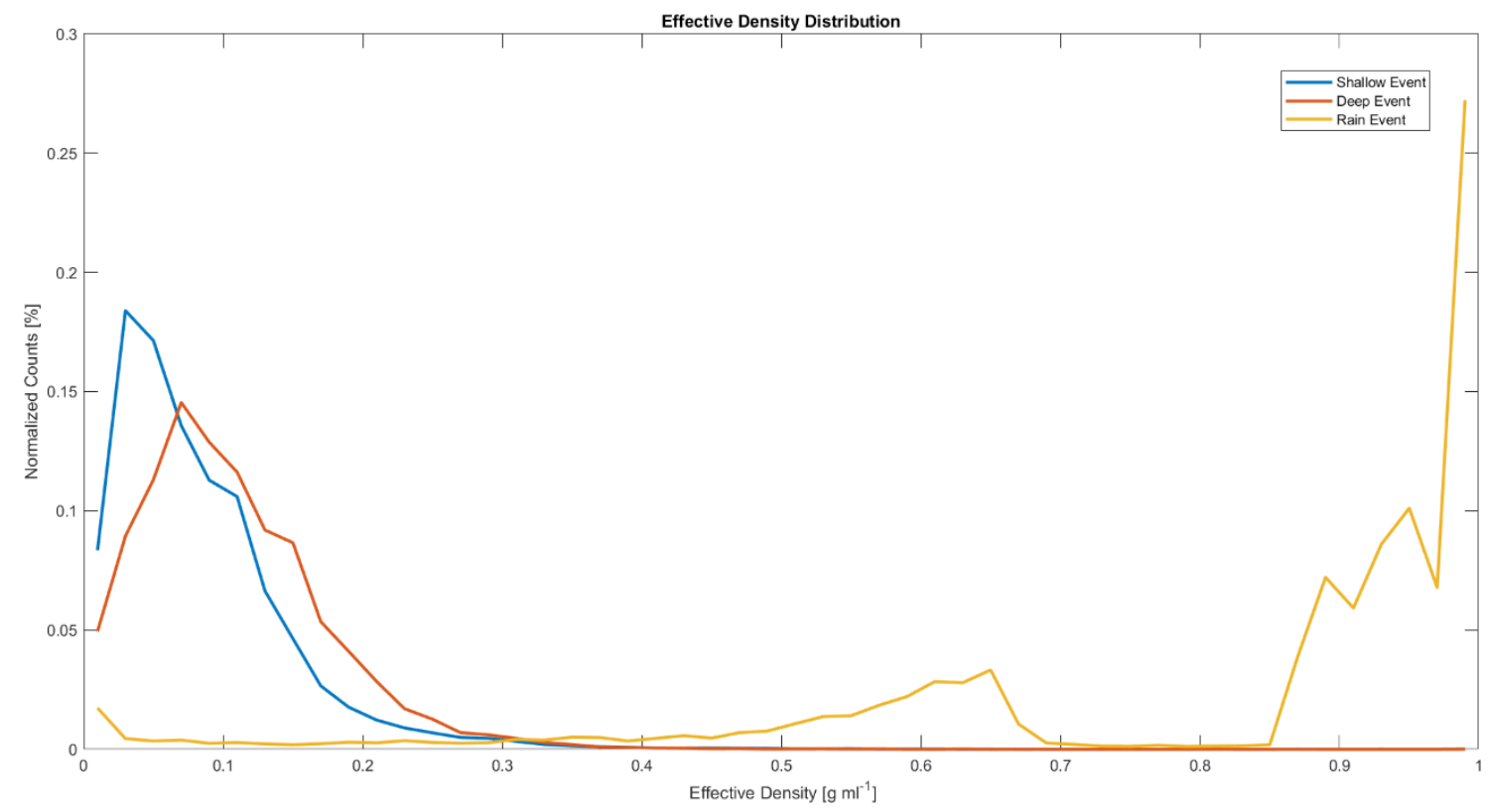

Figure 3.1.31 Effective density distribution for shallow events (blue line), deep events (red line) and rain events (yellow line). Each function has been normalized to its own dataset. Values range from 0 to $1 \mathrm{~g} \mathrm{mt}^{1}$.

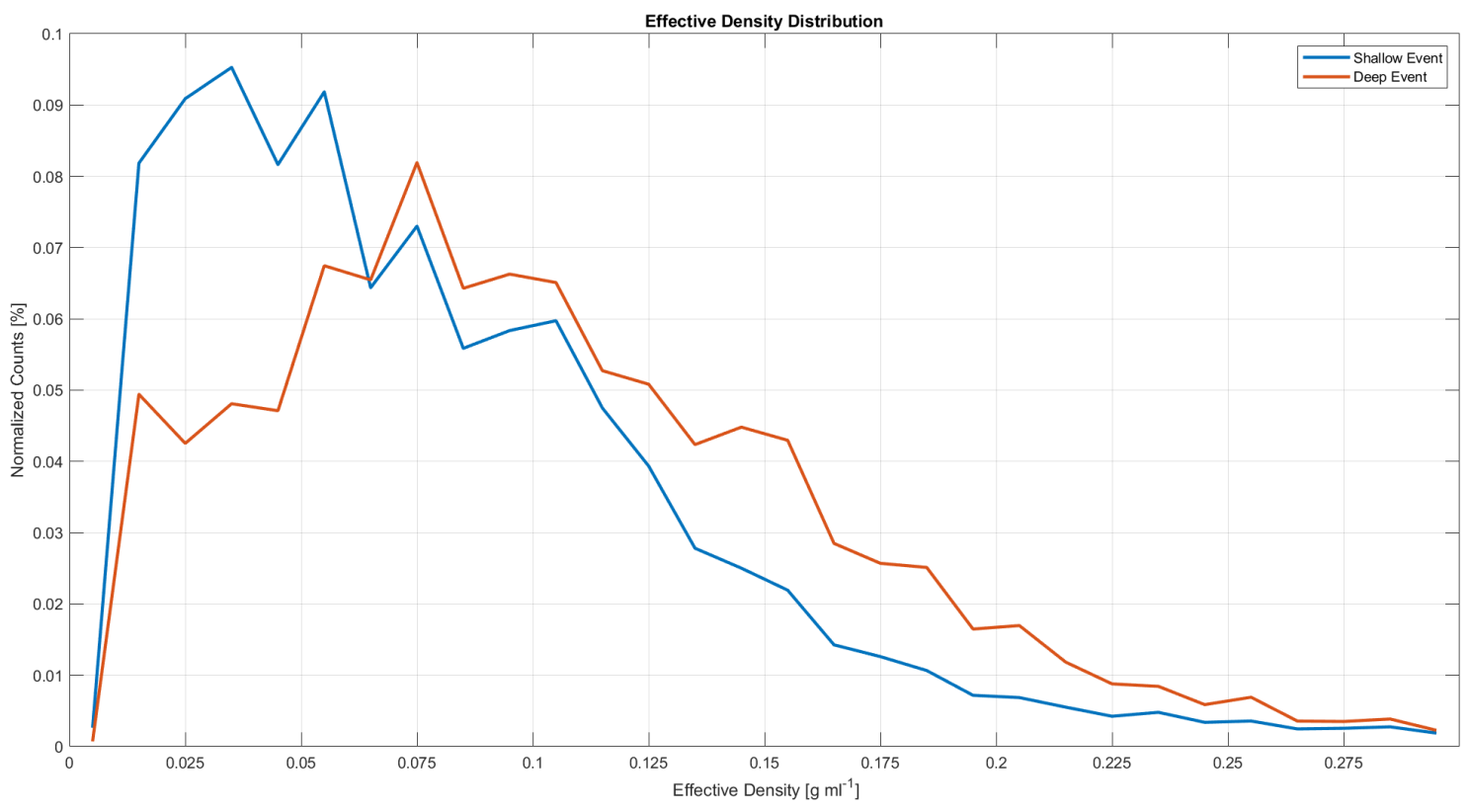

Figure 3.1.32 Effective density distribution for shallow events (blue line) and deep events (red line). Each function has been normalized to its own dataset. Values range from 0 to $0.3 \mathrm{~g} \mathrm{ml}^{1}$. 


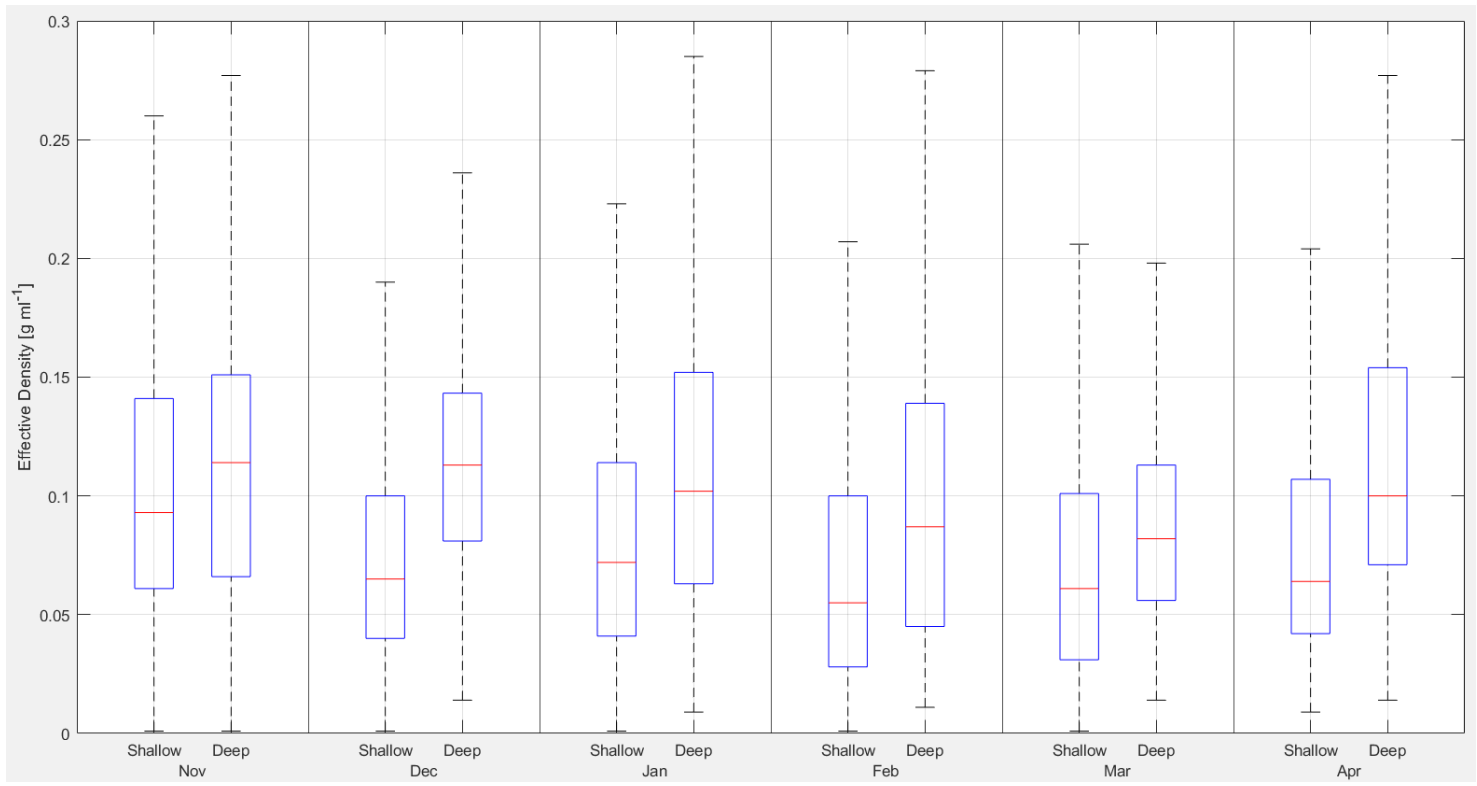

Figure 3.1.33 Boxplot of effective density for shallow and deep events divided for each month from November to April. Outliers are not shown. Shallow events present a lower density than deep events all the time and the months of Feb and Mar have the lowest densities recorded. 


\subsubsection{Particle Size Distribution (PSD)}

The PIP observations for each snow category produced a clear Particle Size Distribution (PSD) of snowflakes. The following figures will present a d 2-dimensional histogram for the PSD as a function of the particle diameter for both deep (Figure 3.1 .34 ) and shallow (Figure 3.1 .35 Shallow) events. Both graphs have been normalized to their corresponding snow category and PSD values have been transformed into logarithmic number with base 10. The main difference between the two images is the distinct high frequency $(0.4 \%-0.5 \%)$ of small particles $\left(0.5 \mathrm{~mm}\right.$ of diameter) with values of PSD at $10^{3} \mathrm{~m}^{-3} \mathrm{~mm}^{-1}$, meanwhile the shallow snow suggests a broader range with lower PSD values (from $5^{*} 10^{1}$ to $5^{*} 10^{2} \mathrm{~m}^{-3} \mathrm{~mm}^{-}$ $\left.{ }^{1}\right)$ for small particles, confirming previous studies on the particle spectra with different instruments (Braham 1990). Generally, a shallow event has a broader distribution also for the particle diameter, suggesting bigger particles and a lower concentration on smaller particles, as it is possible to notice on Figure 3.1 .36, that presents both a synoptic and Lake Effect Snow precipitation during the same day. Wood et al. (2008) proposed a mass-diameter relationship based on the snow particle habit category and considering that a shallow event could have a different growth process than a deep event, the information obtained from this study might support that correlation, since it is possible to assume that snowflakes produced from a Lake Effect Snow event have a different predominant shape than a synoptic snow event. 


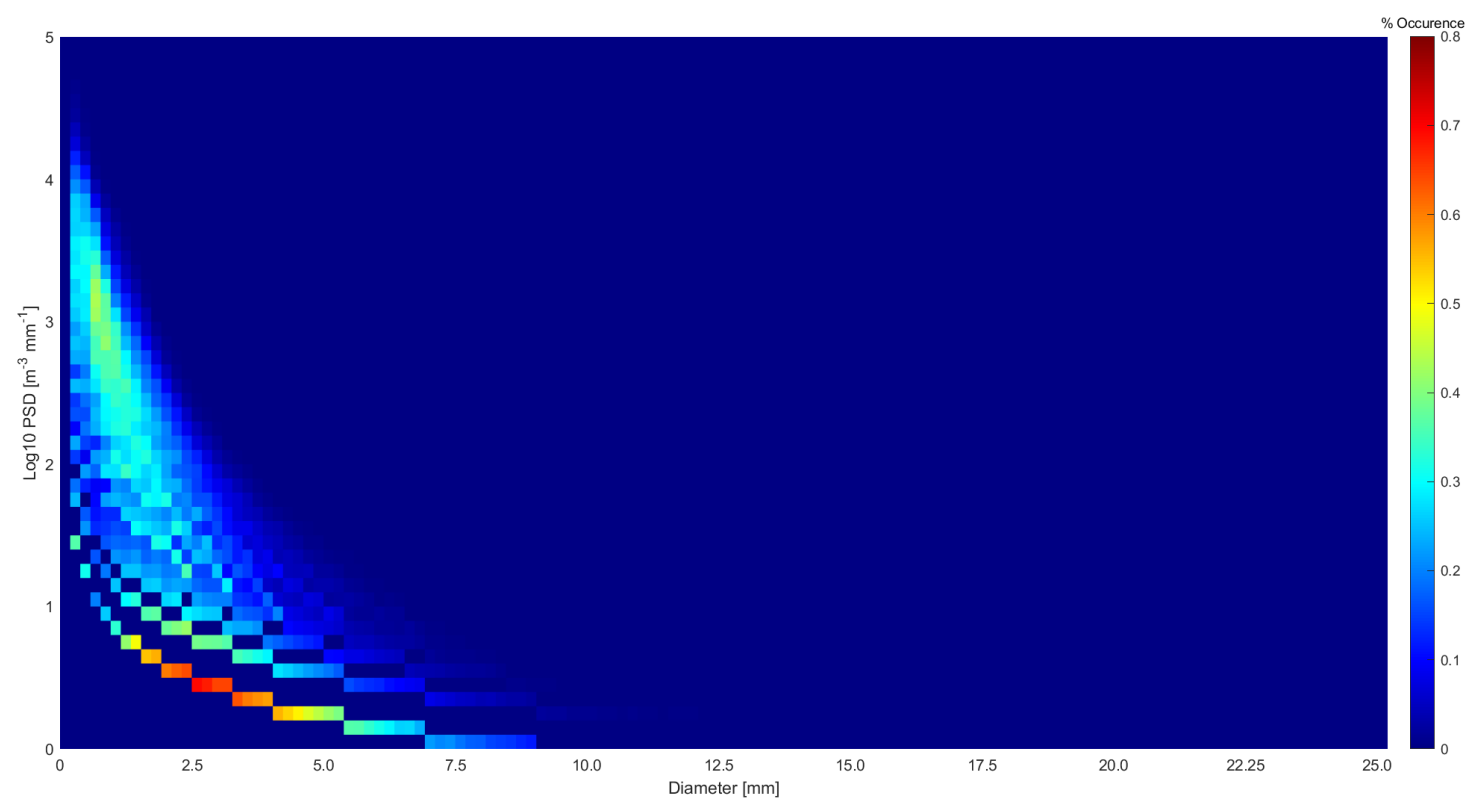

Figure 3.1.34 Deep event. 2-Dimensional histogram of PSD as a function of mean particle diameter. $V$ alues have been normalized on the specified snow category and presented as \% of occurrence. Each bin has a spacing of $0.1 \mathrm{~mm}$. There is a higher $(0.4 \%-0.5 \%)$ occurrence on small particles.

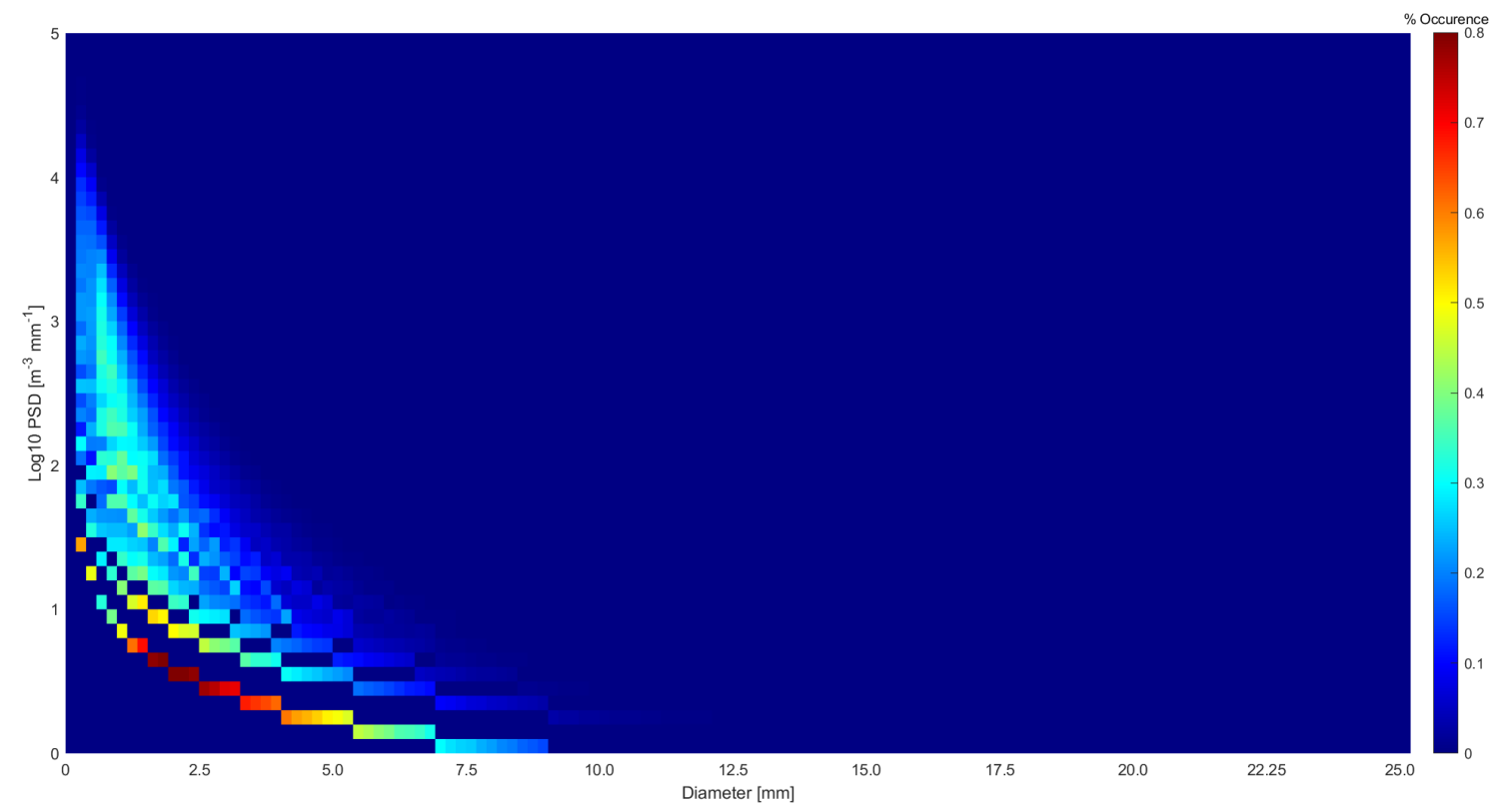

Figure 3.1.35 Shallow event. 2-Dimensional histogram of PSD as a function of mean particle diameter. $V$ alues have been normalized on the specified snow category and presented as \% of occurrence. Each bin has a spacing of $0.1 \mathrm{~mm}$. 

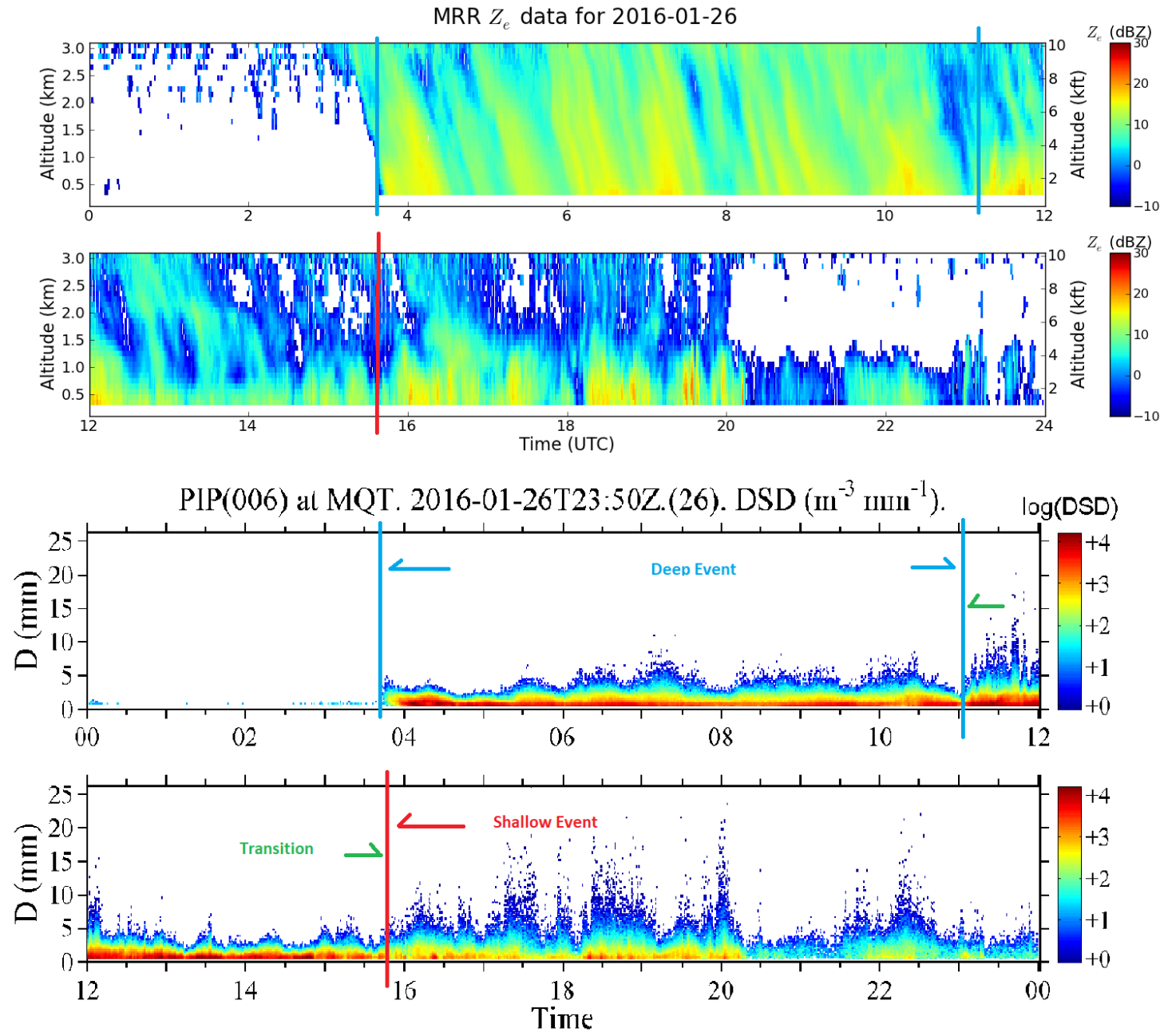

Figure 3.1.36 26 Jan 16'. Presents both deep and shallow events, as it is possible to notice from the DBZ plot. On the lower panel showing the PSD values, it is clear the difference between the two events regarding the distribution of the mean diameter values. 


\subsection{Micro Rain Radar 2 (MRR) Observations}

\subsubsection{Cloud Top Height (CTH) and Vertical Reflectivity Difference ( $\Delta Z)$}

As already discussed in chapter 2.6, the values of Cloud Top Height and reflectivity delta on a vertical profile have been used to proceed with a preliminary sorting. The following images will present the statistic of the distributions during the entire winter season (Figure 3.2 .37) and each month (Figure 3.2 .38). The first figure shows how the majority of the events could be divided with two main CTH values: a deep event, which mostly vertically extends up to $3000 \mathrm{~m}$ or beyond, and a shallow event that on average happens below the height of $1000 \mathrm{~m}$ and could reach values of $1500 \mathrm{~m}$. The value of $3000 \mathrm{~m}$ is a threshold due to the instruments used, since the MRR is capable only acquire information from a relatively low altitude, compared to satellite observations, as the ones recorded with CloudSat, therefore the $3000 \mathrm{~m}$ bin is the highest altitude that MRR can reach. Since it is not possible to distinguish clouds that reach $3000 \mathrm{~m}$ and those that are beyond that observation, all of them are grouped into the same family. Kulie et al. (2016) noticed how CloudSat observations could be successfully divided into two different snowfall modes with shallow cumuliform and deep nimbostratus cloud structures and this study confirms that classification and presents an in-depth analysis using near-surface recordings.

The second figure presents the two categories for each month using a box plot and the differences between a LES event and a synoptic event are evident. Values for a shallow event are on average at $1000 \mathrm{~m}$, with a small decrease during the months of January and February, meanwhile for a deep event, apart the month of November, they are on average at $3000 \mathrm{~m}$, suggesting, also in this case, a drop of $200 \mathrm{~m}$ in January and February. The variance in this case is higher, due to the properties of the event and the shape of the cloud, which could vary significantly during the precipitation. 


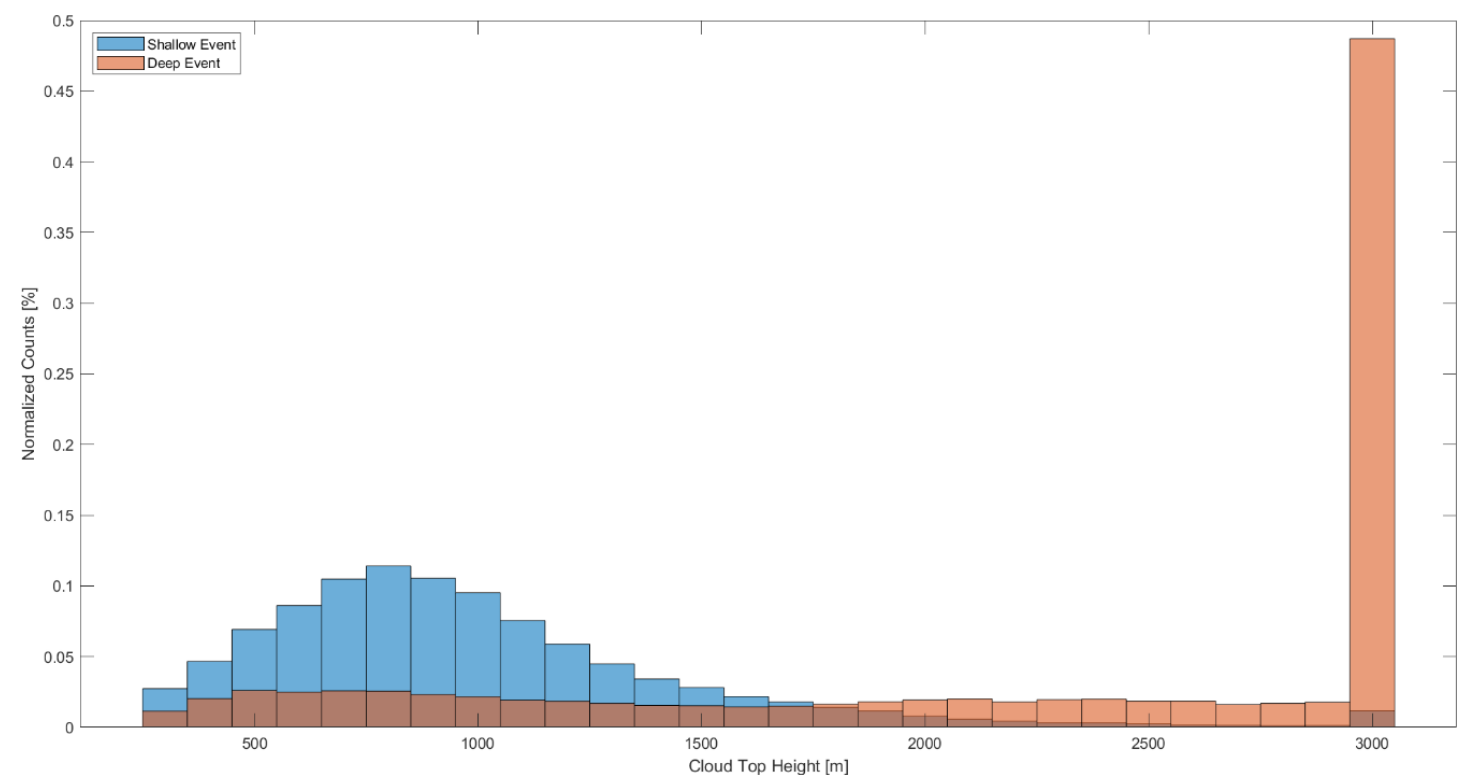

Figure 3.2.37 Histogram of CTH for both shallow (blue) and deep (red) event. It is evident the two main values at $700 \mathrm{~m}$ for a LES event and $3000 \mathrm{~m}$ for a synoptic event.

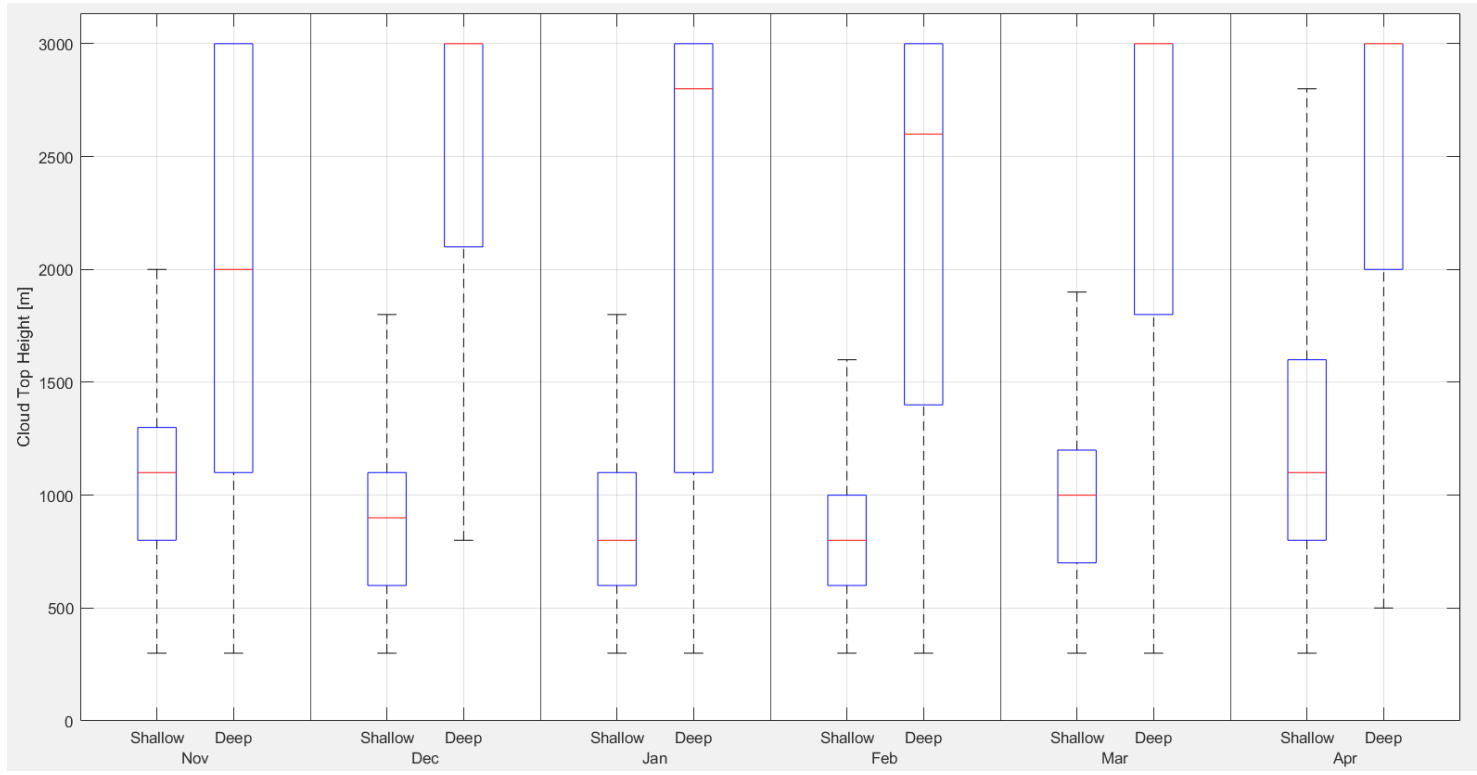

Figure 3.2.38 Box plot of CTH for both shallow and deep event for each month during the winter season. 


\subsubsection{Reflectivity (DBZ)}

The reflectivity factor is the main measurement obtained from the MRR instrument and it has been already discussed how it varies along the axis for each type of precipitation, in the following images it will be presented its distribution with a 2-Dimensional histogram, obtained from values of the entire winter season. Generally, a shallow event (Figure 3.2 .39) will present reflectivity that ranges from -5 to $10 \mathrm{dBZ}$, with a higher concentration between 0 and $5 \mathrm{dBZ}$ and, disregarding the first bin at $300 \mathrm{~m}$ above ground level, there is a small gradient with the decrease of the height, having higher values of reflectivity at lower layers. Most of the observations are located below $1000 \mathrm{~m}$ AGL and usually up to $1500 \mathrm{~m}$ AGL, as already noticed with the analysis of the Cloud Top Height variable. A small portion of values is located at between $2500 \mathrm{~m}$ and $3000 \mathrm{~m}$ AGL, but this behavior could be due by the presence of noise in the last layers of the vertical profile. The statistic of the deep event (Figure 3.2 .40) suggests noticeable difference from the previous one. The reflectivity range is between 0 and $20 \mathrm{dBZ}$, with a delta of 20 units, suggesting a broader variation, and the highest concentration of counts is located at $10 \mathrm{dBZ}$, meaning that, on average, values for a synoptic snow event are $5 \mathrm{dBZ}$ higher than a Lake Effect Snow event. The distribution is mostly constant through the vertical profile with no significant changes, but it is perceptible a small increasing trend from $3000 \mathrm{~m}$ AGL to $1500 \mathrm{~m}$ AGL as far as it concerns reflectivity values. The same analysis has been performed for the rain type precipitation (Figure 3.2 .41) and the behavior of the distribution is similar to the deep event one: values are quite constant along the column and they reach up to the $3000 \mathrm{~m}$ threshold or beyond, it is still present a sort of trend at $2000 \mathrm{~m}$, where the values decrease with the altitude. On average, reflectivity ranges from $0 \mathrm{dBZ}$ to $35 \mathrm{dBZ}$ and the highest counts are between 15 $\mathrm{dBZ}$ and $20 \mathrm{dBZ}$ and the distribution is broader from $300 \mathrm{~m}$ to $700 \mathrm{~m}$ and then it starts to narrow at $1000 \mathrm{~m}$ and it remains constant throughout the whole vertical profile. 


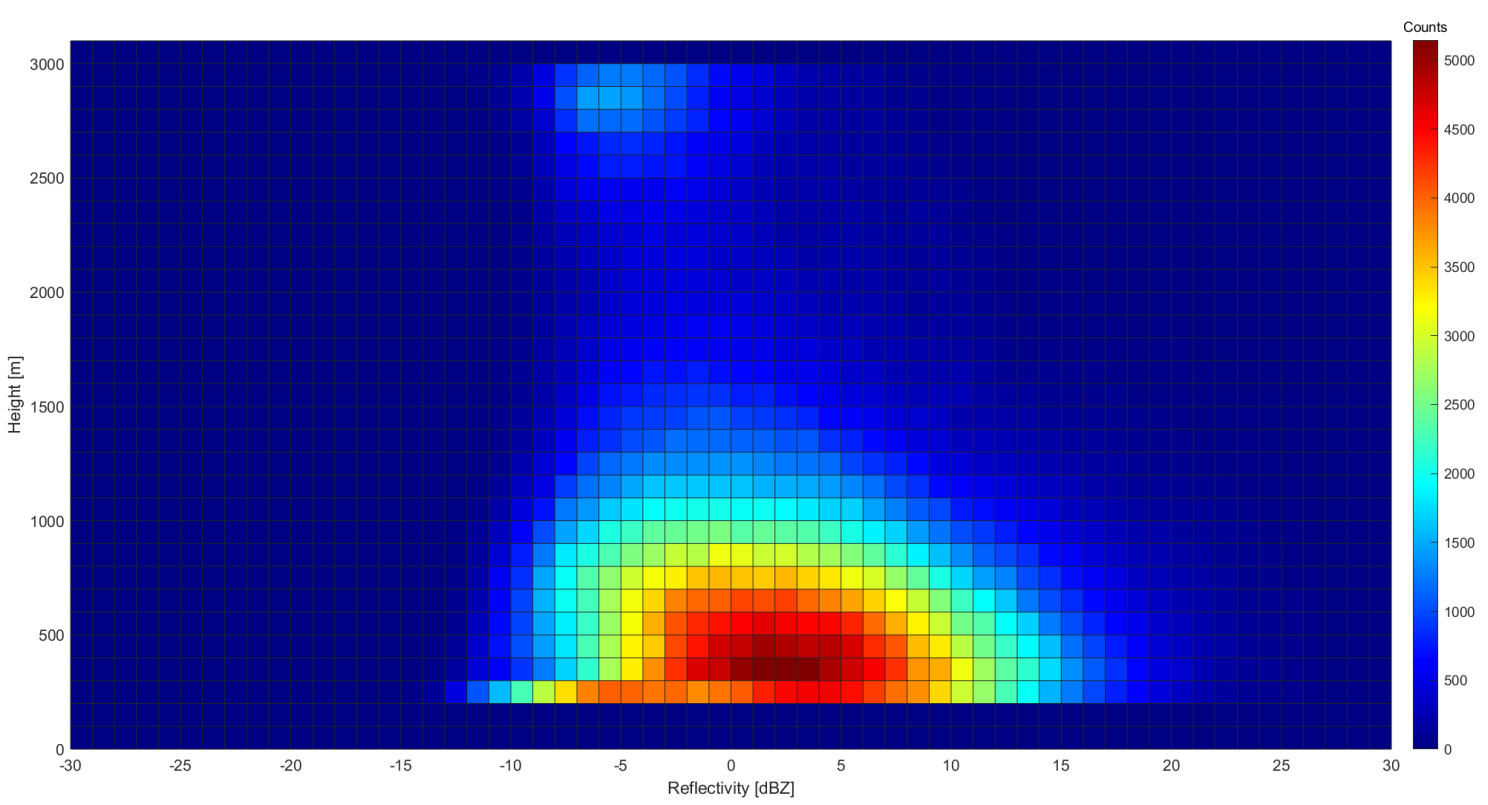

Figure 3.2.39 Two-dimensional histogram of $M R R$ reflectivity for the shallow snow event.

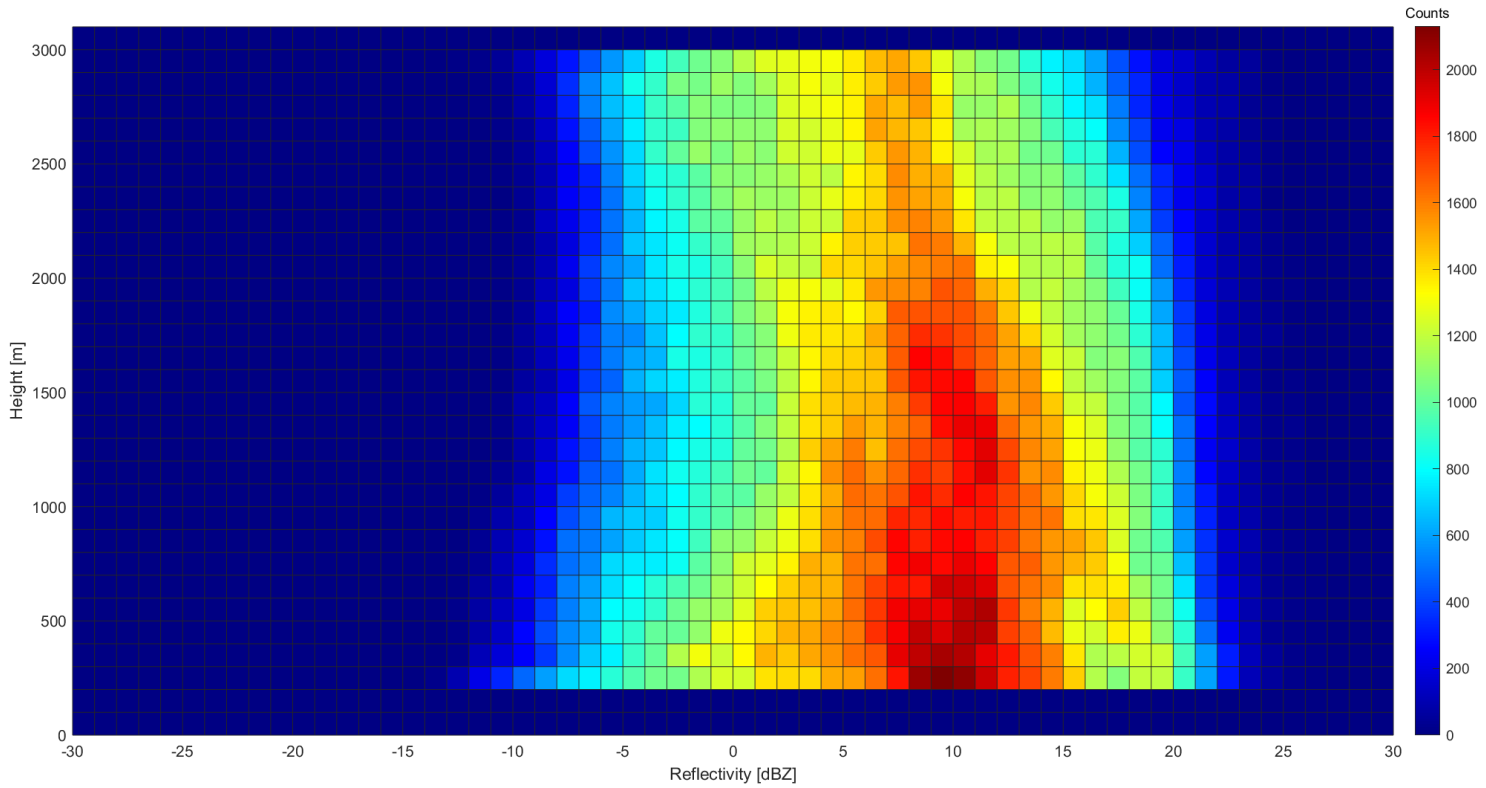

Figure 3.2.40 Two-dimensional histogram of MRR reflectivity for the deep snow event. 


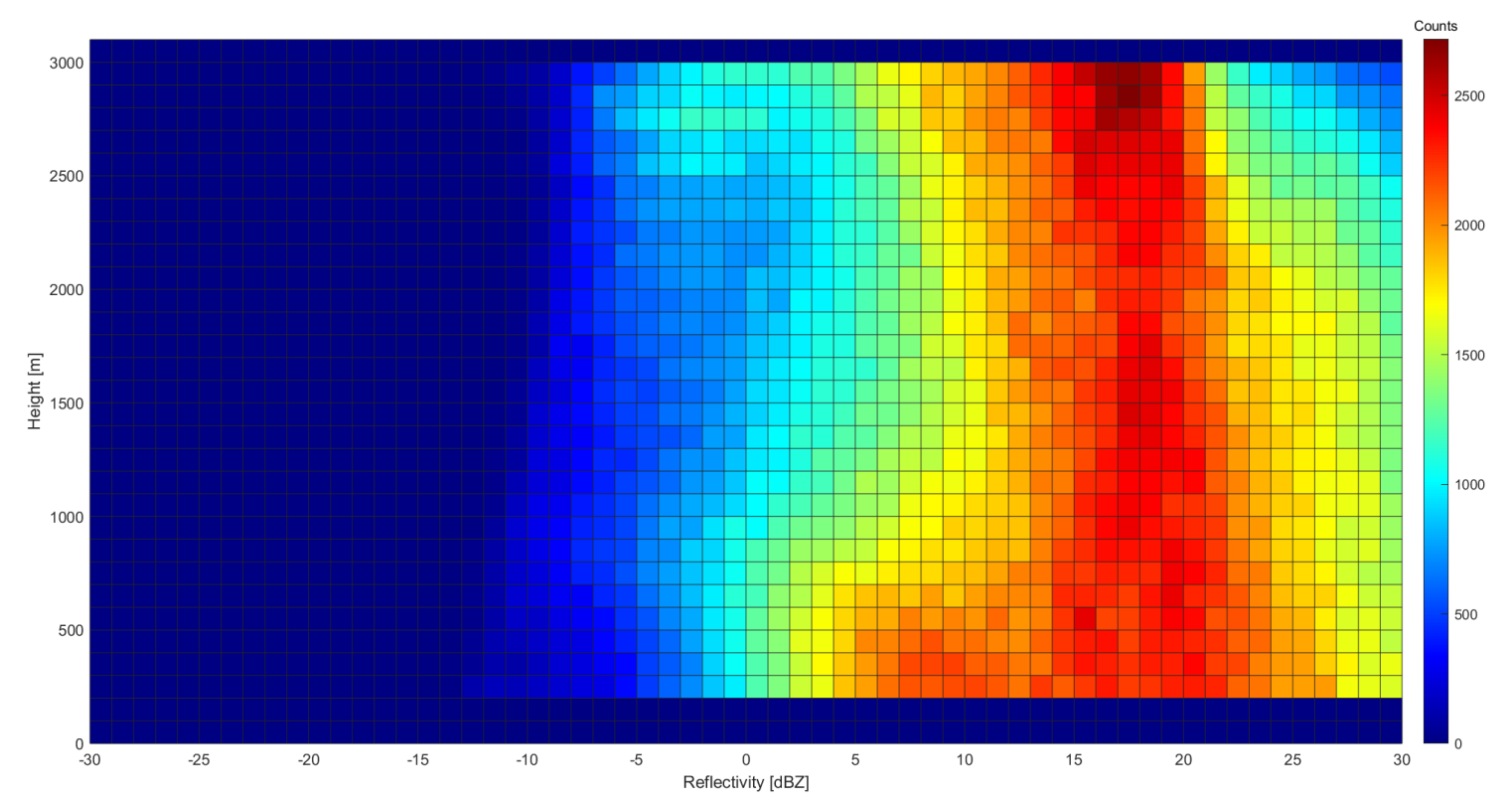

Figure 3.2.41 Two-dimensional histogram of $M R R$ reflectivity for the rain event.

The next two images will present the reflectivity distribution at the $400 \mathrm{~m}$ AGL level, the $300 \mathrm{~m}$ bin has not been used to the different behavior shown in Figure 3.2 .39. The surface values (Figure 3.2 .42 ) present two separate distributions for the two investigated events and it could be assumed a difference of almost $10 \mathrm{dBZ}$ between a shallow and a deep event and, after performing a t-student's test, they can be considered statistically significant. A boxplot of the same dataset is proposed in Figure 3.2 .43 and shows of the difference in the mean $\mathrm{dBZ}$ value for each event is close to $5 \mathrm{dBZ}$ and the trend is relatively constant, with a slight increase in the last month of April. The month of November presents an anomaly in the trend of values previously analyzed and the same behavior was recognized in Figure 3.1 .33 for the effective density variable. 


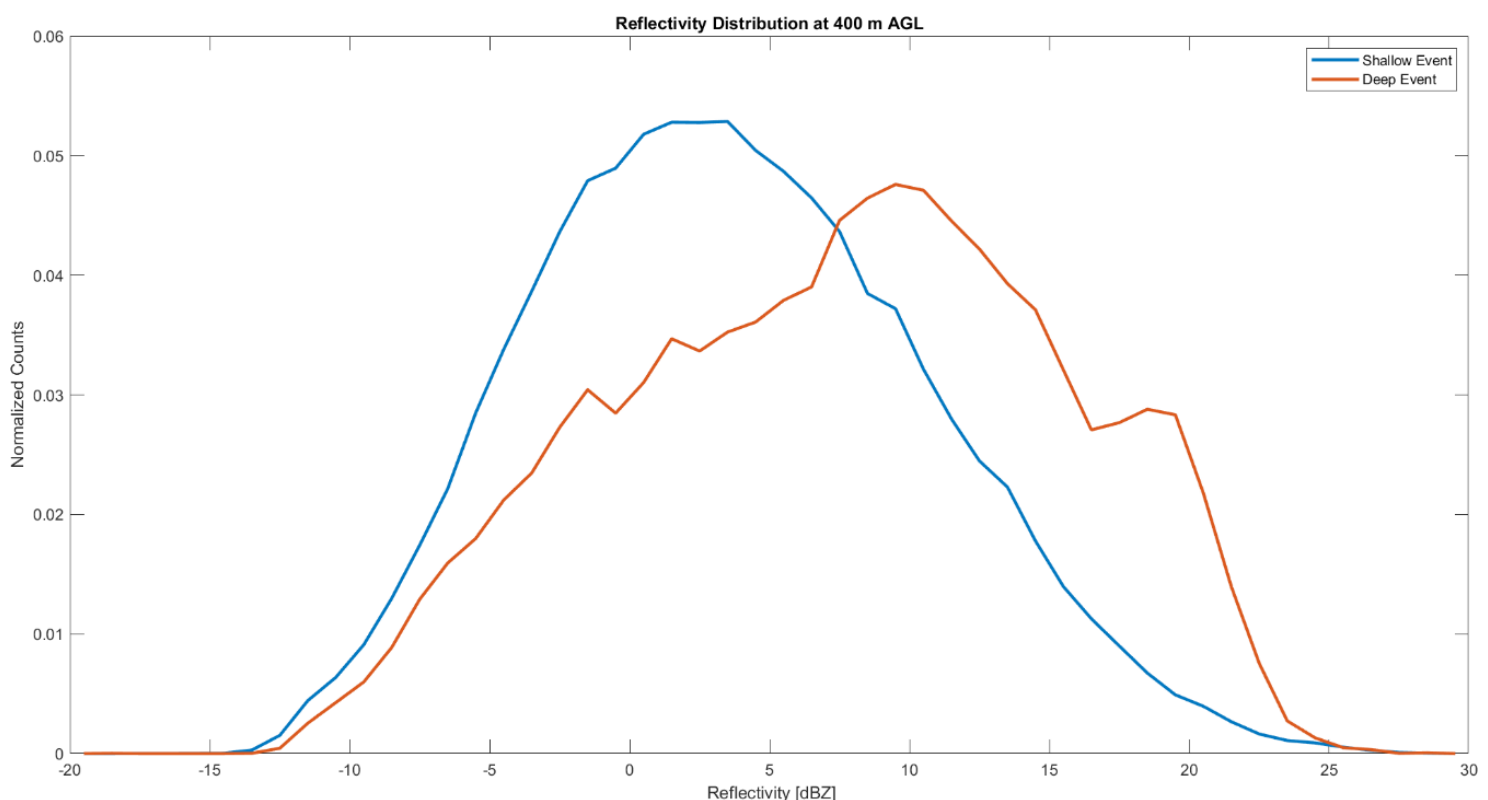

Figure 3.2.42 Plot of reflectivity values for shallow (blue) and deep (red) events. Values are taken from the $400 \mathrm{~m}$ bin.

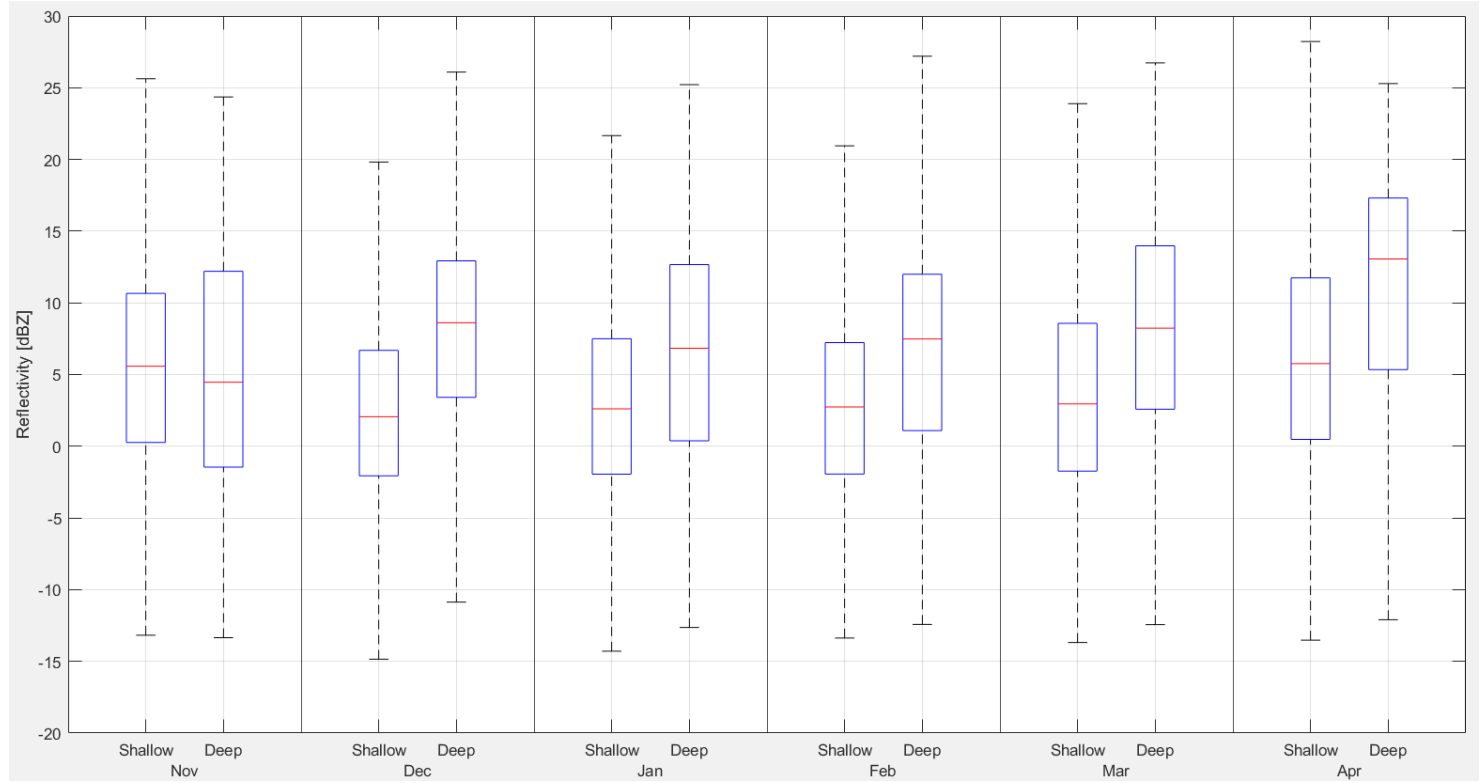

Figure 3.2.43 Boxplot of reflectivity values for shallow and deep events divided for each month from November to April. Outliers are not shown. Values are taken from the $400 \mathrm{~m}$ bin. 


\subsubsection{Doppler Velocity (VEL)}

The Doppler velocity values have the same distribution of DBZ obtained from the MRR, meaning that the observations are spaced $1 \mathrm{~min}$ apart from each other and the vertical profile is composed of bin of $100 \mathrm{~m}$ each and reach up to an altitude of $3000 \mathrm{~m}$ above ground level. Since this variable is investigating the same precipitation already analyzed for DBZ, it is obvious how the two distributions should be similar as far as it concerns the shape of the dataset with the 2-Dimensional histogram. Figure 3.2.44 presents the results for the shallow event, values range from 0 to $1.5 \mathrm{~m} \mathrm{~s}^{-1}$, with a higher concentration between 0.5 and $1 \mathrm{~m} \mathrm{~s}^{-1}$. Most of the observations are located below $1000 \mathrm{~m}$ AGL and usually up to $1500 \mathrm{~m}$ AGL, as already noticed with the analysis of the Cloud Top Height variable. A small portion of values is located at between $2500 \mathrm{~m}$ and $3000 \mathrm{~m}$ AGL, but this behavior could be due by the presence of noise in the last layers of the vertical profile. It is also noticeable a small portion of values in the ranges of negative values, which can be explained with the presence of updrafts and an inversion of the direction of air movements during the precipitation and it could be related with the lower density of snow particles from a Lake Effect Snow event. Figure 3.2 .45 shows the distribution for the deep event and, as noticed with the DBZ variable, it appears to be almost invariant along the column, with a slight negative trend at $2000 \mathrm{~m}$, where values decrease with the altitude. The Doppler velocity ranges from 0.5 to $2 \mathrm{~m} \mathrm{~s}^{-1}$ and a higher concentration is between $1 \mathrm{~m} \mathrm{~s}^{-1}$ and $1.5 \mathrm{~m} \mathrm{~s}^{-1}$, meaning that also the Doppler velocity presents a higher mean in the deep event than the shallow event. Unlike the 2D histogram for DBZ, the distribution of the dataset for the rain type (Figure 3.2 .46 ) is different and suggests two separate clusters of observation: high Doppler velocity with low altitude and low Doppler velocity with high altitude. The portion with higher values of velocity represent the actual precipitation with rain droplets, meanwhile the other one, with lower values, is the portion of the cloud without precipitation. This behavior is shown in a daily plot (Figure 3.2 .47) from the MRR, where, most of the time, it is evident a clear separation between two zones in the profile with different values and that line can be identified as the "bottom of the cloud". Considering only the cluster of actual precipitation, values of Doppler velocity have a broader distribution compared to the other

types of event and it ranges from 1.5 to $7.5 \mathrm{~m} \mathrm{~s}^{-1}$, having the highest concentration at $5 \mathrm{~m} \mathrm{~s}^{-1}$. 
The "bottom of the cloud" varies significantly, showing most of the values up to $2000 \mathrm{~m}$, but several episodes suggested an altitude of $3000 \mathrm{~m}$ or higher.

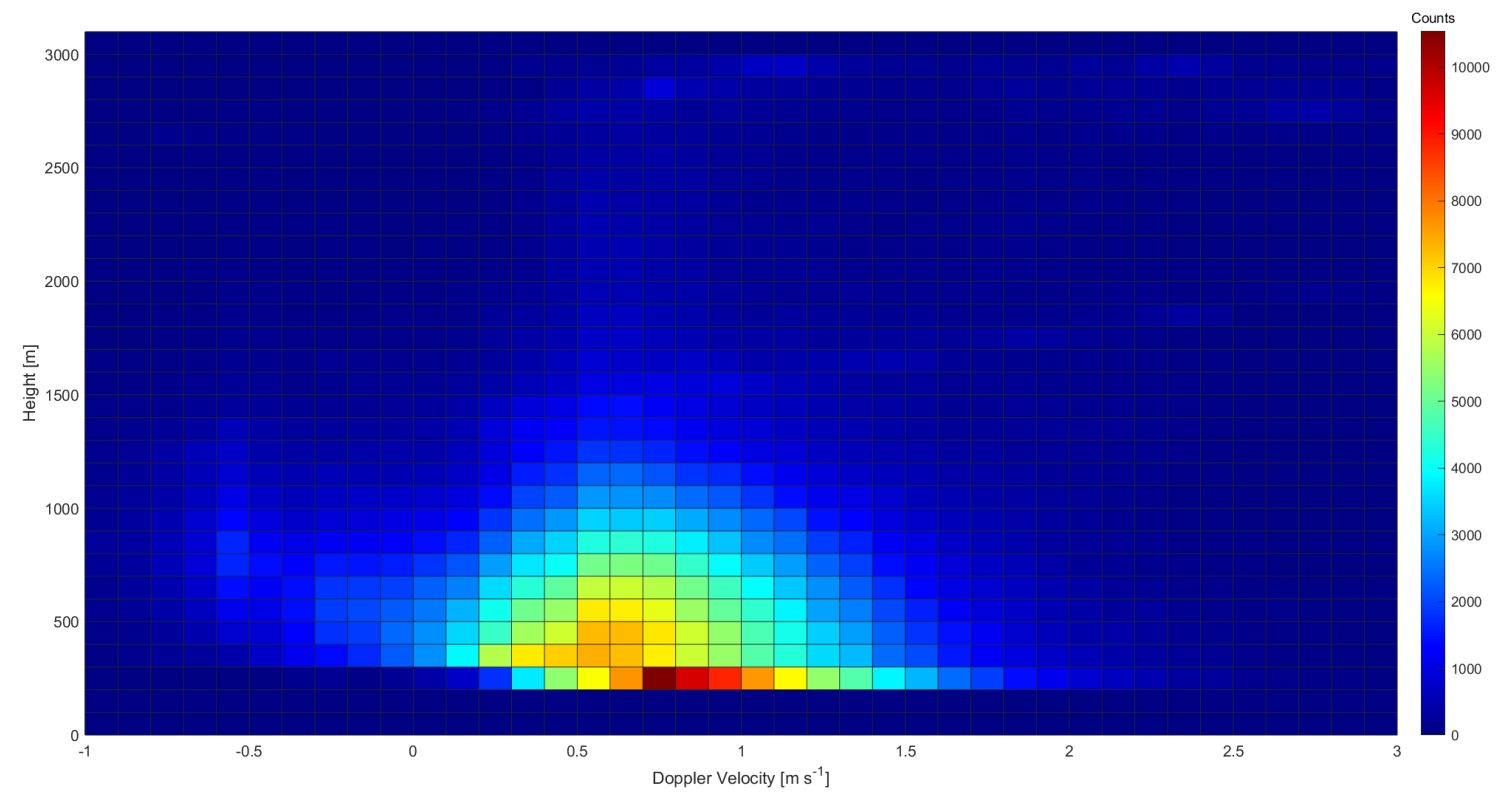

Figure 3.2.44 Two-dimensional histogram of Doppler Velocity for the shallow snow event.

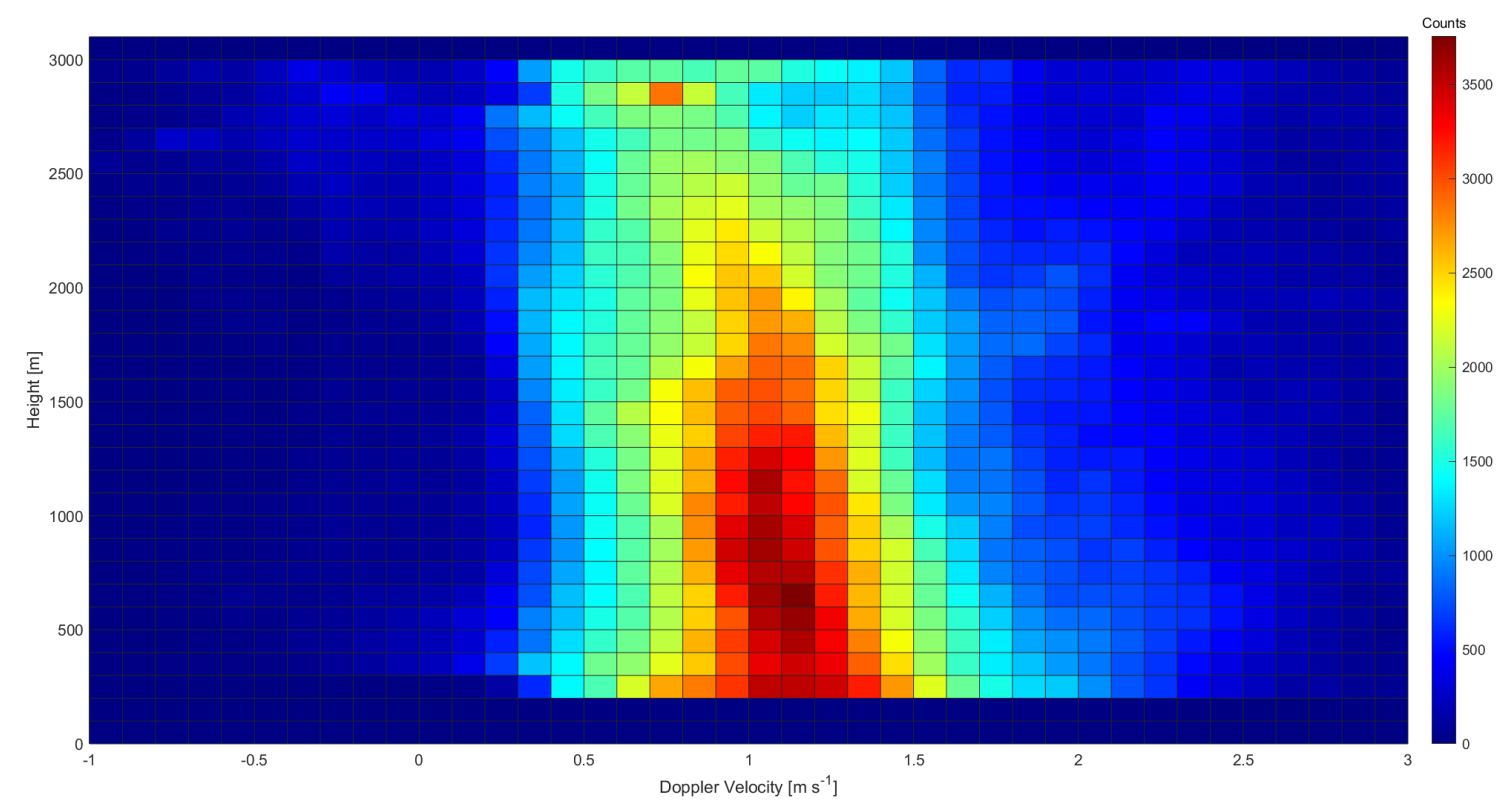

Figure 3.2.45 Two-dimensional histogram of Doppler Velocity for the deep snow event. 


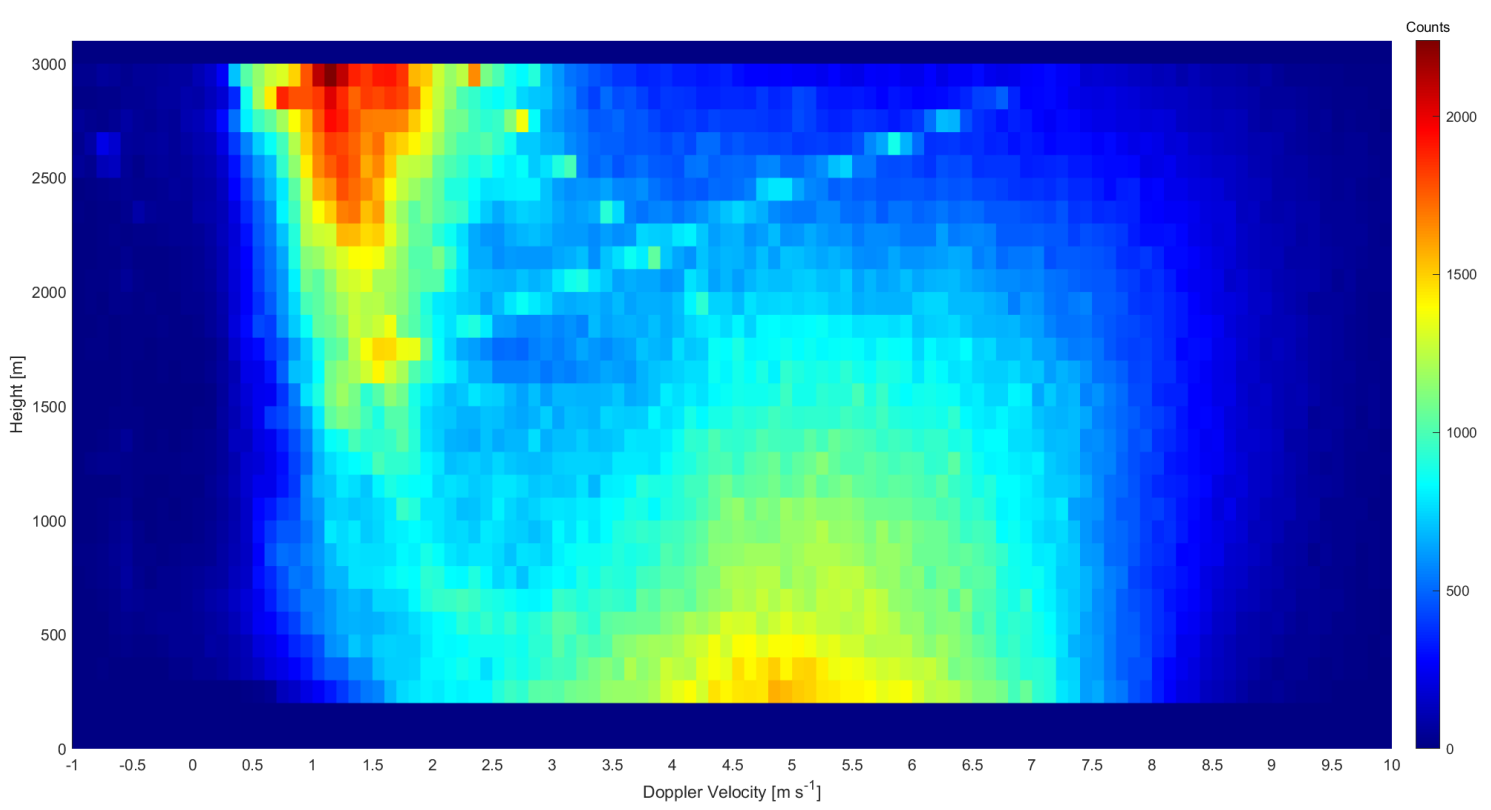

Figure 3.2.46 Two-dimensional histogram of Doppler Velocity for the rain event.
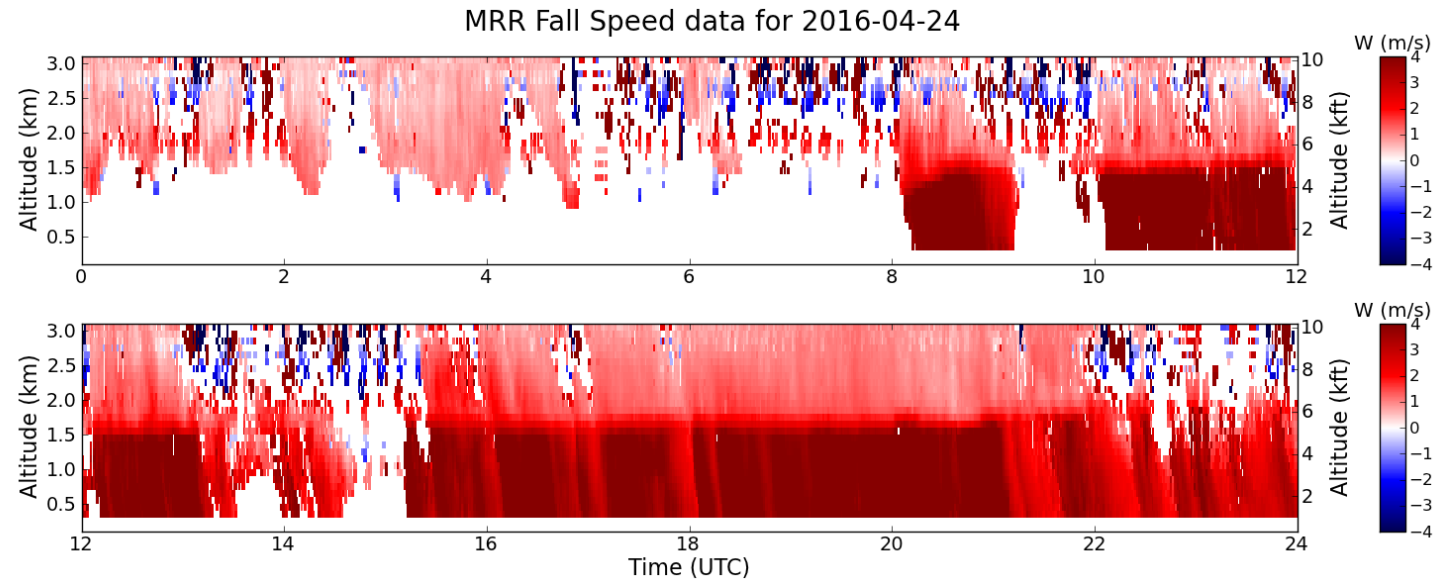

Figure 3.2.47 Rain episode on the 24 April '16 showing the fall speed of particles. It is evident a clear separation between to different fall velocities at $1.5 \mathrm{~km}$ mark. This line is identified as "bottom of the cloud". 
The next two images will present the Doppler velocity distribution at the $400 \mathrm{~m}$ level, disregarding the first bin located at an altitude of $300 \mathrm{~m}$. The plot of surface values (Figure 3.2 .48) for both shallow and deep event presents two distinct mean values for the two events investigated. The Lake Effect Snow event has its peak at $0.5 \mathrm{~m} \mathrm{~s}^{-1}$ and shows a significant amount of values with negative velocities due to the updrafts, meanwhile the synoptic snow event has its peak at $1.25 \mathrm{~m} \mathrm{~s}^{-1}$, with almost no observations of negative velocities. The difference between the two events is hence calculated to be $0.75 \mathrm{~m} \mathrm{~s}^{-1}$ and is considered statistically significant at a confidence level of 95\%, after performing a t-student's test. Figure 3.2 .49 present the distribution of the dataset during each month and it is remarkable how the values were relatively constant during the whole winter season, with similar behavior also for the outliers. On February, values dropped slightly to increase again until April. 


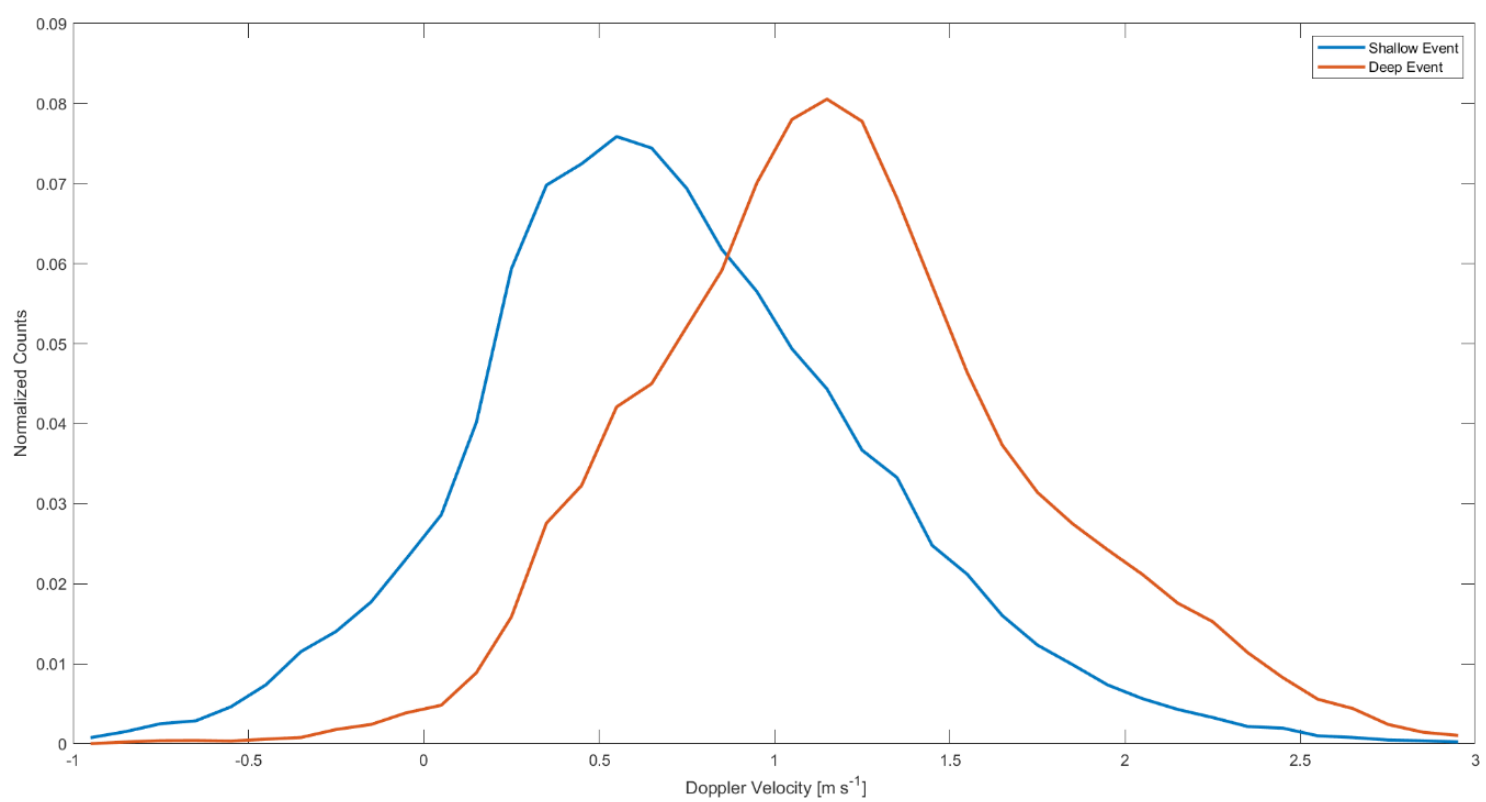

Figure 3.2.48 Plot of Doppler Velocity values for shallow (blue) and deep (red) events. Values are taken from the $400 \mathrm{~m}$ bin.

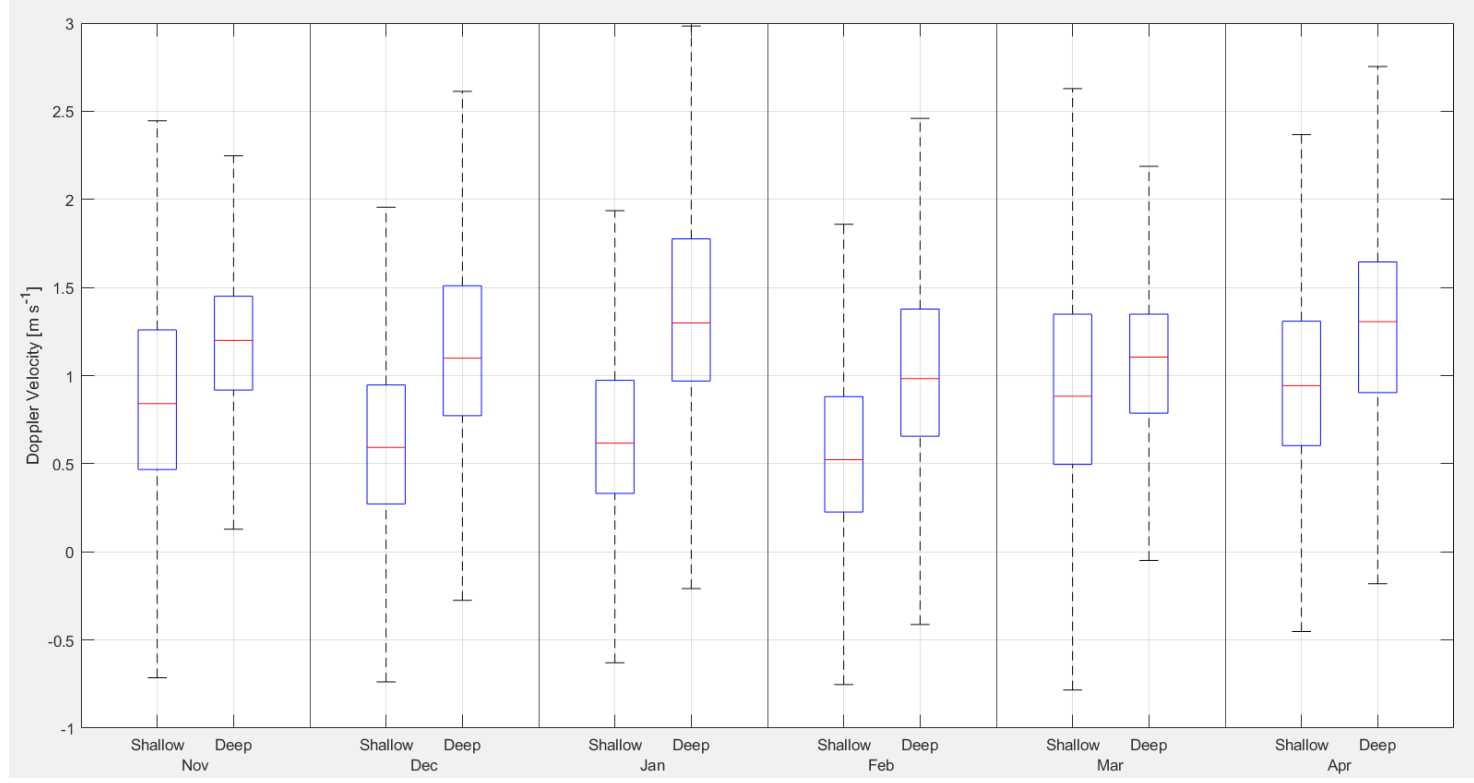

Figure 3.2.49 Boxplot of Doppler Velocity values for shallow and deep events divided for each month from November to April. Outliers are not shown. V alues are taken from the $400 \mathrm{~m}$ bin. 


\subsubsection{Doppler Spectral Width (SW)}

The last variable obtained from the MRR is the Doppler spectral width, measured in $\mathrm{m} \mathrm{s}^{-1}$, which can be influenced by several effects as the spread, range of terminal fall speeds of the scatterers (more pronounced for rain than snow), turbulence of the air (convection), vertical wind shear and antenna motion. The 2-dimensional histograms of the dataset are slightly different by shape and values from the previous two variables already discussed. Figure 3.2.50 shows the shallow event distribution and it is noticeable how the distribution is skewed to the left side of the graph, a clear difference from DBZ and eDens, where the data appeared as a blob a with a slight negative trend, which is more accentuated with the spectral width. Values observed go from $300 \mathrm{~m}$ to up to $1500 \mathrm{~m}$ above ground level, with few counts at $2500-3000 \mathrm{~m}$ level, due probably by noise in the sky. It ranges from 0.1 to $0.8 \mathrm{~m} \mathrm{~s}^{-1}$ and the highest counts are between 0.25 and $0.5 \mathrm{~m} \mathrm{~s}^{-1}$. The deep event distribution (Figure 3.2 .51) presents the characteristic vertical profile up to $3000 \mathrm{~m}$ with invariant values, as already noticed with the previous variables. The spectral width ranges from 0.1 to $0.6 \mathrm{~m} \mathrm{~s}^{-1}$ and the highest counts are between 0.2 and $0.35 \mathrm{~m} \mathrm{~s}^{-1}$, which seem to overlap with the values observed from the shallow event distribution. The last 2-dimensional histogram presented is for the rain type event and this dataset still present two distinct clusters, as already observed with the Doppler velocity. In the group related with the actual precipitation the spectral width ranges from 0.6 to $1.3 \mathrm{~m} \mathrm{~s}^{-1}$ and the highest counts are between 0.9 and $1.15 \mathrm{~m} \mathrm{~s}^{-1}$. It is still present a positive trend in this cluster, where spectral width values increase with the of the altitude, but this time the behavior is more accentuated, as already noticed with the other events. 


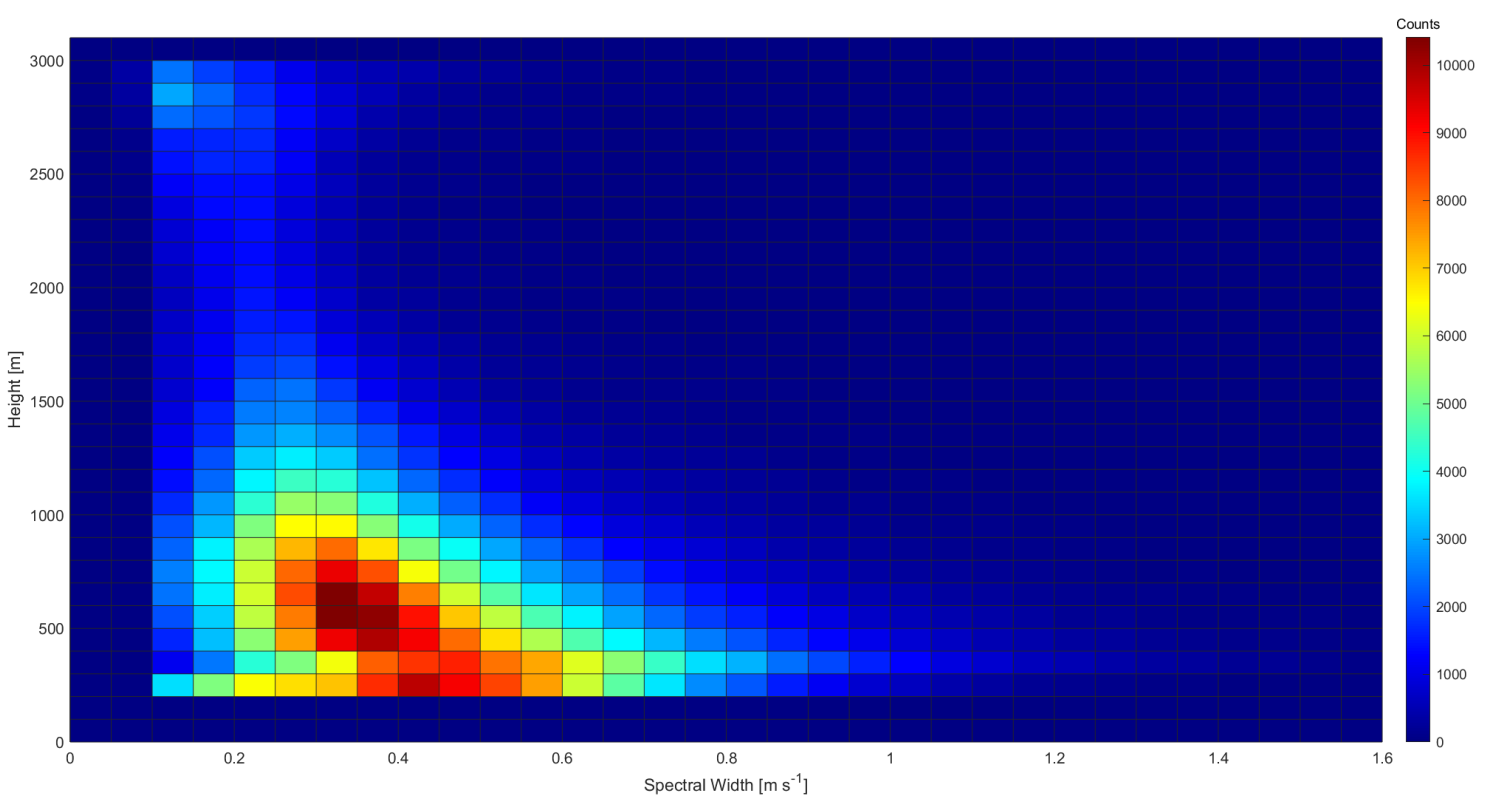

Figure 3.2.50 Two-dimensional histogram of spectral width for the shallow snow event.

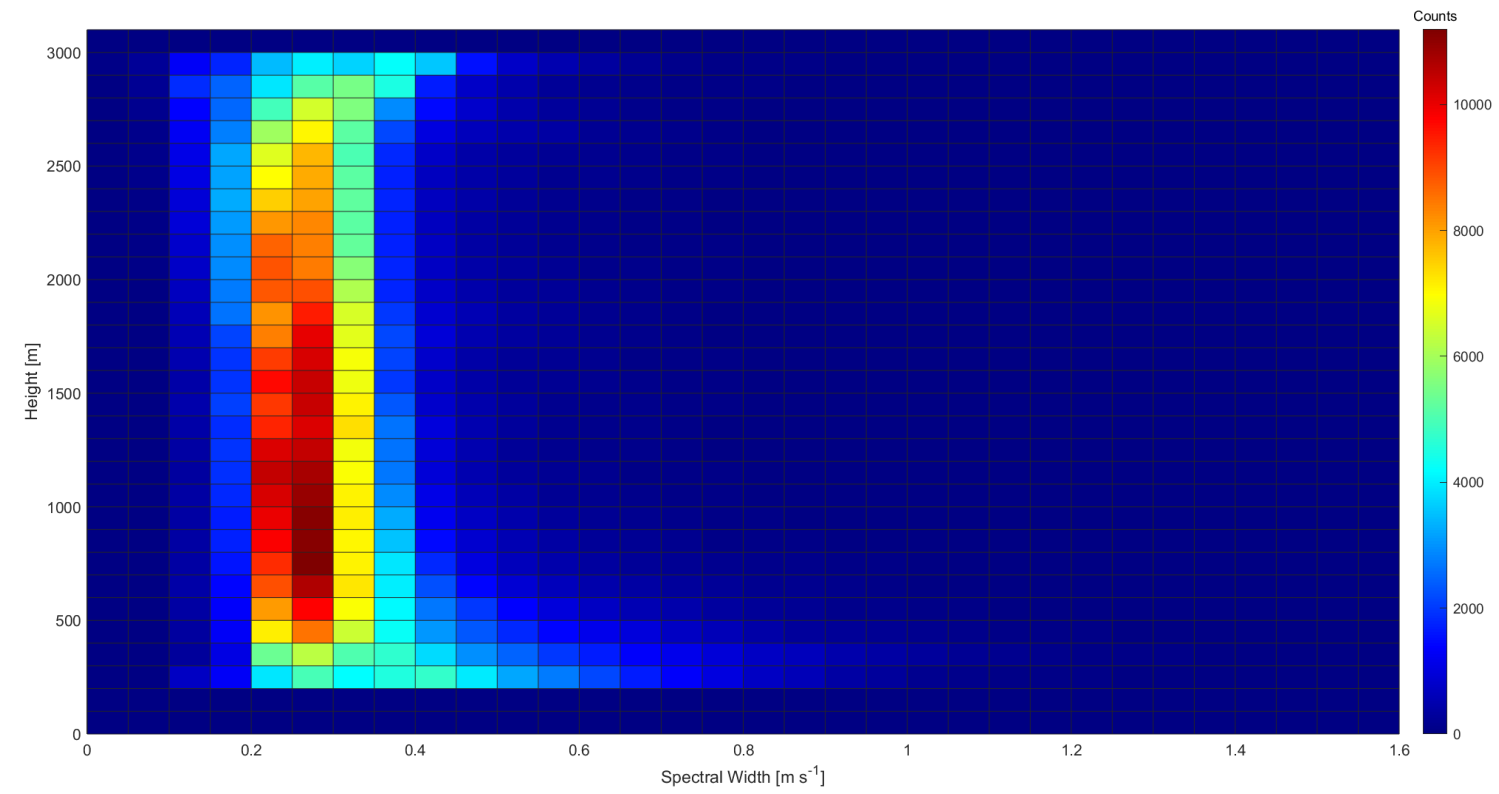

Figure 3.2.51 Two-dimensional histogram of spectral width for the deep snow event. 


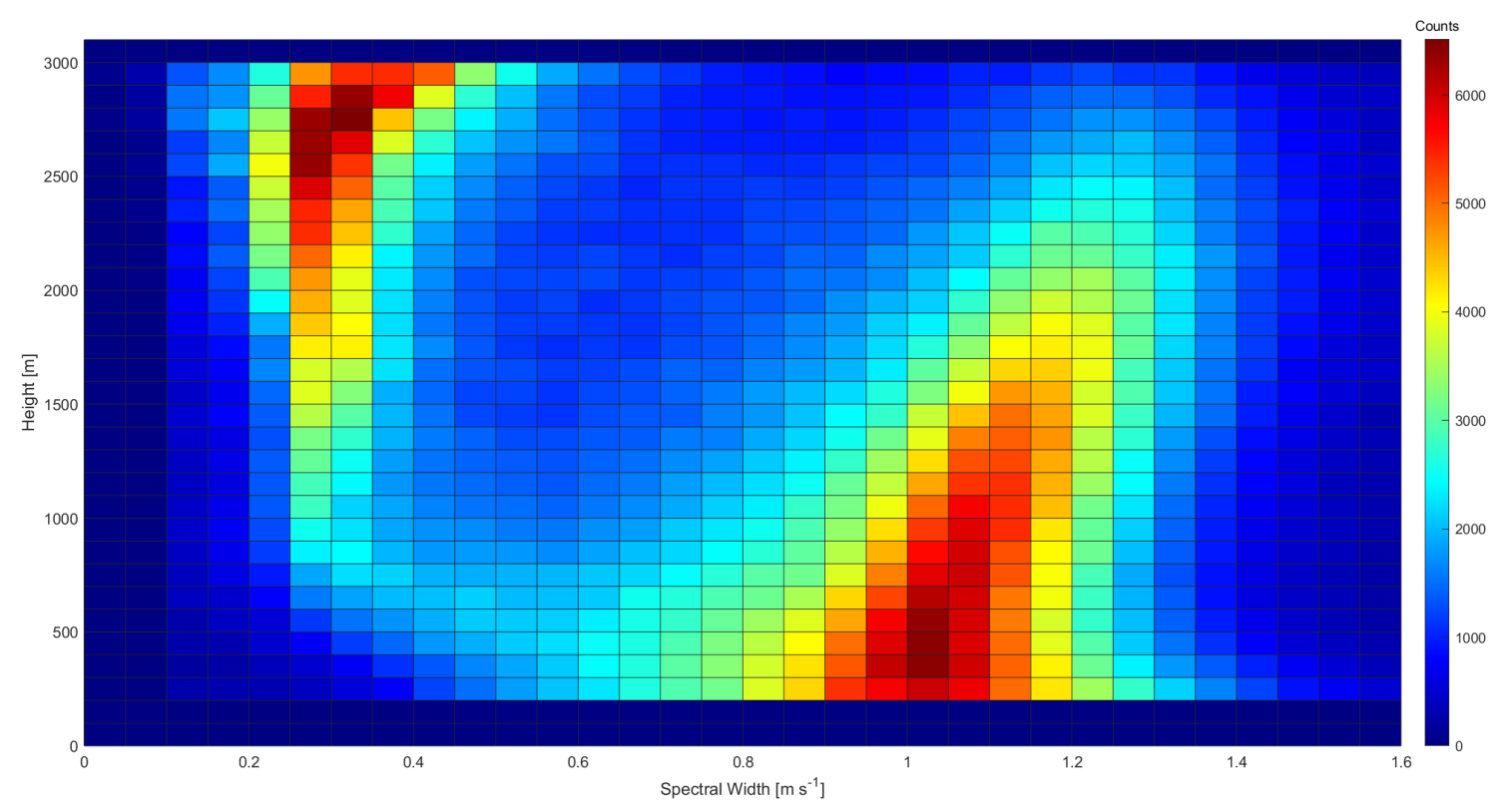

Figure 3.2.52 Two-dimensional histogram of spectral width for the rain event.

The next two images will present the spectral width distribution at the $400 \mathrm{~m}$ level, disregarding the first bin located at an altitude of $300 \mathrm{~m}$ above ground level. The plot of surface values for both shallow and deep events presents two distinct mean values for the two events investigated, but they are relatively close to each other. The Lake Effect Snow event has its peak at $0.5 \mathrm{~m} \mathrm{~s}^{-1}$ with a broad distribution, meanwhile the synoptic snow event has its peak at $0.25 \mathrm{~m} \mathrm{~s}^{-1}$ with a narrower distribution. The difference between the two events is equal at $0.25 \mathrm{~m} \mathrm{~s}^{-1}$, but is not considered statistically significant at a confidence level of $95 \%$, meaning that the two distribution could be part of the same family of values. The group of boxplots (Figure 3.2 .54) for each month during the whole winter season shows how the two event types present separate mean values, but the boxes cover almost the same range and, despite few oscillation, they can be considered relatively constant. 


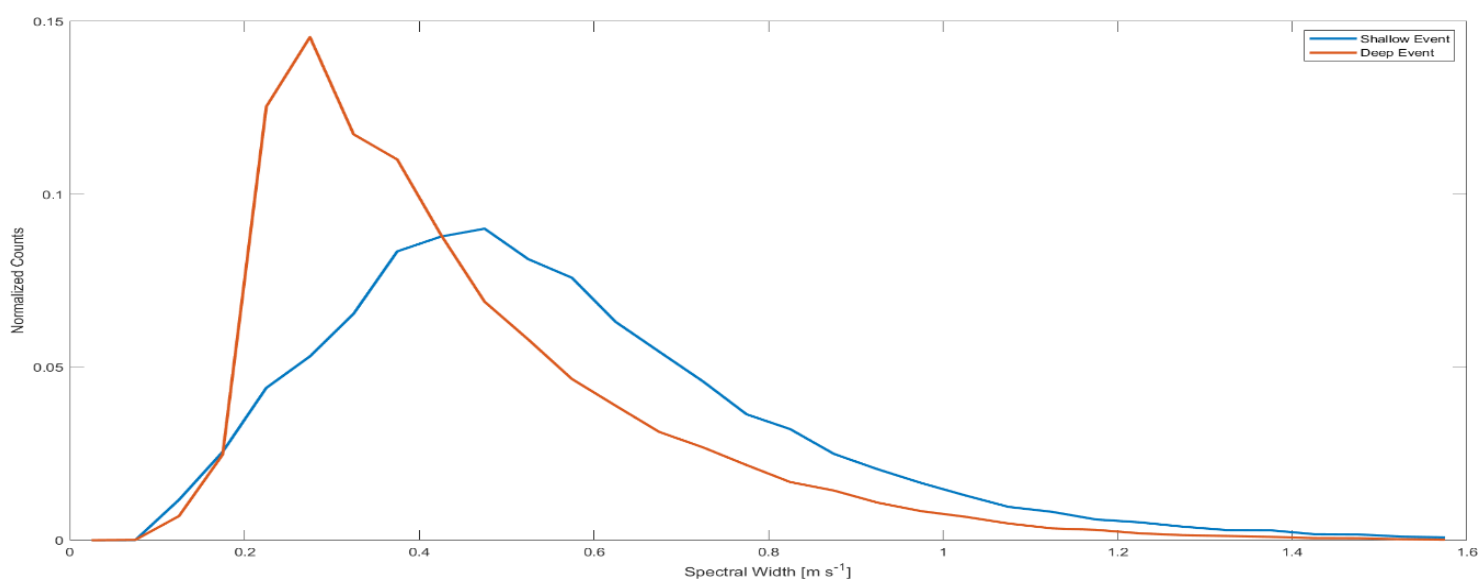

Figure 3.2.53 Plot of spectral width values for shallow (blue) and deep (red) events. Values are taken from the $400 \mathrm{~m}$ bin.

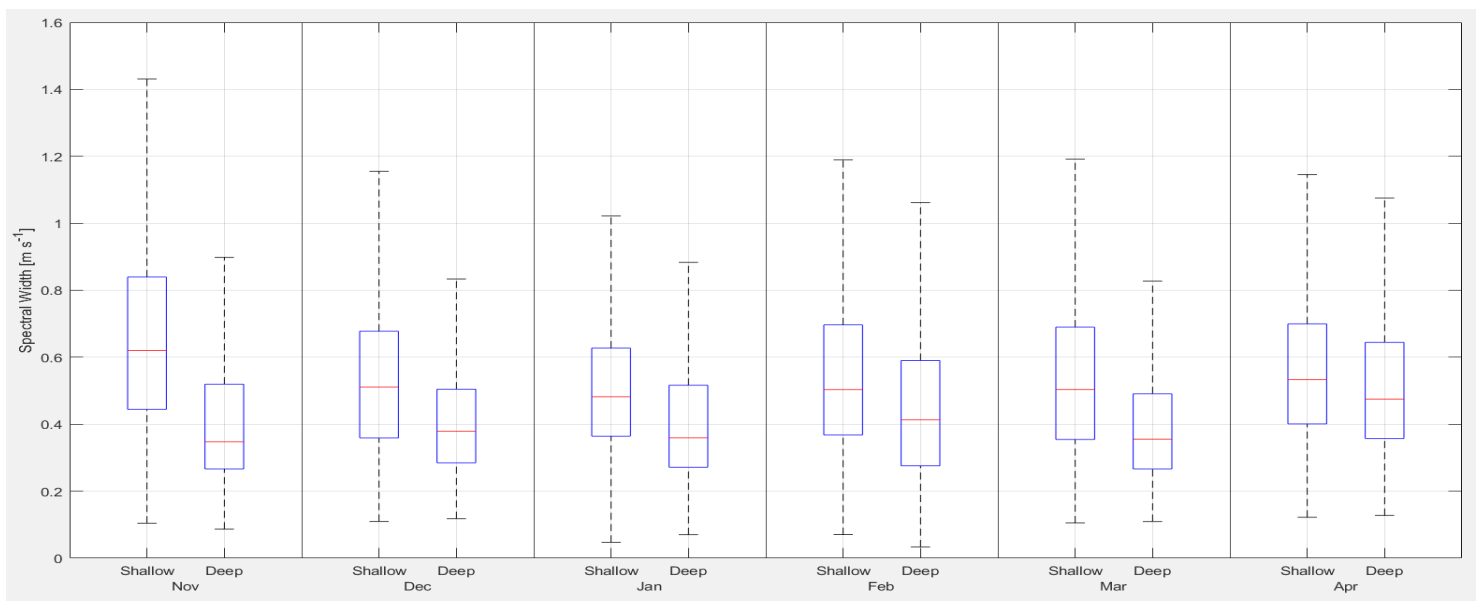

Figure 3.2.54 Boxplot of spectral width values for shallow and deep events divided for each month from November to April. Outliers are not shown. Values are taken from the $400 \mathrm{~m}$ bin. 


\subsection{Ancillary Data}

\subsubsection{Wind Direction and Speed (WDIR and WSPD)}

The first ancillary data analyzed is wind speed and wind direction, both collected at the Marquette site from the whole period of this study. The wind rose plot of the period 2014 2017 (Figure 3.3 .55) and during the winter season (Figure 3.3 .56) are on average similar as far as it concerns direction and speed. Both of them show a predominant direction from the West side and the component from SSW is reduced by almost 3\% from the complete period to the winter period. In addition, the speed variable is similar between the two datasets, making them relatively identical. Two different behaviors can be found with the shallow snow event (Figure 3.3 .57) and the deep snow event (Figure 3.3 .58 ), having the first one with a main component from NW and the second one from SSW. In the northern hemisphere, the Lake Effect Snow has generally a wind direction from NW (Figure 3.3 .59) after crossing a water body and generally the precipitations occur on the East side of the lake, so noticing this type of orientation with a shallow event is not surprising and confirms the kind of precipitation. As mentioned in chapter 1.2, the Upper Peninsula is wide only 32 $\mathrm{km}$, making it possible for the air mass to cross it still maintaining its moisture content and therefore produce a snow event. The deep snow event (Figure 3.3 .58), however, has a dominance of winds that originate from the land, SSW, but presents also all other directions with a small percentage of occurrence, meanwhile the shallow event from E to SW has

mostly $0 \%$ of occurrence. In general, shallow events have a higher wind speed than deep events, where Lake Effect Snow events can reach up to $10 \mathrm{~m} \mathrm{~s}^{-1}$ and the synoptic snow event barely touch the $6 \mathrm{~m} \mathrm{~s}^{-1}$ mark. 


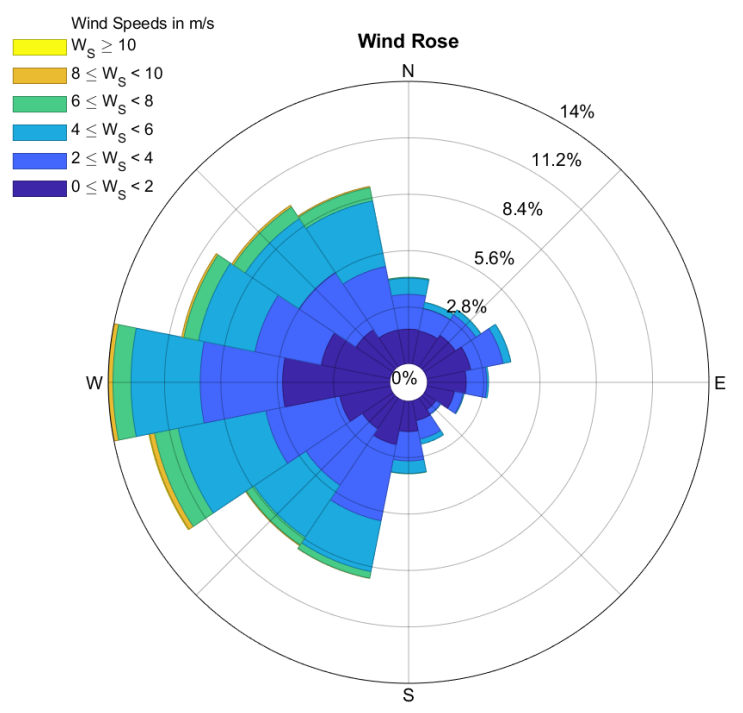

Figure 3.3.55 Wind rose plot. 2014 - 2017 period. NWS MQT.

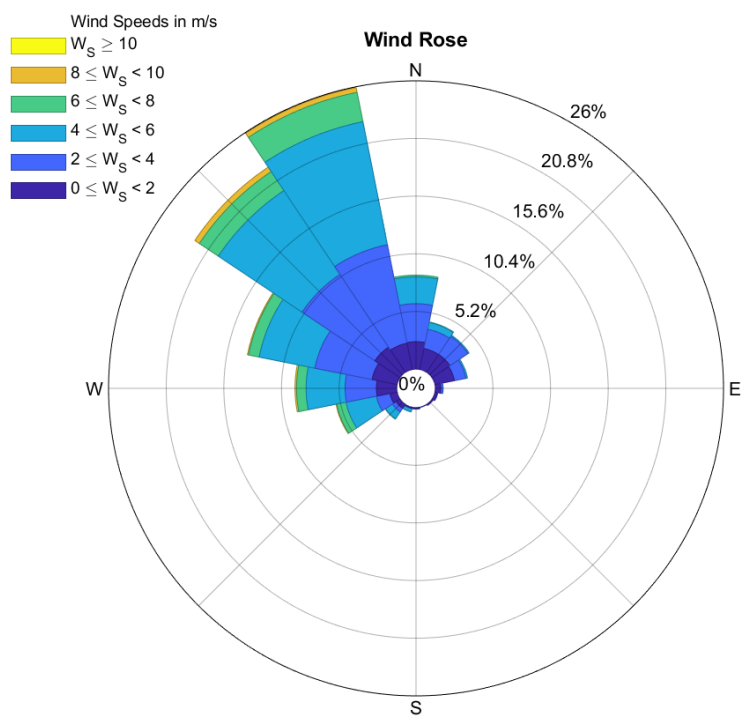

Figure 3.3.57 Wind rose plot. $2014-2017$ period, from November to April (Winter Season). Shallow Snow Event. NWS MQT.

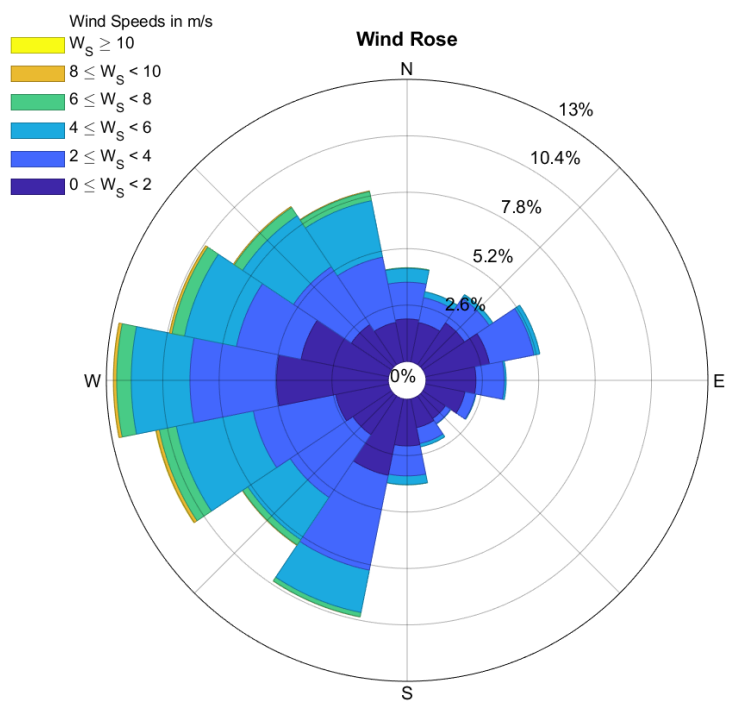

Figure 3.3.56 Wind rose plot. 2014 - 2017 period, from November to April (Winter Season).

NWS MQT.

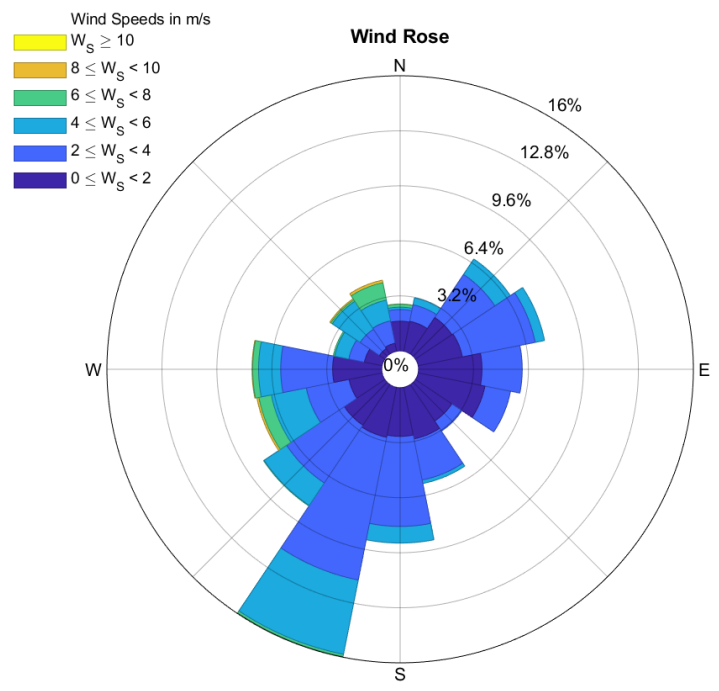

Figure 3.3.58 Wind rose plot. 2014 - 2017 period, from November to April (Winter Season). Deep Snow Event. NWS MQT. 


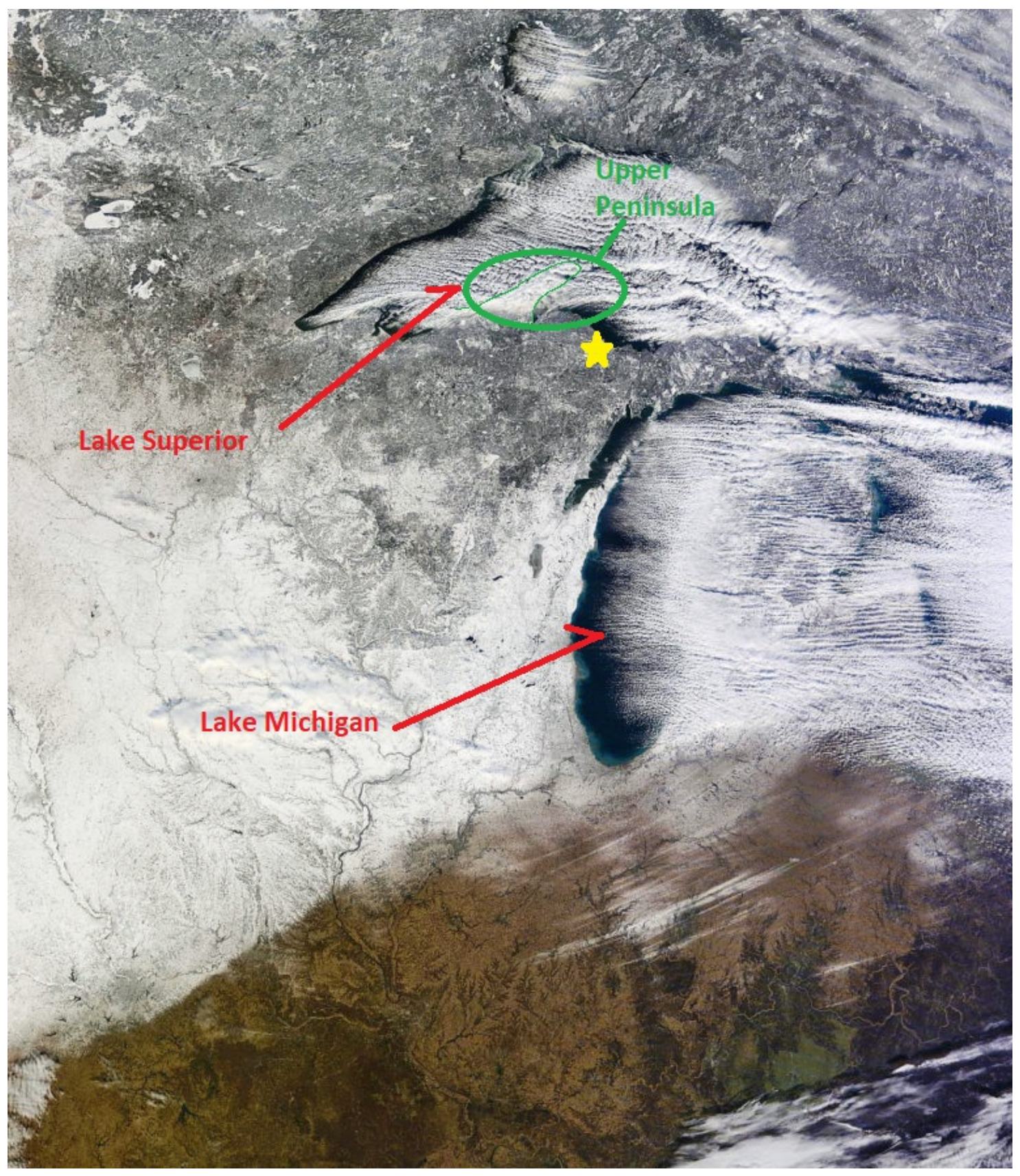

Figure 3.3.59 An image of lake effect snow captured by the MODIS weather satellite in 2015. The silhouette of the Upper Peninsula is marked with a green line. NWS Marquette office located with the yellow star. CIMSS. 
The dataset for both shallow (Figure 3.3 60 - Figure 3.3 .65) and deep event (Figure 3.3 .66 - Figure 3.3 .71) has been partitioned for each month during the winter season, from November to April. The distribution for the Lake Effect Snow event is mostly narrow and dominant at the NNW direction, meanwhile at the beginning and ending of the winter season it become slightly broader, with a significant amount of wind coming from the East side during the month of April. The only outlier present in this distribution is the month of December, where the dominant direction is from West, meaning that it is coming mostly from the land. Generally, the wind speed is distributed evenly among the months investigated, without any significant low value, but a noticeable peak in November. The deep event has winds coming from SSW in December and January, then the range starts to be broader from February and it appears a dominant component from NE and the East side in general, which could be related to orographic events. Winds never exceed a speed of $6 \mathrm{~m} \mathrm{~s}^{-1}$, apart in November, when the main direction is from W and not SSW as usual. During the whole winter season it is noticeable a component from NNW, with a speed between 6 and $10 \mathrm{~m} \mathrm{~s}^{-1}$, this behavior could be related to deep snow events enhanced by lake interactions, as it has been already discussed that usually winds related with shallow events have a higher wind speed and a wind direction from NNW. 


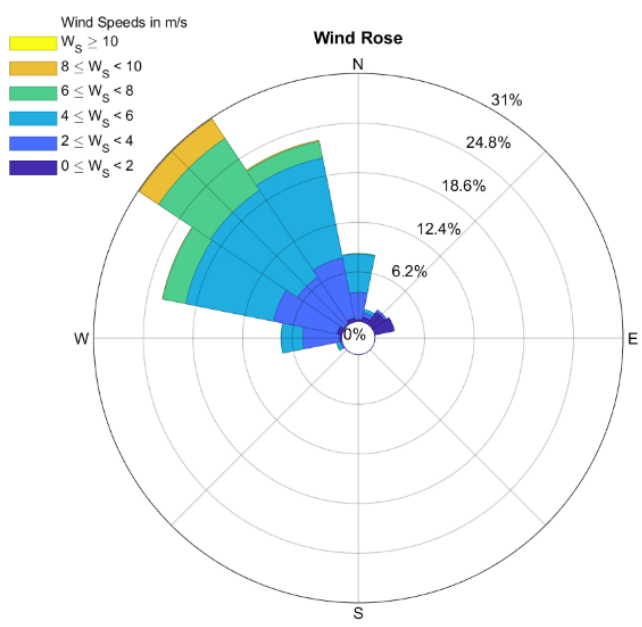

Figure 3.3.60 Wind plot. Shallow event, Nov.

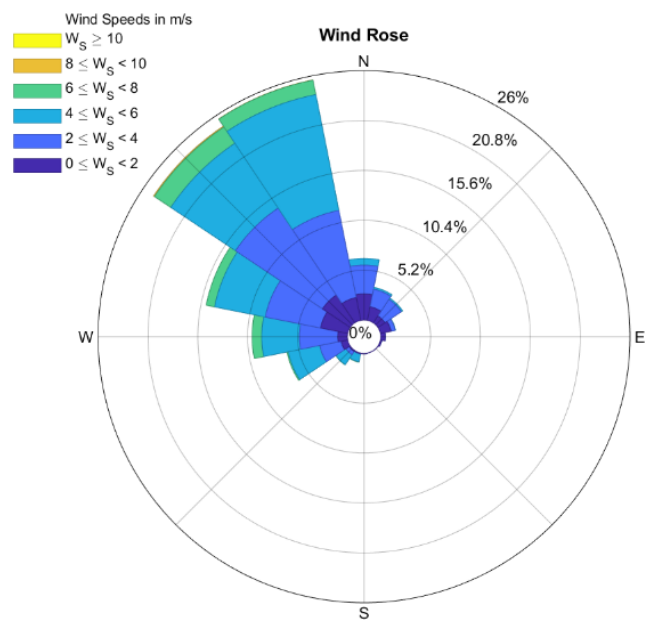

Figure 3.3.62 Wind plot. Shallow event, Jan.

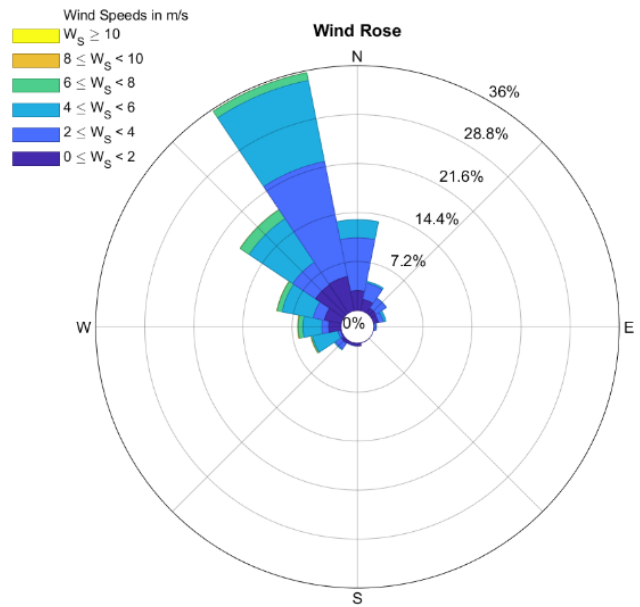

Figure 3.3.64 Wind plot. Shallow event, Mar.

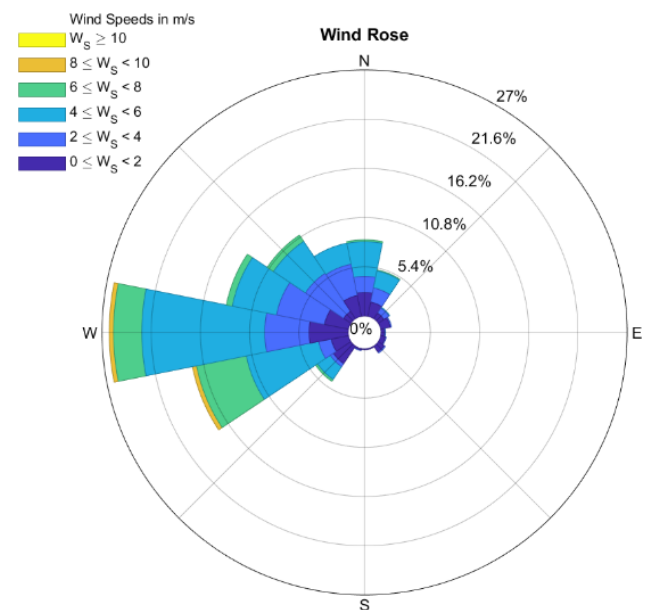

Figure 3.3.61 Wind plot. Shallow event, Dec.

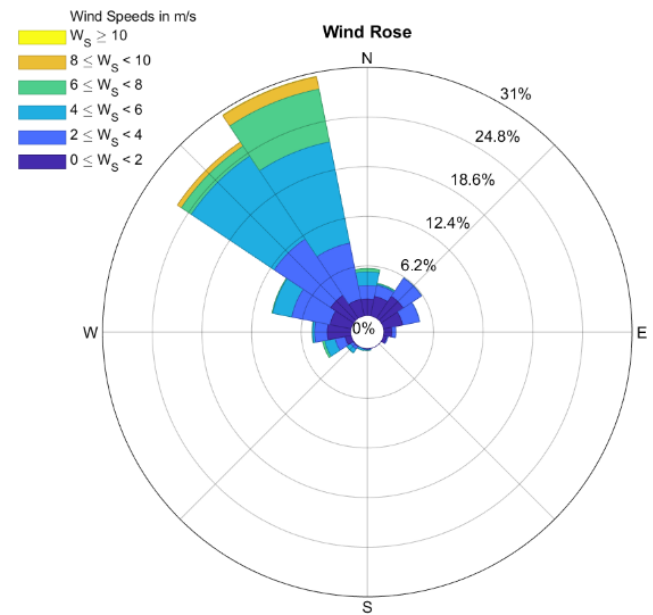

Figure 3.3.63 Wind plot. Shallow event, Feb.

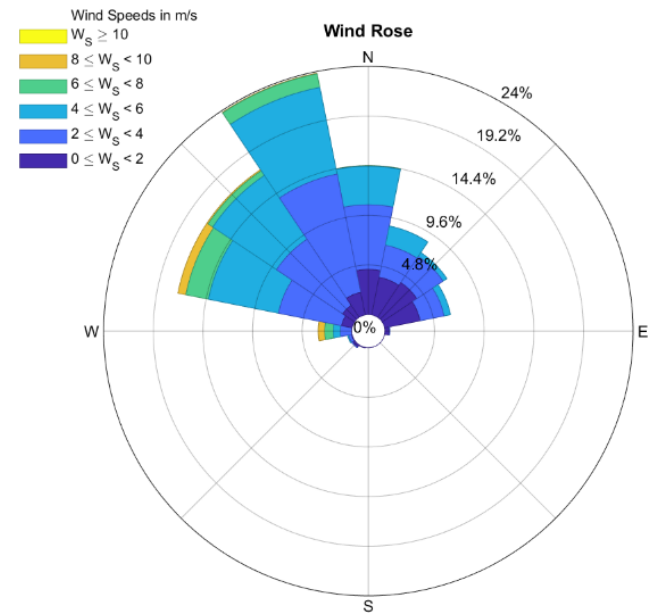

Figure 3.3.65 Wind Rose plot. Shallow event, Apr. 


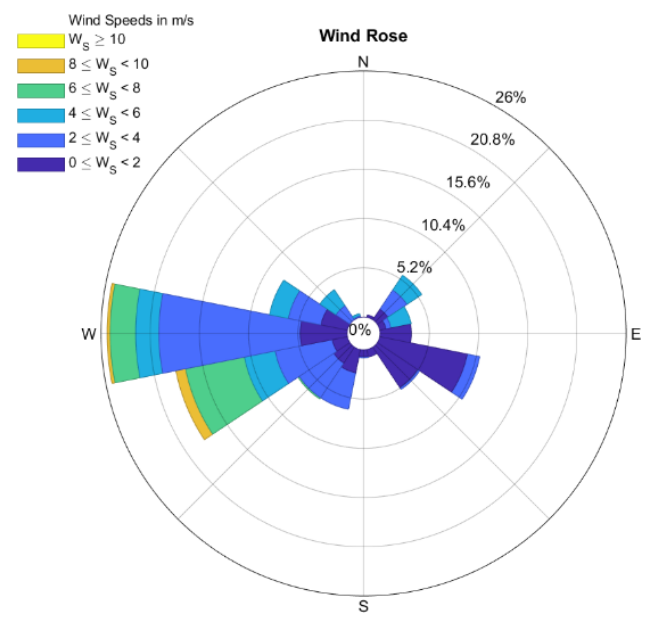

Figure 3.3.66 Wind plot. Deep event, Nov.

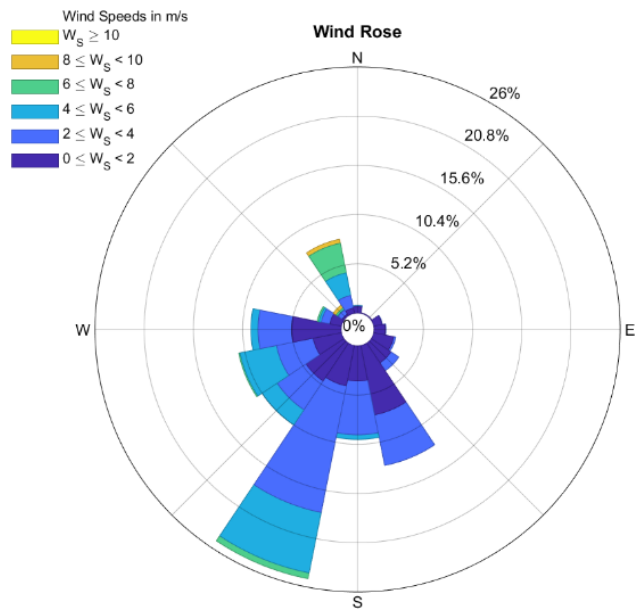

Figure 3.3.68 Wind plot. Deep event, Jan.

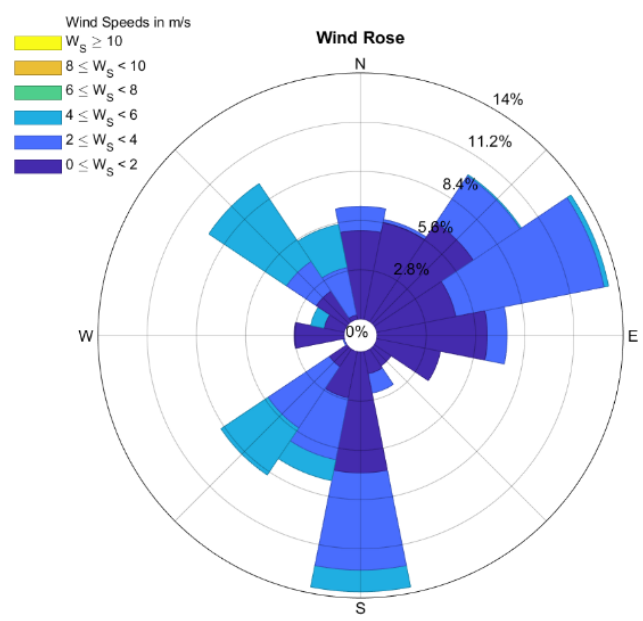

Figure 3.3.70 Wind plot. Deep event, Mar.

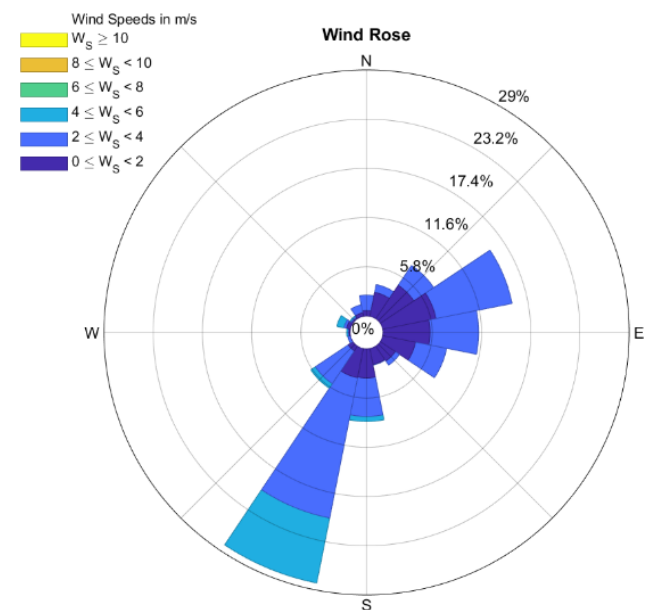

Figure 3.3.67 Wind plot. Deep event, Dec.

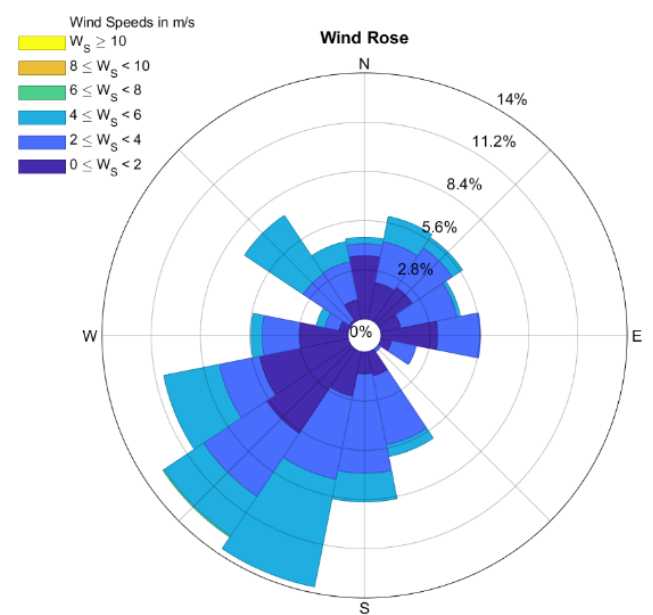

Figure 3.3.69 Wind plot. Deep event, Feb.

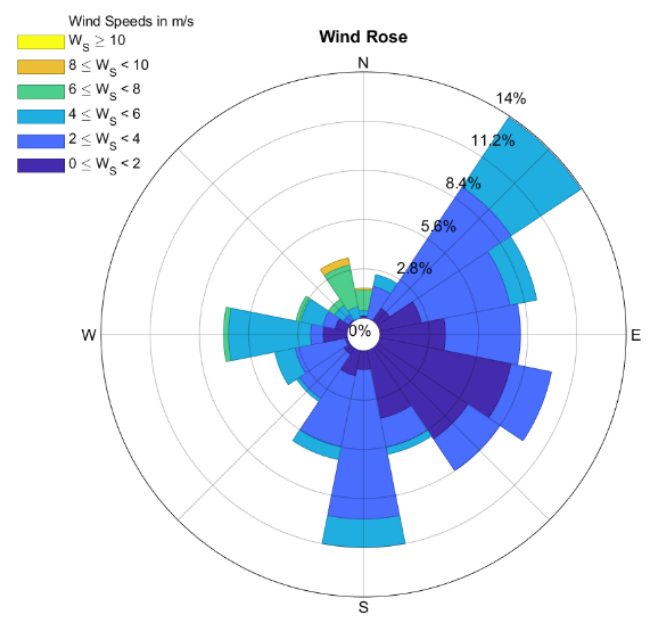

Figure 3.3.71 Wind plot. Deep event, Apr. 


\subsubsection{Surface Pressure (PRES)}

The surface pressure is the only variable investigated where values for the deep event are lower than the shallow event. Figure 3.3 .72 shows the trend of both dataset and the synoptic snow event presents a narrower distribution, with a drastic drop in values from 1022 to $1030 \mathrm{hPa}$. The deep event has two noticeable peaks at 1008 and $1013 \mathrm{hPa}$, whereas the shallow event has a main peak at $1018 \mathrm{hPa}$. The group of box plots (Figure 3.3 .73 ) suggests a noticeable difference in mean values during the months of February and January, only December has both mean values close to each other. The dataset proved to be statistically significant at a confidence level of $95 \%$.

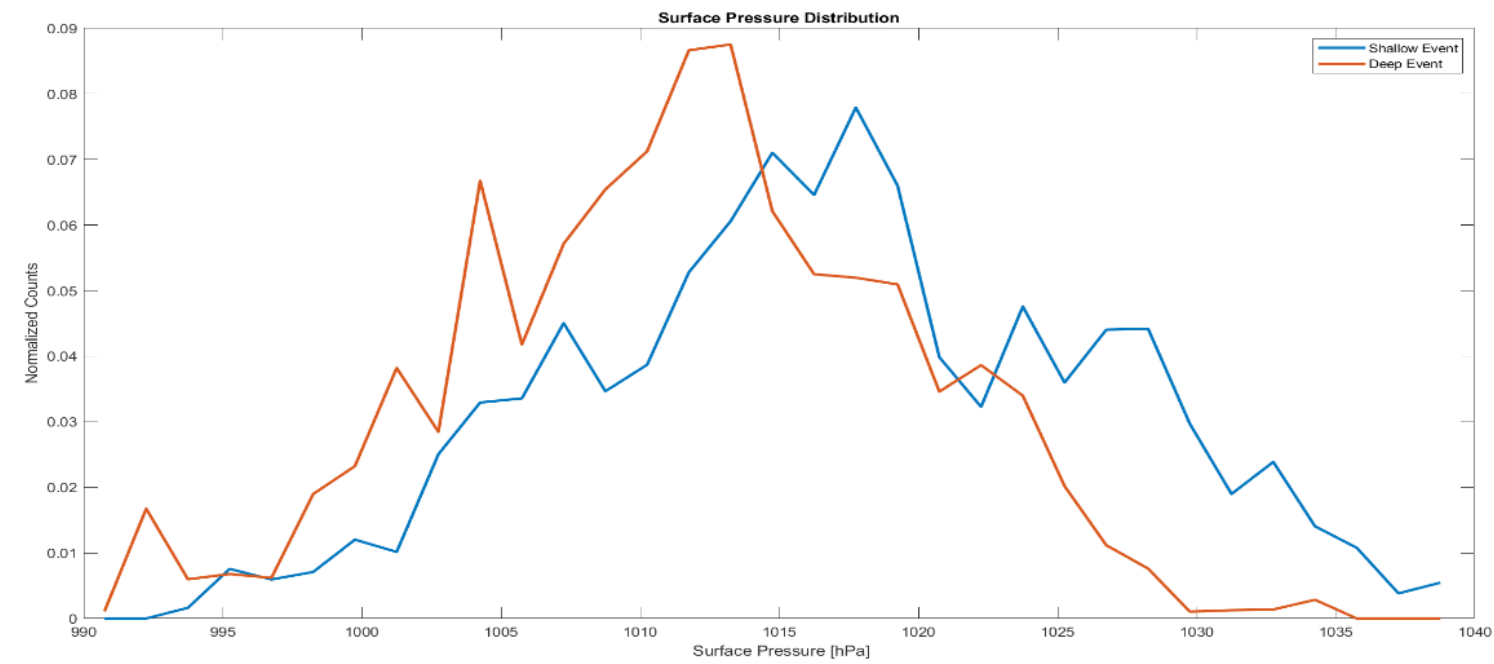

Figure 3.3.72 Plot of pressure values for shallow (blue) and deep (red) events. Surface values. 


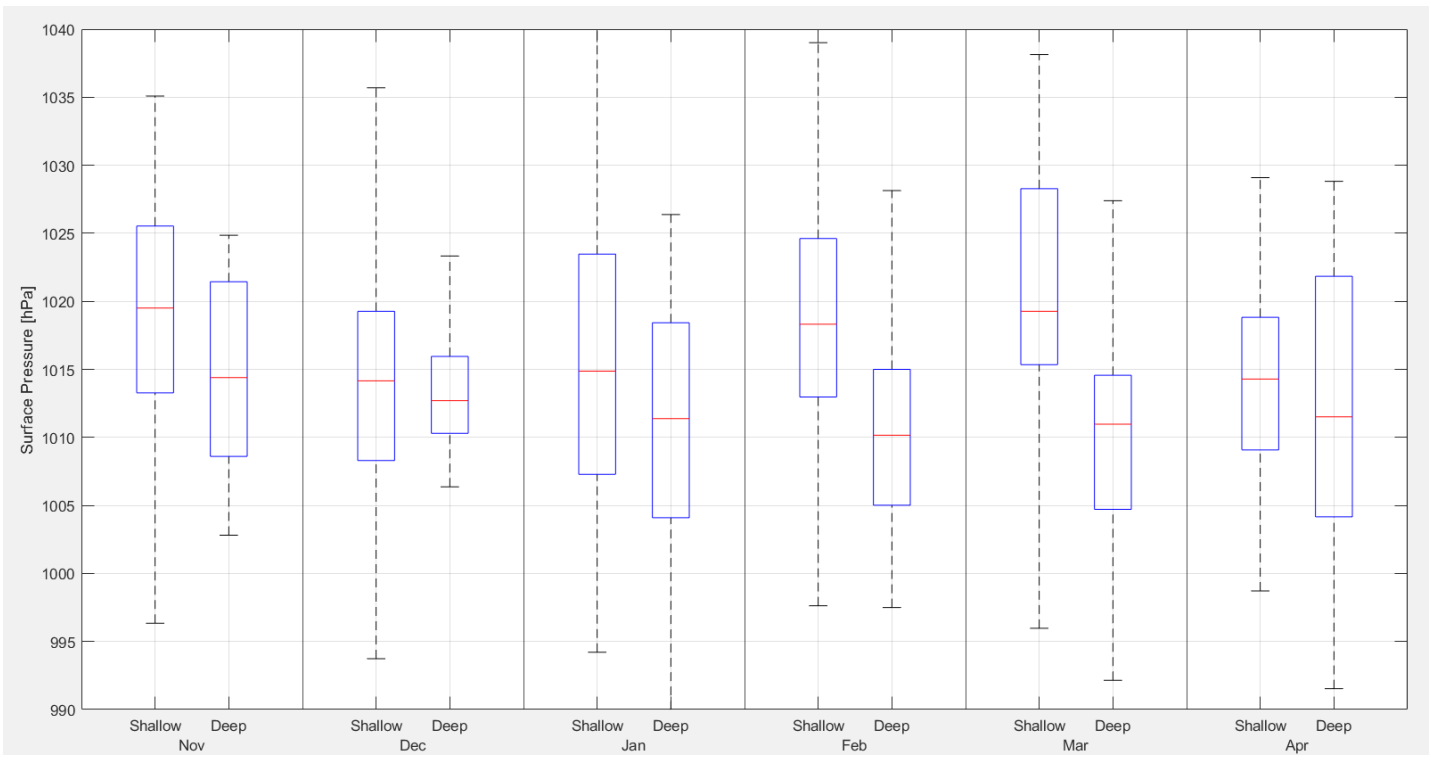

Figure 3.3.73 Boxplot of pressure values for shallow and deep events divided for each month from November to April. Outliers are not shown. Surface values.

\subsubsection{Surface Temperature (TSFC)}

As presented in the surface temperature plot (Figure 3.3 .75 ), the shallow event is generally colder than a deep event of roughly $7{ }^{\circ} \mathrm{C}$ and has a broader distribution. The Lake Effect Snow event has two main predominant temperature values that range from -15.5 to $12.5^{\circ} \mathrm{C}$ and from -9.5 to $5.5^{\circ} \mathrm{C}$, probably related with a colder period during central months of the winter season and a warmer one, during the shoulder months. The synoptic snow event has its major peak at $-1.5^{\circ} \mathrm{C}$, close to freezing temperature, and has a narrower distribution, having most of the observations between $-4{ }^{\circ} \mathrm{C}$ and $0{ }^{\circ} \mathrm{C}$. There are three minor peaks at $13.5^{\circ} \mathrm{C},-9.5^{\circ} \mathrm{C}$ and $-6.5^{\circ} \mathrm{C}$, but they could be related with embedded shallow events during a deep snow event. The box plot group confirms the presence of a warmer period during shoulder months and colder period in January and February. The difference between the mean values is statistically significant. 


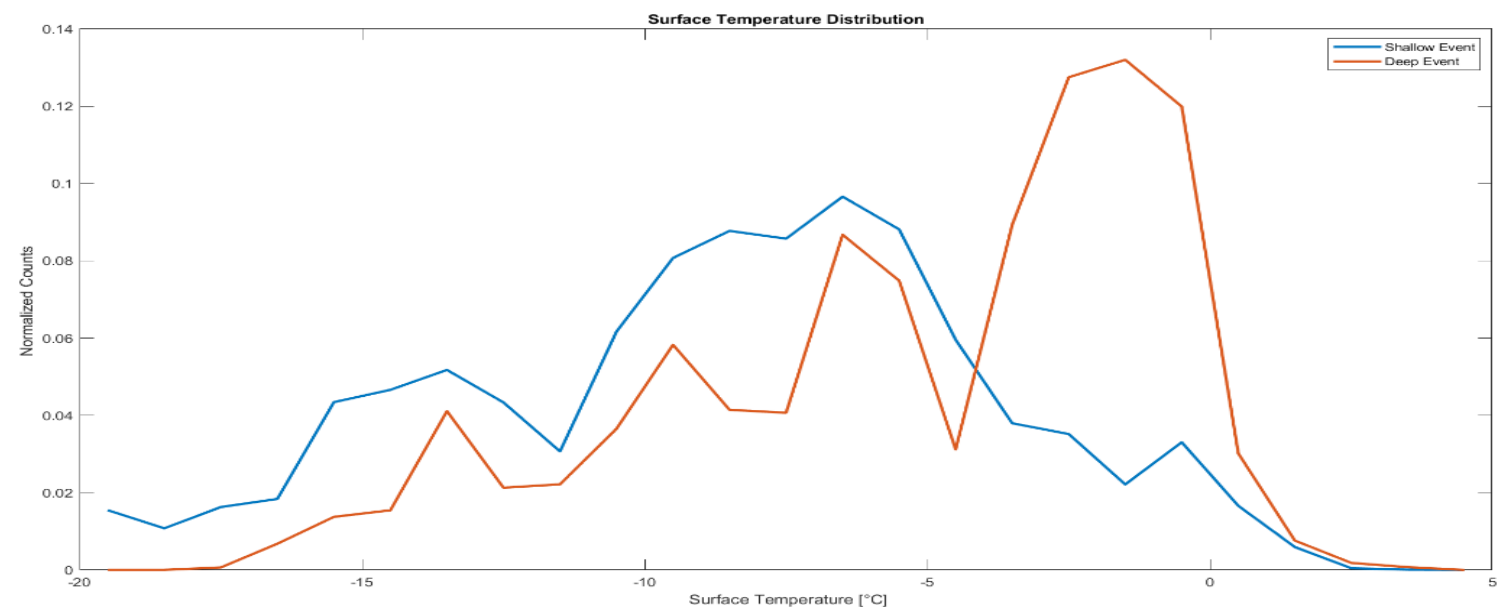

Figure 3.3.74 Plot of temperature values for shallow (blue) and deep (red) events. Surface values.

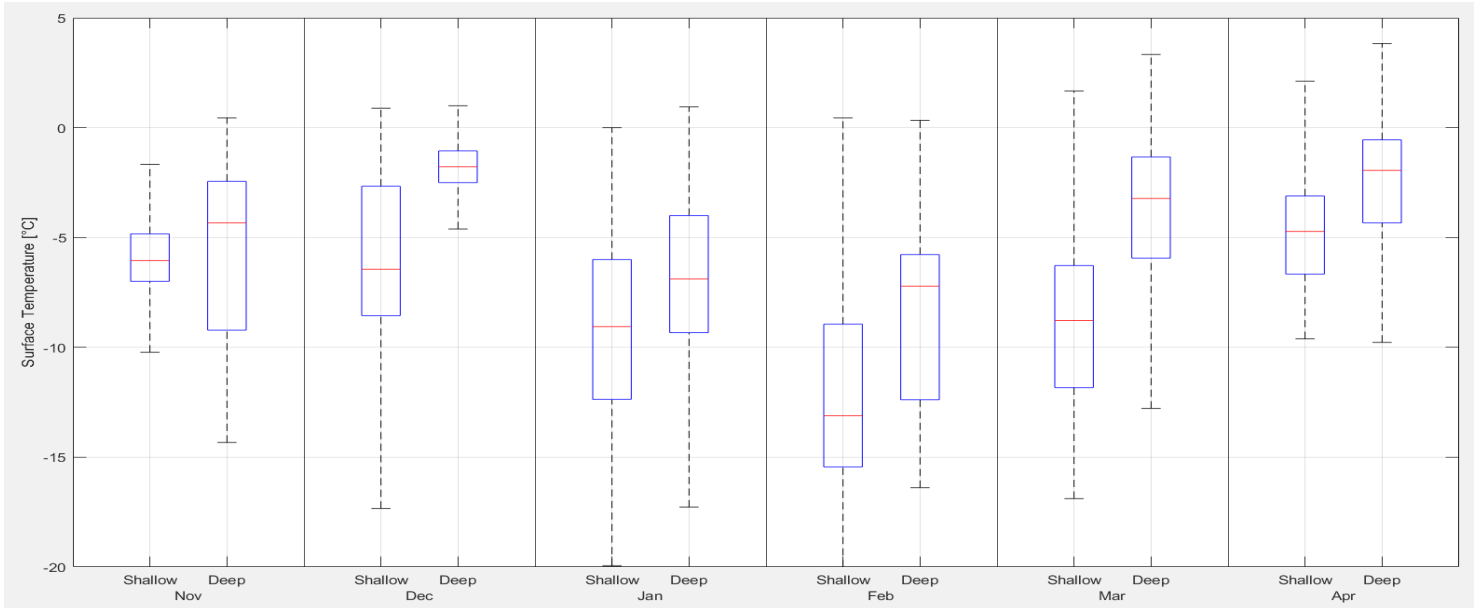

Figure 3.3.75 Boxplot of temperature values for shallow and deep events divided for each month from Nov to Apr. Surface values. 


\subsubsection{Relative Humidity (RH)}

The relative humidity is the last variable investigated among the information obtained from the surface. It is defined as the ratio between the water vapor present in the air and the amount needed for saturation at the same temperature. A value of $100 \%$ of relative humidity means that the air is completely saturated and cannot hold any more water vapor, therefore creates the possibility to rain. Usually the max ratio is found where the clouds are forming, but it could be much less near the ground. Figure 3.3 .76 shows the distribution for the two types of event and the deep event has a narrower distribution, which occurs mostly over $90 \%$ of $\mathrm{RH}$ with a peak at $94 \%$, meanwhile the shallow event one is broader and ranges from $85 \%$ to $95 \%$, with a peak at $87 \%$. The box plot group does not show much variation during the winter season, in not in December and March. 


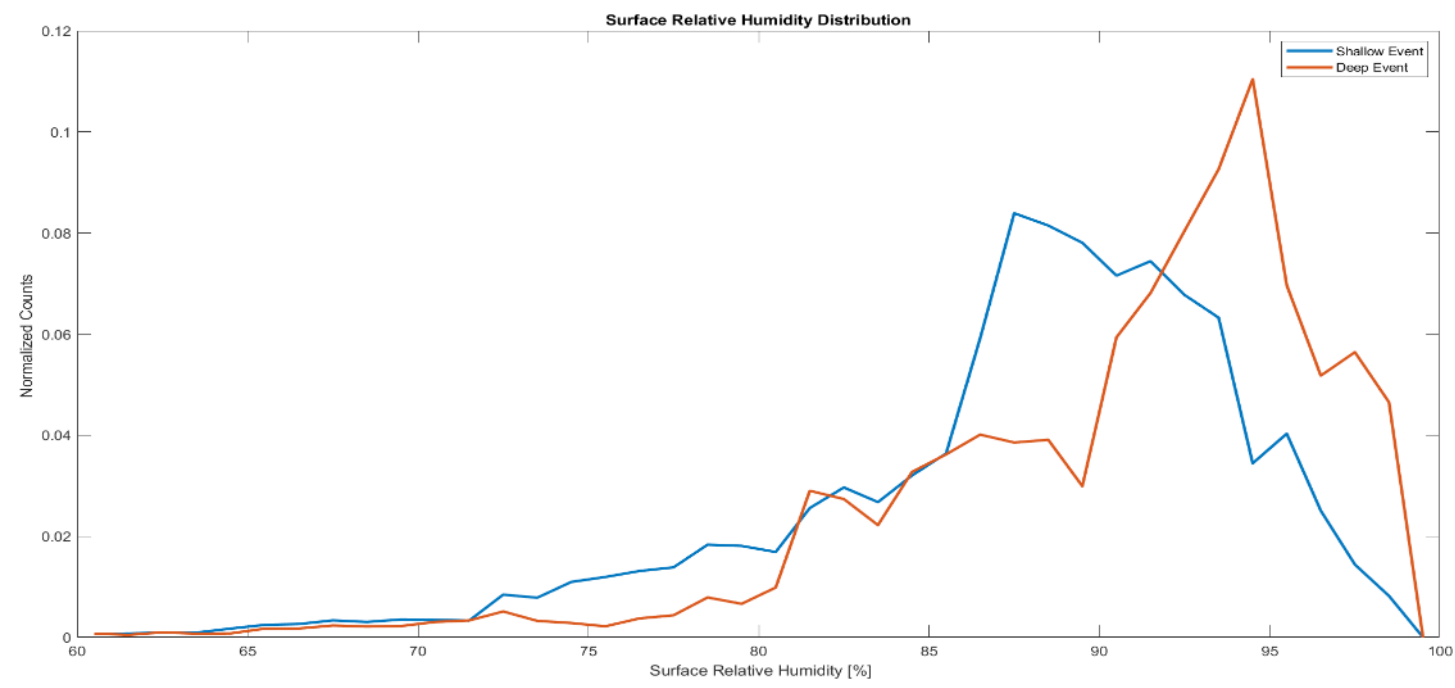

Figure 3.3.76 Plot of relative humidity values for shallow (blue) and deep (red) events. Surface values.

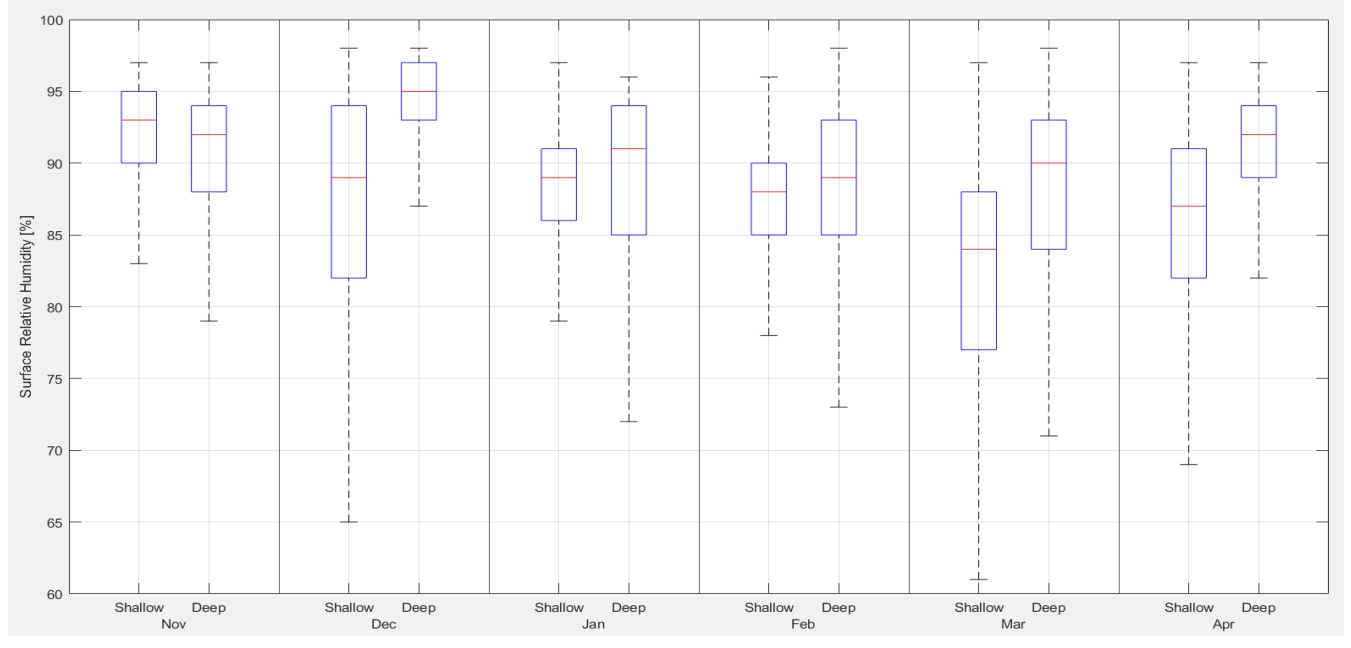

Figure 3.3.77 Boxplot of $\mathrm{RH}$ values for shallow and deep events divided for each month from Nov to Apr. Surface values. 


\subsection{Reanalysis Data}

The reanalysis dataset used in this chapter has been taken from the Copernicus websites (https://cds.climate.copernicus.eu/) related to ERA5. Values of specific variables as surface temperature, pressure and snow density have been taken in consideration and compared with the same values of those variables obtained from the NWS office, in order to evaluate any correlation or difference between the two datasets. The horizontal resolution of ERA5 is $0.1^{\circ} \times 0.1^{\circ}$ with a native resolution of $9 \mathrm{~km}$ and a grid from $46.5 \mathrm{~N}$ to $46.6 \mathrm{~N}$ and $87.5 \mathrm{~W}$ to 87.6 $\mathrm{W}$ is used, but instead of performing an average within the $2 \mathrm{x} 2$ matrix created, it has been decided to utilize the values located at $46.5 \mathrm{~N}, 87.6 \mathrm{~W}$, because closer to the NWS office (Figure 3.4 .78). The time resolution of ERA5 is hourly, meanwhile the data from the NWS office is in minutes, therefore an average over 60 minutes has been performed and the result is adequately shifted to synchronize the two datasets and every day is concatenated with the next one. Before starting with the analysis, it is necessary to remember how the type of data from the NWS office is punctual, therefore related to a specific location and the values could differ in a space manner. As with the previous calculations, only values when the snow precipitation event is happening are used.

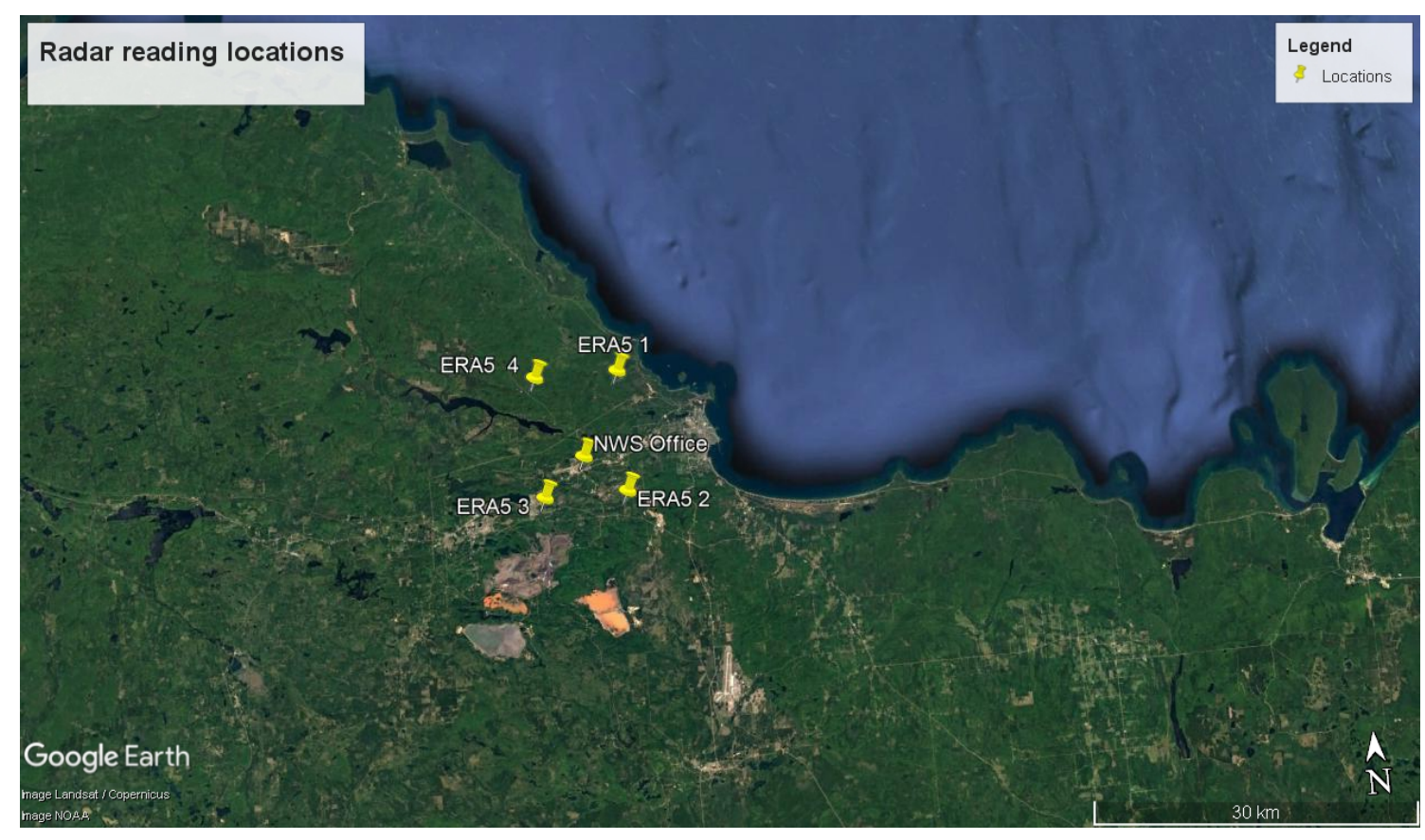

Figure 3.4.78 Radar reading locations. NWS Office (46.53, -87.55), ERA1(46.6, -87.5), ERA2(46.5, -87.5), ERA3(46.5, -87.6), ERA4(46.6, -87.6). Google earth image. 


\subsubsection{Comparison between data from ERA5 and NWS Office}

The temperature values obtained from ERA5 are measured in $\mathrm{K}$, meanwhile the NWS office offers values in ${ }^{\circ} \mathrm{C}$ and so the data from ERA5 has been converted in Celsius subtracting the value of 273.15 from the K measurement. Figure 3.4 .80 and Figure 3.4 .79 show the surface temperature trend for both shallow and deep events and it is noticeable how the measures have a high correlation with high temperatures, but low temperatures, mostly happening during night times, are not recorded correctly from ERA5, probably because of the location of the NWS office, that could have lower temperatures compared to other locations. The next two figures (Figure 3.4 .81, Figure 3.4 .82) present a scatter plot of the two datasets and values over $-7.5{ }^{\circ} \mathrm{C}$ have a higher correlation, with most of the values falling within the $95 \%$ prediction interval, meanwhile below $-7.5{ }^{\circ} \mathrm{C}$ the dispersion is higher and more values fall outside the $95 \%$ prediction interval. The shallow event presents almost a bimodal behavior with two clusters, one located between $-10{ }^{\circ} \mathrm{C}$ and $-5^{\circ} \mathrm{C}$ and the other one centered at $-15{ }^{\circ} \mathrm{C}$. The deep event has a bigger cluster from $-5^{\circ} \mathrm{C}$ to $0^{\circ} \mathrm{C}$, as already seen with analyses in chapter 3.3.3. 


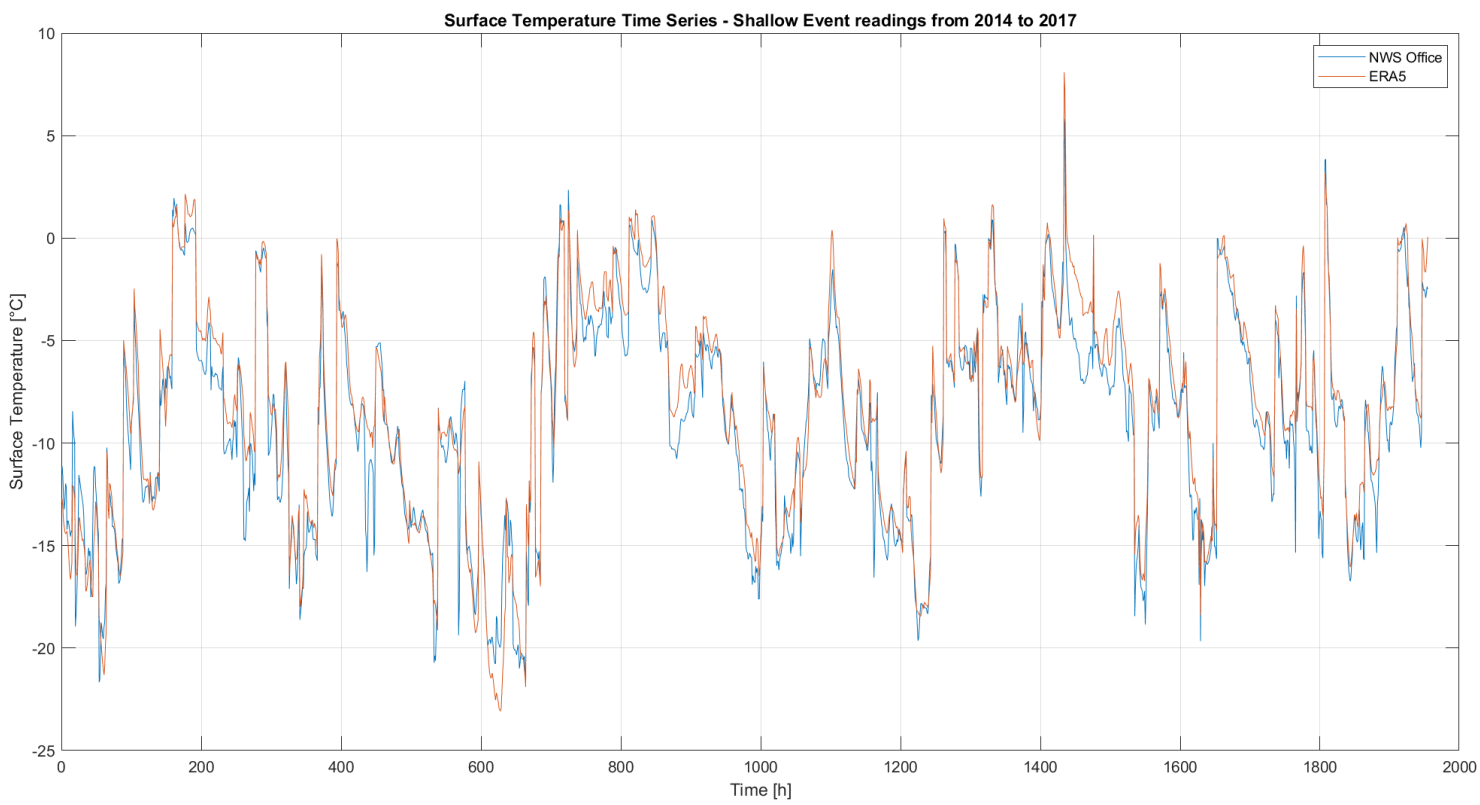

Figure 3.4.79 Surface temperature time series for shallow event readings from 2014-2017, only values when there is a precipitation are taken into consideration. Comparison between NWS Office dataset (blue line) and ERA5 dataset (red). Most of the values overlap, except for low temperatures.

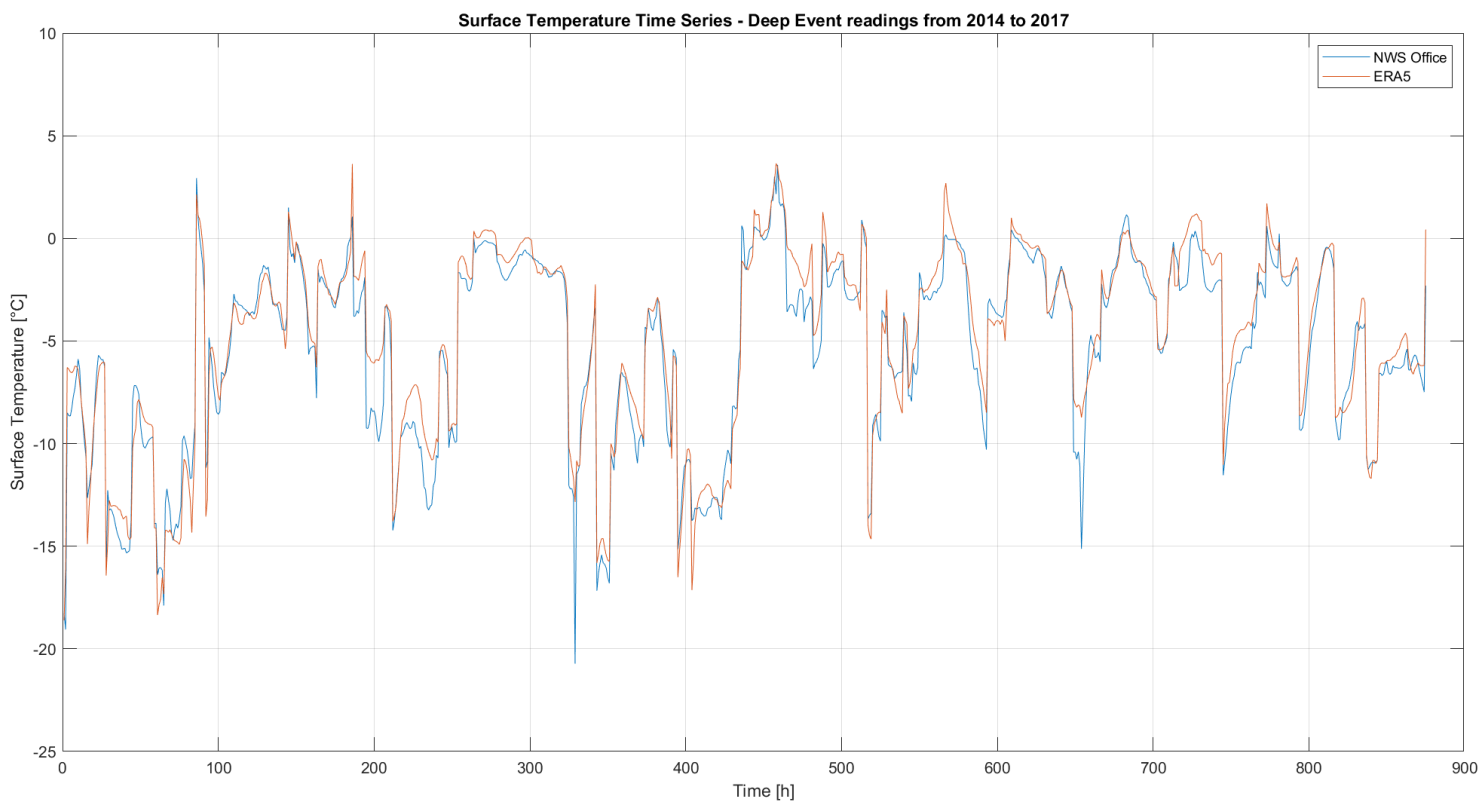

Figure 3.4.80 Surface temperature time series for deep event readings from 2014-2017, only values when there is a precipitation are taken into consideration. Comparison between NWS Office dataset (blue line) and ERA5 dataset (red).. Most of the values overlap, except for low temperatures. 


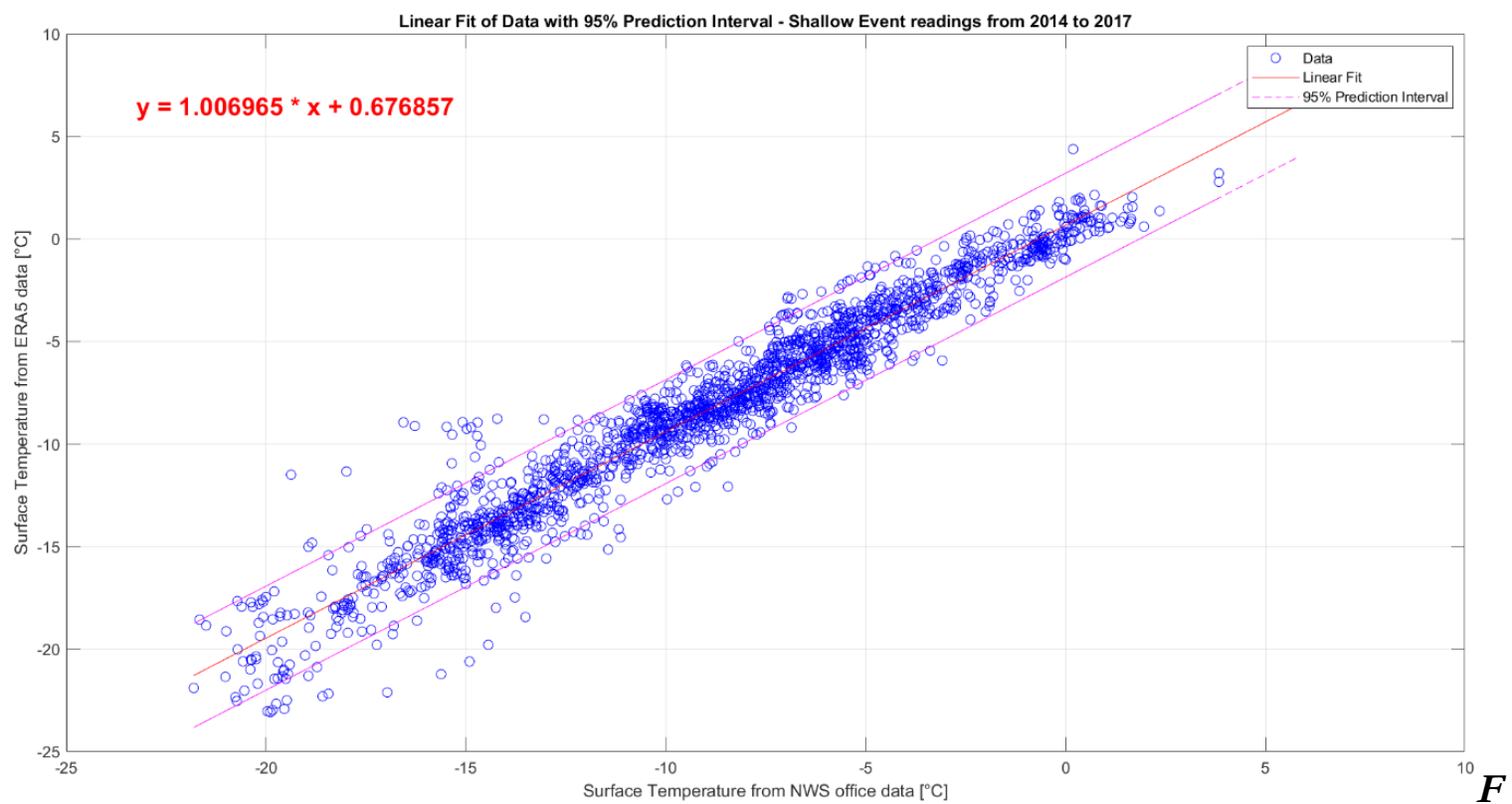

igure 3.4.81 Scatter plot of both surface temperature datasets from NWS Office and ERAS for shallow event readings from 2014-2017, only values when there is a precipitation are taken into consideration. High correlation and low dispersion for higher temperature and higher dispersion for lower temperatures.

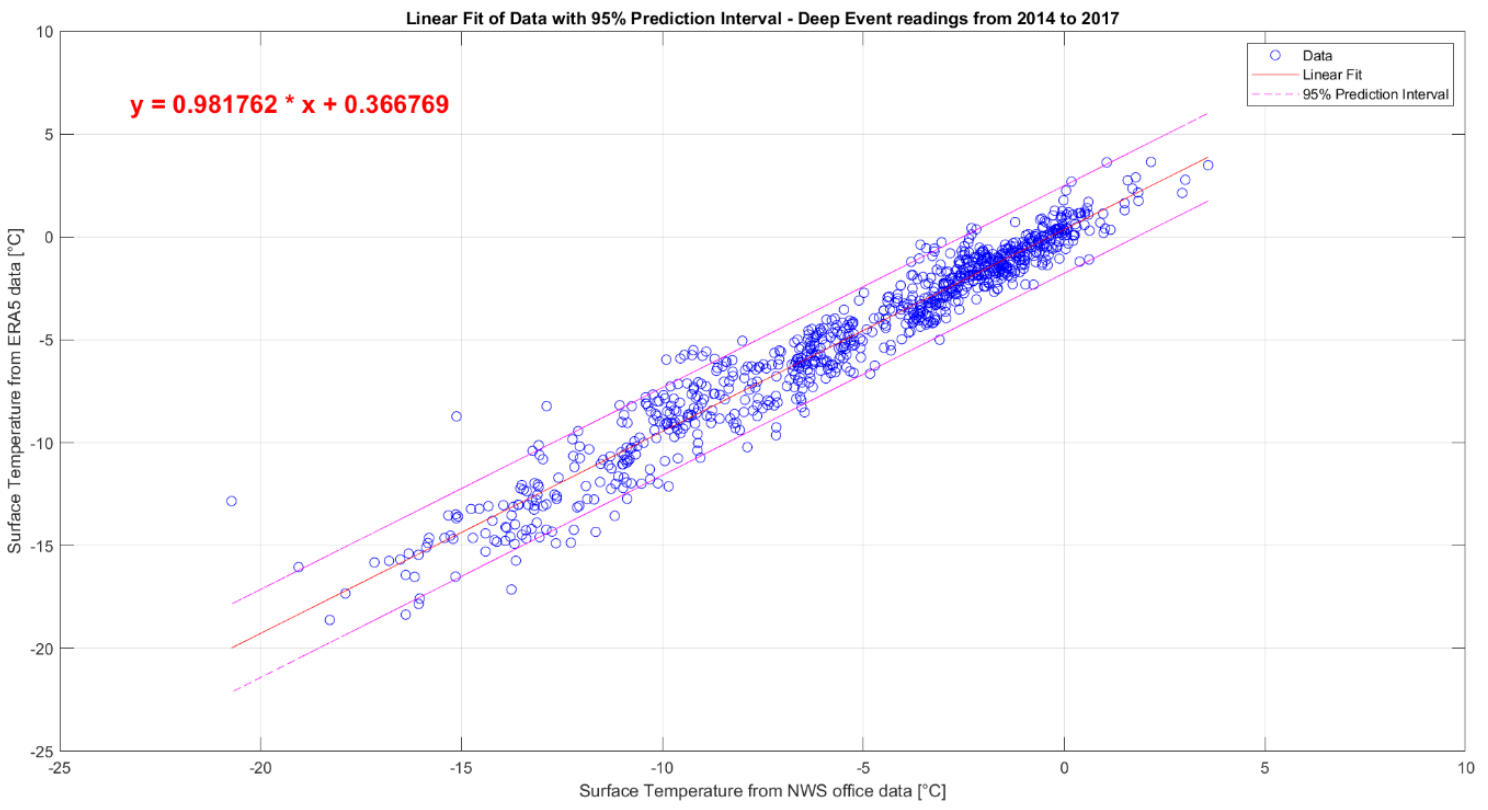

Figure 3.4.82 Scatter plot of both surface temperature datasets from NWS Office and ERA5 for deep event readings from 2014-2017, only values when there is a precipitation are taken into consideration. High correlation and low dispersion for higher temperature and higher dispersion for lower temperatures. 
The next variable investigated is the surface pressure (Figure 3.4 .83, Figure 3.4 .84). Values from the NWS office are measured in $\mathrm{hPa}$ and ERA5 gives measurements in $\mathrm{Pa}$, therefore a conversion is necessary to compare the two datasets. The trend of concatenated days has a similar behavior for both families of data. The scatter plots (Figure 3.4 .85, Figure 3.4 .86) show a high correlation for both shallow and deep events. It is also noticeable how, on average, a deep event has lower pressure values than a shallow event, as already discussed in chapter 3.3.2.

ERA5 provides snow density readings in $\mathrm{kg} \mathrm{m}^{-3}$ unit, meanwhile data from PIP is measured in $\mathrm{g} \mathrm{ml}^{-1}$, and therefore, before proceeding with the analysis, it has been necessary to convert the data from ERA5 with the correct unit of measurement. Figure 3.4 .87 and Figure 3.4 .88 present the trend along every day and the two families suggest a low correlation, which could be due by the different resolution from the two instruments and the location. ERA5 values have a reading every hour, meanwhile the PIP offers a measurement every minute, producing more accurate values; moreover, snow density could change significantly within a small distance and this could explain the difference between the two datasets.

Values of surface temperature and pressure have a high correlation between data from ERA5 and from the NWS Office in Marquette; on the contrary, ERA5 snow density values do not have a significant correlation. The following table presents $\mathrm{R}$ squared values for each correlation between ERA5 and the NWS Office. $\mathrm{R}^{2}$ values range from 0 to 1 and the closer they are to 1 , the stronger the correlation is.

\begin{tabular}{lcc}
\hline \multicolumn{1}{c}{ Variable } & Shallow Event & Deep Event \\
\hline Surface Pressure & 0.9864 & 0.9748 \\
Surface Temperature & 0.9426 & 0.9449 \\
Snow Density & 0.0101 & 0.0705 \\
\hline \hline
\end{tabular}

Table 3.4.1.5 Table of $R$ squared values for each variable investigated from the reanalysis. 


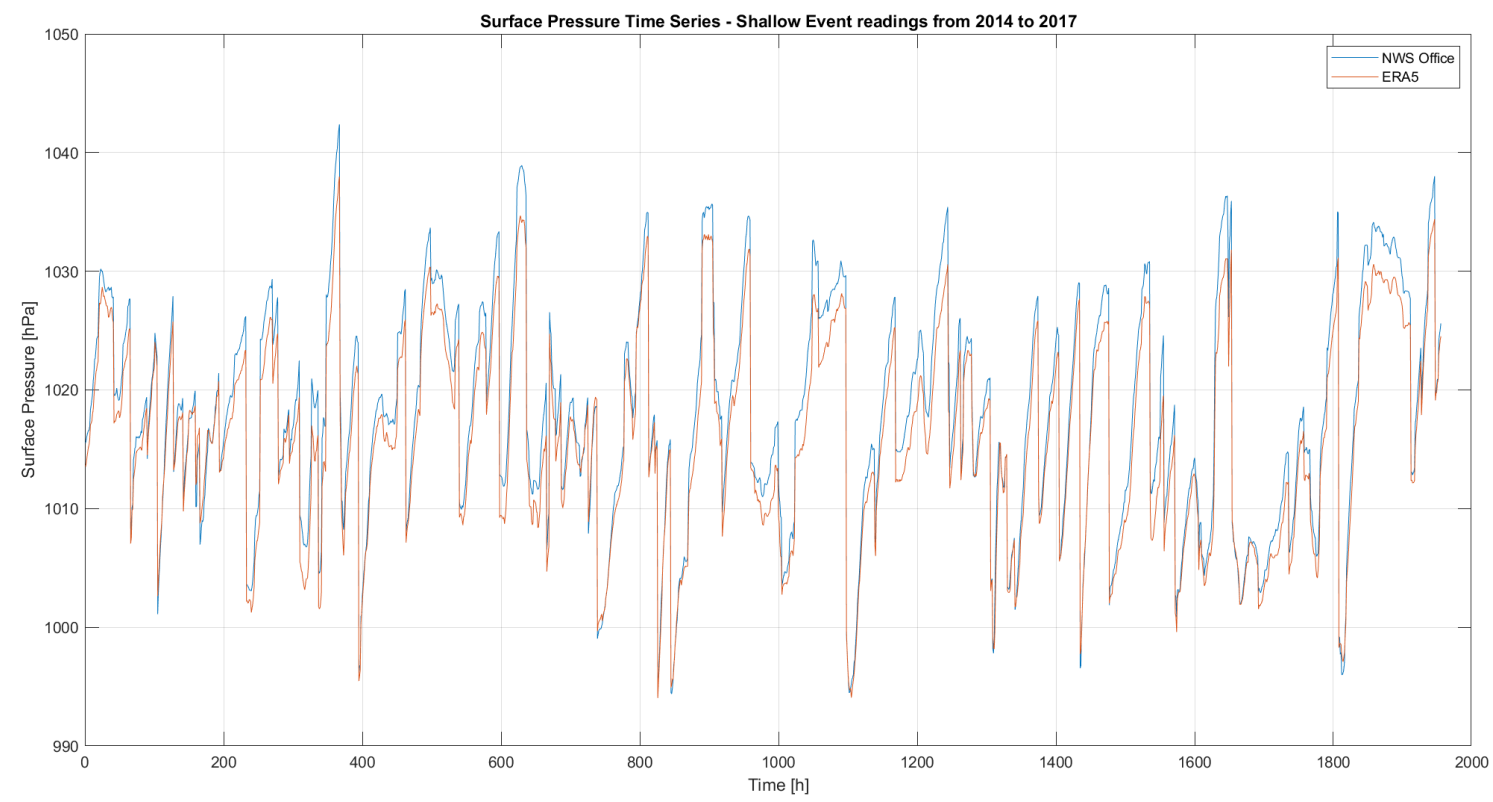

Figure 3.4.83 Surface pressure time series for shallow event readings from 2014-2017, only values when there is a precipitation are taken into consideration. Comparison between NWS Office dataset (blue line) and ERA5 dataset (red). Both groups suggest the same dataset.

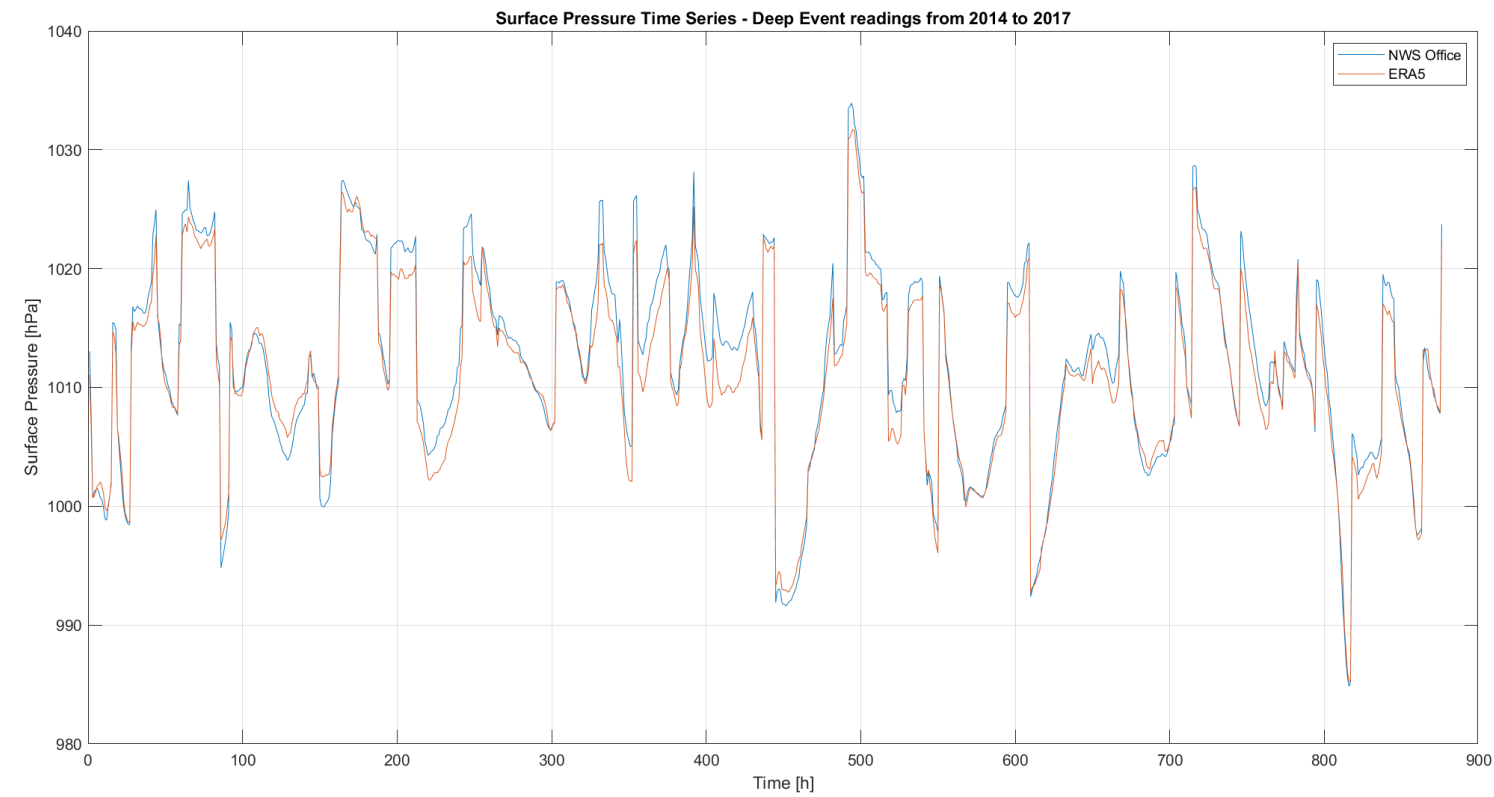

Figure 3.4.84 Surface pressure time series for deep event readings from 2014-2017, only values when there is a precipitation are taken into consideration. Comparison between NWS Office dataset (blue line) and ERA5 dataset (red). Both groups suggest the same dataset. 


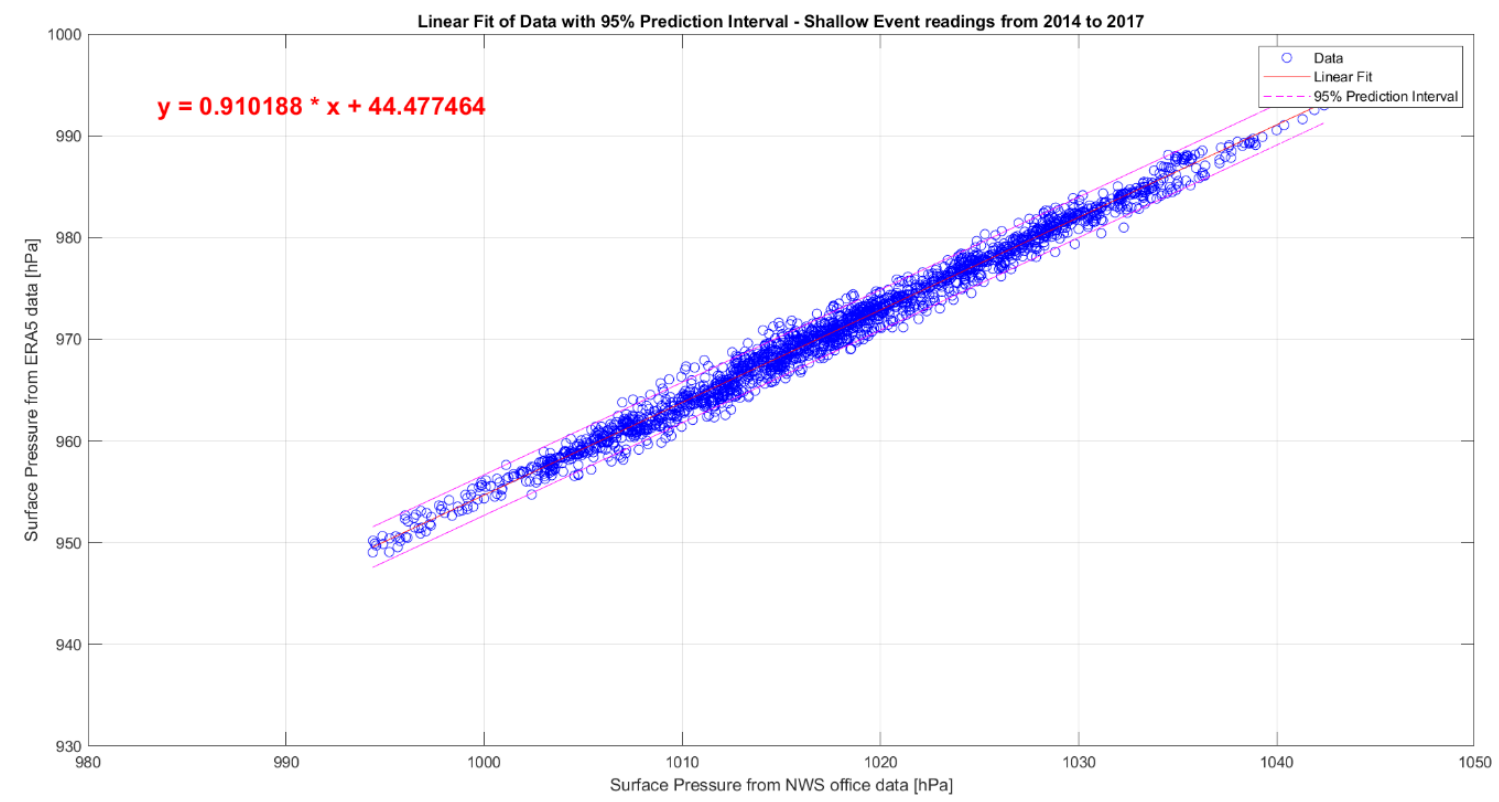

Figure 3.4.85 Scatter plot of both surface pressure datasets from NWS Office and ERA5 for shallow event readings from 2014-2017, only values when there is a precipitation are taken into consideration. There is a bigh correlation along every value, with a slightly higher dispersion at 1010-1020 bPa.

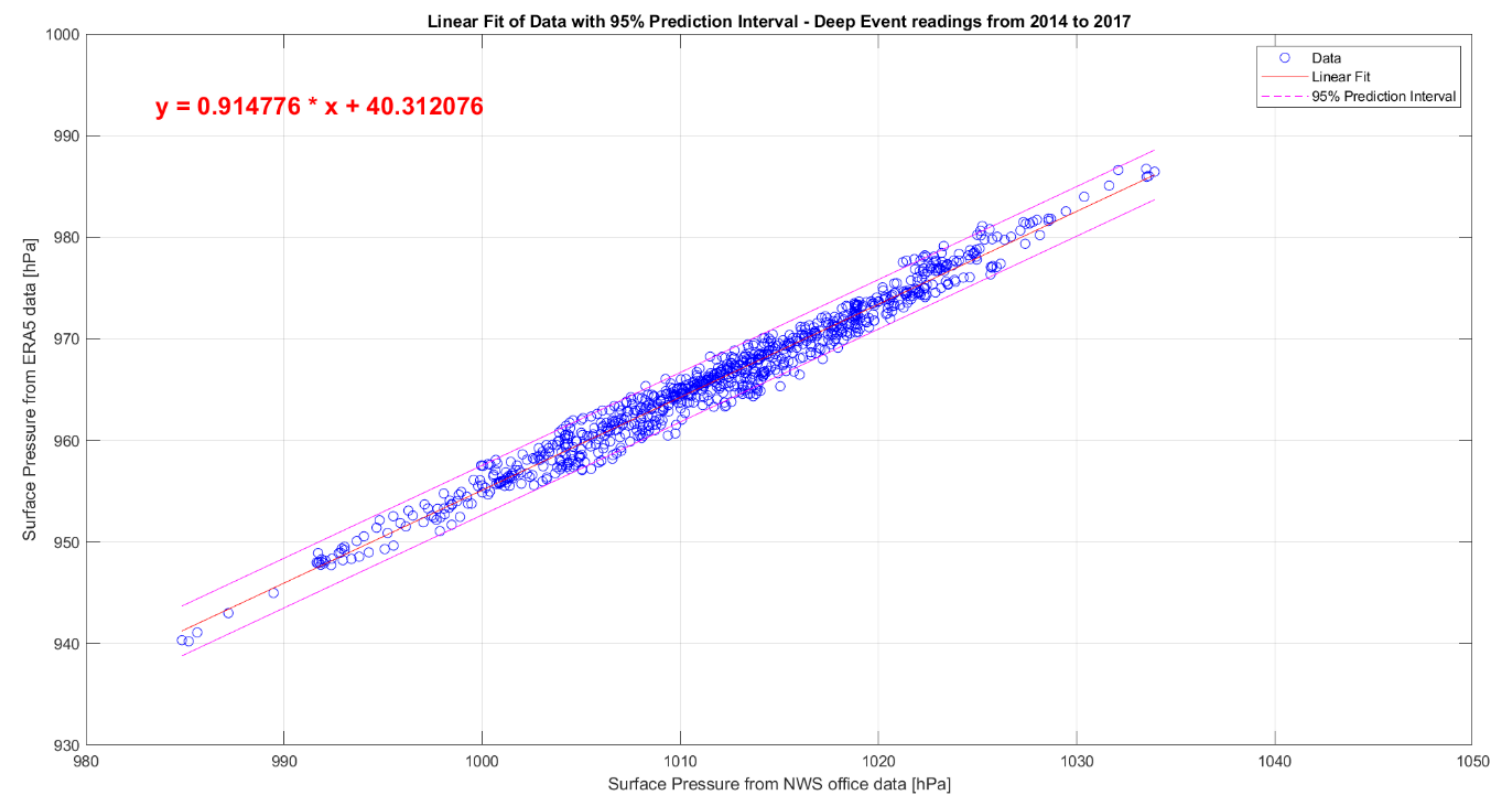

Figure 3.4.86 Scatter plot of both surface pressure datasets from NWS Office and ERA5 for deep event readings from 2014-2017, only values when there is a precipitation are taken into consideration. There is a high correlation along every value. 


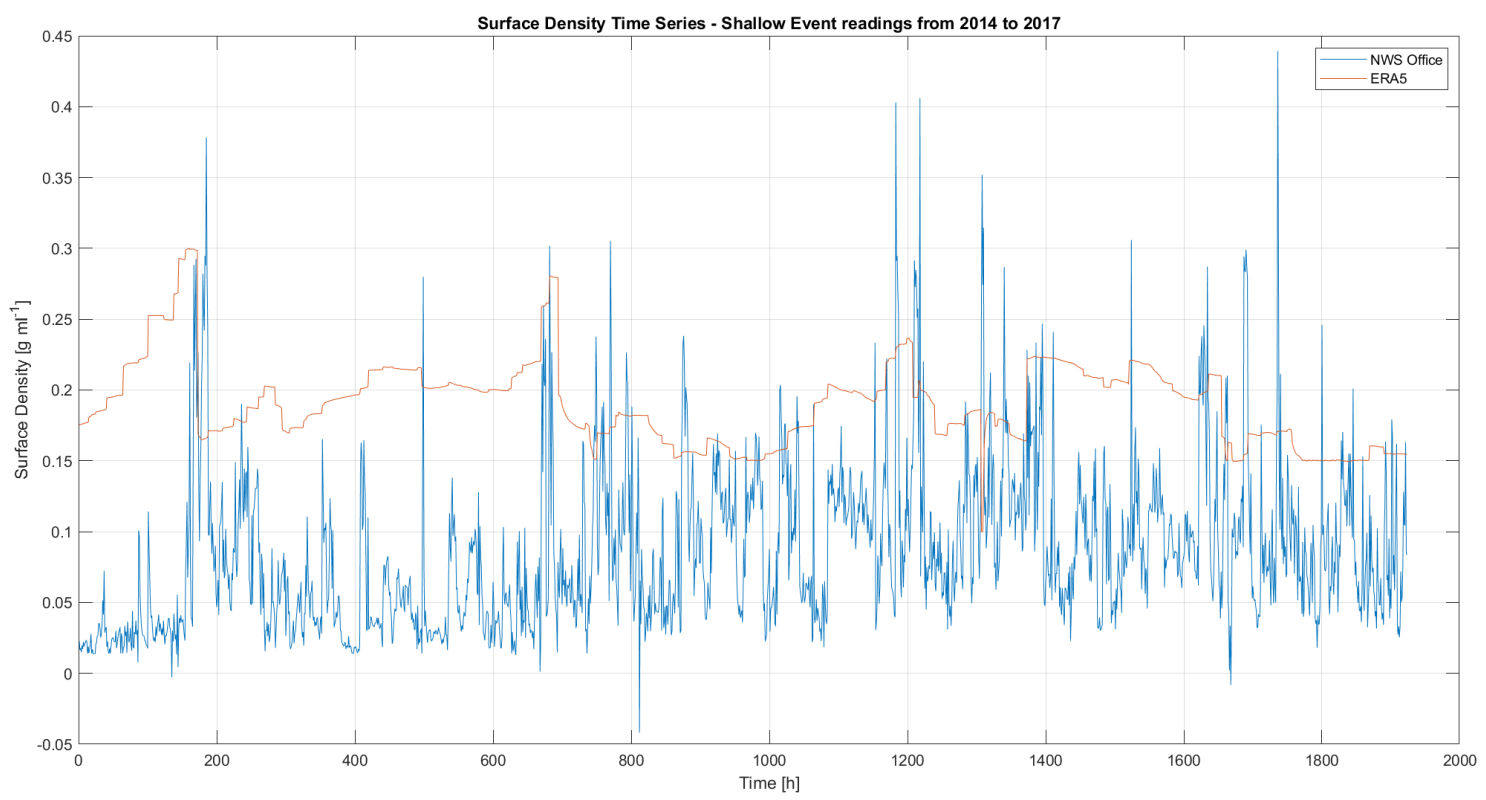

Figure 3.4.87 Snow Density time series for shallow event readings from 2014-2017, only values when there is a precipitation are taken into consideration. Comparison between NWS Office dataset (blue line) and ERA5 dataset (red). It is not possible to observe the same trend for the two categories.

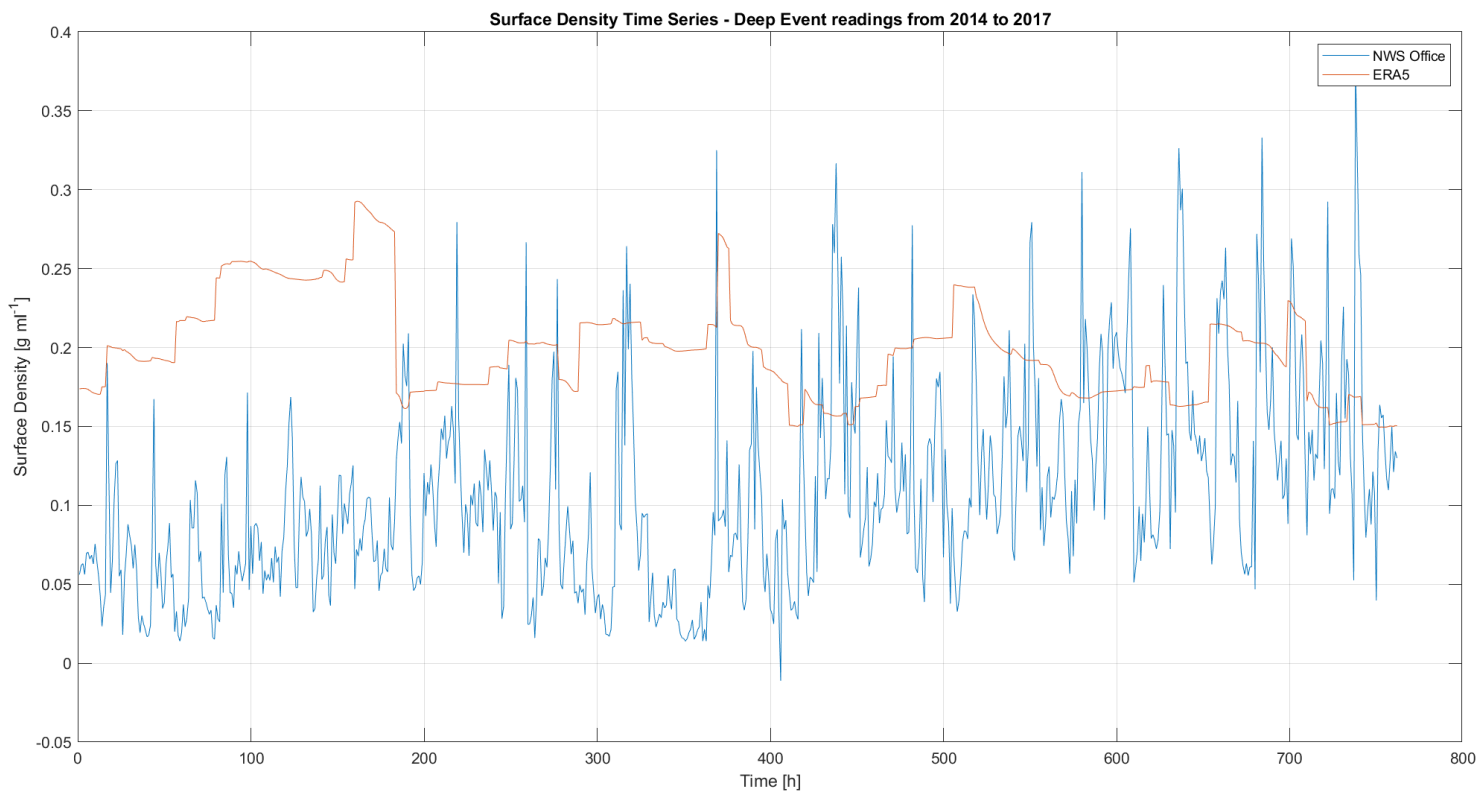

Figure 3.4.88 Snow Density time series for deep event readings from 2014-2017, only values when there is a precipitation are taken into consideration. Comparison between NWS Office dataset (blue line) and $E R A 5$ dataset (red). It is not possible to observe the same trend for the two categories. 


\subsubsection{Data Validation}

One of the main restrictions that the data obtained from the MRR is that the vertical profile reaches up to $3000 \mathrm{~m}$ of altitude and is not capable to read reflectivity and Doppler velocity beyond that level. On the other hand, ERA5 reanalysis data have a vertical coverage that covers the whole atmosphere, from $1000 \mathrm{hPa}$ to $1 \mathrm{hPa}$, and thus allow the identification of the cloud properties throughout the whole troposphere.

The variables used in this chapter are the fraction of cloud cover and the mean Surface Level Pressure (SLP). The first one is defined as the proportion of a grid box covered by cloud (liquid or ice); it varies between zero and one and is dimensionless. The second one is the pressure of the atmosphere at the surface of the Earth, adjusted to the height of mean sea level; contours of mean sea level pressure also indicate the strength of the wind and tightly packed contours show stronger winds.

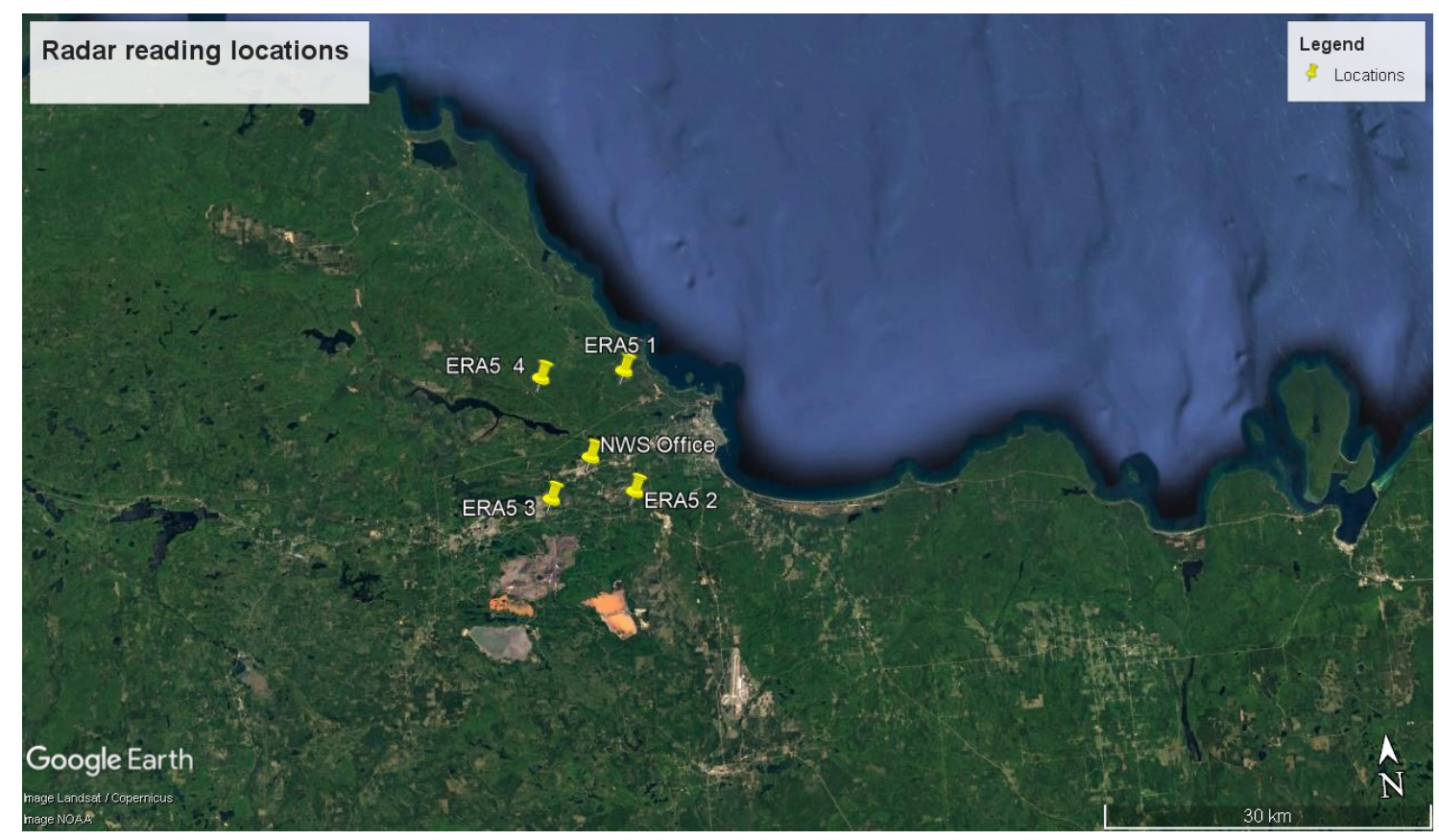

Figure 3.4.89 Radar reading locations. NWS Office (46.53, -87.55), ERA1(46.6, -87.5), ERA2(46.5, -87.5), ERA3(46.5, -87.6), ERA4(46.6, -87.6). Google earth image. 
To proceed with the validation of observations obtained from the MRR with the readings from ERA5, it has been necessary to extrapolate specific days with a long enough event that is $6 \mathrm{~h}$ or more, and then values of Cloud Top Height from both dataset are compared. As already mentioned, it has been preferred to use the readings from the location ERA5 3 (46.5, -87.6), rather than averaging the values from ERA5 1, ERA5 2, ERA5 3 and ERA5 4, because it was the closest point to NWS Office (46.53, -87.55). Moreover, ERA5 3 and ERA5 1 are $13.5 \mathrm{~km}$ apart from each other and their values do not have a significant difference, therefore the results from ERA5 3 can be assumed similar to those that NWS Office would have showed, considering that they are $5.2 \mathrm{~km}$ apart.

Days with a shallow event present a strong correlation between CTH values from MRR (Figure 3.4 .92) and ERA5 (Figure 3.4 .93), meaning that the trend is similar in both situations. The main characteristic highlighted with the ERA5 plot is that the clouds generally range from $952 \mathrm{hPa}$ to $800 \mathrm{hPa}$, suggesting a relatively thin cloud and below the level of $925 \mathrm{hPa}$ there are no cloud fraction values, confirming that the dataset is providing only cloud readings and the snow precipitation is not showed. On the other hand, this behavior was impossible to identify from the MRR observations with either reflectivity or Doppler velocity values, so a new information regarding the Lake Effect Snow event can be added, confirming that it can be recognized as "shallow" event and the main clouds are thin. Unfortunately, the vertical resolution of ERA5 is not high enough, therefore the distinctive pulsing behavior, that is recognizable with MRR observations, is not presented with this instrument. 
Days with a deep event confirm that almost all of them extend beyond the value of $3000 \mathrm{~m}$ of altitude, which was set up as a height limit with the MRR instrument. Kulie et al. (2016) already proposed a classification with CloudSat 2B-CLDCLASS that divides observed snowproducing clouds into two categories, associating a nimbostratus cloud to a synoptic or deep snow event and a stratocumulus cloud to a shallow/convective or Lake Effect snow event. They observed that the shallow snowfall cloud thickness distribution peaks between $\sim 1$ and $2 \mathrm{~km}$, meanwhile a nimbostratus cloud thickness distribution is centered near $4-5 \mathrm{~km}$. Almost the same values that have been observed in this study, considering the $3 \mathrm{~km}$ limit imposed by the MRR vertical resolution. It also needs to be taken into consideration that the average height of these events cloud change with the location, as noticed with the analyses performed from Kristovich et al. (2017). Considering what has been previously mentioned, it is possible to confirm the hypothesis that a deep snowfall event cloud extends over the $3 \mathrm{~km}$ thresholds and, generally, it ranges from $925 \mathrm{hPa}$ to $200 \mathrm{hPa}$ providing similar results with those suggested by Kulie. Most of the values observed are above the level of $925 \mathrm{hPa}$, suggesting the location of the cloud bottom at that value, as already noticed with a shallow snowfall event cloud. 

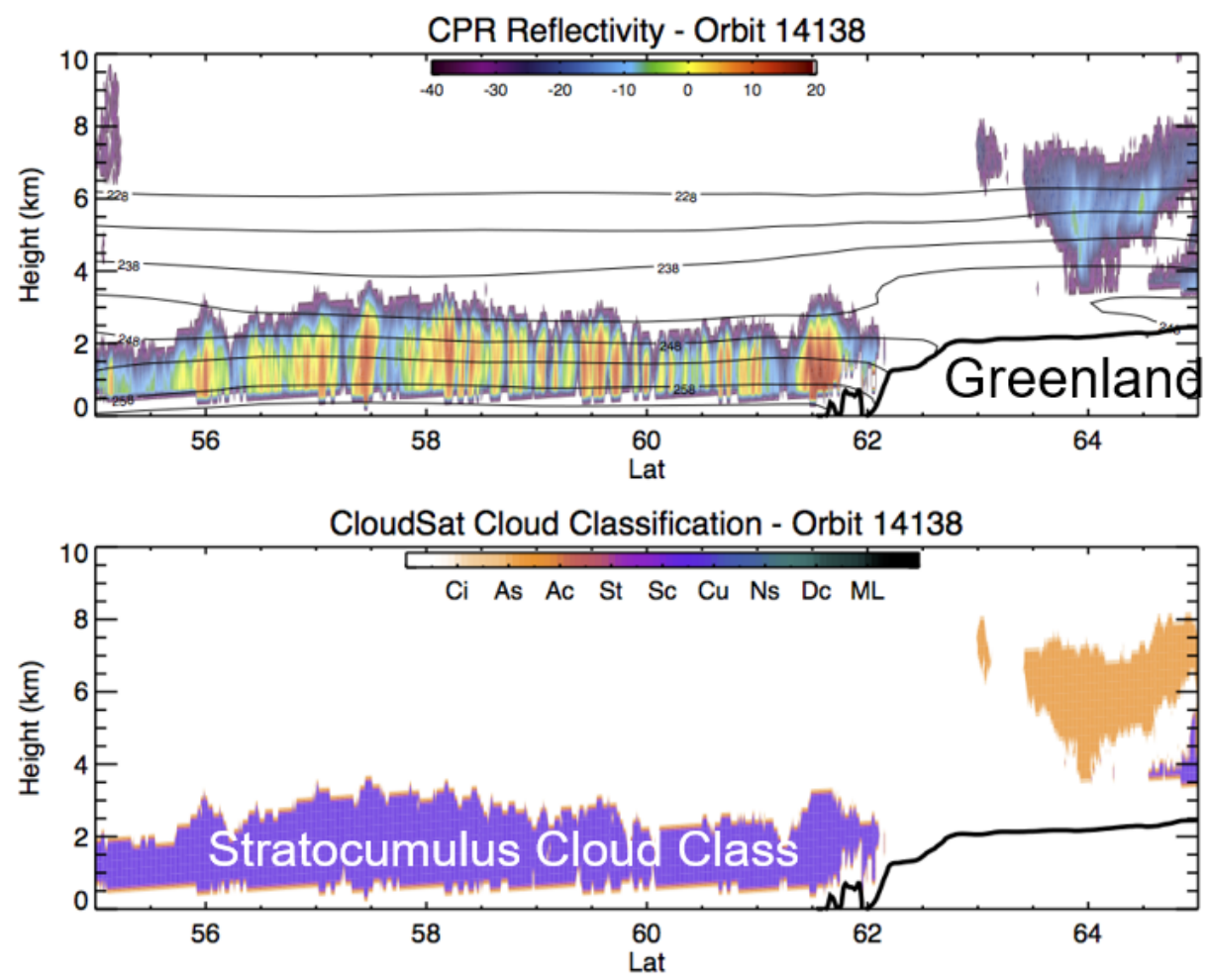

Figure 3.4.90 (top) CloudSat CPR reflectivity factor (dBZ) profiles from the 2B-GEOPROF product and (bottom) cloud classifications from the 2B-CLDCLASS product for a section of orbit 14138 on 24 Dec 2008. ECMWF temperature profiles (K) are also shown in the top (thin black lines). The thick black solid line is Greenland's land surface from the digital elevation database contained in the 2B-GEOPROF product. This case is predominantly classified as stratocumulus (Sc). Kulie et al., 2016. 

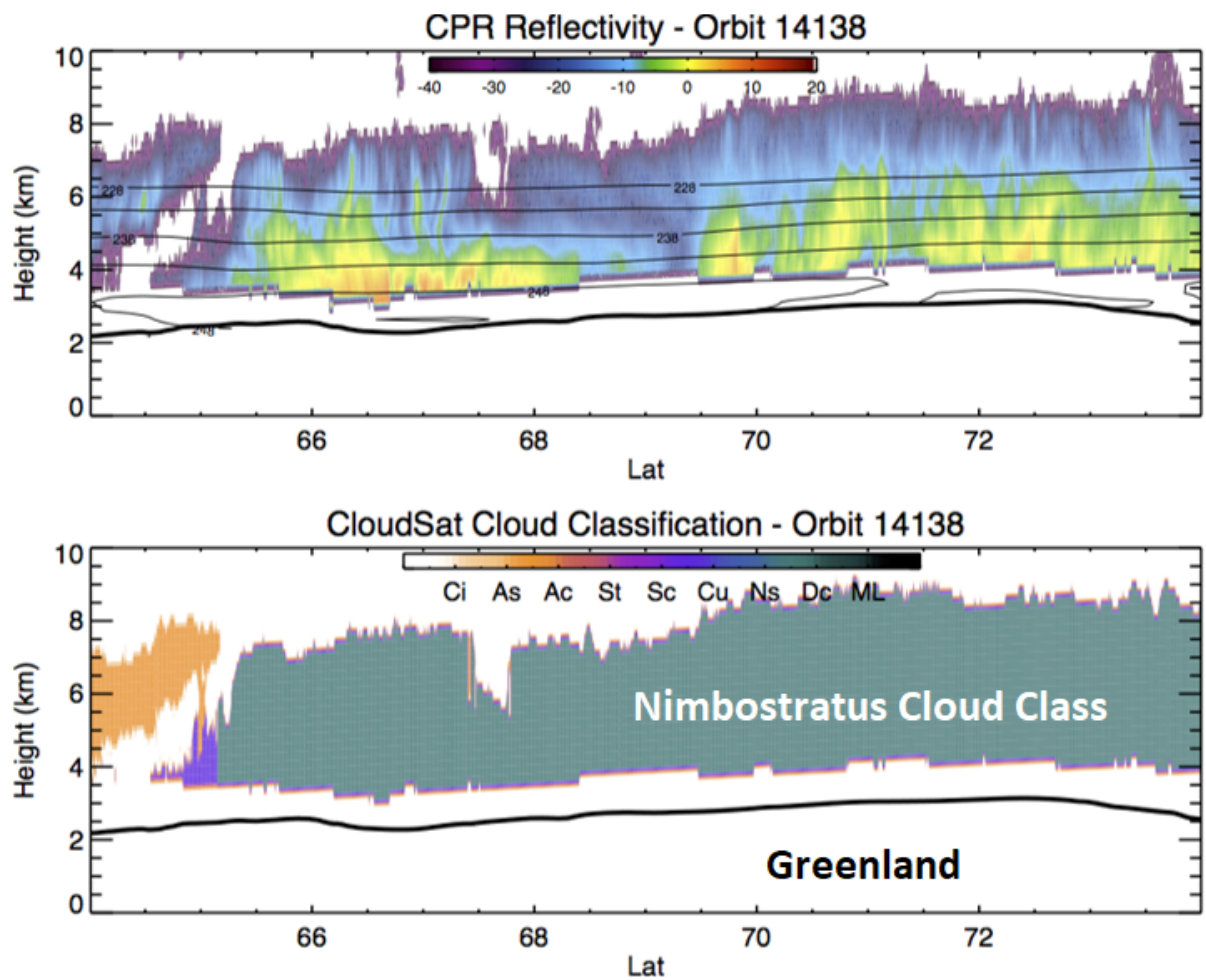

Figure 3.4.91 As in the previous figure, but for a synoptic snowfall event over Greenland. This is a continuation of the same orbit shown in the previously image as CloudSat traverses Greenland. This case is classified as nimbostratus (Ns). Kulie et al., 2016. 

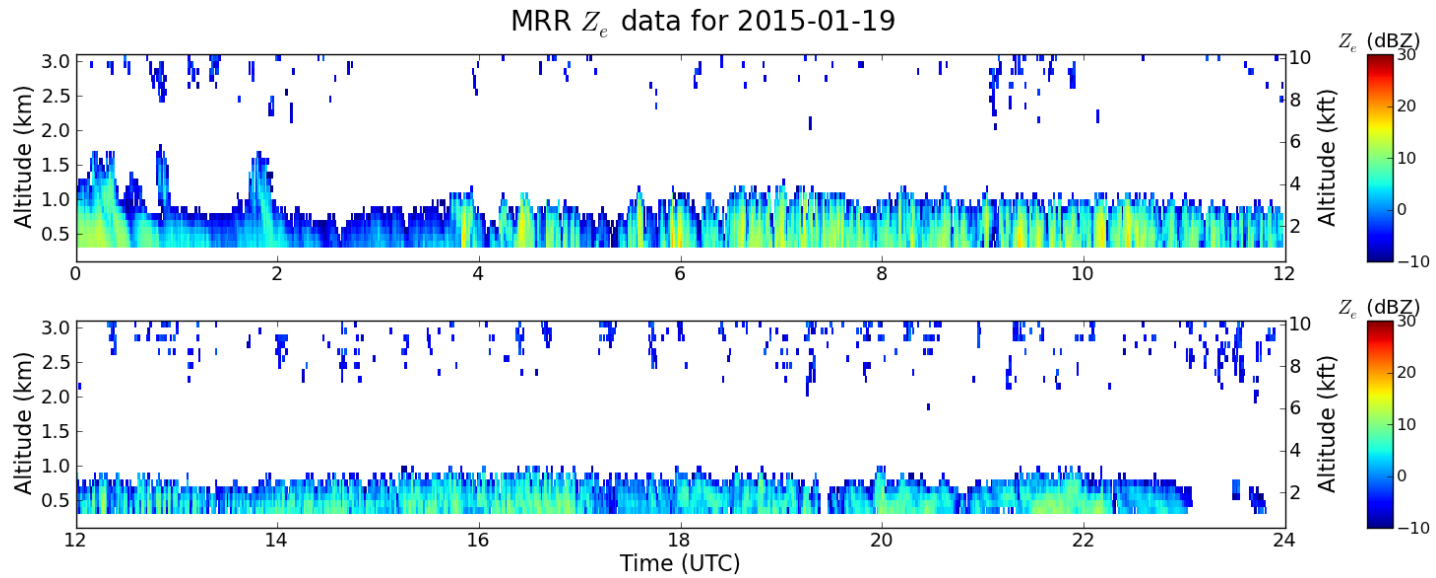

Figure 3.4.92 Shallow event, 19 Jan '15. DBZ values from MRR observations.

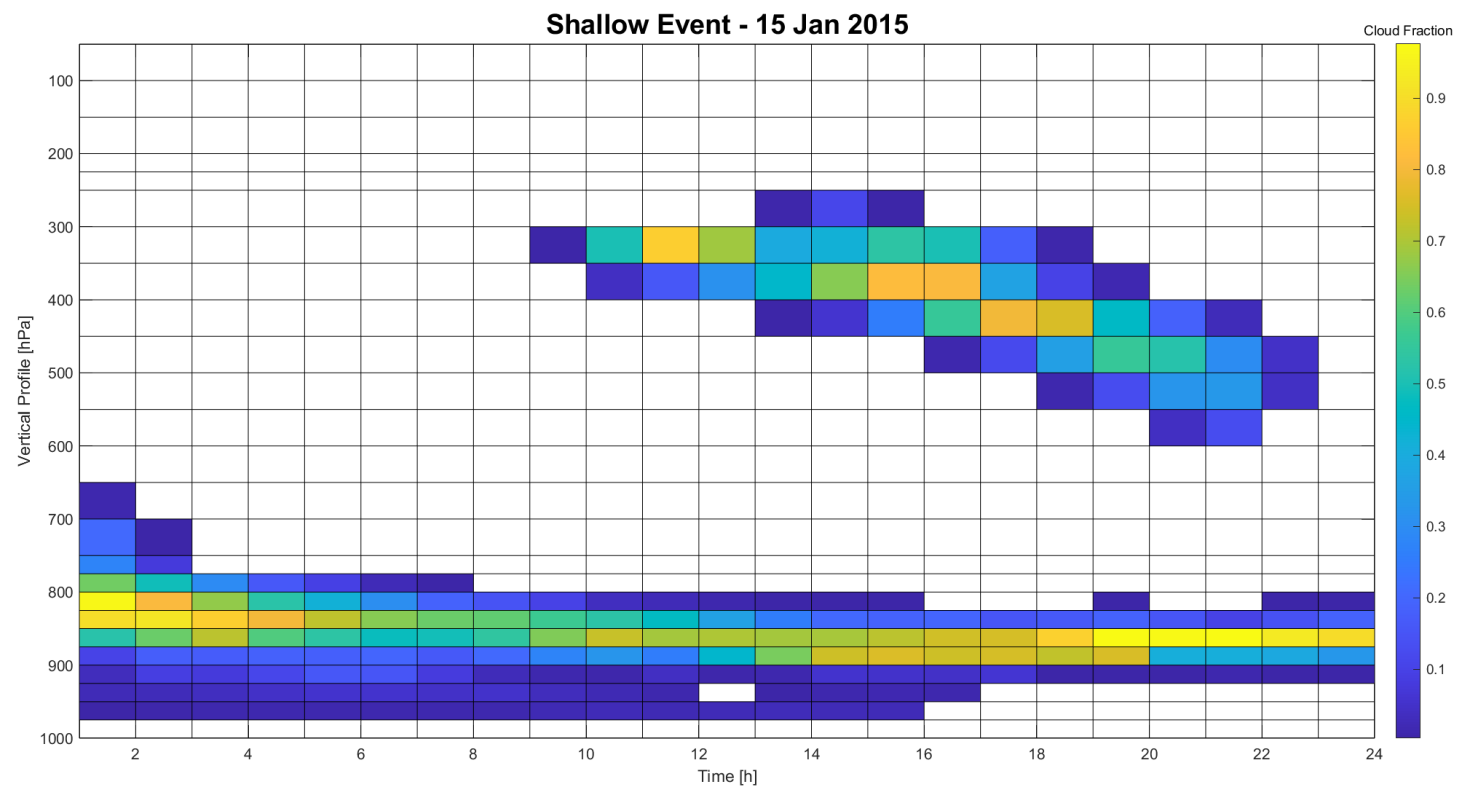

Figure 3.4.93 Shallow Event, 19 Jan '15. Cloud Fraction values from ERA5 observations. 

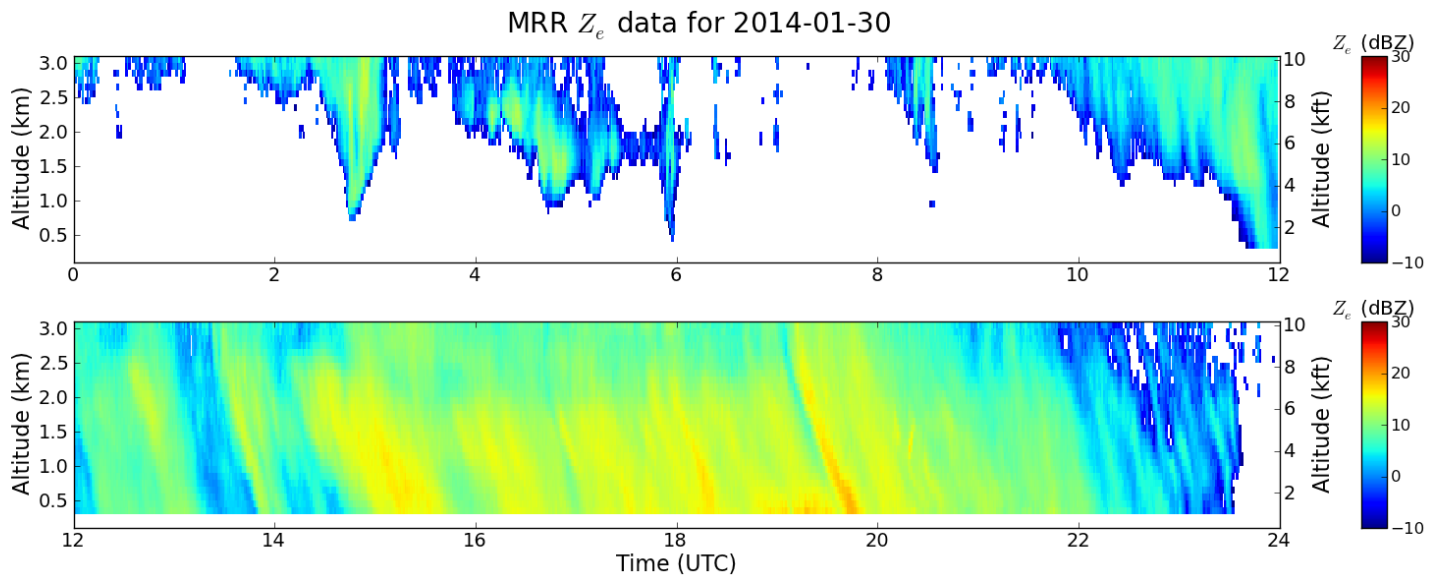

Figure 3.4.94 Deep event, 30 Jan '15. DBZ values from MRR observations.

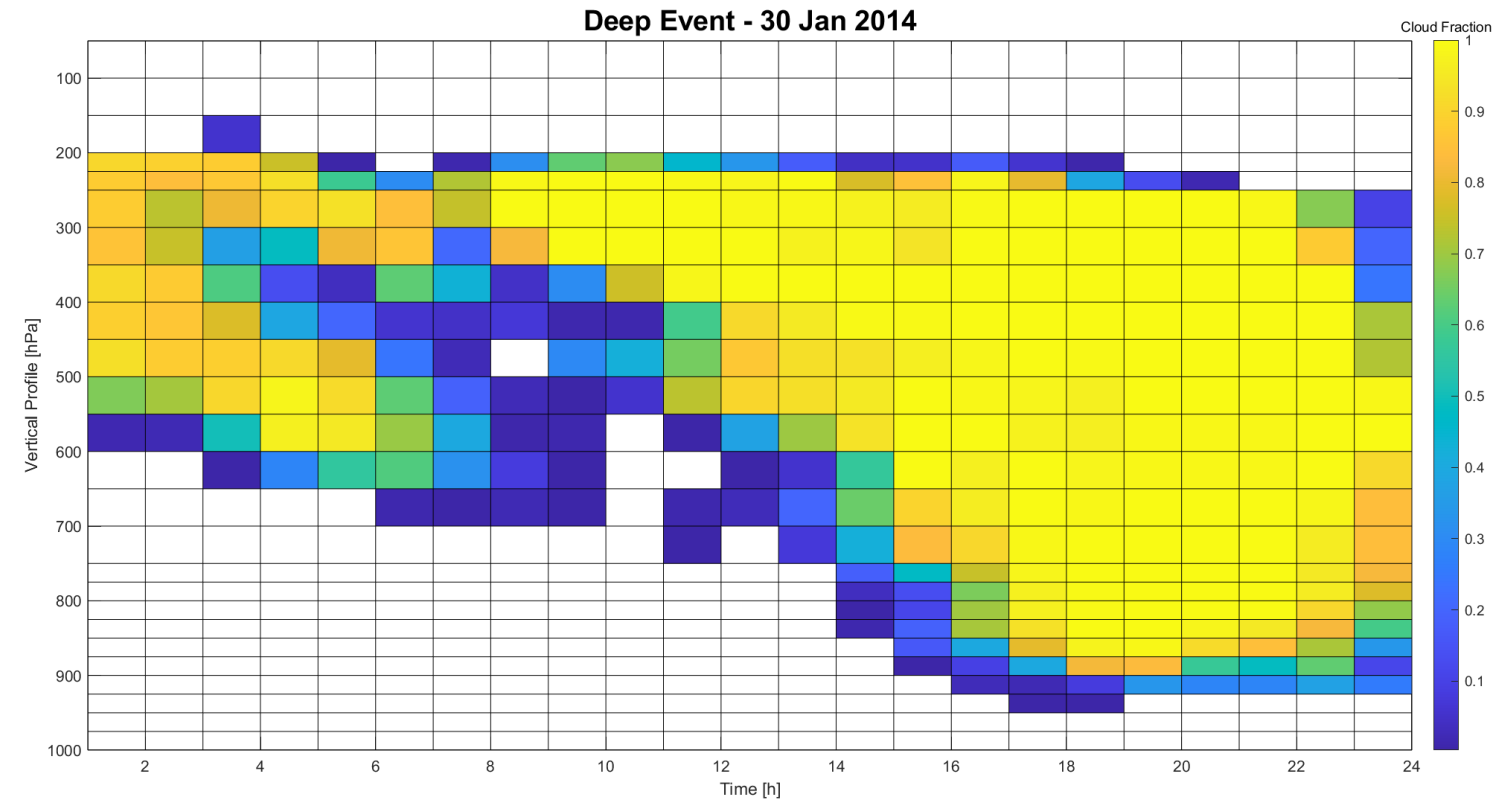

Figure 3.4.95 Deep event, 30 Jan '15. Cloud Fraction values from ERA5 observations. 
The second dataset used for the data validation is the Sea Level Pressure and it shows the pressure paths in a specific location. In order to have a wider point of view, the grid of the analysis has been extended to the whole area of Lake Superior and it has been investigated a reading every $2 \mathrm{~h}$. The first behavior that is possible to notice within both shallow and deep events is that, on average, there is a drastic pressure drop that overlaps with the presence of the water body (Figure 3.4 .96 ).

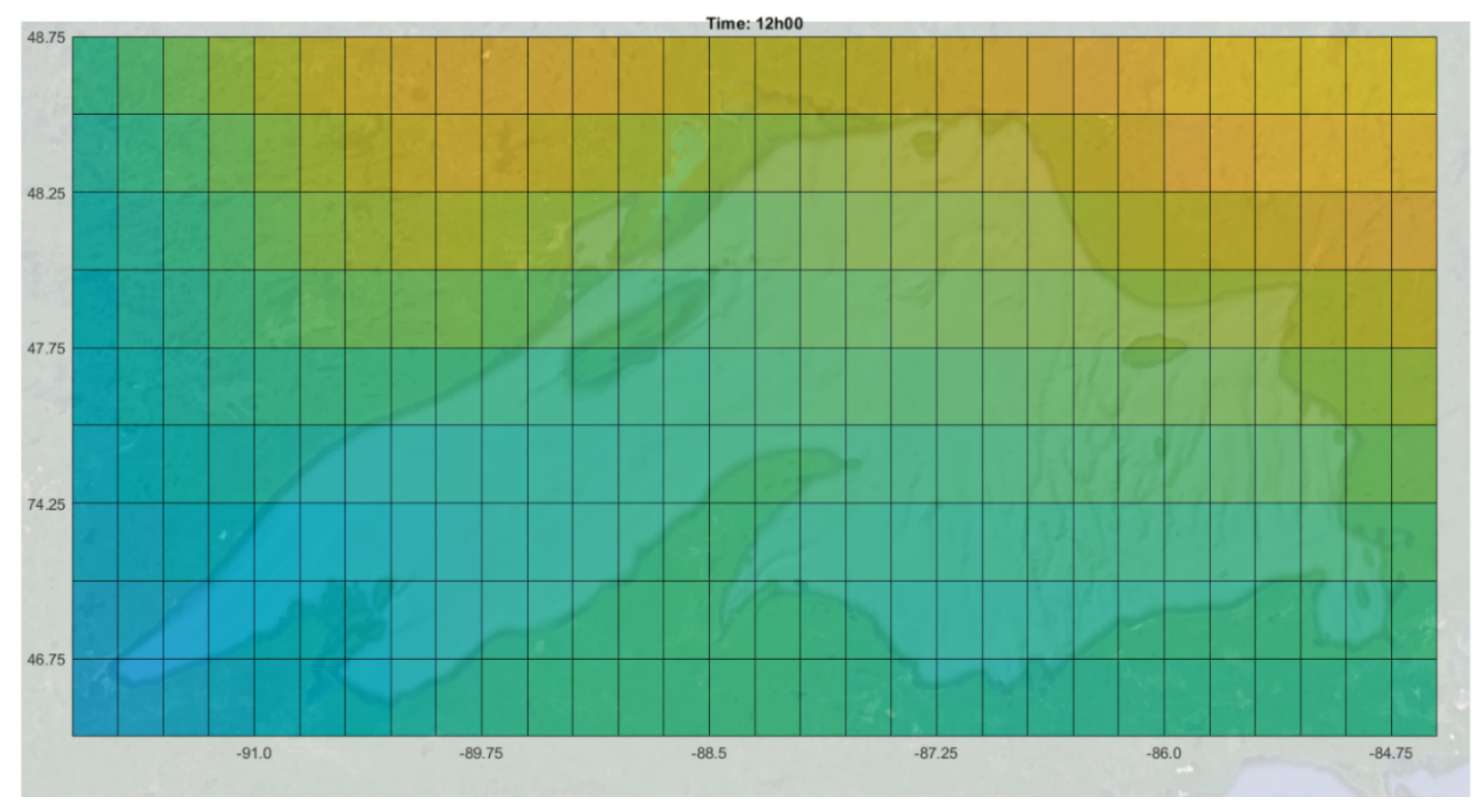

Figure 3.4.96 19 Jan '15, 12b00. Overlap of pressure values with the satellite image. 
Generally, during a shallow event, pressure values have a migration path that goes from NNW to S-SE, as it has been already discussed with the analysis of the wind direction, and are lower on the lake surface while the precipitation is happening. Then they tend to increase their value or reduce the gradient between the land surface and water surface when the precipitation is not occurring or, hypothetically, there is no more moisture transportation over the lake. On average, pressure values are higher during shallow events than deep events, confirming the observation discussed previously using the ancillary data. On average, it is noted that a high-pressure mass moves toward the area when the precipitation is occurring. A deep event will present a migration path from $\mathrm{W}$ to $\mathrm{E}$ or accordingly to the wind direction distribution already analyzed in the previous chapters. The pressure values tend to be uniform compared with those observed with a shallow event, the gradient between land and water surface is less prominent and, on average, the variance of the pressure distribution is smaller. The values observed in both cases confirm the result obtained from previous analyses that a shallow event has a higher surface pressure than a deep one. On average, these characteristics describe a shallow or deep event, but they do not have a persistent occurrence to distinguish one type from the other one by only inspecting the surface pressure.

In order to better understand the mechanisms that correlate pressure trends and type of snowfall, it has been decided to investigate the Sea Level Distribution on a larger scale that goes from $41^{\circ}$ to $51^{\circ} \mathrm{N}$ and from $-77.5^{\circ}$ to $-97.5 \mathrm{~W}$, covering the area of the western Great Lakes. For this analysis only events longer than 6 hours have been taken into consideration and have been merged with the SLP dataset, creating a map that averages all the values during the occurrence of a specific type of snowfall. It is evident how a deep and a shallow snow event have different pressure ranges, having a synoptic snowfall linked with a lowpressure extratropical cyclone structure, meanwhile a Lake Effect Snow event is characterized by a high-pressure structure. This observation is confirmed by the results suggested on chapter 3.3.2 and from other authors that already suggested this type of distinction. Usually, it has been noted that the snowfall is more intense in the outer rim of the structure and it reduces its intensity when the high/low pressure center approaches the area of study. 

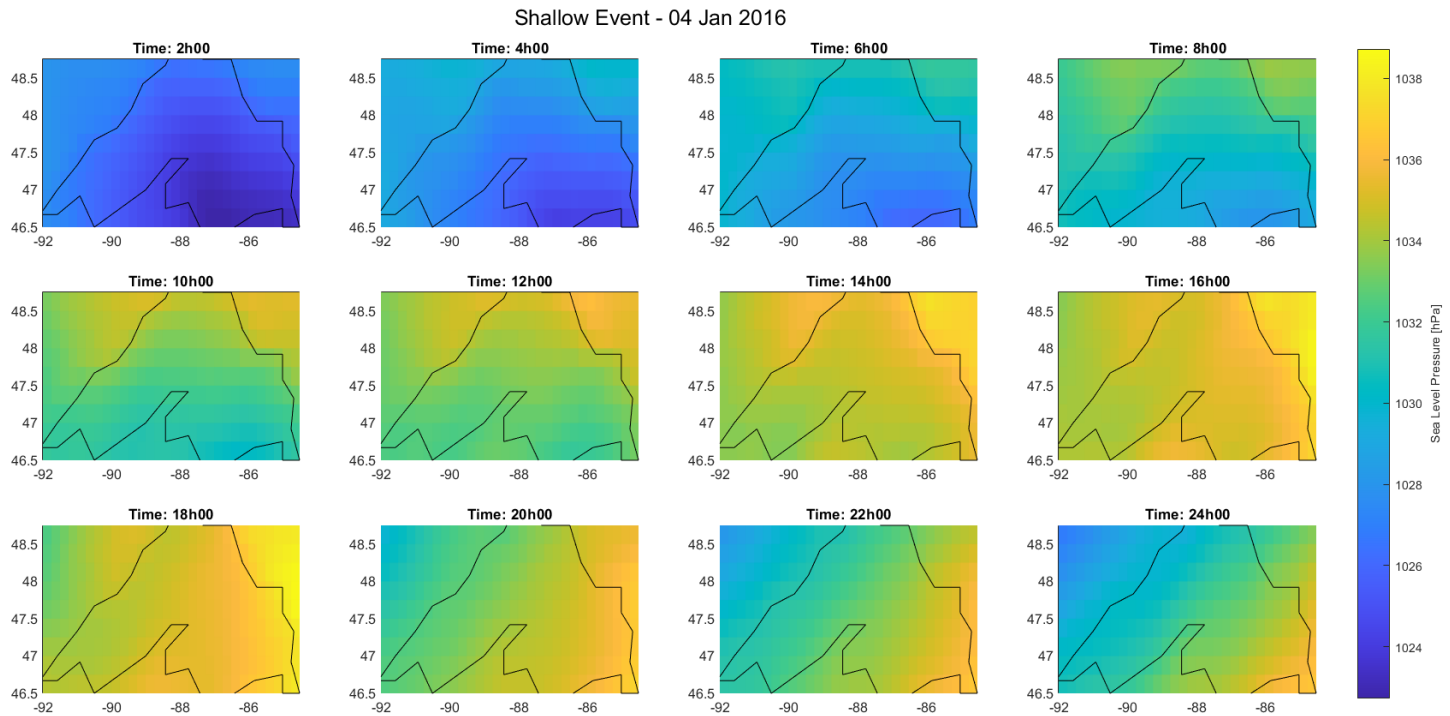

Time: 22 h00
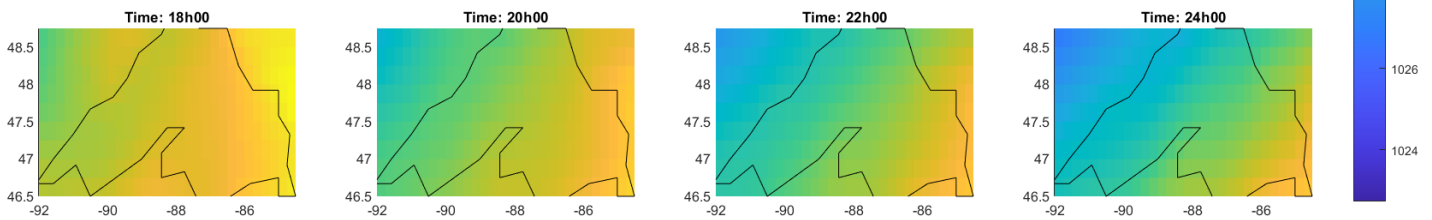

Figure 3.4.97 Shallow Event. 4 Jan '16. The panel shows a reading every $2 \mathrm{~h}$ and longitude/ latitude are measured in Decimal Degrees (DD). It can be assumed a general direction from N-NW to $S$-SE and it is possible to notice a strong gradient between land and lake surface pressure during the snow event, which goes from $00 h 00$ to $12 b 00$ and then it fades out in the next hours, considering that the precipitation reduces its intensity.

MRR $Z_{e}$ data for 2016-01-04
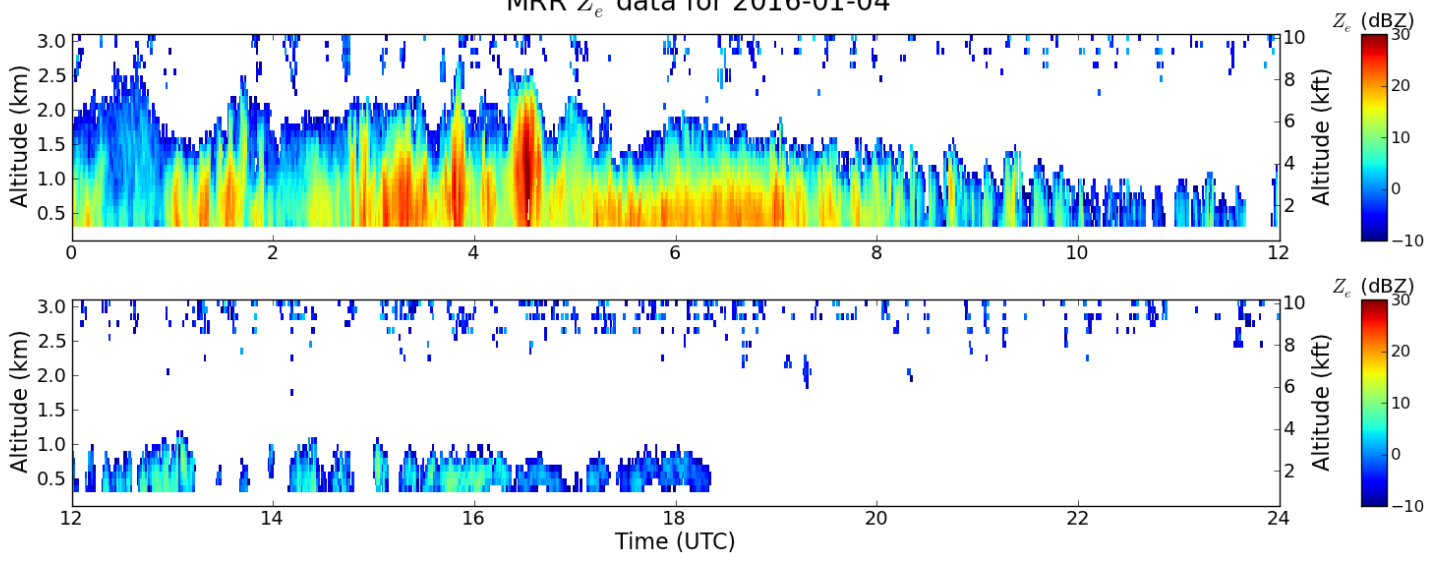

Figure 3.4.98 Shallow Event. 14 Jan '16. Reflectivity vertical profile from MRR. 

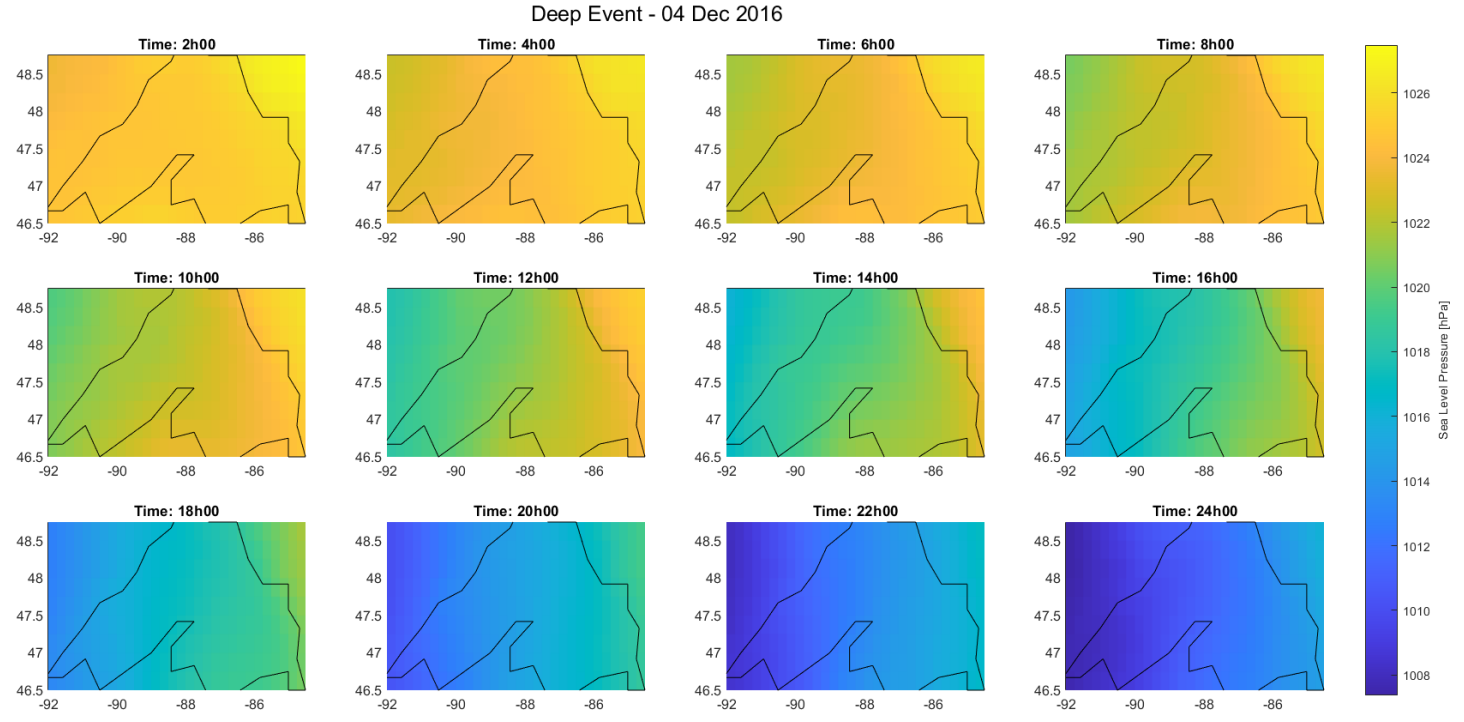

Figure 3.4.99 Deep Event. 4 Dec '16. The panel shows a reading every $2 \mathrm{~h}$ and longitude/ latitude are measured in Decimal Degrees (DD). A gradient between land and lake surface is almost absent and a lowpressure mass moves towards the area when the precipitation is occurring.

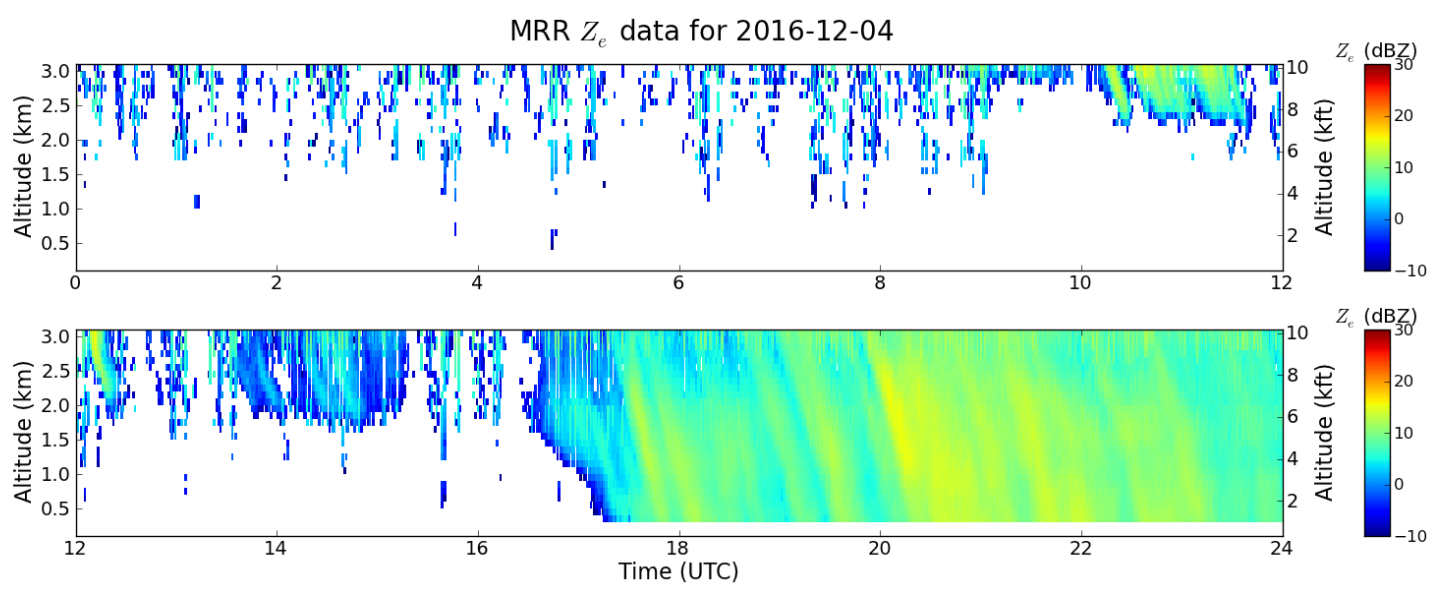

Figure 3.4.100 Deep Event. 4 Dec'16. Reflectivity vertical profile from MRR. 


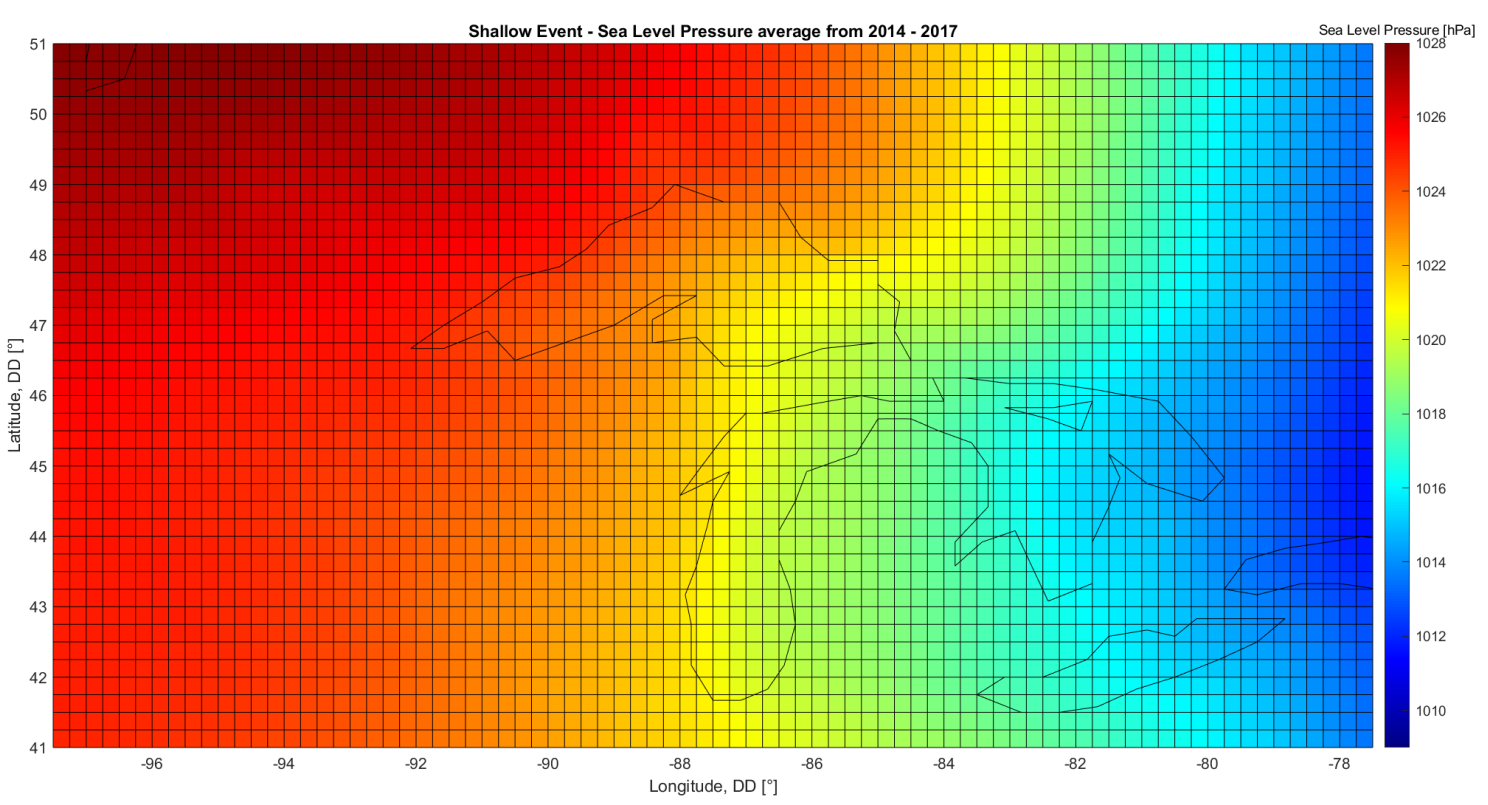

Figure 3.4.101 Shallow event. Sea Level Pressure values averaged during snowfall events from 20142017. The red zone (bigh pressure) is mainly located in the NW section of the area.

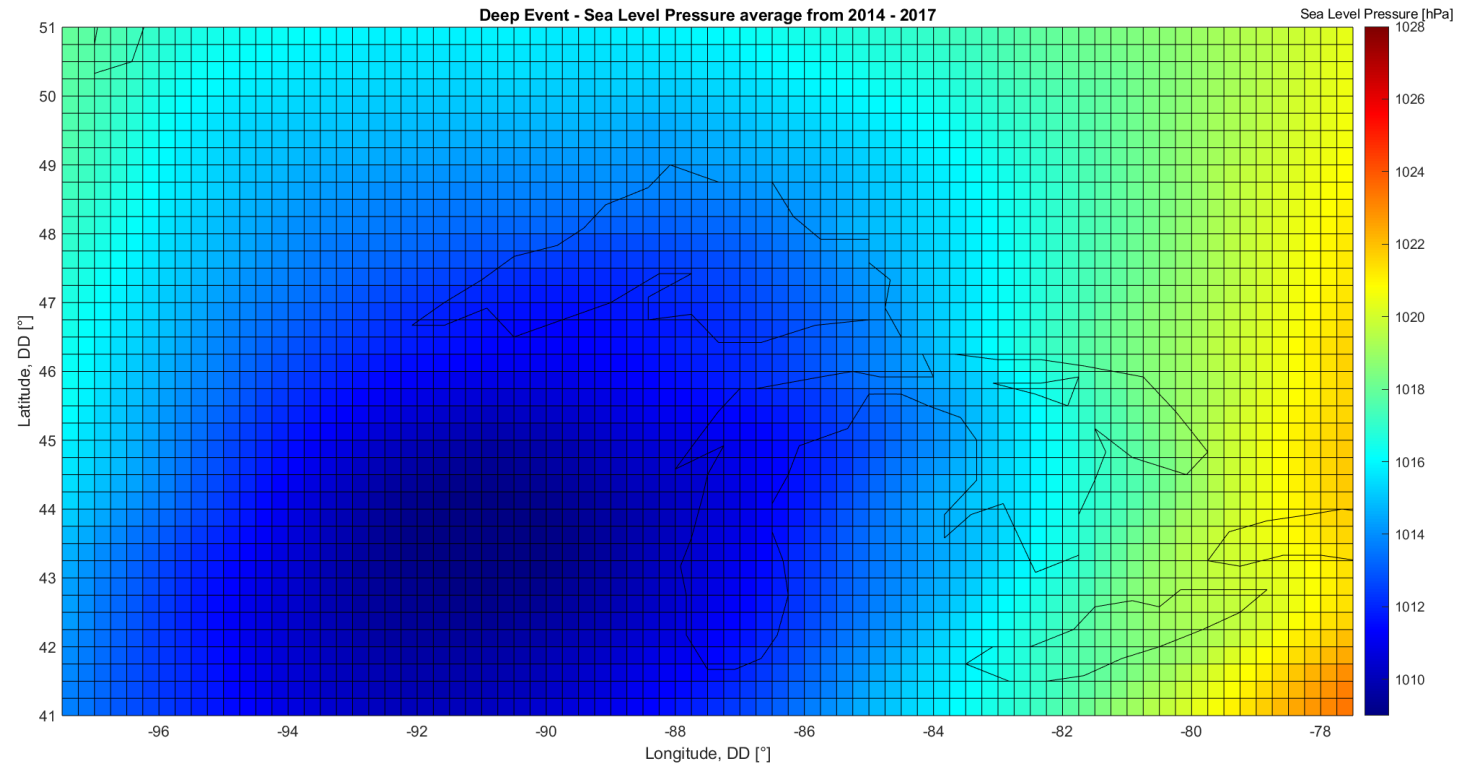

Figure 3.4.102 Deep event. Sea Level Pressure values averaged during snowfall events from 2014-2017. The blue zone (low pressure) is mainly located in the SW section of the area. 


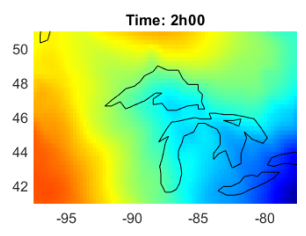

Time: $10 \mathrm{~h} 00$

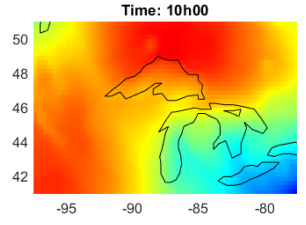

Time: 18 h00

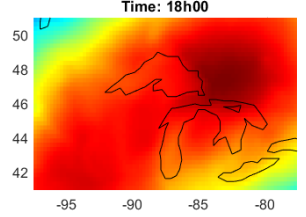

Shallow Event - 04 Jan 2016

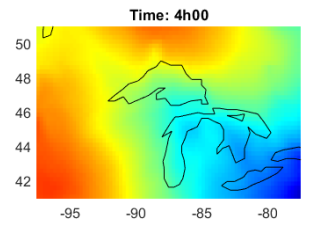

Time: $12 \mathrm{~h} 00$

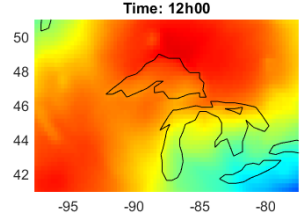

Time: 20 h00

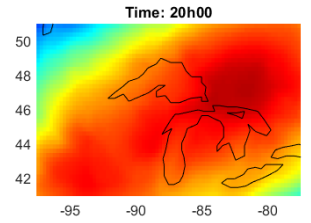

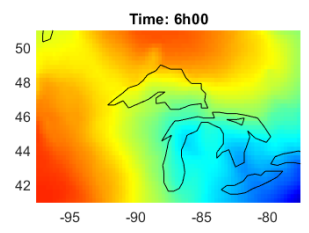

Time: 14 h00

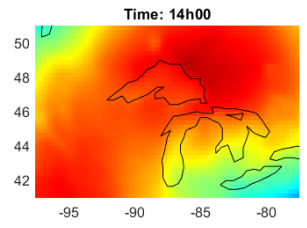

Time: $22 \mathrm{~h} 00$

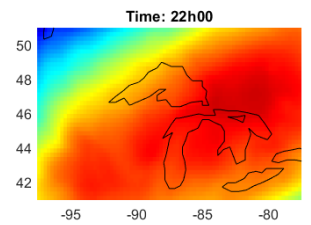

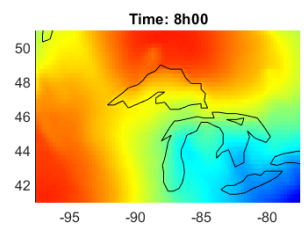

Time: 16 h00

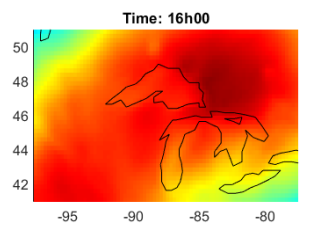

Time: 24h00

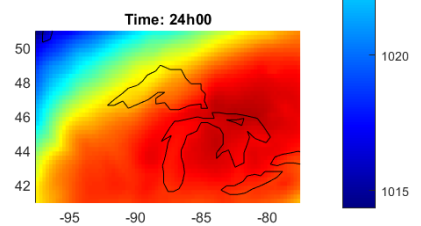

Figure 3.4.103 Shallow Event - 04 Jan '16. The snowfall event occurs from 00 b00 to 18h00, with more intense reflectivity values until $10 \mathrm{~b} 00$ and less intense values from $10 \mathrm{~b} 00$ to $18 \mathrm{~h} 00$. This seem to be related with the high-pressure zone moving closer to the area, which could reduce the intensity of reflectivity.

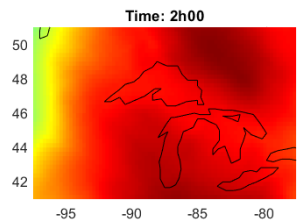

Time: 10 h00

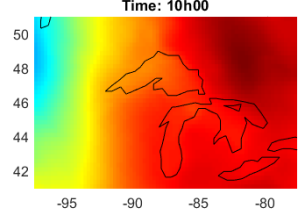

Time: $18 \mathrm{~h} 00$

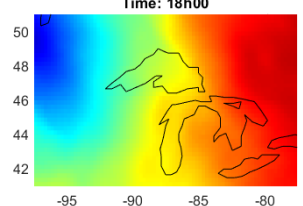

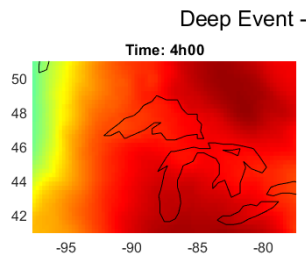

Time: 12 h00

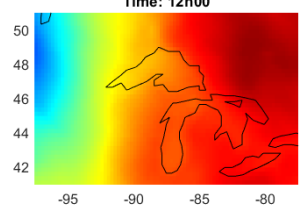

Time: $\mathbf{2 0 h 0 0}$

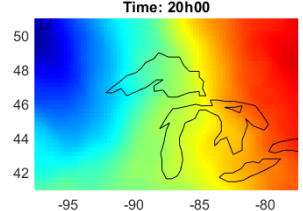

Time: 6 h00

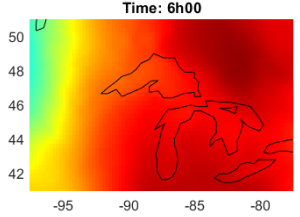

Time: $14 \mathrm{~h} 00$

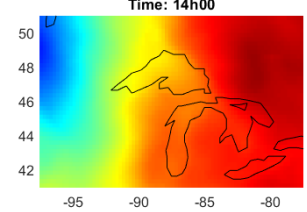

Time: 22 h00

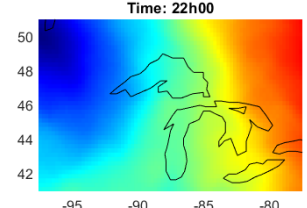

Time: 8 h00

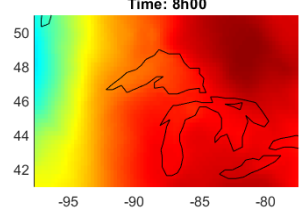

Time: $16 \mathrm{~h} 00$

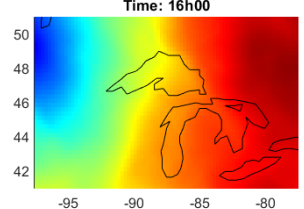

Time: $24 \mathrm{~h} 00$

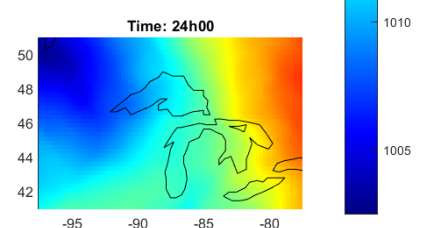

Figure 3.4.104 Deep Event - 04 Dec '16. The event occurs from 18 h00 to 24h00, which is linked with the low-pressure zone moving toward the area of study. Before that time, with a higher pressure situation, there is no snowfall. 


\section{Event Classification}

Once all the analyses have been calculated for each variable from MRR, PIP and ancillary data, it has been necessary to set up thresholds in order to write an automated code able to distinguish the two types of snow event. Each variable distribution, despite having a specific mean, has a range that overlaps between a shallow and a deep event; therefore, it has been not possible to create distinct categories and it has been decided to proceed with the classification with a score system.

Before starting with the actual snow classification, this code will consider the particle effective density obtained from the PIP and divides the precipitation into three categories: snow (edens below $0.3 \mathrm{~g} \mathrm{ml}^{-1}$ ), snow-rain mix (edens between $0.3 \mathrm{~g} \mathrm{ml}^{-1}$ and $0.8 \mathrm{~g} \mathrm{ml}^{-1}$ ) and rain (edens over $0.8 \mathrm{~g} \mathrm{ml}^{-1}$ ). This decision has been made based on the density distribution collected with previous analyses, where most of the snow observations fell within the range 0 and $0.3 \mathrm{~g} \mathrm{ml}^{-1}$ and rain observations were from 0.8 to $1.0 \mathrm{~g} \mathrm{ml}^{-1}$, considering that rain drops should have an effective density close to water density.

For every minute, each variable (Table 3.4.2 .6) is analyzed and it can have a score that goes from \pm 0.5 to \pm 3 points, based on how well it performs with the classification. The individual scores can be either positive (deep event) or negative (shallow event), therefore if

a specific parameter is related with a synoptic event, it will have a score from +0.5 to +3 , meanwhile it will be from -3 to -0.5 if it is linked with a Lake Effect Snow event. In order to assign these scores, variables are compared with predetermined ranges, that are obtained from the monthly statistics, after applying a block bootstrap method, using 1000 resamples, and a $95 \%$ percentile method; then values have been refined with a trial and error method. In case that the two ranges overlap and the value falls in both of them, the variable will obtain a null score due to the too high uncertainty and will not contribute to the final score. Once all the individual scores have been calculated for every variable at a specific time, they will be summed up all together and the results will be used to produce the snow differentiation: if the value is greater than zero, it will classify the precipitation as deep event, otherwise if it is lower than zero, it will classify the precipitation as shallow event. 


\begin{tabular}{lcc}
\hline \multicolumn{1}{c}{ Variables } & Shallow Event Score & Deep Event Score \\
\hline Reflectivity Factor[dBZ] & -1.0 & +1.0 \\
Doppler Velocity $\left[\mathrm{m} \mathrm{s}^{-1}\right]$ & -1.0 & +1.0 \\
Effective Density $\left[\mathrm{g} \mathrm{m}^{-1}\right]$ & -1.0 & +1.0 \\
Surface Temperature $\left[{ }^{\circ} \mathrm{C}\right]$ & -1.0 & +1.0 \\
Surface Pressure $[\mathrm{hPa}]$ & -1.0 & +1.0 \\
Relative Humidity [\%] & -0.5 & +0.5 \\
Wind Direction [ $\left.{ }^{\circ}\right]$ & -2.0 & +2.0 \\
Cloud Top Height $[\mathrm{m}]$ & -3.0 & +3.0 \\
\hline \hline
\end{tabular}

Table 3.4.2.6 V ariables used in the classification code and their score points.

The following code is an extract relative to the $\mathrm{CTH}$ variable of the score system in the evaluation code. In this case the score points assigned to each reading could be either +3 or -3 , meaning that this is one of the most important variables to evaluate the differences between shallow and deep events.

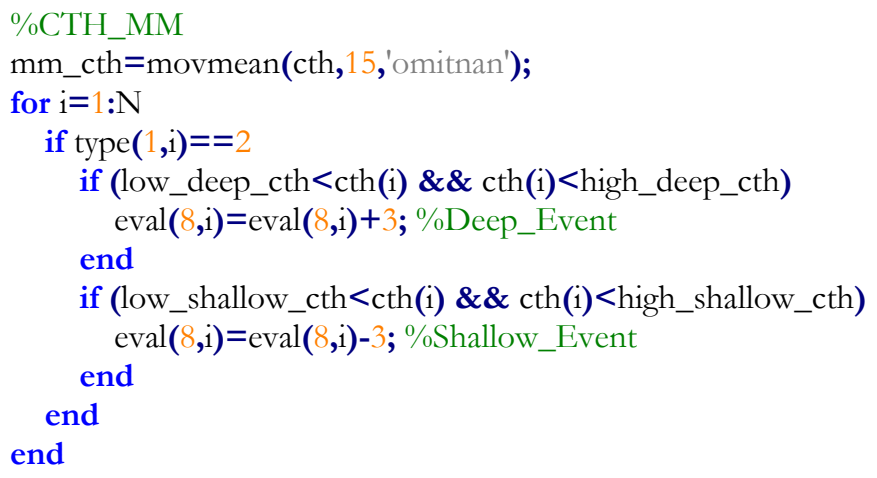

In case of a specific type of event (either shallow or deep), the code has an accuracy of $\sim 99 \%$, which drops to $96 \%$ if it is an enhanced shallow event and to $\sim 92 \%$ if it is a shallow event embedded in a deep event. 
In the following images, it is possible to see the result of the code that is able to distinguish a deep event snowfall from a small event with mixed snow and rain happening from $18 \mathrm{~h} 30$ to $19 \mathrm{~h}$

30.

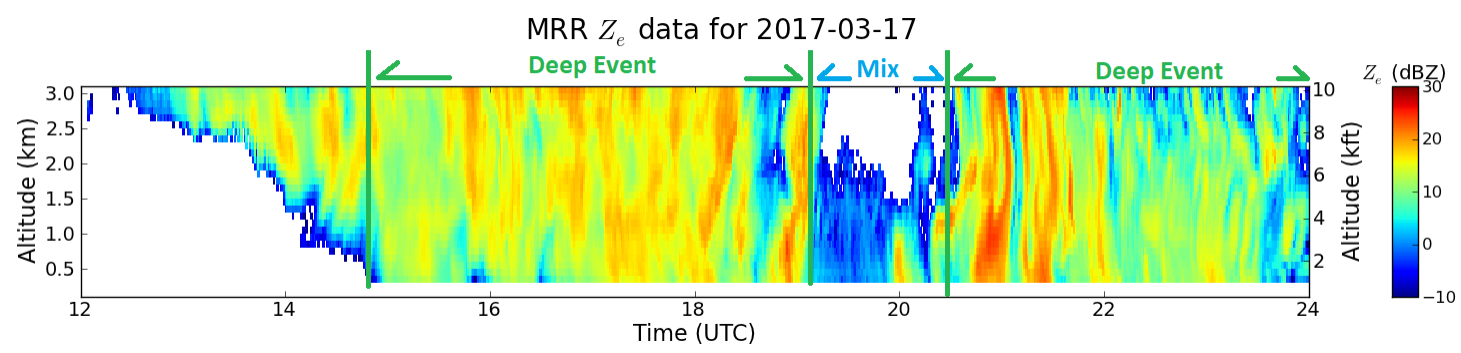

Figure 3.4.105 MRR reflectivity vertical profile. 17 March '17.

PIP(006) at MQT. 2017-03-17T23:50Z. (76). eDensity. (gm ml ${ }^{-1}$ )

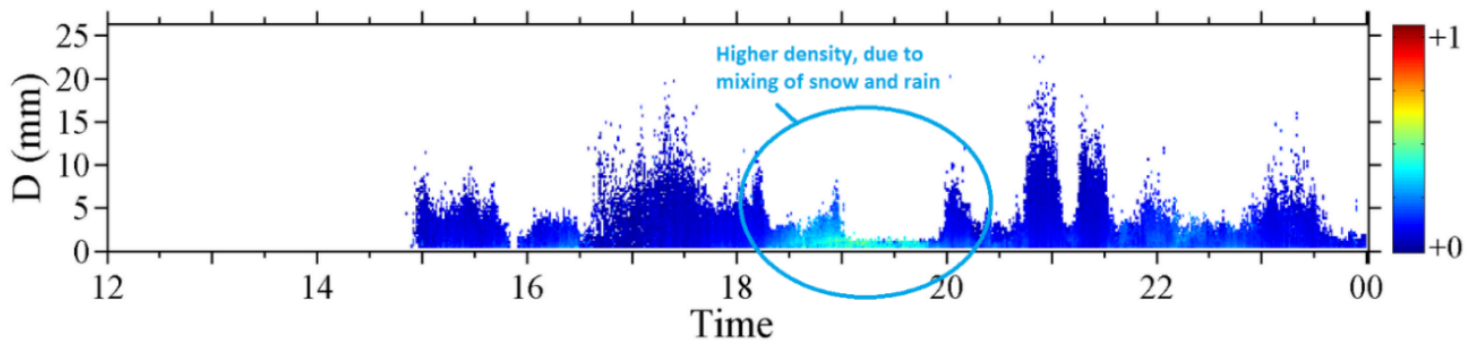

Figure 3.4.106 Effective Density profile. 17 March '17.

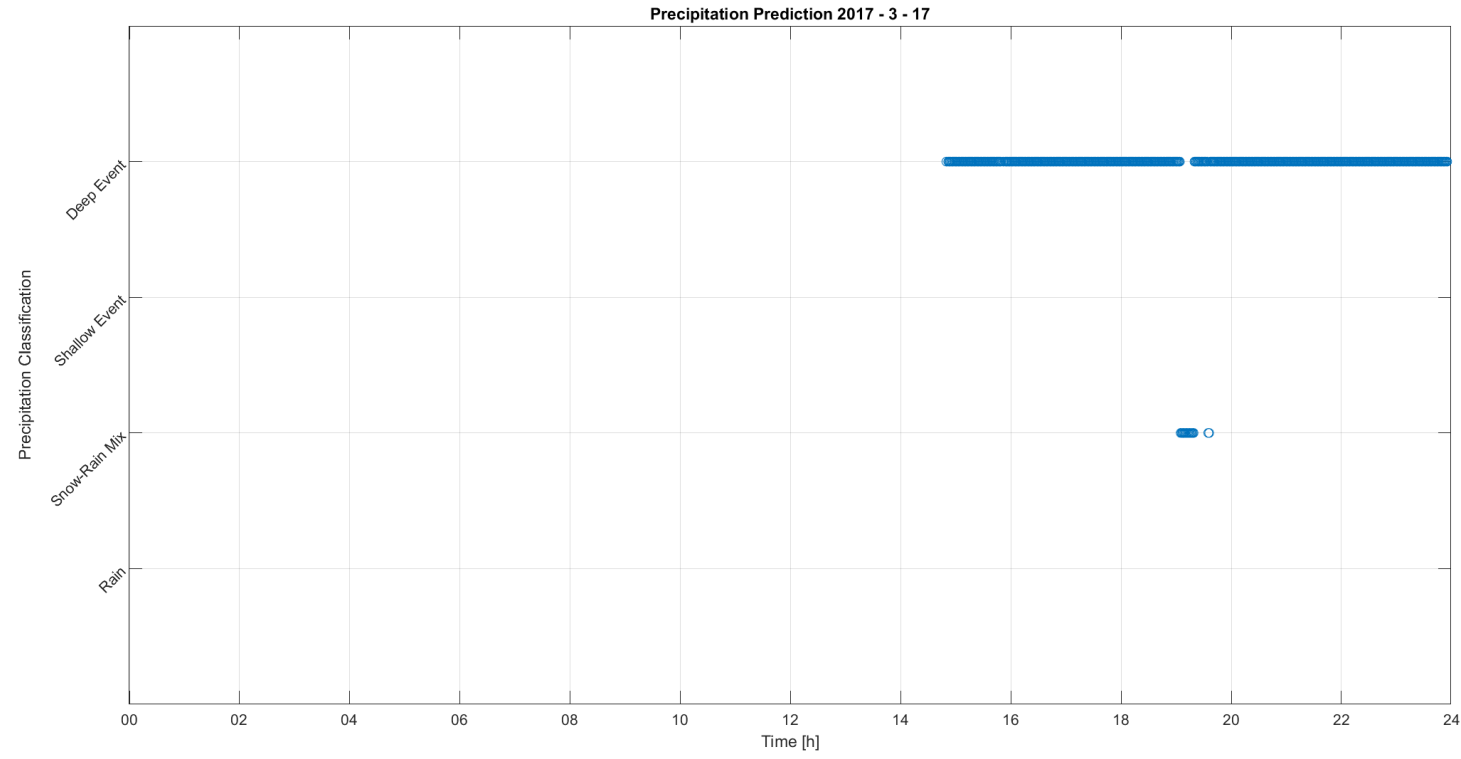

Figure 3.4.107 Code output. Classification of two main categories: deep snow event and a mixed snow-rain event. 


\subsection{Deep Event}

The near surface MRR reflectivity values are higher for the deep snow events than the shallow ones, indicating a more intense snowfall along the vertical profile and a higher particle density, therefore more mass in the particles. Usually these characteristics could lead on average to a higher snow-rate, as it has been described in previous studies how a deep event generally is more intense than a shallow one (Matrosov et al., 2002). During a deep snow event, the vertical profile is uniform, without significant changes within the reflectivity values especially below the $2000 \mathrm{~km}$ threshold, suggesting different processes as either aggregational growth ceases, or mean particle size reaches a steady state through complementary particle growth and decay, or the PSD evolves in a way where the reflectivity remains constant (i.e., larger numbers of smaller particles, particle shape/backscattering property changes) (Pettersen et al., 2020). The higher Doppler velocity observed on the nearsurface level confirms the presence of higher density particles, meanwhile its value increases from the $2000 \mathrm{~km}$ threshold until reaching the surface, similarly to other synoptic-scale snowstorms studies (Stark et al., 2013). Temperatures are warmer and the support of a higher relative humidity might generate a higher ice water content that is constant with high reflectivity values (Yuter and Houze, 2003). As mentioned in the previous chapters, a deep snow event can be considered as a synoptic-dynamically driven event from midlatitude cyclones and having frontal structures that is associated with warmer temperatures and high moisture content, along with lower surface pressure values (Leather and Ellis, 1996). The wind direction is almost constant through the season, with South-SouthWest as the main direction, with the exception of shoulder months (November and April) that have a broader range of winds. Generally, the wind speed is moderate and goes from $2 \mathrm{~ms}^{-1}$ to $6 \mathrm{~ms}^{-1}$, but it can go up to a higher range from $6 \mathrm{~ms}^{-1}$ to $10 \mathrm{~ms}^{-1}$ with a North-West direction when deep snow events are enhanced by surface winds that traverse over Lake Superior, when the surface is typically open. Wang et al. (2012) noted how this type of lake interaction is more common early in the winter season, due to the absence of ice over Lake Superior. 


\subsection{Shallow Event}

Reflectivity values obtained from MRR observations are similar to previous studies of Lake Effect Snow events, where reflectivity values generally increase toward the surface and have lower values compared to a synoptic snow event (Minder et al., 2015). Despite having similar a similar behavior, it is not possible to compare results from this study with another one, since other cases could have higher reflectivity values $(\sim 15 \mathrm{dBZ})$ or cloud top height values $(\sim 2-2.5 \mathrm{~km})$, but it is not surprising, since they took place in different locations. Kristovich et al. (2017) analyzed the LES system over Lake Ontario, where snowfalls are more intense, because the location of the observations is placed on the East shore of the lake and longlake-axis-parallel (LLAP) single lake effect bands occur, despite the multi-band wind-parallel lake-effect events taking place at the NWS Office in Marquette. Moreover, it is necessary to remember how the lake fetch is reduced, but not cancelled, by the Keweenaw Peninsula and Huron Mountains located to the Northwest. The PSD analysis indicated the presence of fewer small particles and more large particles than the observations for a deep event and this could be explained by a probable cloud sublimation during a shallow event that could reduce the number of small particles, creating an increase of large particles (Barthold and Kristovich, 2011). PIP observations suggest a lower density than a deep event and this could lead to a fluffy and low-density aggregates. A synoptic snow event has warmer temperatures and could be characterized by the presence of needles, meanwhile a shallow event has colder temperatures and the mean temperature (one of them, since the temperature distribution for a LES is bimodal) falls in the dendritic growth zone range from $-12^{\circ} \mathrm{C}$ to $-18^{\circ} \mathrm{C}$, which is one of the keys to have a fluffy behavior. The Doppler velocity has a lower mean compared to a deep event and the presence of a relatively high Doppler spectral width, suggest a turbulent vertical motion related with convective snowfall processes and the negative values may suggest an updraft of light particles and the continue movement could lead to a consistent enhance snow aggregation, promoting particle growth (Lo and Passarelli, 1982). The shallow event has a higher wind speed compared to a deep event and its direction comes from North-Northwest, confirming the fetching over the surface of Lake Superior, which is the main characteristic of Lake Effect Snow production. During colder months the range of directions narrows, due to the lake freezing and therefore a less open surface area, since this type of snowfall event need a not frozen surface to initiate and sustain convection 
movements. Lake Superior generally freezes first on the far western and eastern regions and then at the center because the ice formation is directly correlated with the bathymetry of the lake, where it is easier to form ice over shallower areas. Moreover, higher surface pressures and colder surface temperatures are predominant with postfrontal cold-air outbreaks over the lake, which generate Lake Effect Snow production (Agee and Hart, 1990).

\section{Conclusions}

This study analyzes several snowfall observations during multiple winter seasons and using the data obtained from a vertical profiling radar (MRR), surface video disdrometer (PIP) with the help of ancillary data, it has been possible to distinguish the main differences between synoptic snowfall events (deep) and Lake Effect Snow events (shallow). Due to the nature of this project, having readings from one single location (NWS Office located in Marquette), values obtained from the statistics of each variable cannot be applied to any event, but, on the contrary, it is possible to use the correlation of the same variable between a deep and shallow event to predict the behavior of other events in different places. It has been found that a shallow event occurs twice as much frequent as a deep event, however a deep event is more intense than a shallow event, meaning that, overall, they contribute in the same way at the snow accumulation. Another important aspect that this project analyzed is the difference in reflectivity values that each snow event type has and therefore the difference in growth processes that could occur along the vertical profile. Despite the data used was satisfactory enough to produce a valid statistic for each variable, it will be necessary to continue this study with more winter seasons and improve the accuracy of values obtained and analyze their correlations. 


\section{References}

Agee E.M. and Hart M.L., (1990), Boundary Layer and Mesoscale Structure over Lake Michigan during a Wintertime Could Air Outbreak, Journal of the Atmospheric Sciences, Vol. 47 No. 19, 2293-2316

Barthold F.E. and Kristovich D.A., (2011), Observations of the Cross-Lake Cloud and Snow Evolution in a Lake-Effect Snow Event, Monthly Weather Review, Vol. 139, 2386-2398

Casella D. et al. (2017), Evaluation of the GPM-DPR snowfall detection capability: Comparison with CloudSat-CPR, Atmospheric Research, 1-22

Eichenlaub V.L., (1970), Lake effect snowfall to the lee of the Great Lakes: its role in Michigan, Bulletin of American Meteorological Society, Vol. 51 No. 5, 403-413

Heymsfield A.J. et al., (2008), Exponential Size Distribution for Snow, Journal of the Atmospheric Sciences, Vol. 65, 4017-4031

Judson A. and Doesken N., (2000), Density of Freshly Fallen Snow in the Central Rocky Mountains, Bulletin of the American Meteorological Society, Vol 81 No. 7,1577-1588.

Kneifel S. et al., (2011), Observation of snowfall with a low-power FM-CW K-band radar (Micro Rain Radar), Meteorological Atmospheric Physic, Vol. 113, 75-87

Kristovich, D.A. et al., 2017, The Ontario Winder Lake-Effect Systems Field Campaign, Bulletin of American Meteorological Society, Vol. 98, 315-332

Kulie M.S. and Milani L., (2018), Seasonal variability of shallow cumuliform snowfall: A CloudSat perspective, Quarterly Journal of the Royal Meteorological Society, Vol. 144 No. 1, 329-343

Kulie M.S. et al., (2016), A Shallow Cumuliform Snowfall Census Using Spaceborne Radar, Journal of Hydrometeorology, Vol. 17, 1261-1279

Le M. and Chandrasekar V., (2019), Ground Validation of Surface Snowfall Algorithm in GPM DualFrequency Precipitation Radar, Journal of Atmospheric and Oceanic Technology, Vol. 36, 607619

Leathers D.J. and Ellis A.W., (1996), Synoptic Mechanisms Associated with Snowfall Increases to the Lee of Lakes Erie and Ontario, International Journal of Climatology, Vol. 16, 1117-1135

Lo K.K. and Passarelli R.E., (1982), The Growth of Snow in Winter Storms: An Airbone Observational Study, Journal of the Atmospheric Sciences, Vol. 39 No. 4, 697-706

Maahn M. and Kollias P., (2012), Improved Micro Rain Radar snow measurements using Doppler spectra post-processing, Atmospheric Measurement Techniques, Vol. 5, 2661-2673

Matrosov et al., (2002), Profiling Cloud Ice Mass and Particle Characteristic Size from Doppler Radar Measurements, Journal of Atmospheric and Oceanic Technology, Vol. 19, 1003-1018 
Minder J.R. et al., (2015) The Evolution of Lake-Effect Convection during Landfall and Orographic Uplift as Observed by Profiling Radars, Monthly Weather Review, Vol. 143, 4422-4442

Newman A.J. et al., (2009), Presenting the Snowflake Video Imager (SVI), Journal of Atmospheric and Oceanic Technology, Vol. 26, 167-179

Norton D.C. and Bolsenga S.J., (1993), Spatiotemporal Trends in Lake Effect and Continental Snowfall in the Laurantian Great Lakes, 1951-1980, Journal of Climate, Vol. 6, 1943-1956

Notaro et al., (2015), Dynamically Downscaled Projections of Lake-Effect Snow in the Great Lakes Basin, Journal of Climate, Vol. 28, 1661-1684

Peters G. et al., (2002), Rain observations with a vertically looking Micro Rain Radar (MRR), Boreal Environment Research, Vol. 7, 353-362

Pettersen C. et al., (2020), A Composite Analysis of Snowfall Modes from Four Winter Season in Marquette, Michigan, Journal of Applied Meteorology and Climatology, Vol. 59, 103-124

Potter J.G., (1965), Water Content of Freshly Fallen Snow, Meteorological Branch, Dept. of Transport, Toronto, ON, Canada, CIR-4232, TEC-569, 1-12.

Roebber et al, (2003), Improving Snowfall Forecasting by Diagnosing Snow Density, American Metereological Society, Vol 18, 264-286

Roscoe R. Braham Jr., (1990), Snow Particle Size Spectra in Lake Effect Snows, American Metereological Society, Vol 29, 200-207

Saavedra P. et al., (2012), Partitioning of cloud water and rainwater content by ground-based observations with the Advanced Microwave Radiometer for Rain Identification (ADMIRARI) in synergy with a micro rain radar, Journal of Geophysical Research, Vol. 117 D05203, 1-18

Serreze M.C. et al., (1998), Characteristics of Snowfall over the Eastern Half of the United States and Relationships with Principal Modes of Low-Frequency Atmospheric V ariability, Journal of Climate, Vol. 11, 234-250

Stark D. et al., (2013), Observed Microphysical Evolution for Two East Coast Winter Storms and the Associated Snow Bands, Monthly Weather Review, Vol. 141, 2037-2057

Stephens G.L. et al., (2002), The Cloudsat mission and the A-Train, A New Dimension of SpaceBased Observations of Clouds and Precipitation, Bulletin of the American Meteorological Society, 1771-1790

Stephens G.L. et al., (2008), CloudSat mission: Performance and early science after the first year of operation, Journal of Geophysical Research, Vol. 113 D00A18, 1-18

Suriano Z.J. and Leathers D.J., (2017), Synoptically Classified Lake-Effect Snowfall Trends to the Lee of Lakes Erie and Ontario, Climate Research, Vol. 74, 1-13

Tiira J. et al., (2016), Ensemble mean density and its connection to other microphysical properties of falling snow as observed in Southern Finland, Atmospheric Measurement Techniques, Vol. 9, 4825-4841 
Von Lerber A. et al, (2018), V alidation of GMI Snowfall Observations by Using a Combination of Weather Radar and Surface Measurements, Journal of Applied Meteorology and Climatology, Vol. 57, 797-820

Wang J. et al., (2012), Temporal and Spatial V ariability of Great Lakes Ice Cover, 1973-2010, Journal of Climate, Vol. 25, 1318-1329

Wang Y. et al., (2013), Liquid water in snowing clouds: Implications for satellite remote sensing of snowfall, Atmospheric Research, Vol. 131, 60-72

Waples J.T. et al., (2008), The Laurentian Great Lakes, North American Continental Margins, $81-73$

Weksh D. et al., (2016), Understanding Heavy Lake-Effect Snowfall: The Vertical Structure of Radar Reflectivity in a Deep Snowband over and downwind of Lake Ontario, Monthly Weather Review, Vol. 144, 4221-4244

Woods C.P. et al., (2008), Size Spectra of Snow Particles Measured in Wintertime Precipitation in the Pacific Northwest, Journal of the Atmospheric Sciences, Vol. 65, 189-205 


\section{A.Appendix}

a. Code

function output=snow(file_name)

$\mathrm{DBZ}=$ ncread(file_name,'DBZ');

DBZ $($ DBZ $==-9999)=\mathrm{NaN}$;

$\mathrm{PSD}=$ ncread(file_name,'PSD');

$\operatorname{PSD}(\mathrm{PSD}==-99)=\mathrm{NaN}$;

VEL=ncread(file_name,'MRR_DOP_VEL');

VEL $($ VEL $==-99)=\mathrm{NaN}$;

EDENS=ncread(file_name,'EDENSITY').';

EDENS $($ EDENS $==-99)=\mathrm{NaN}$;

EDENS(EDENS $<=0$ ) $=\mathrm{NaN}$;

TSFC =ncread(file_name,'TSFC').';

TSFC $($ TSFC $==-9999)=\mathrm{NaN}$;

TSFC $($ TSFC $==-99)=\mathrm{NaN}$;

PRES=ncread(file_name,'PRES').';

PRES $($ PRES $==-99)=\mathrm{NaN}$;

RH=ncread(file_name,'RH').';

RH $(\mathrm{RH}==-9999)=\mathrm{NaN}$;

$\mathrm{RH}(\mathrm{RH}==-99)=\mathrm{NaN}$;

WIND_DIR=ncread(file_name,'WIND_DIR').';

WIND_DIR(WIND_DIR==-9999) $=360$;

WIND_DIR(WIND_DIR $==0$ ) $=360$;

year=ncread(file_name,'YEAR');

month=ncread(file_name,'MONTH');

day $=$ ncread(file_name, 'DAY');

$[\mathrm{M}, \mathrm{N}]=\operatorname{size}(\mathrm{DBZ})$;

$\%$ Check for precipitation $($ True $=1$, False $=0)$

prec $=$ zeros $(1, \mathrm{~N})$;

for $\mathrm{i}=1: \mathrm{N}$

if $(\sim$ isnan(DBZ $(3, \mathrm{i}))) \boldsymbol{\&} \boldsymbol{\&}(\sim \operatorname{isnan}(\operatorname{EDENS}(\mathrm{i})))$ $\operatorname{prec}(1, \mathrm{i})=1$

else

$\operatorname{prec}(1, \mathrm{i})=0$;

end

end

$\% \mathrm{DBZ}$

$\mathrm{dbz}=\mathrm{zeros}(\mathrm{M}, \mathrm{N})$;

for $\mathrm{i}=1: \mathrm{N}$

if $\operatorname{prec}(1, \mathrm{i})==1$

$\operatorname{dbz}(:, i)=\operatorname{DBZ}(:, \mathrm{i})$;

else

$\mathrm{dbz}(:, \mathrm{i})=\mathrm{NaN}$;

end

end

$\%$ VEL

vel=zeros $(\mathrm{M}, \mathrm{N})$;

for $\mathrm{i}=1: \mathrm{N}$

if $\operatorname{prec}(1, \mathrm{i})==1$ 


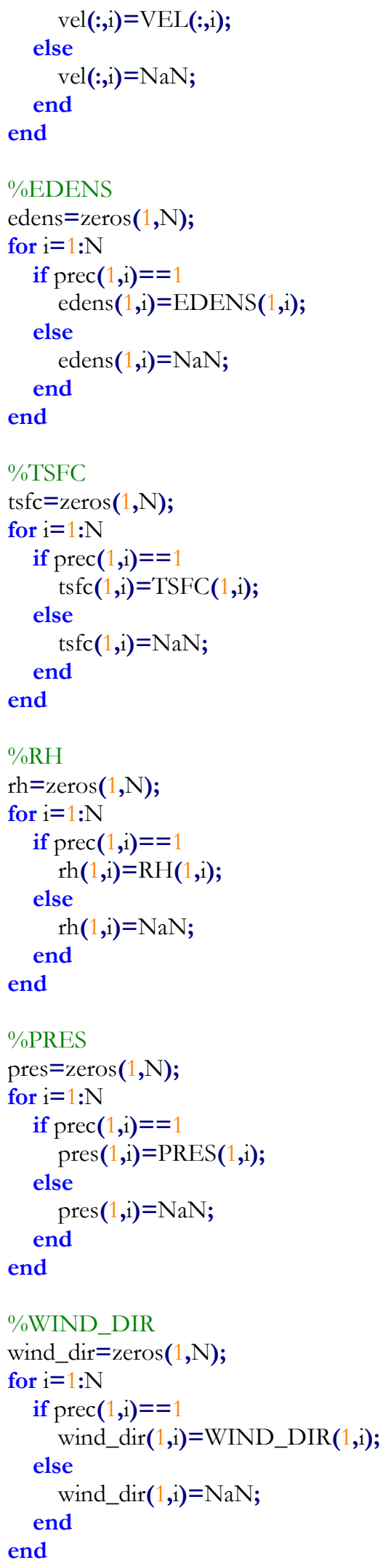




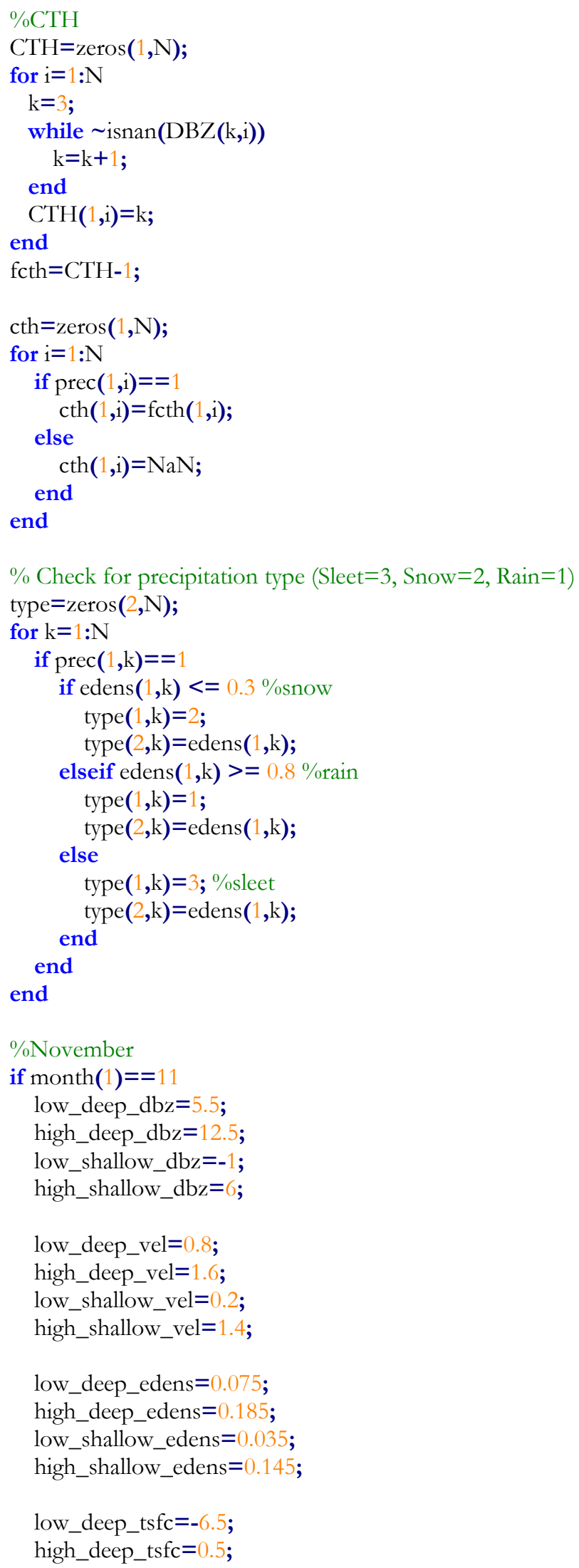




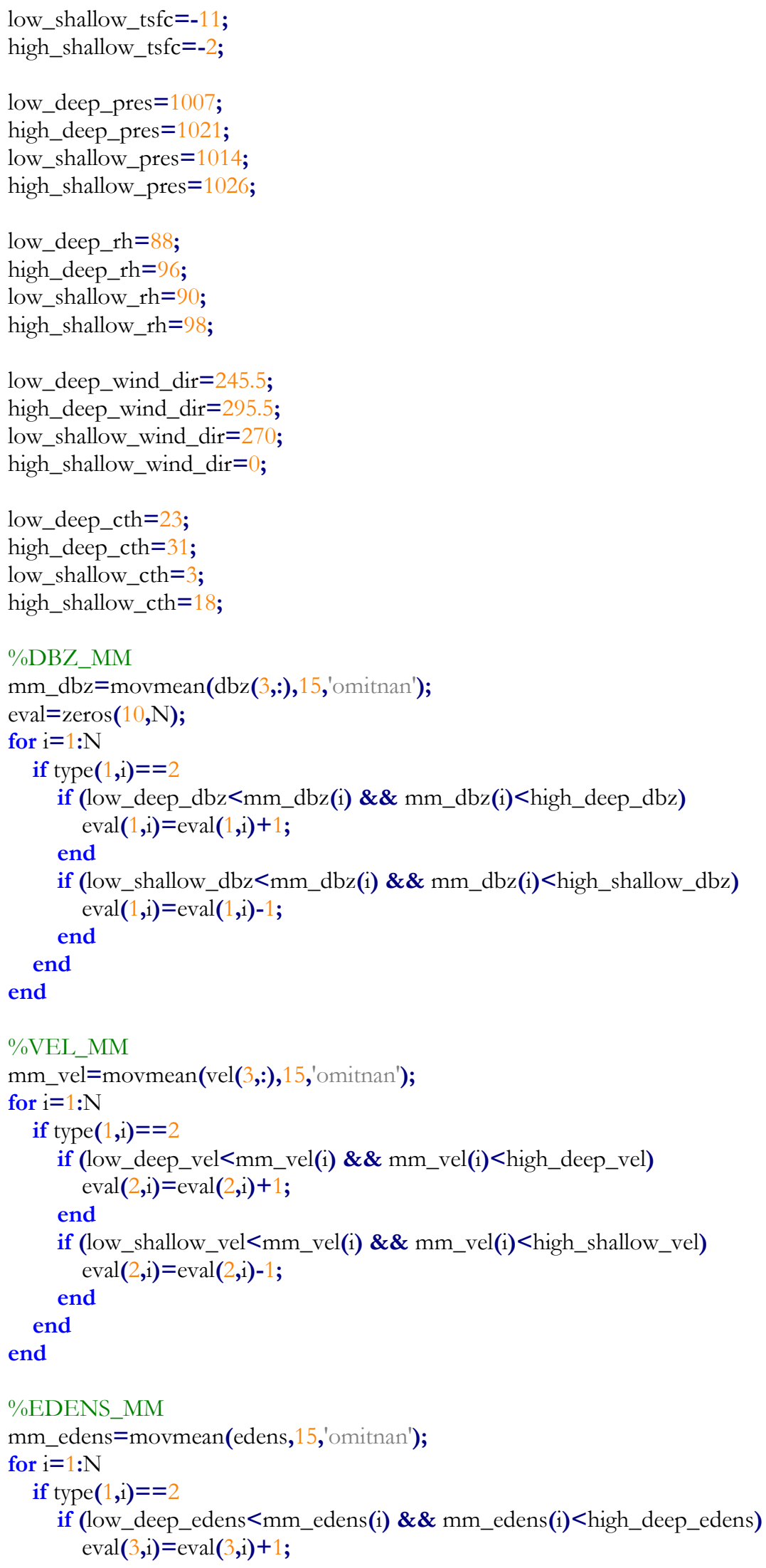




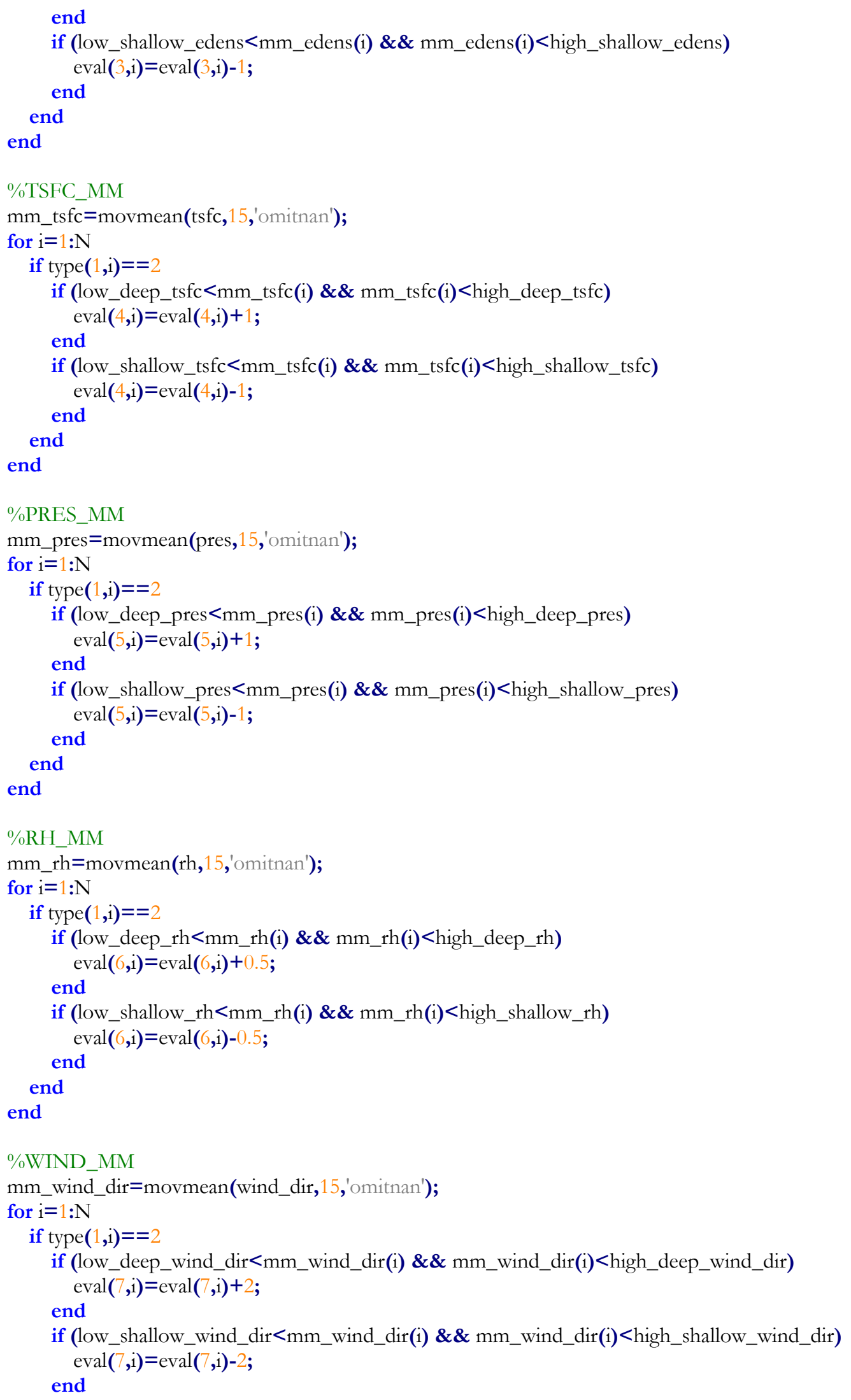




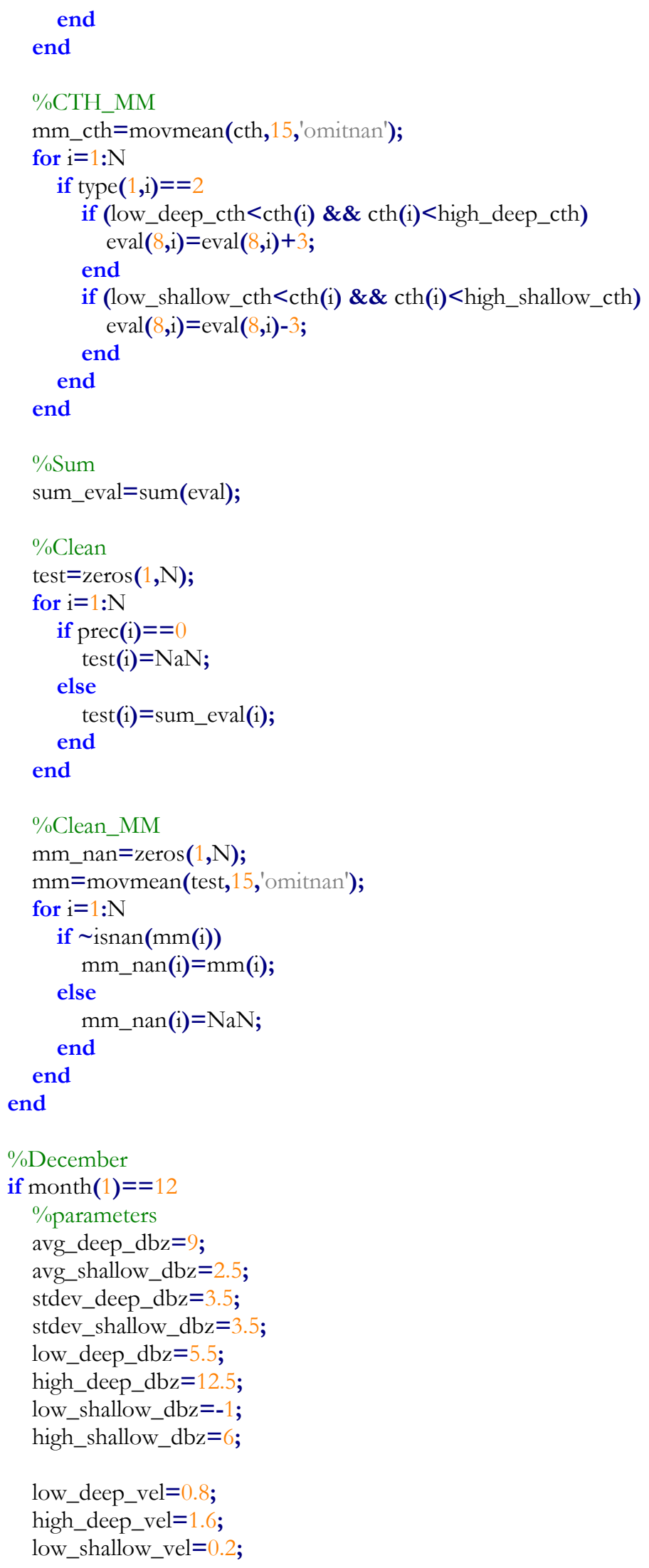




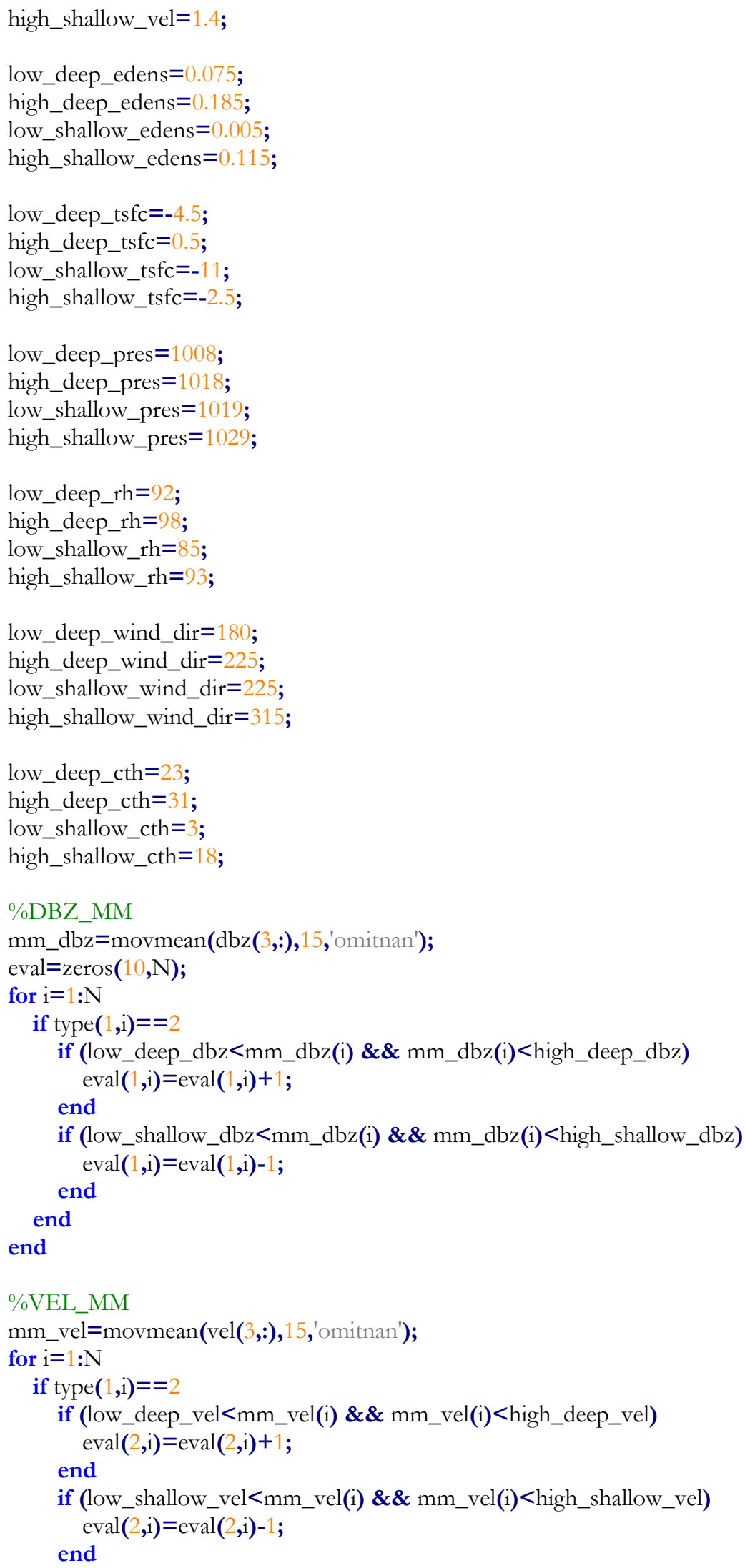




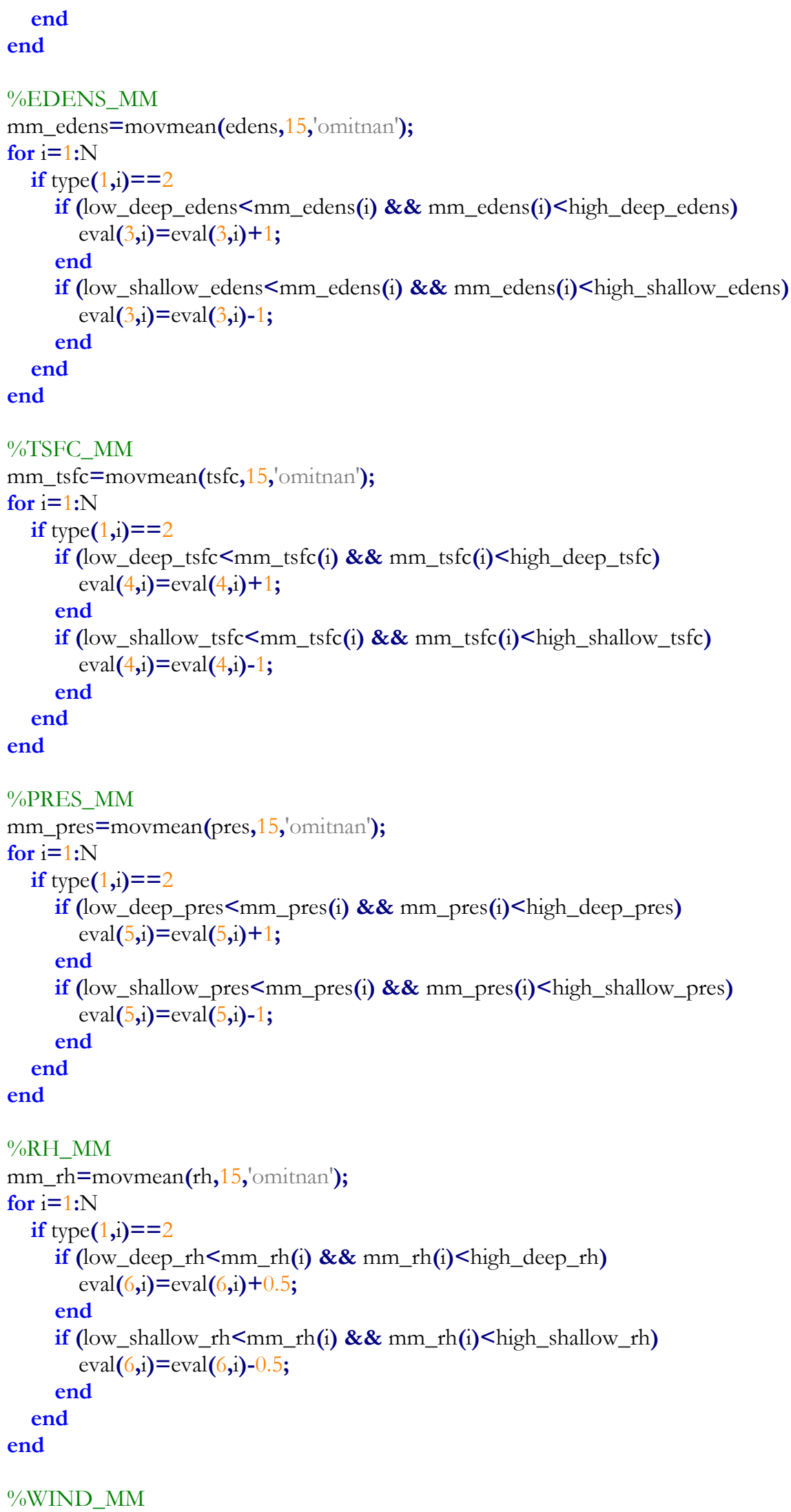




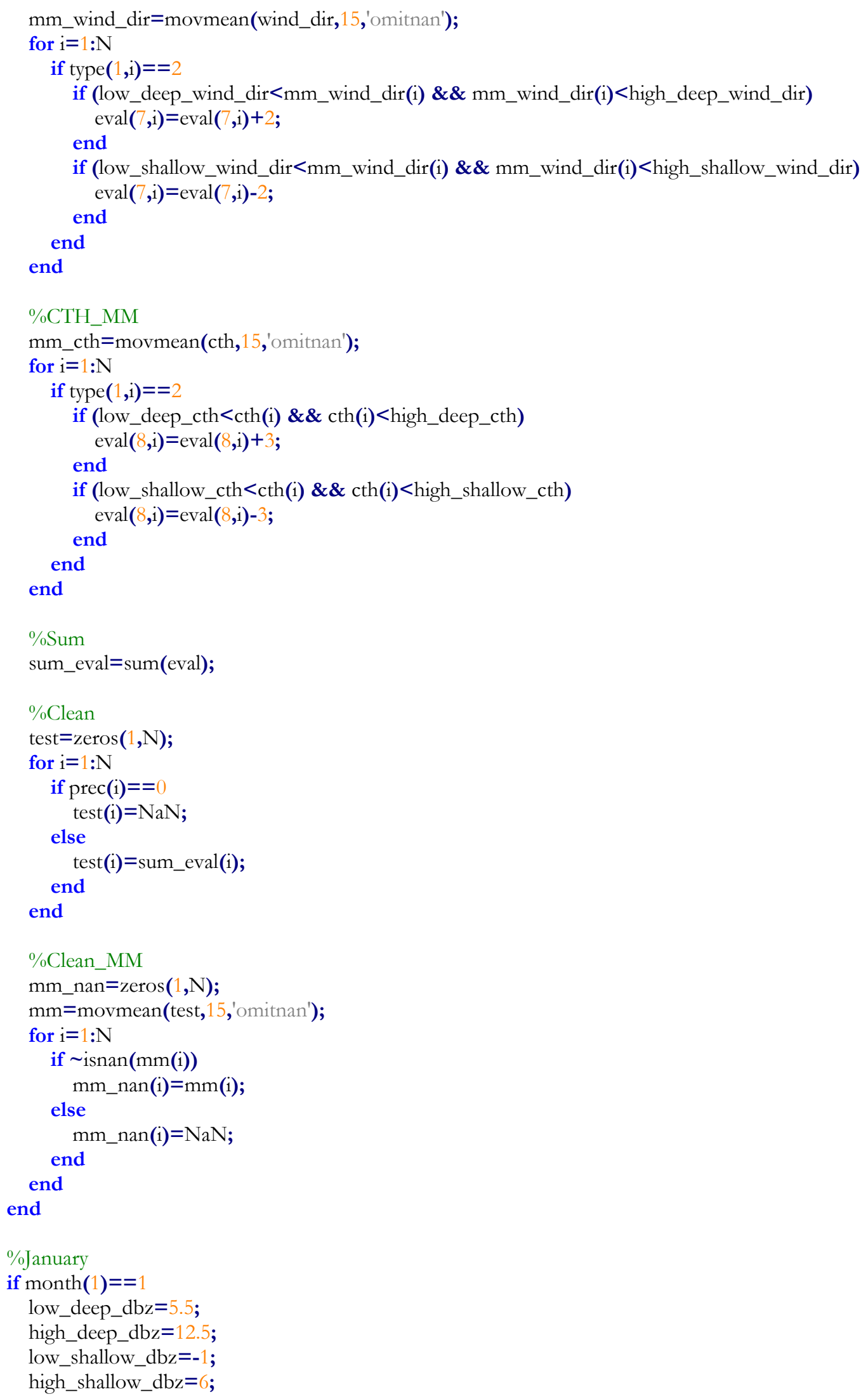




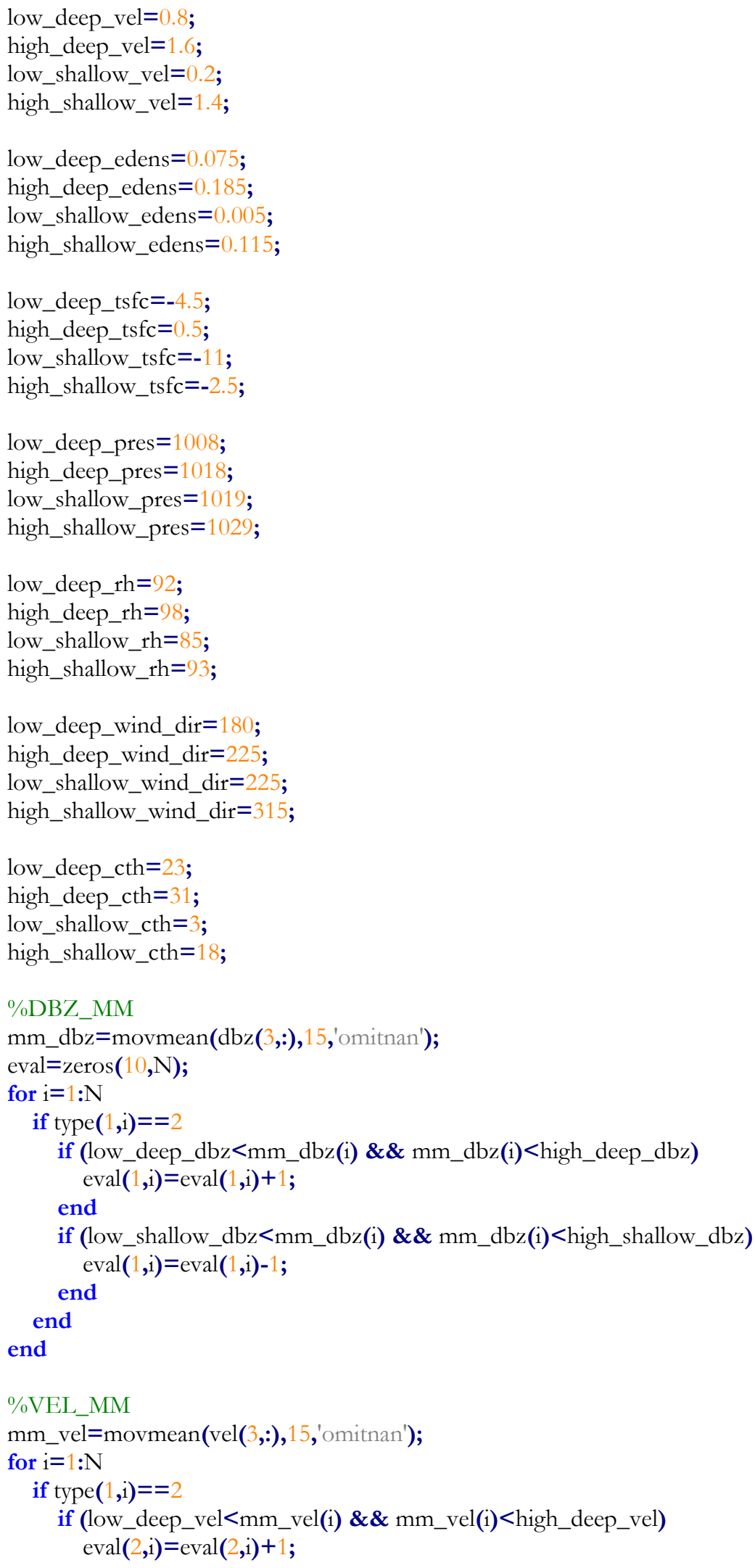




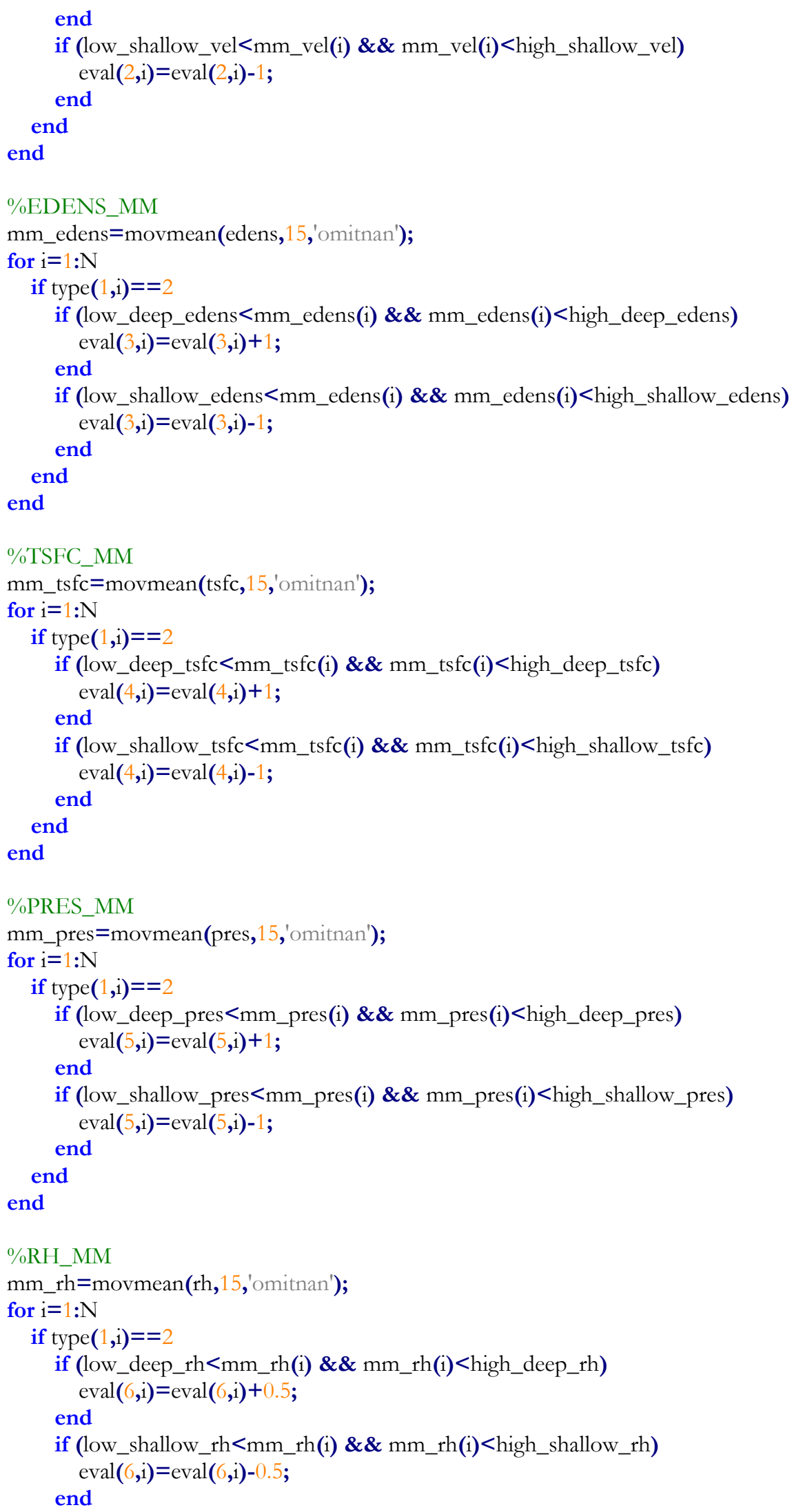




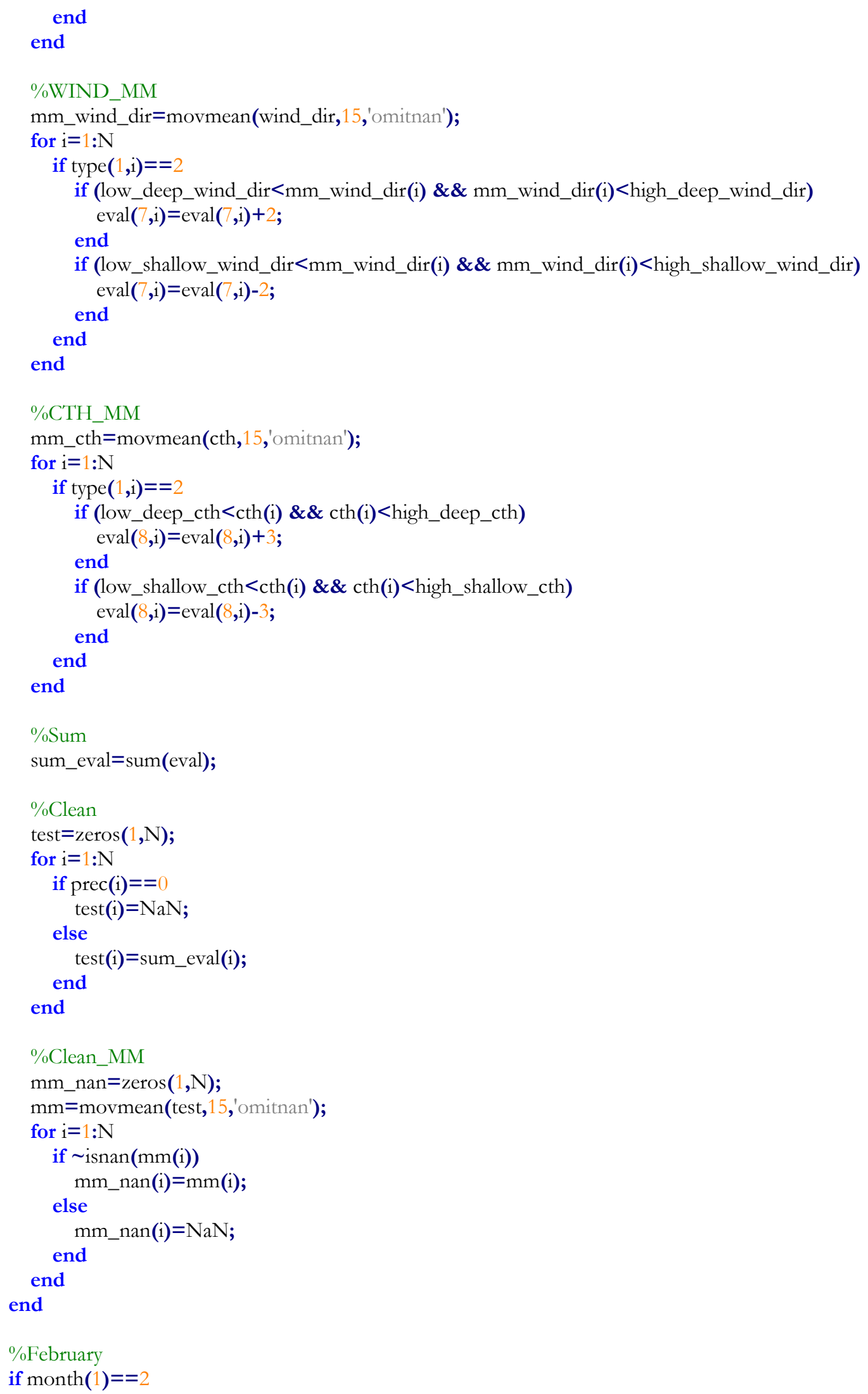




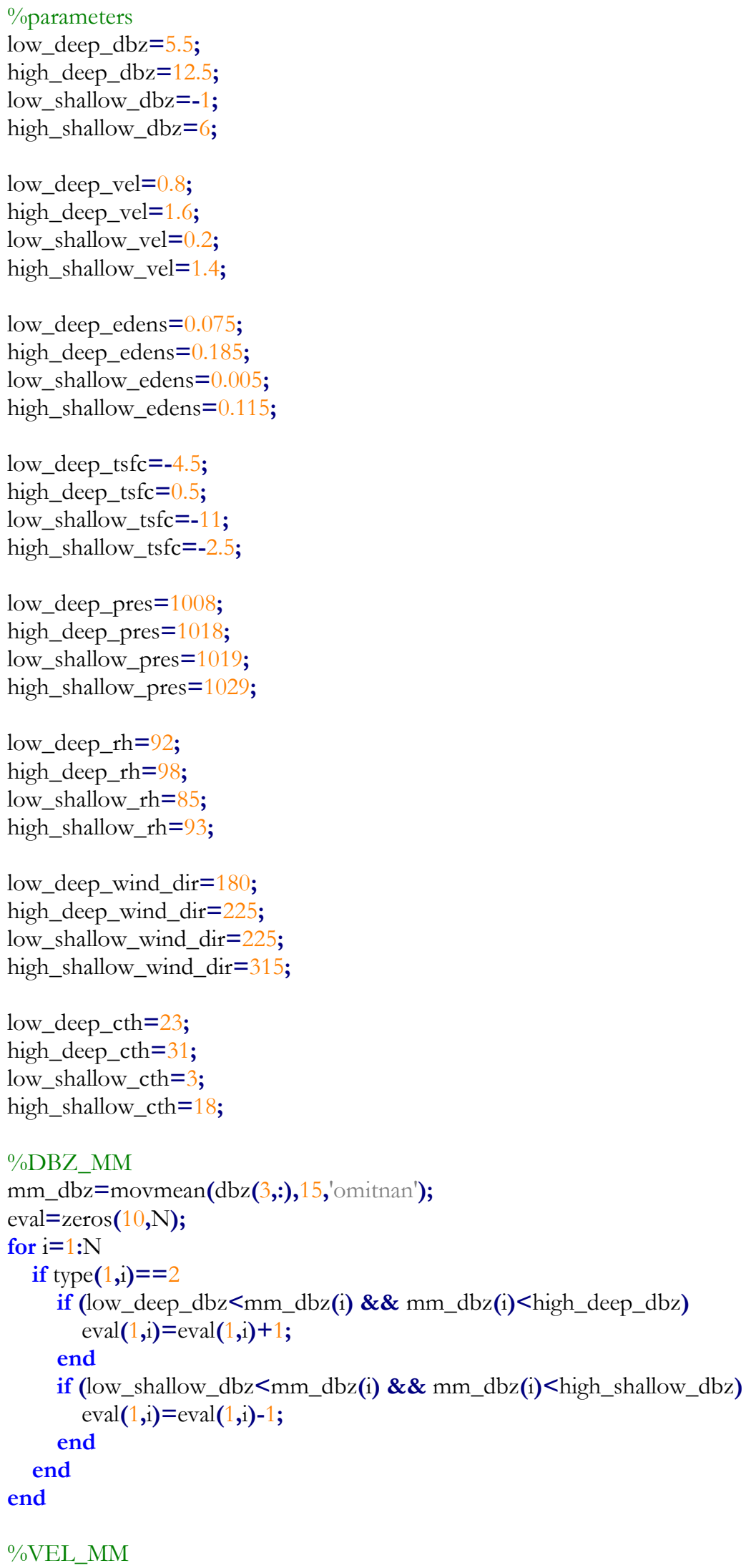




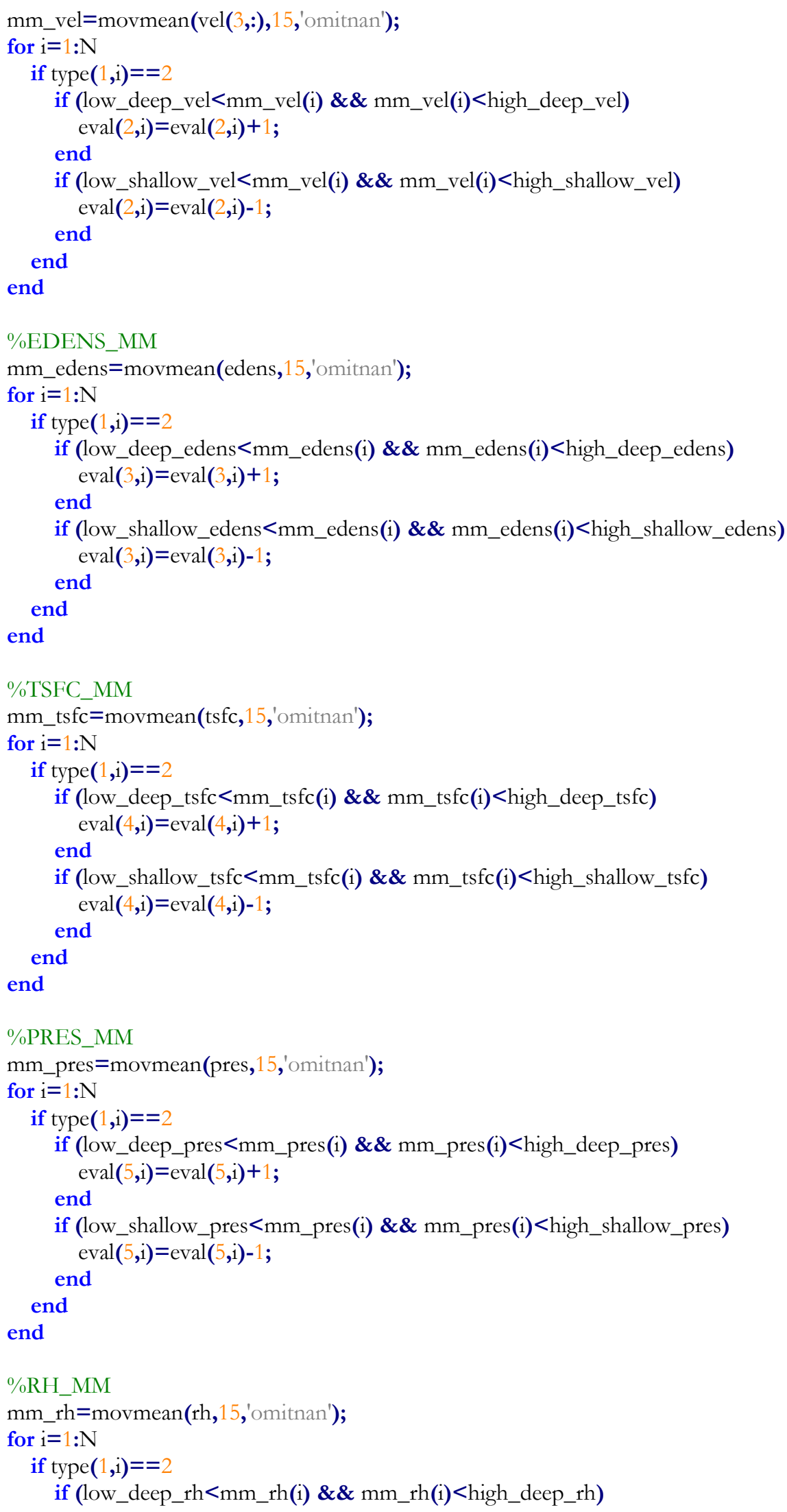




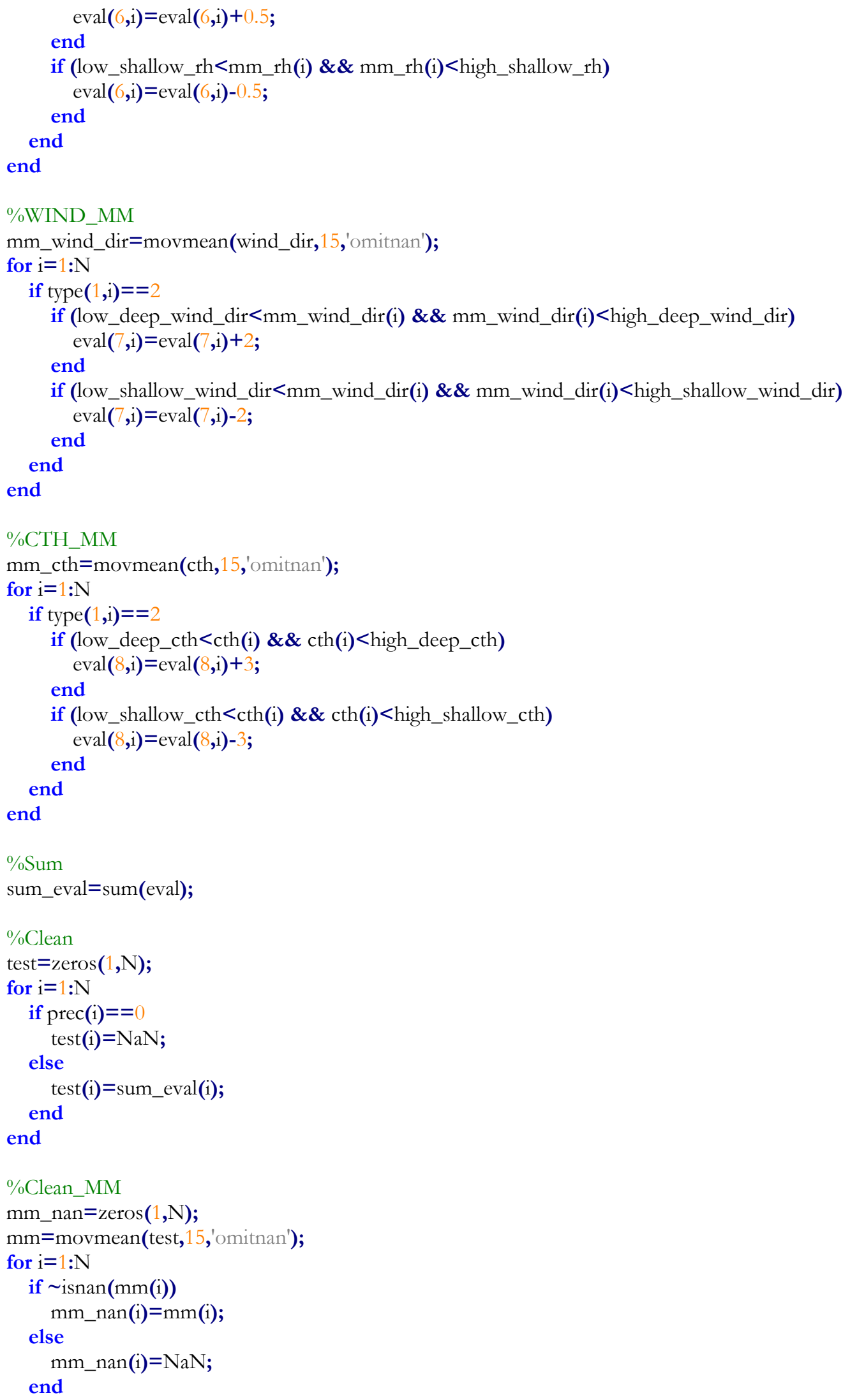




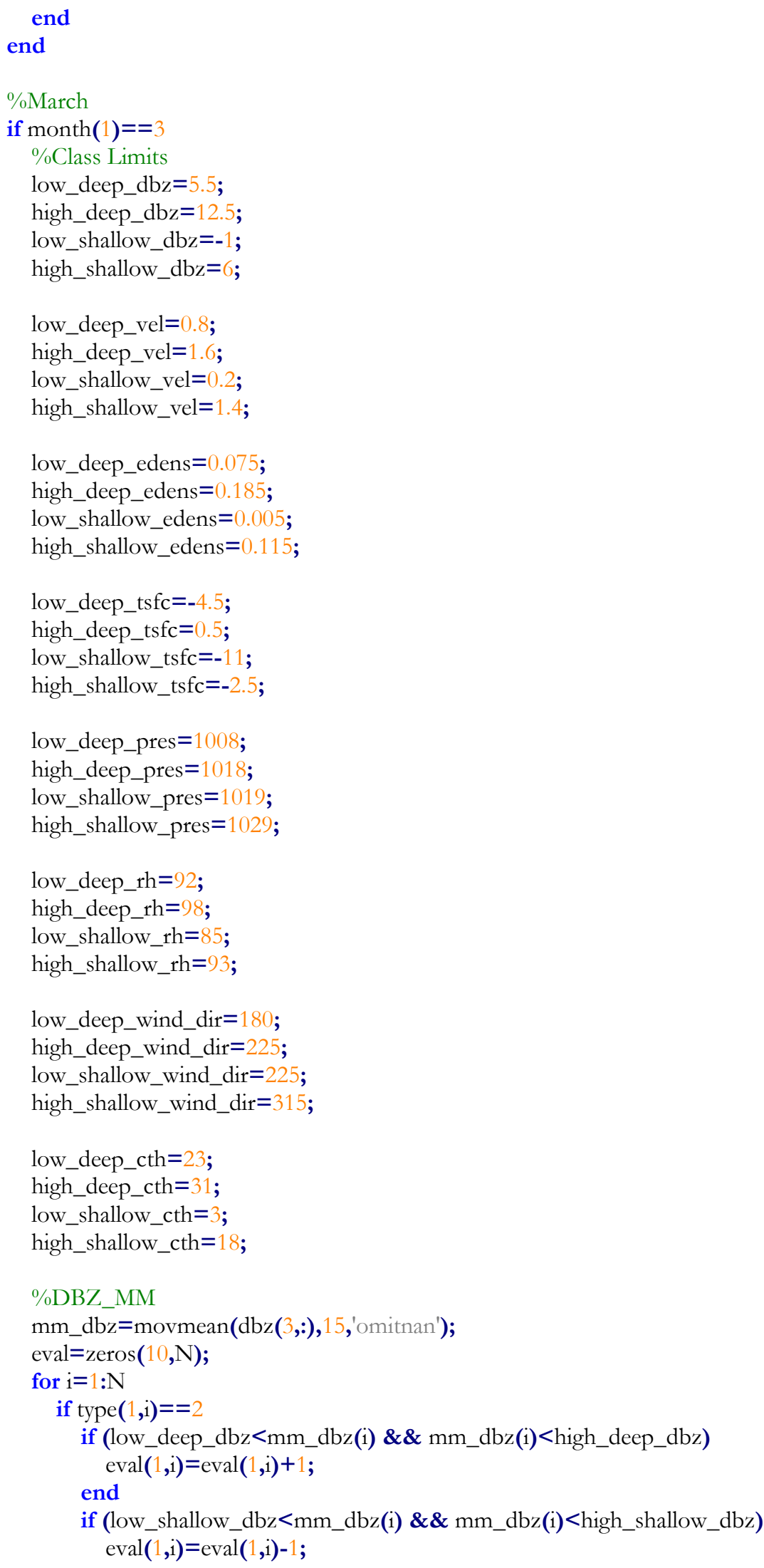




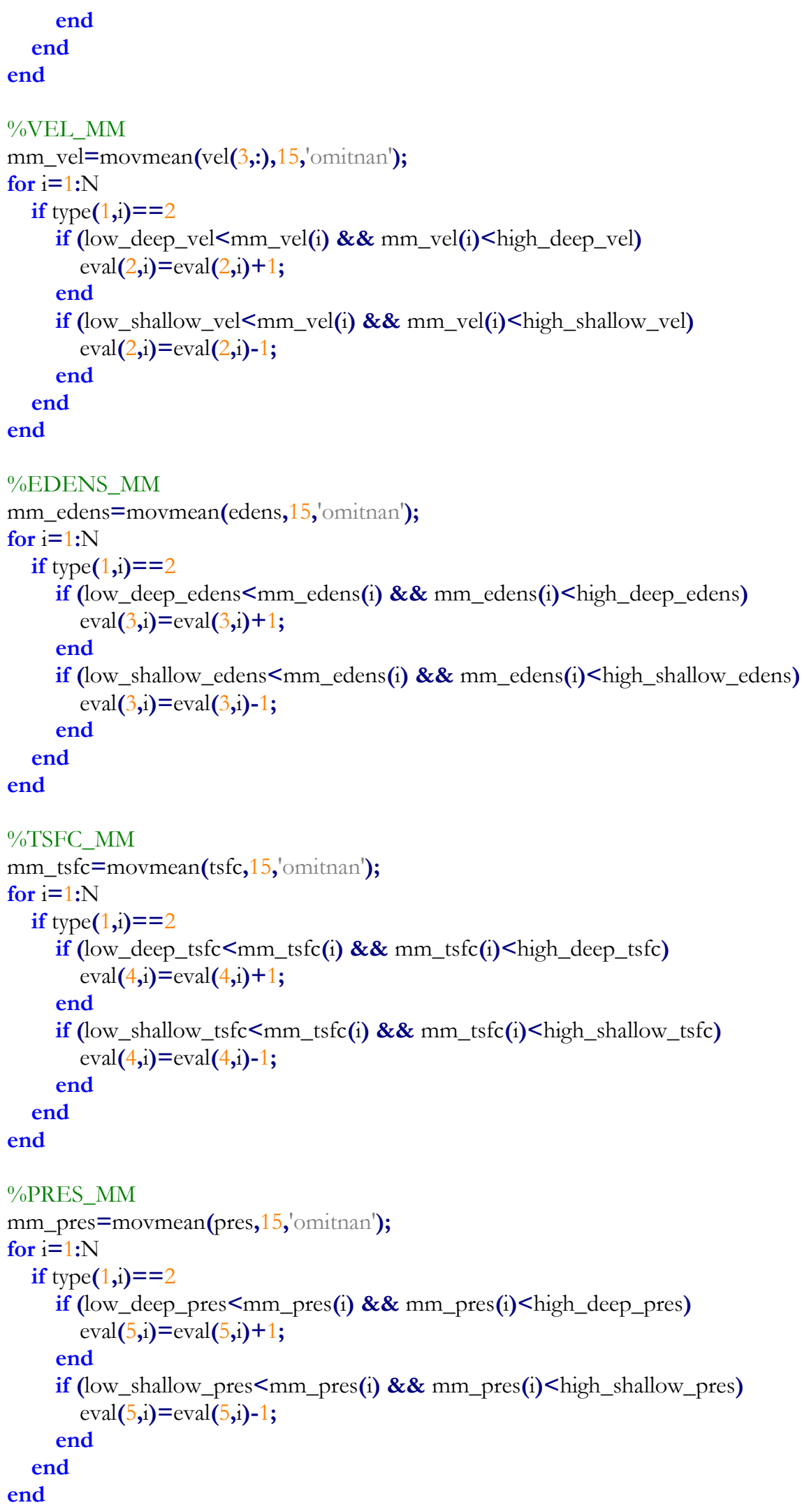




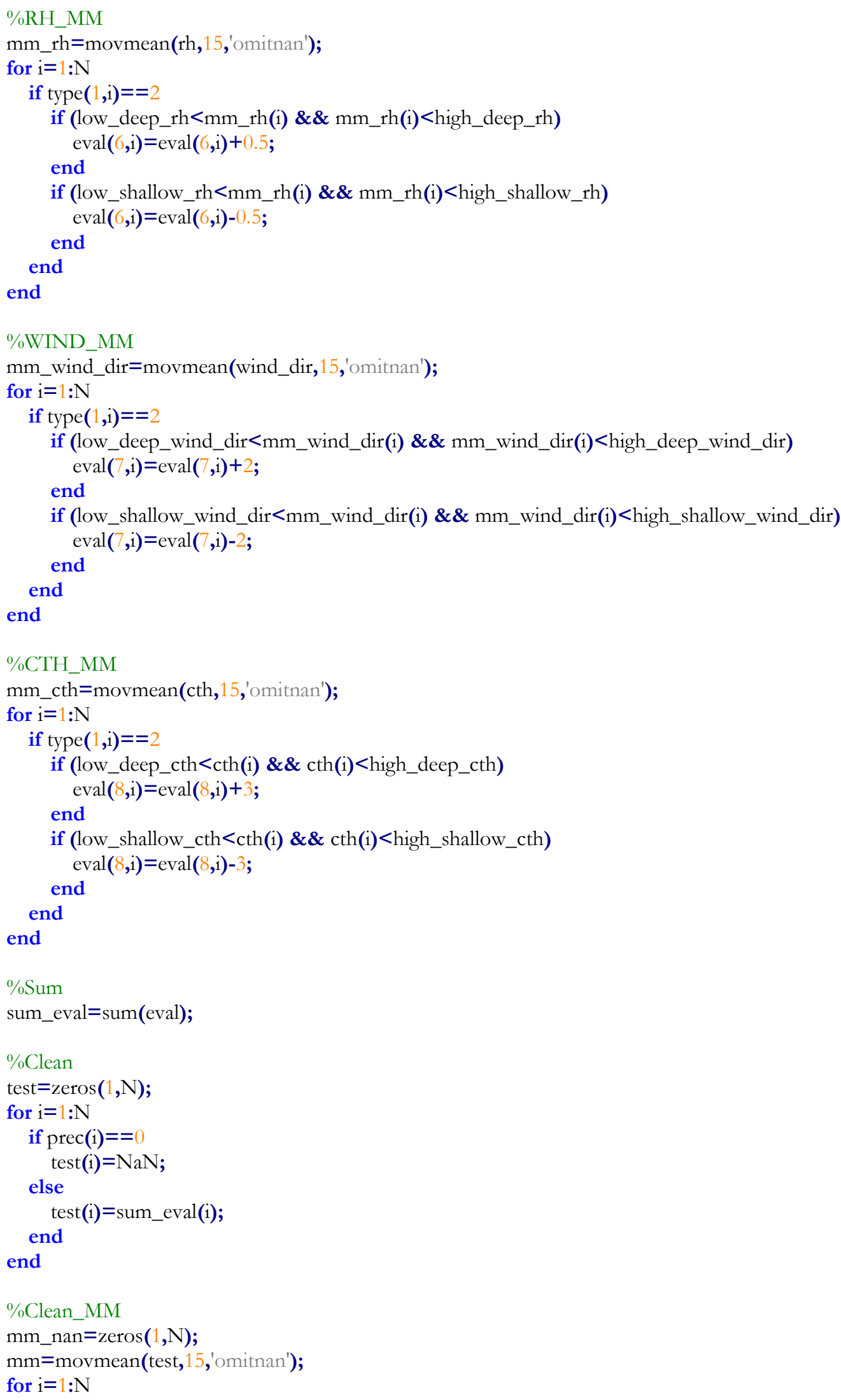




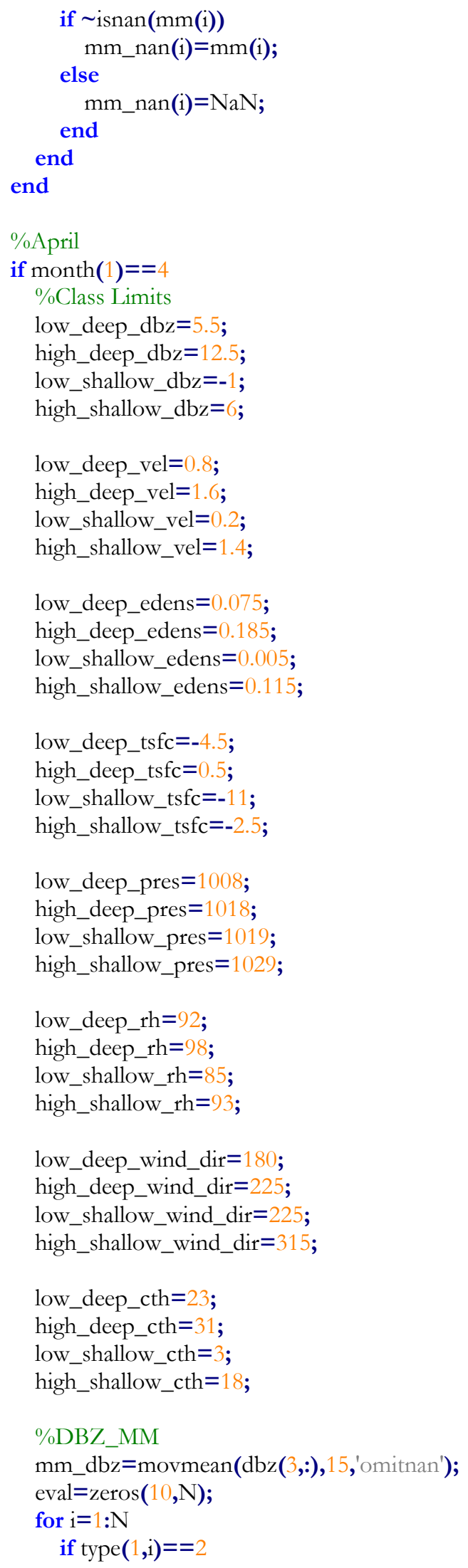




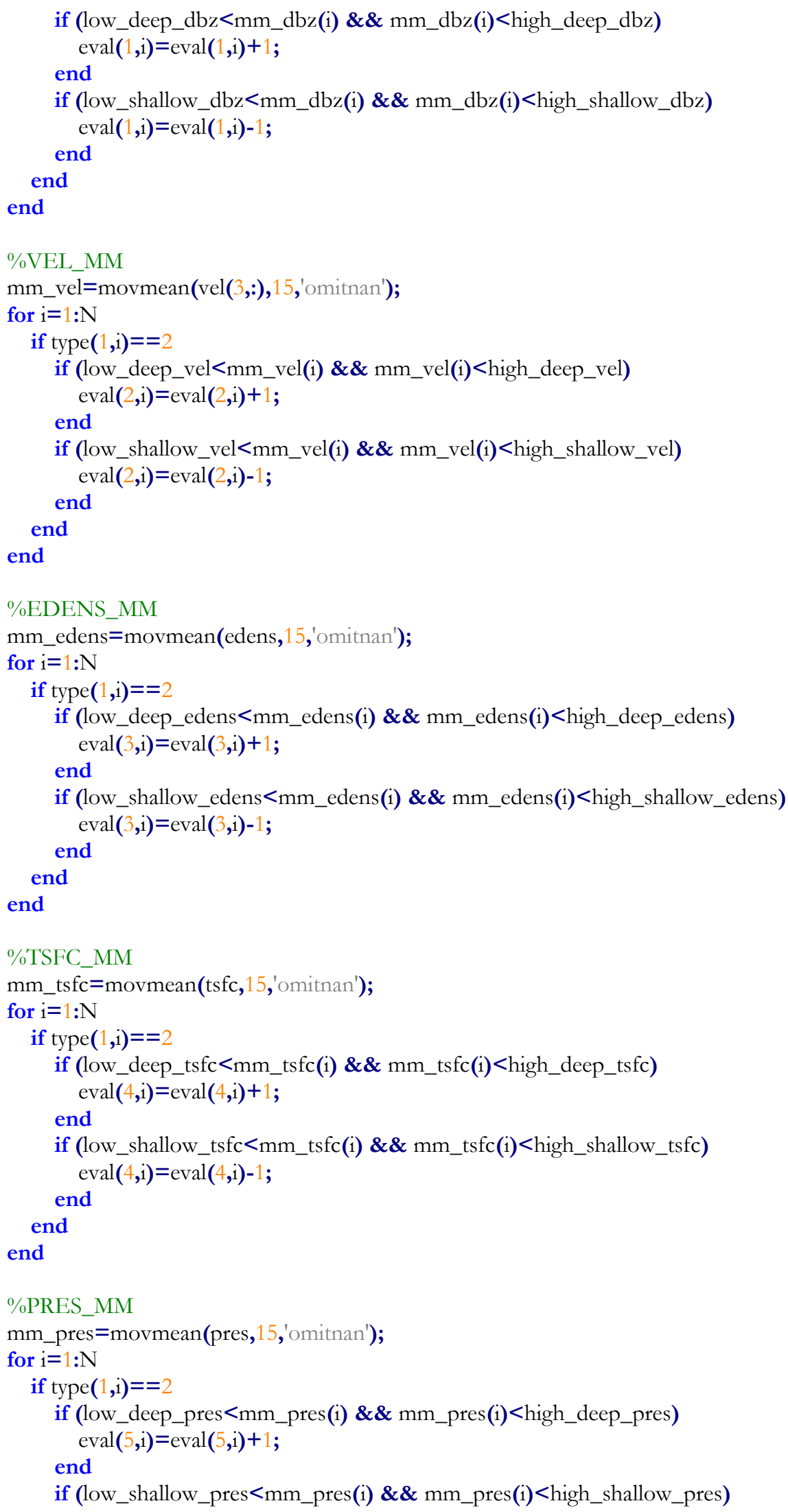




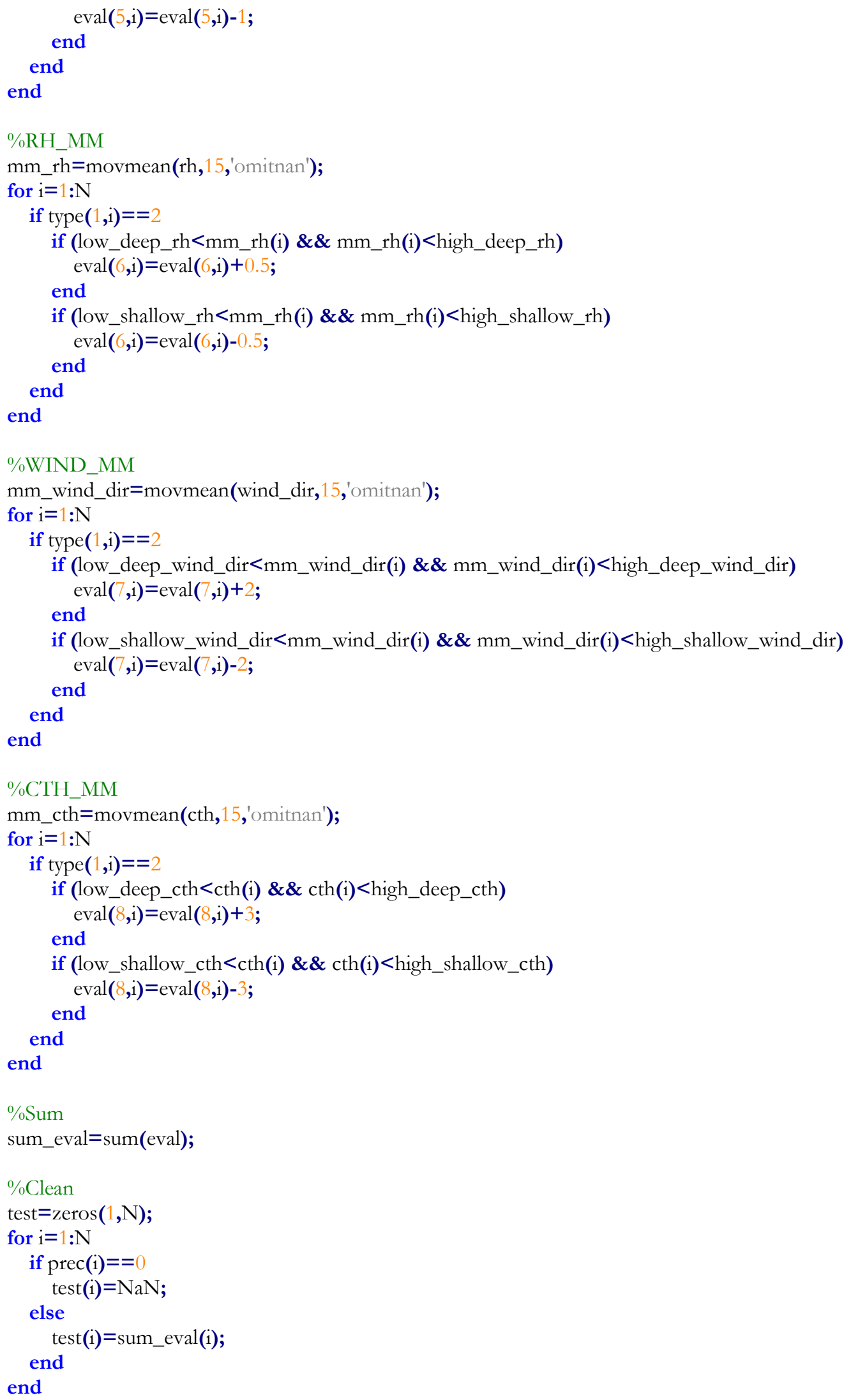




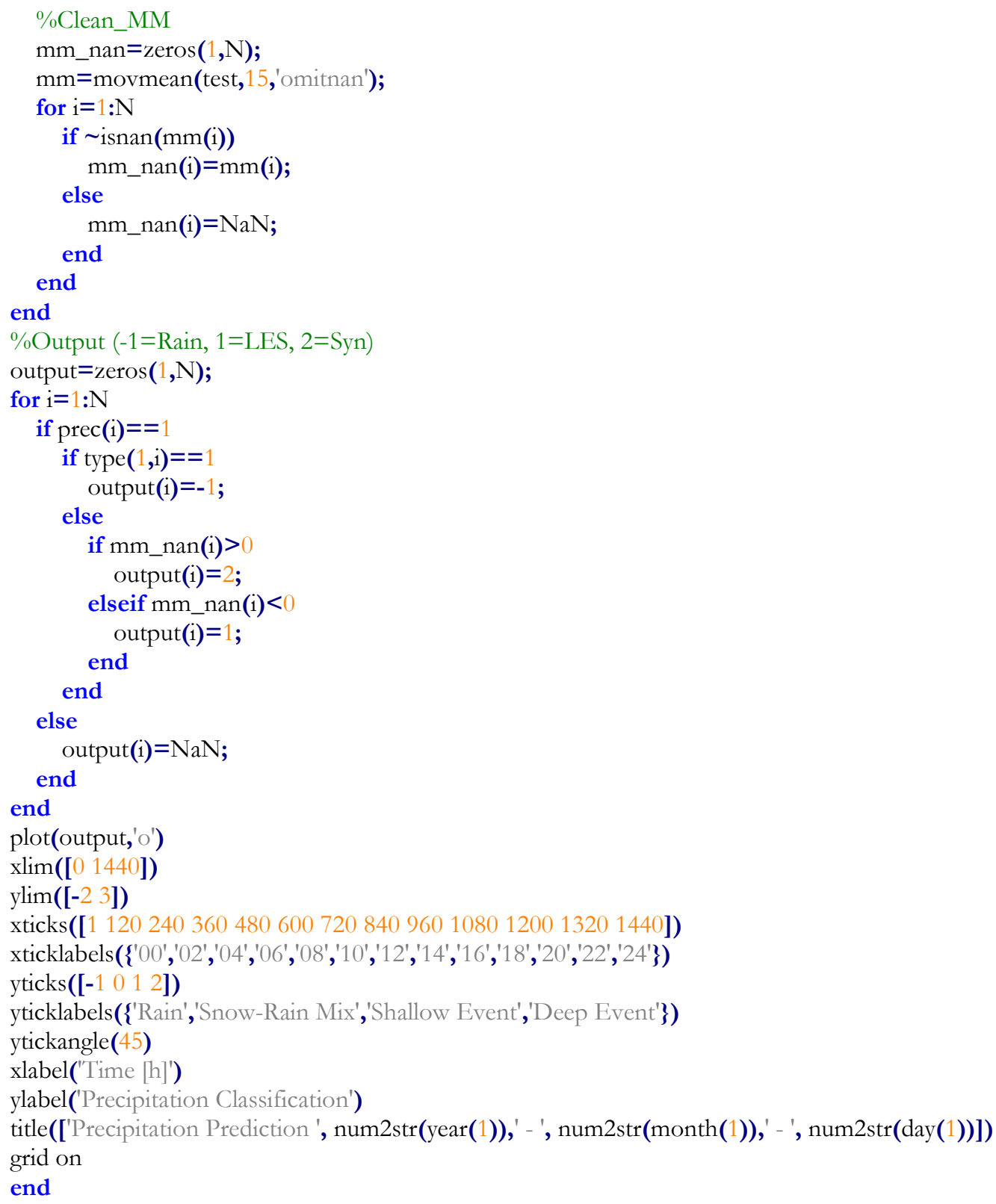


b. Sea Level Pressure Examples
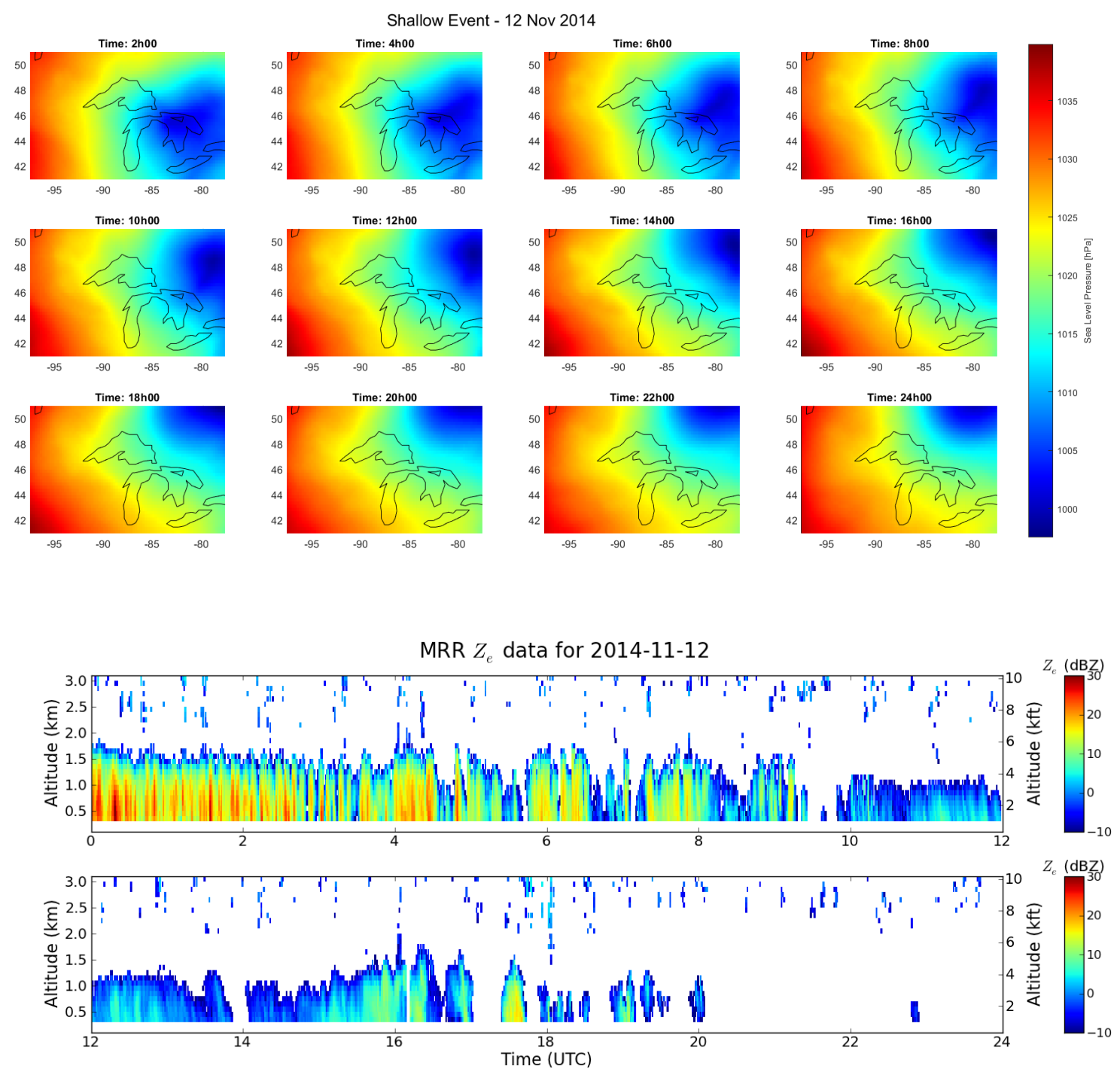

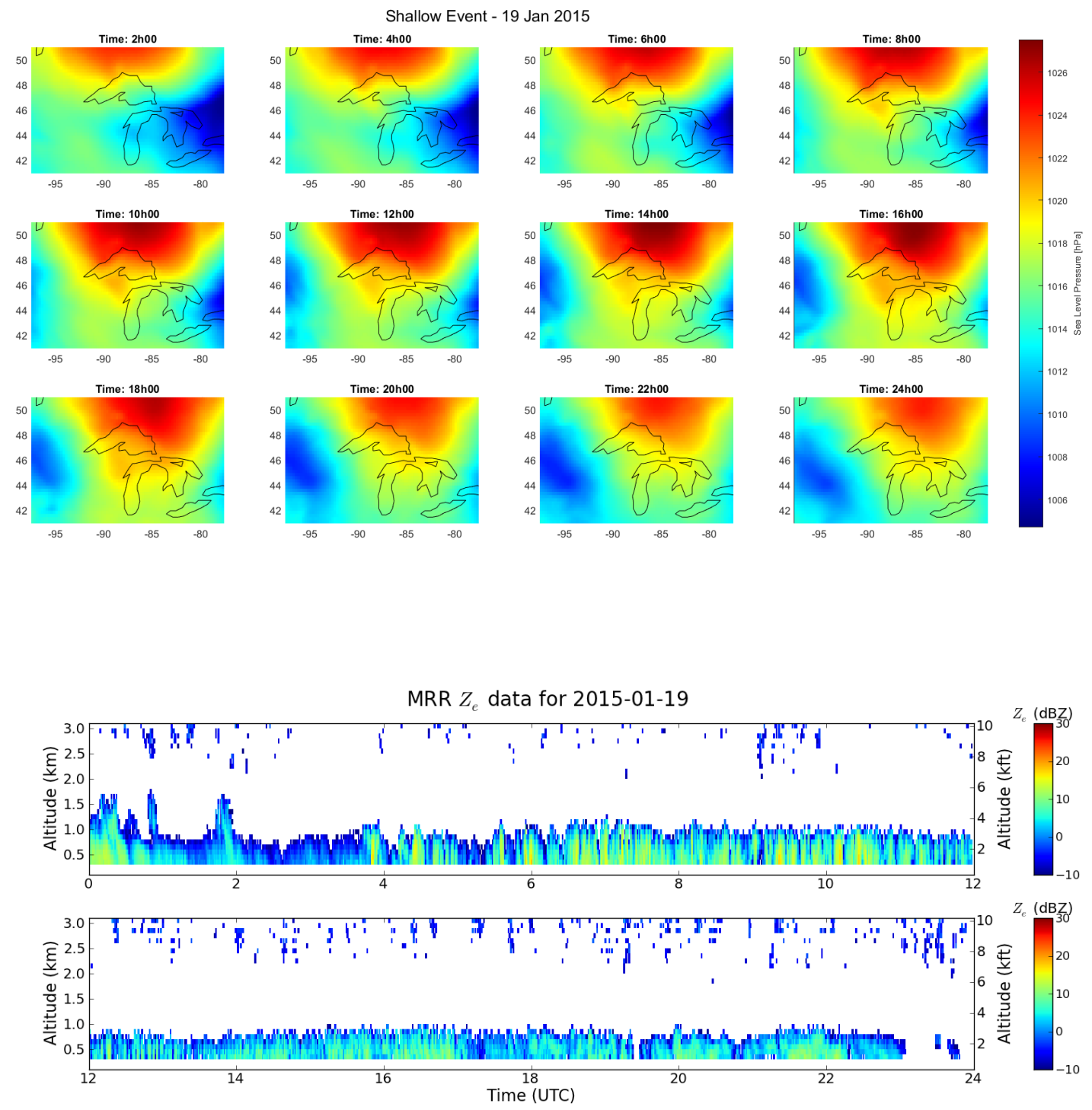


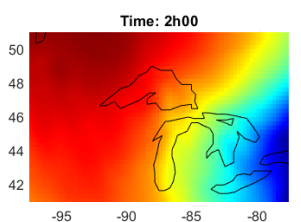

Time: 10 hoo

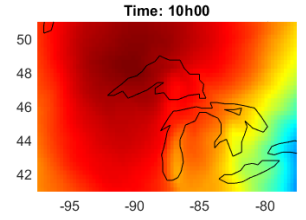

Time: $18 \mathrm{~h} 00$

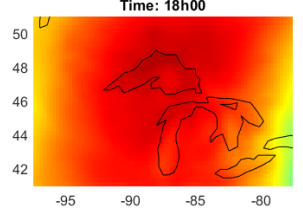

Shallow Event - 15 Feb 2015

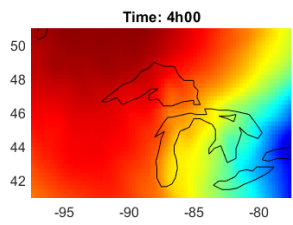

Time: 12 h00

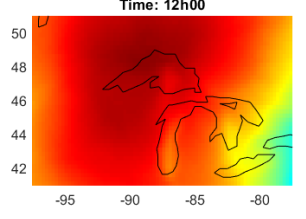

Time: 20 h00

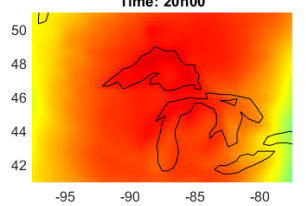

Time: 6 h00

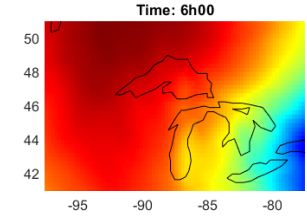

Time: $14 \mathrm{~h} 00$

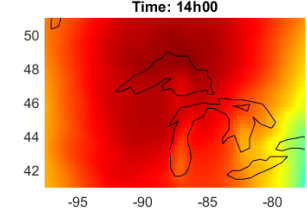

Time: 22h00

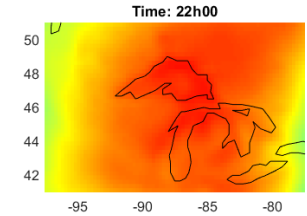

Time: 8 h00

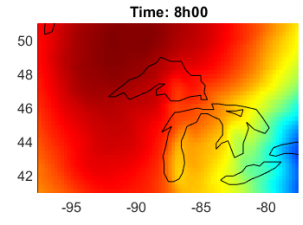

Time: 16 hoo

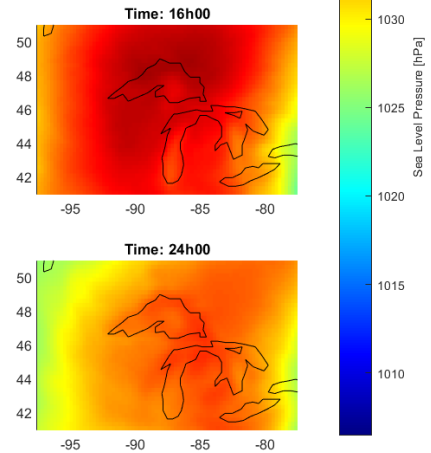

MRR $Z_{e}$ data for 2015-02-15
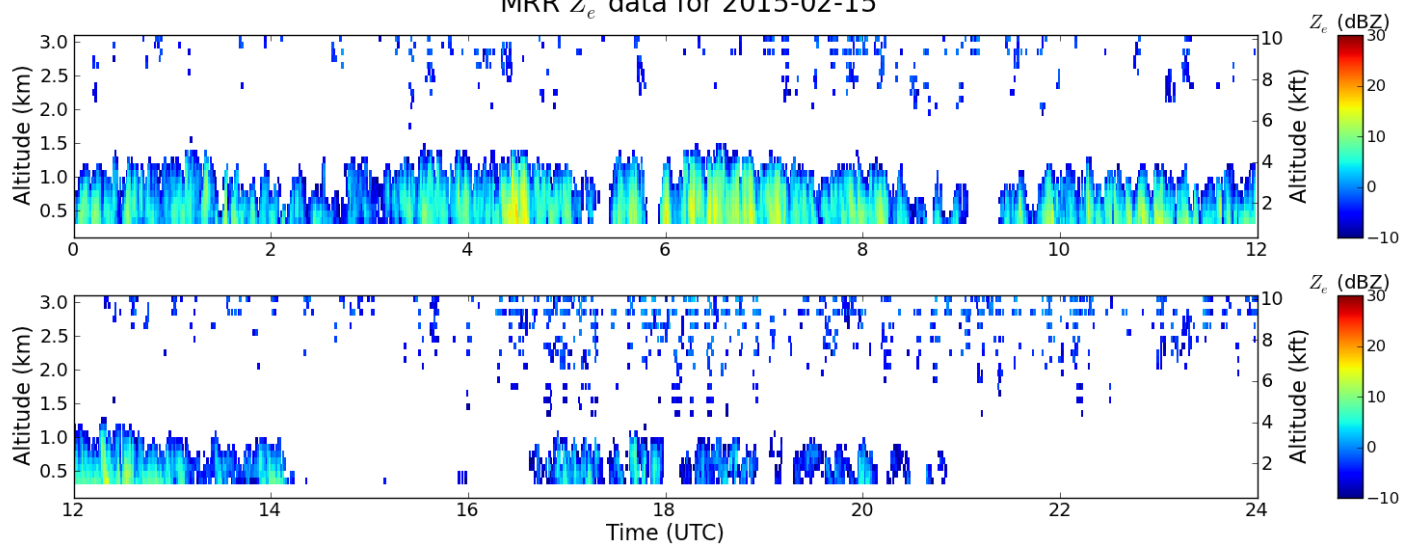

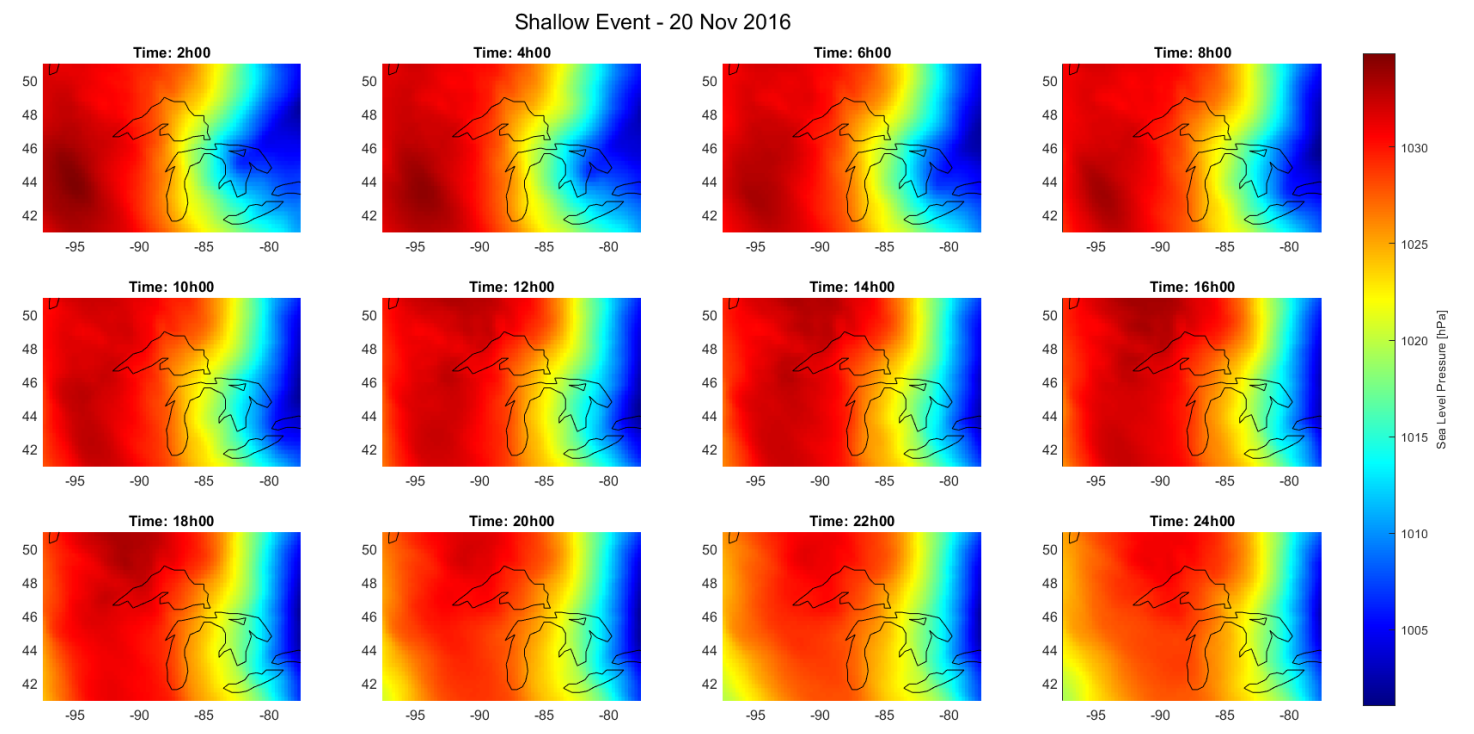

MRR $Z_{e}$ data for 2016-11-20
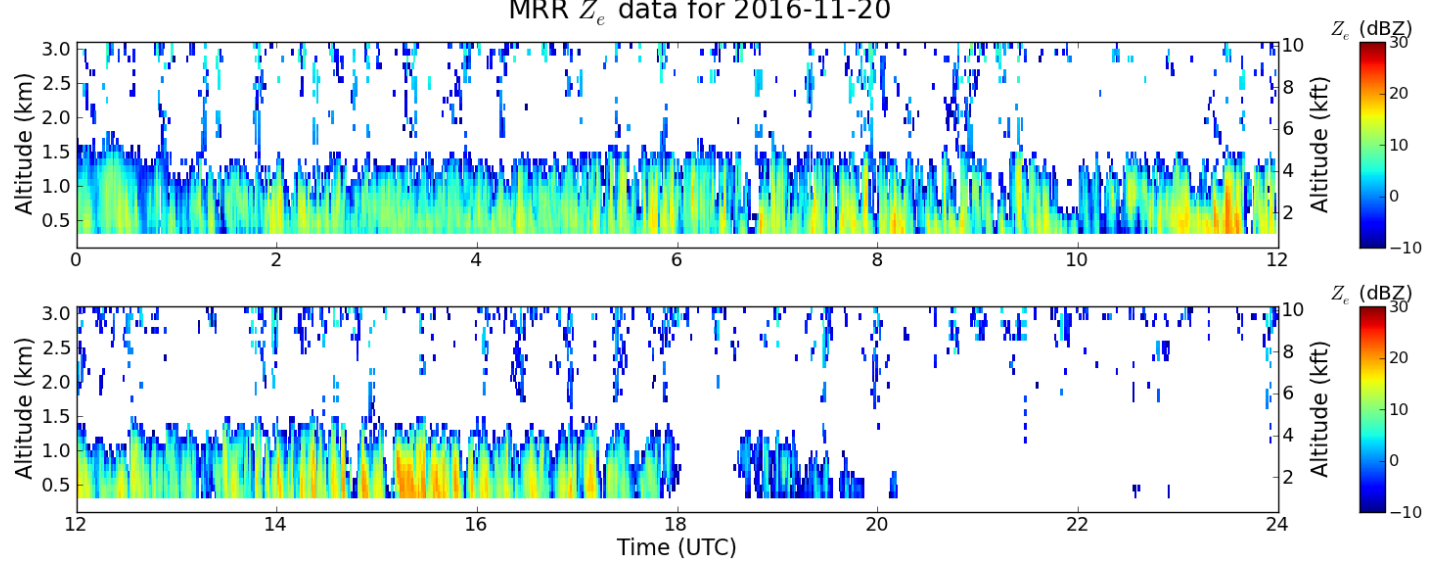

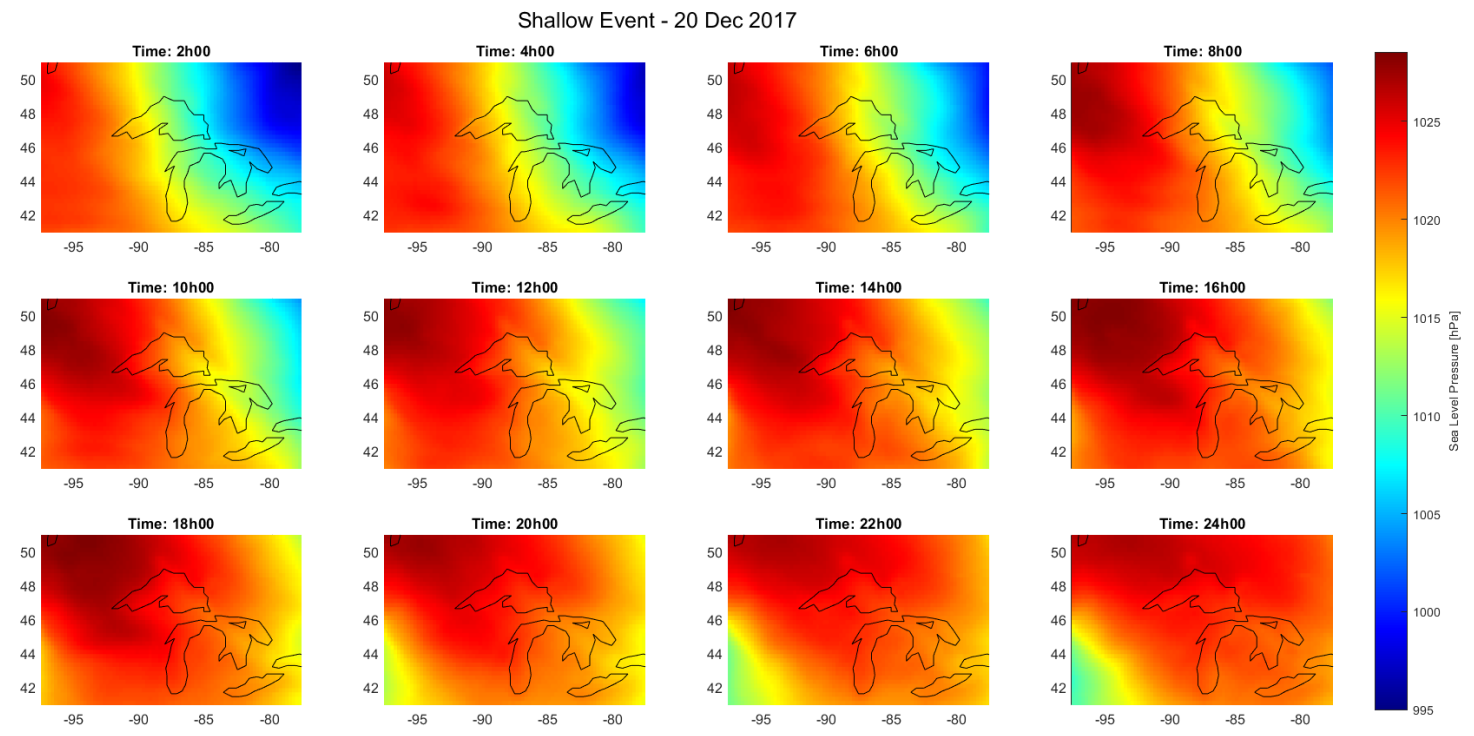

MRR $Z_{e}$ data for 2017-12-20
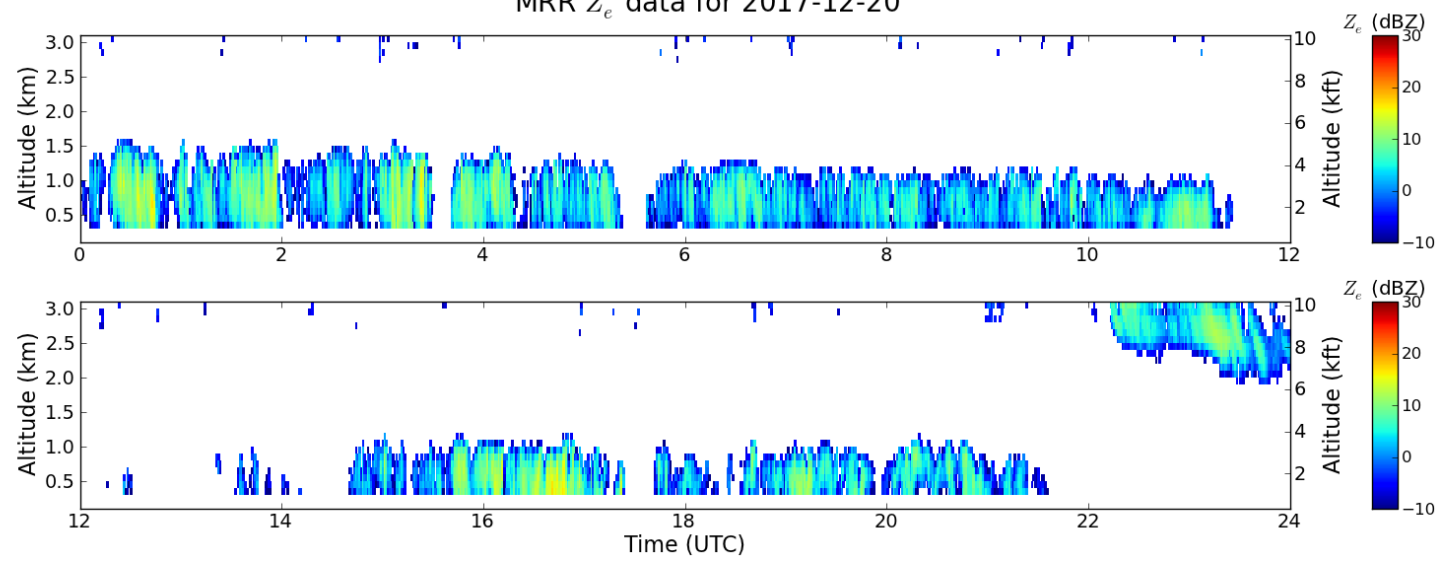

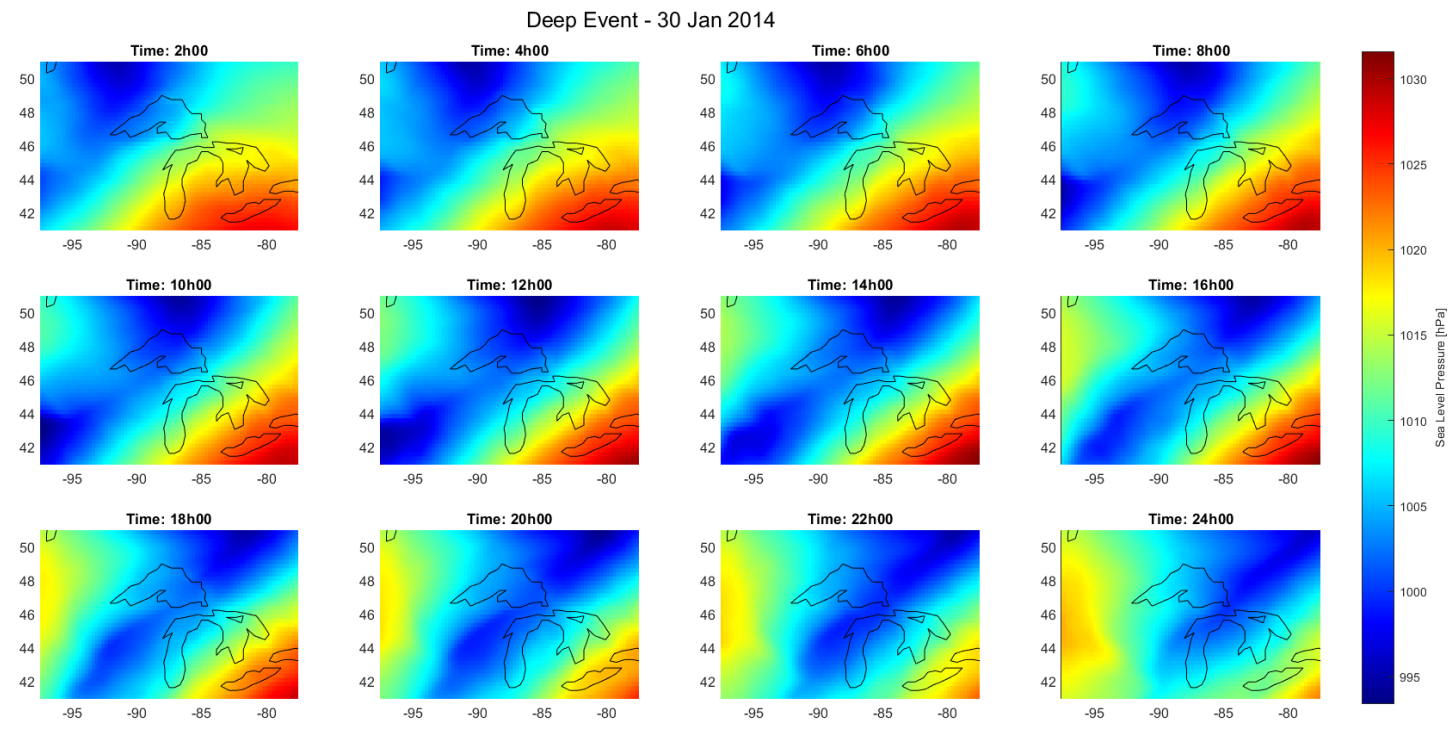

MRR $Z_{e}$ data for 2014-01-30
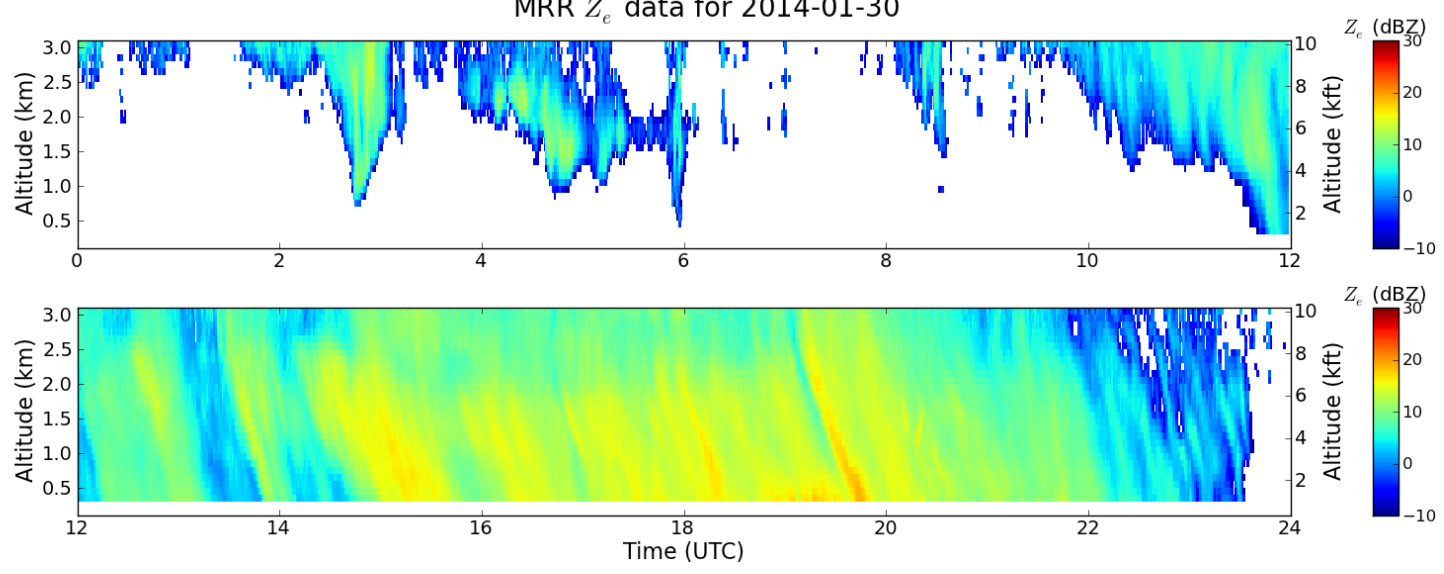

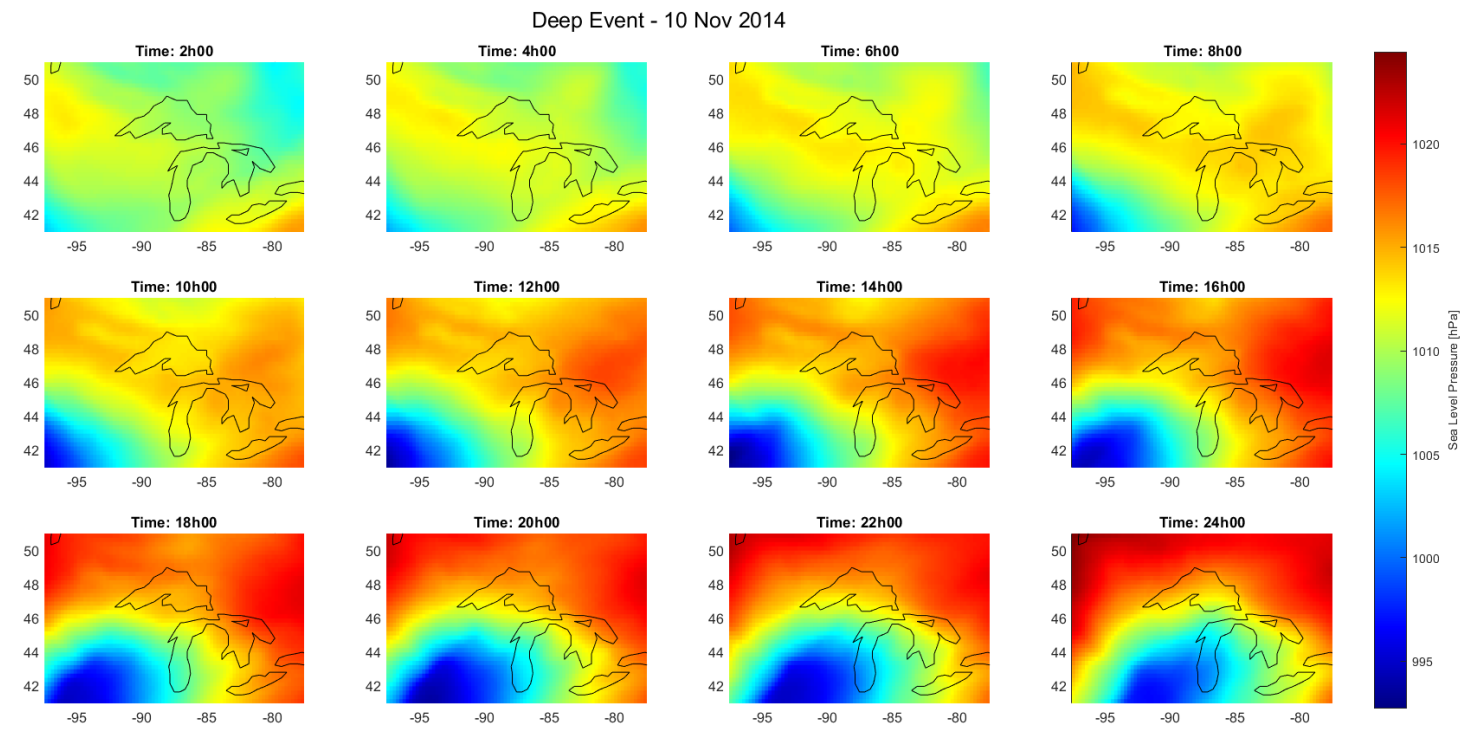

MRR $Z_{e}$ data for 2014-11-10
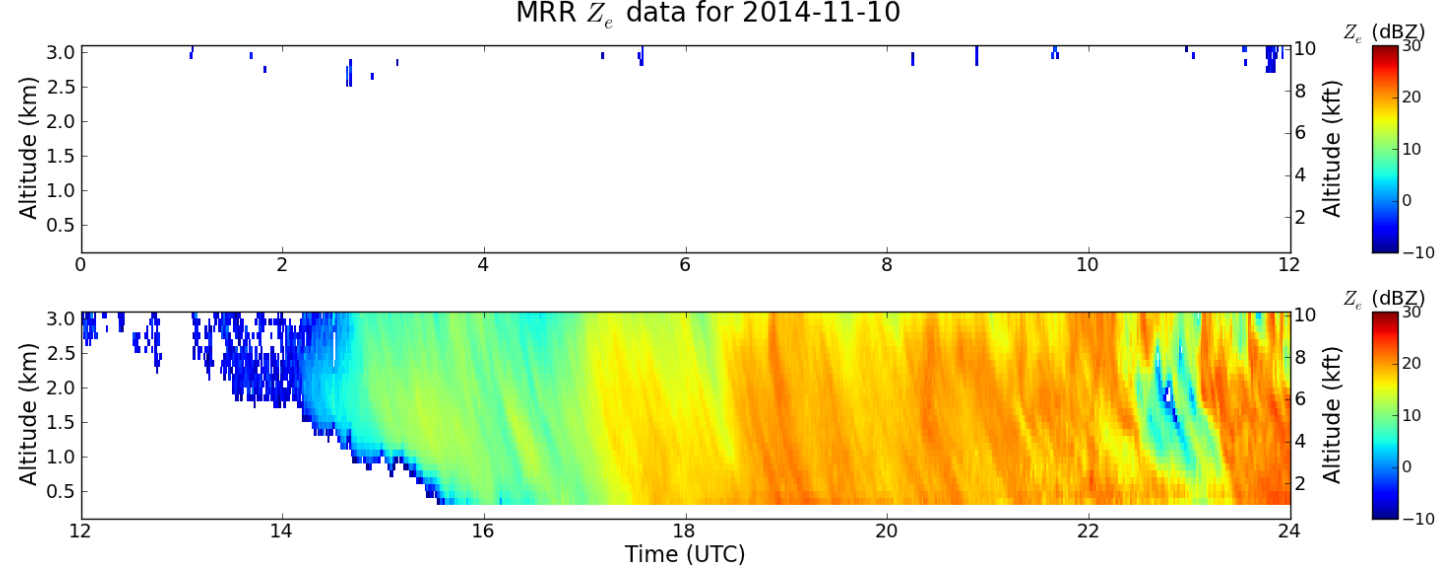

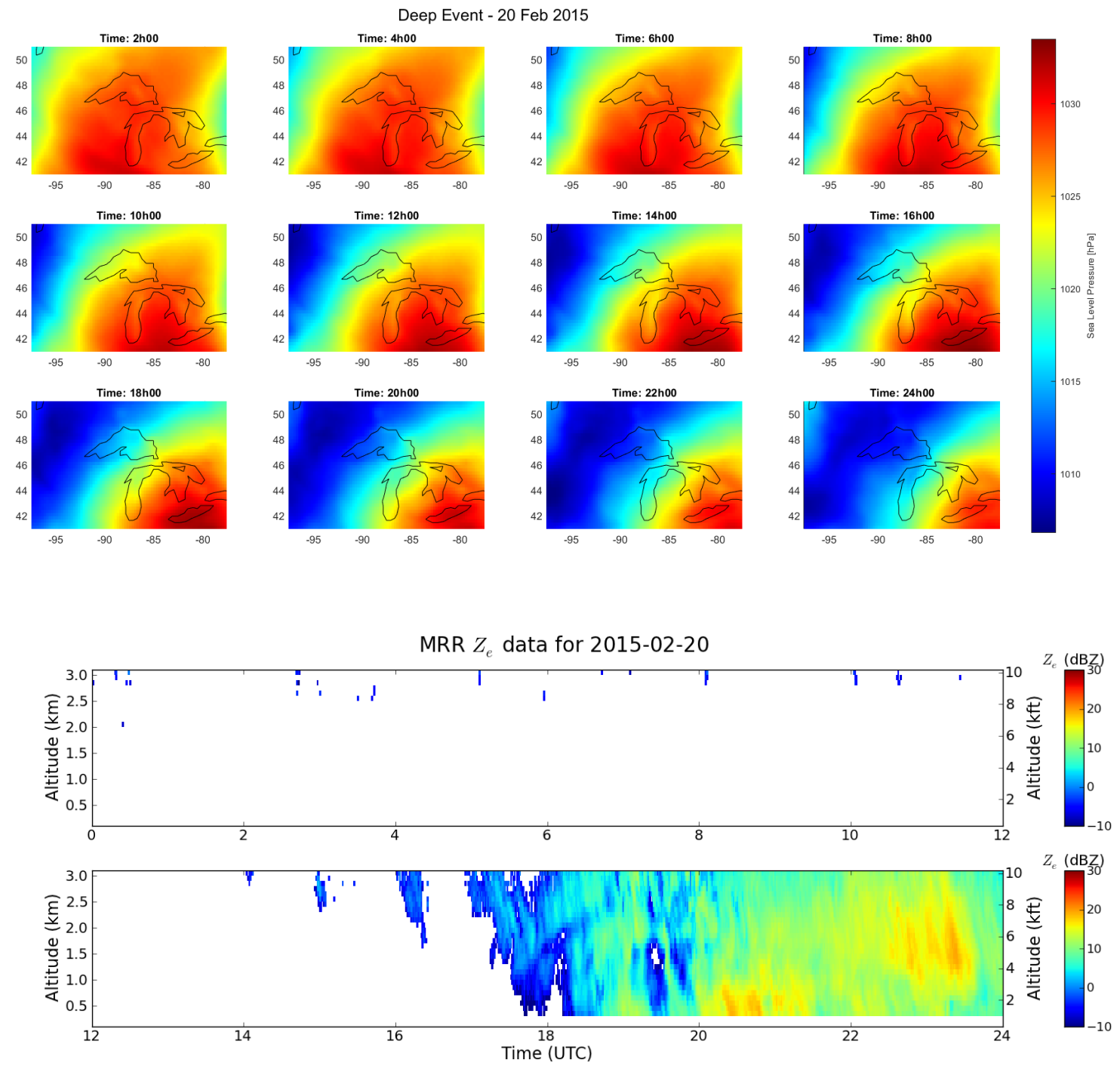

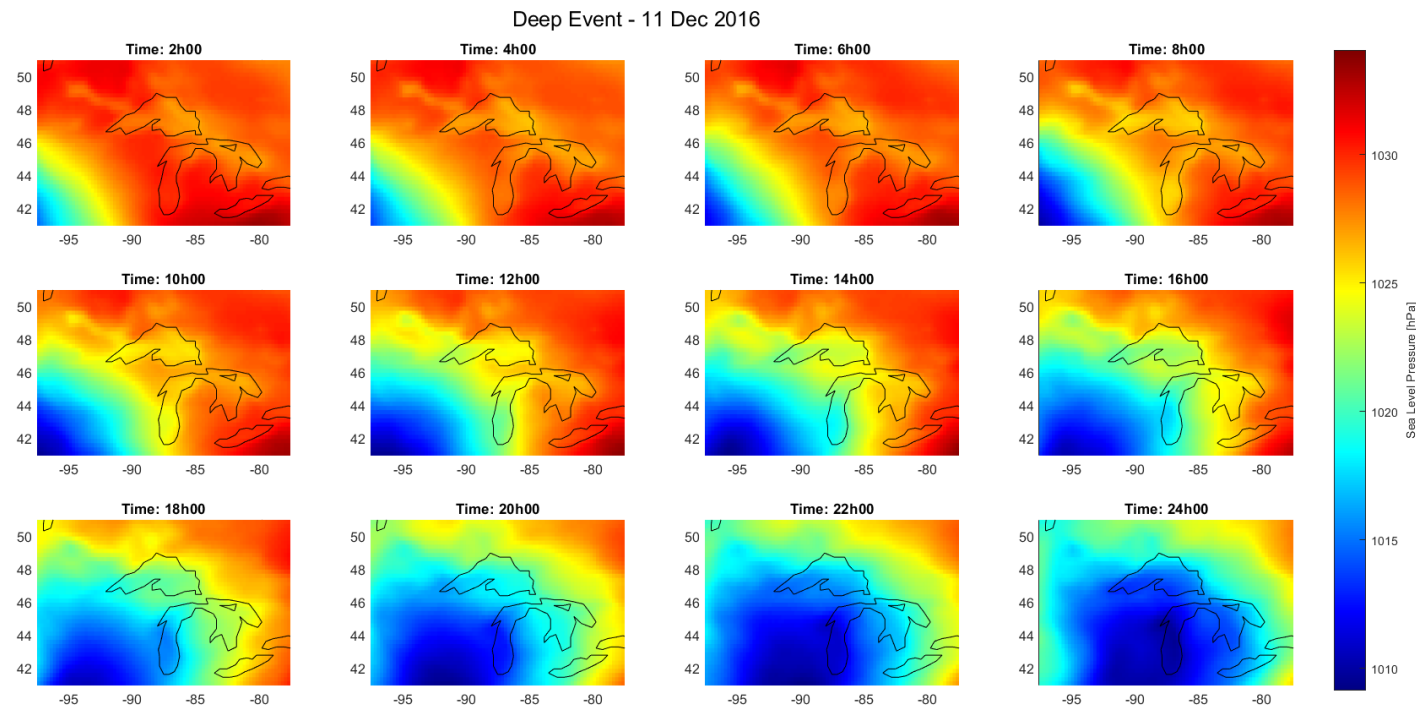

MRR $Z_{e}$ data for 2016-12-11
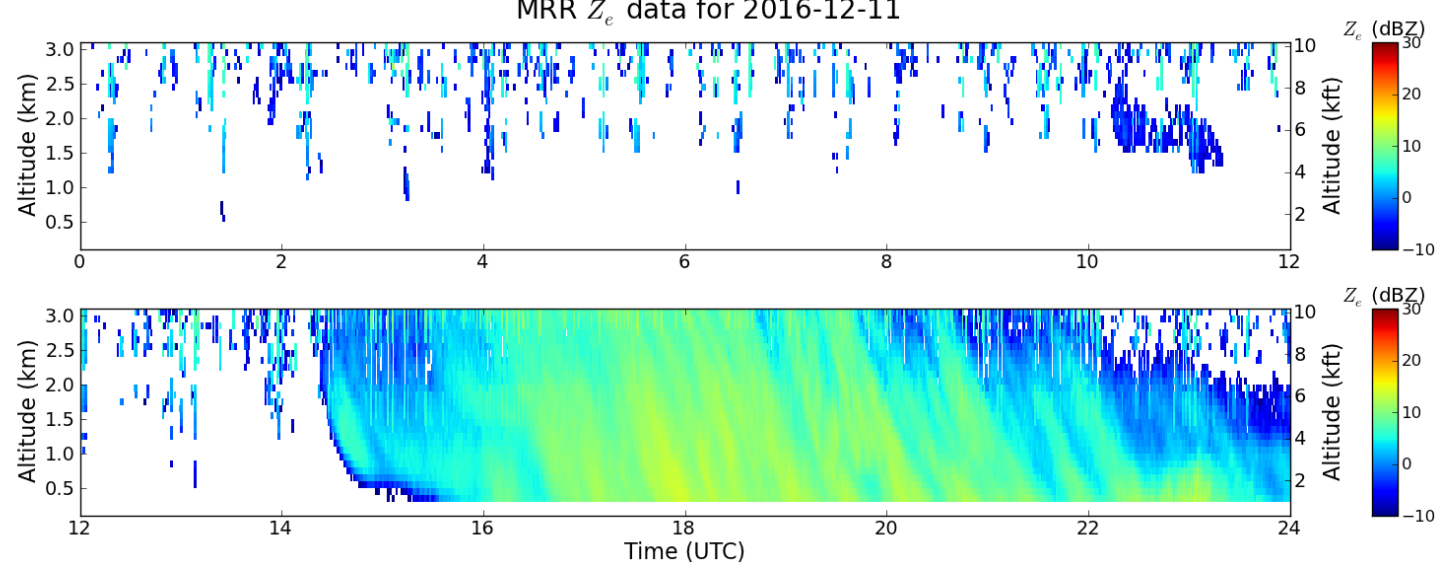

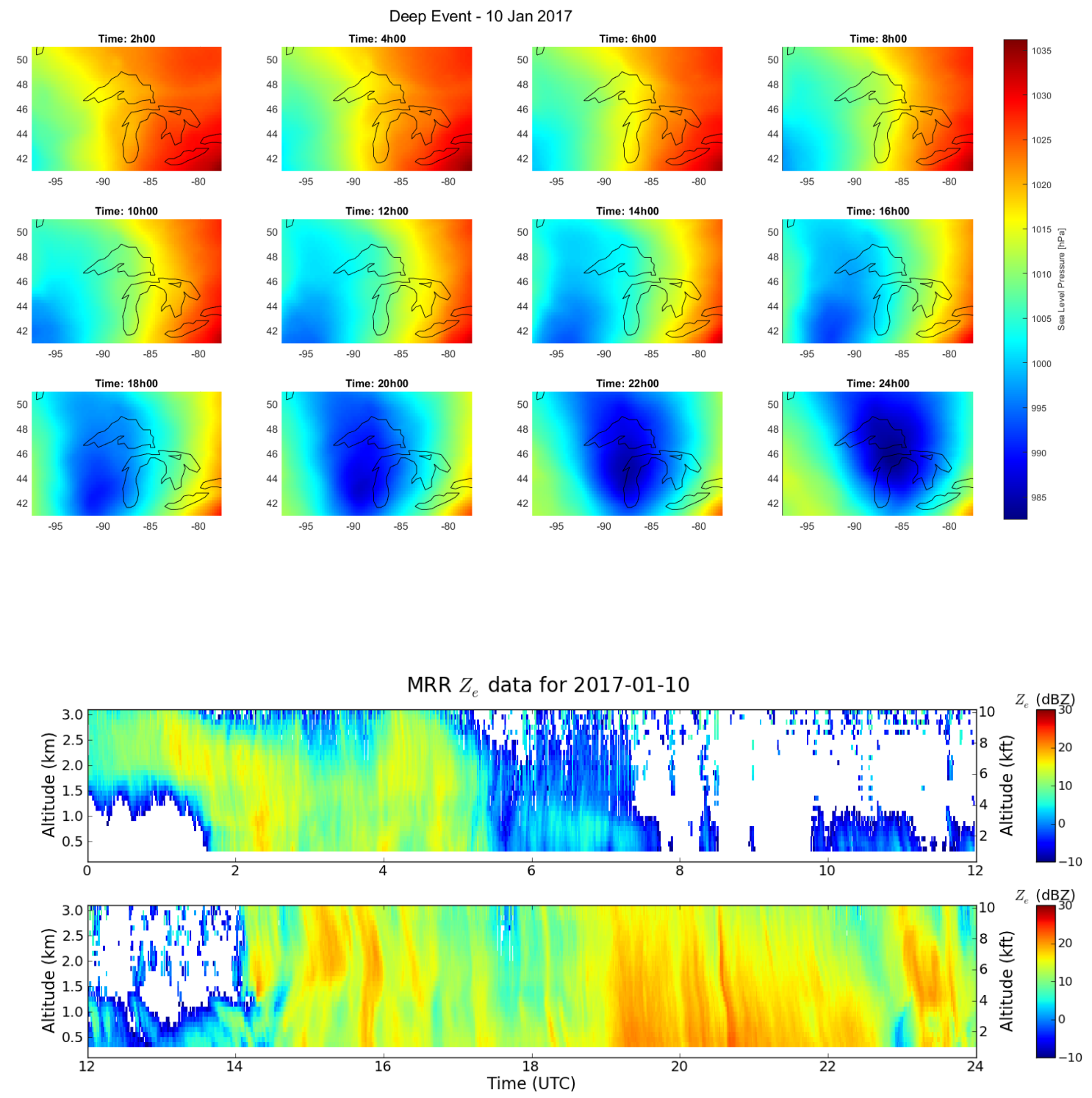